\title{
I Iik
}

\section{grituent Sitmpolypen}

\section{Dit}

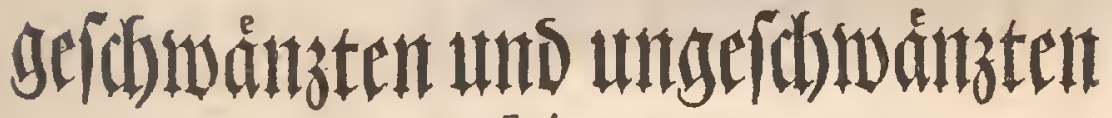

z a $\mathfrak{a} \mathfrak{i} \mathfrak{i} \mathfrak{e}$
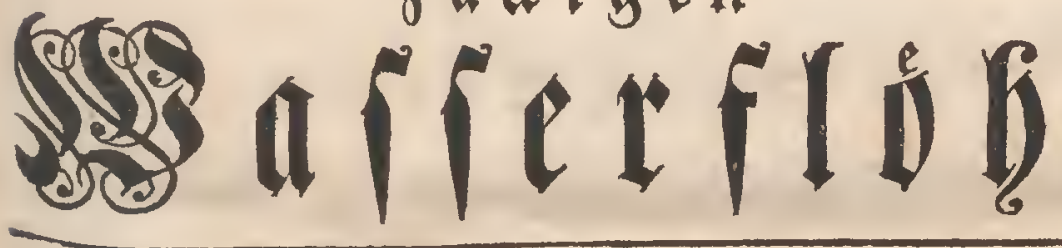

UIID

cine befondere art fleiner:

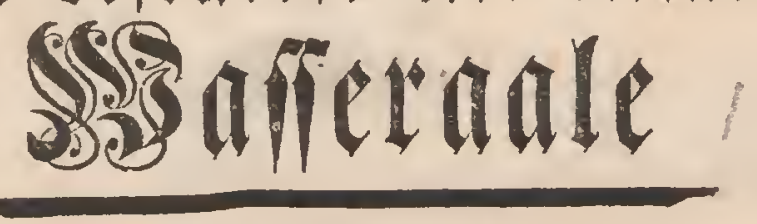

befdrieben yon

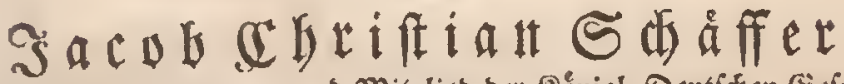

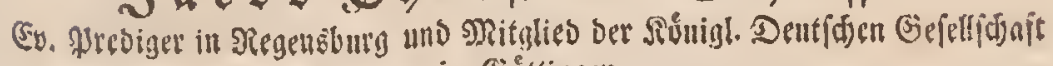
in Bớttingen.

Debfi orey Kupfertafeln mit figuten in Sarben.

Regertsburty, gebrudt bey Emanud 210am 2Seif. 1755. 


\section{放 弥}

\section{Senlec. Epift. LXIV.}

Multum adhuc reftat operis, multumque reftabit; nec vili nato poft mille faecula præcltidetur occtfio aliquid adhuc adiiciendi.

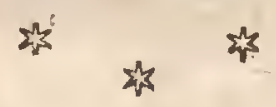




\section{Dent}

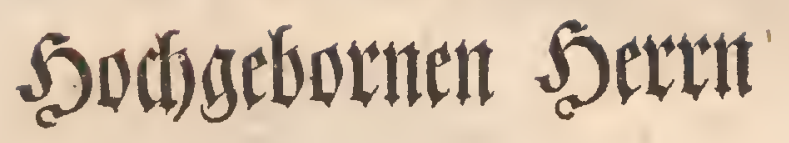

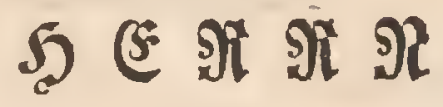

.

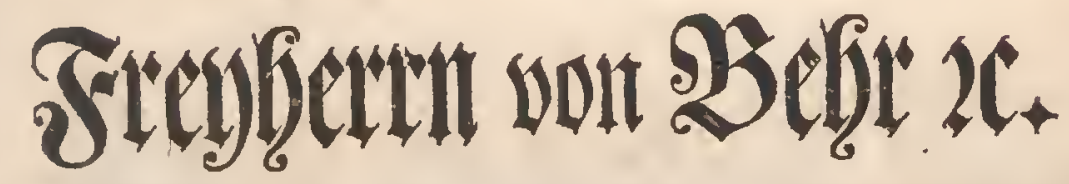

St. Montigl. Majeitát von Groß̧oritannien

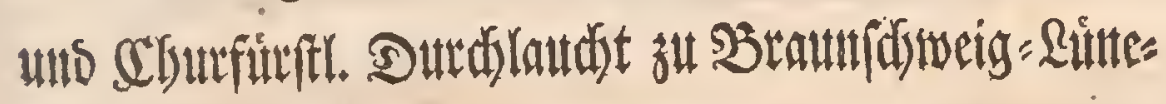

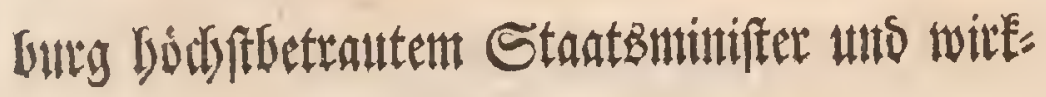

liffent geffeimett siatbe 

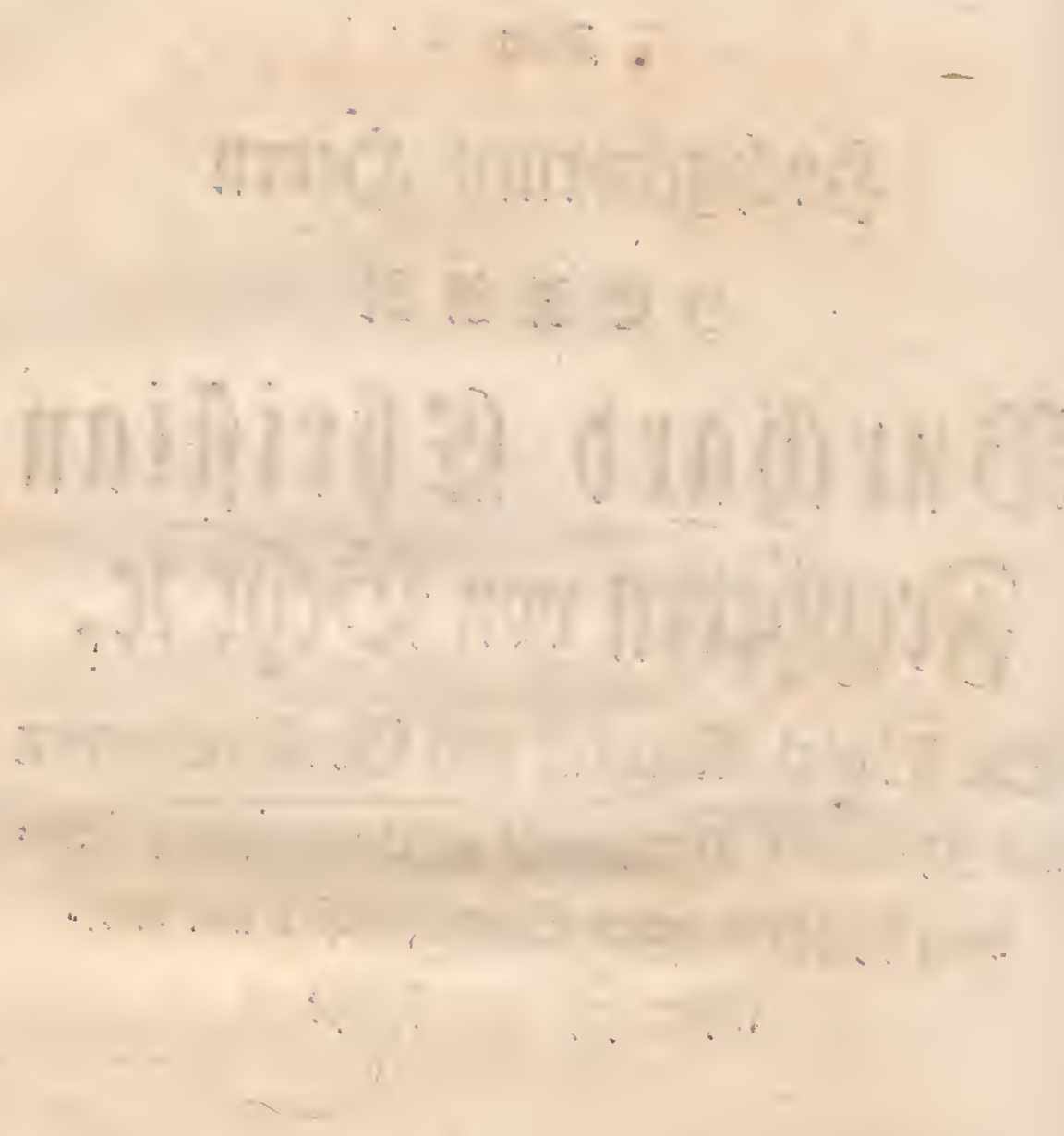


\section{Socthgeforter Frenfert,

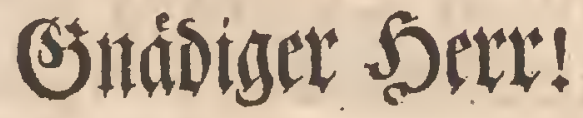

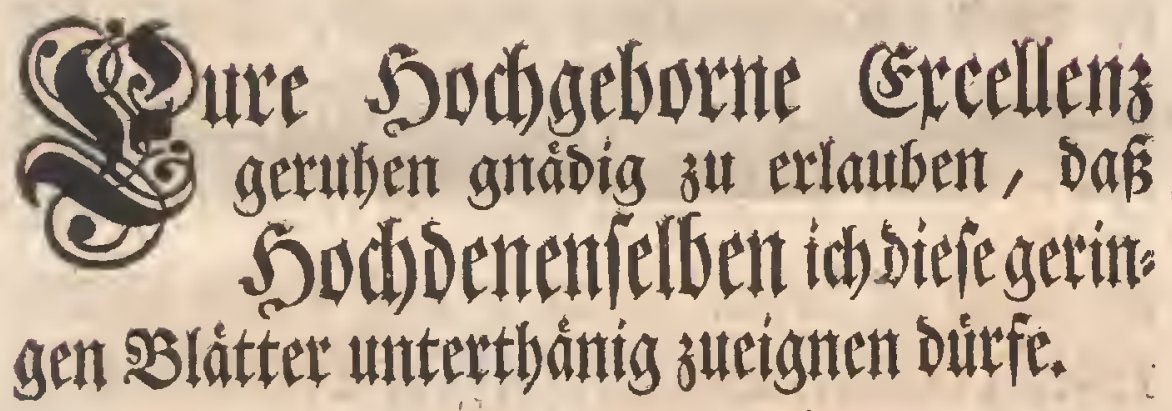

3wo Ltrfachent werben meitte Jitewheit. redhtfertigen. Sie bolbe Ginabe, weldhe Silte Sod)gebotne Excellents, wáb. retto Seto biefigen Iufentlbaltz, mit be: zeiget baben, etrordert cin óffentlicbes Merf: mal 


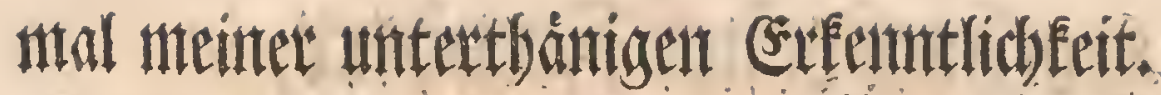
Eute Sodideborte Excellent baben

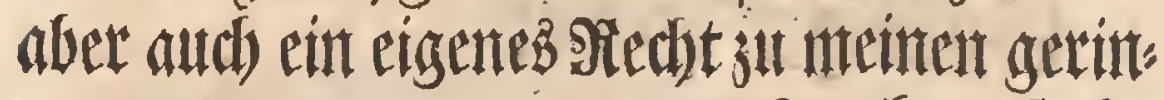

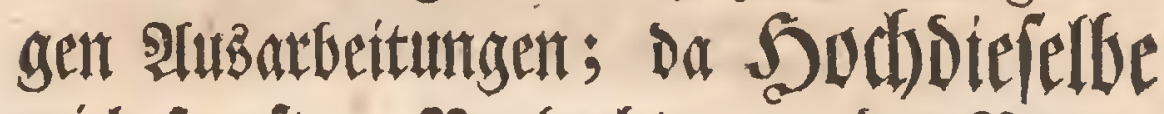

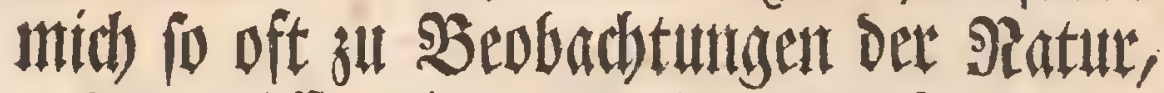

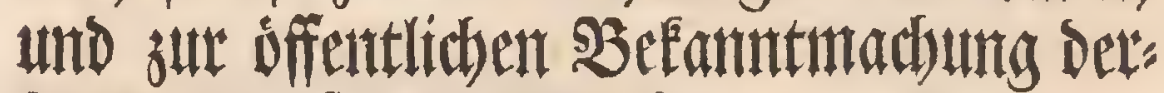
felbent, aufgemuntert babett. Şt) wet:

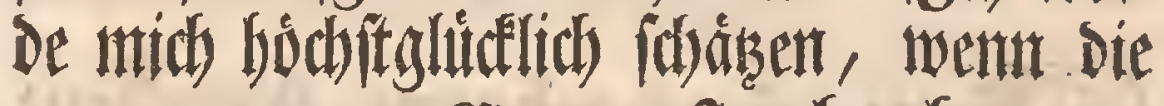
gegenwairtigen (Ettret Sod)gebotnent

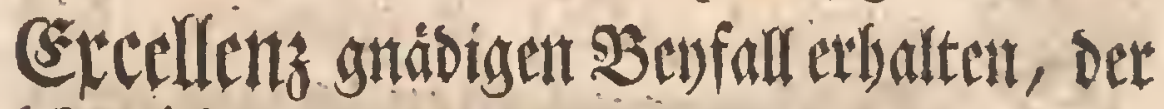
idd mich) zu bebarrlicher boben Syuld unter:

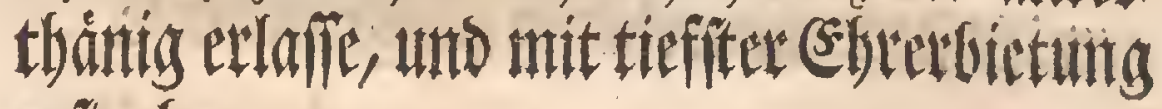
crifterbe

\section{(Eitrex 5od)gebotten Extellents}

Regentsbitry,

Dett ร. Zpril

175\%.

'unterthånigen

Sacob ecbriftant Sráffer. 


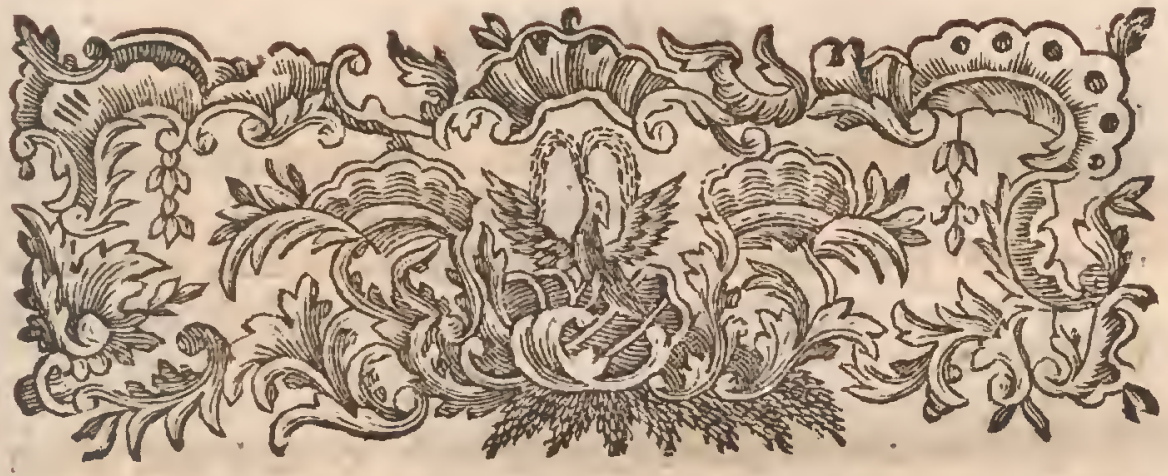

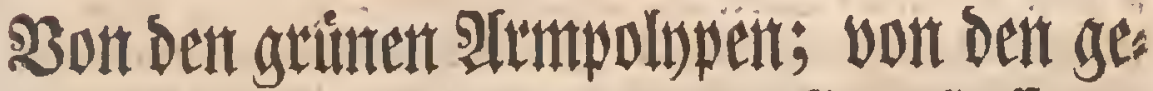

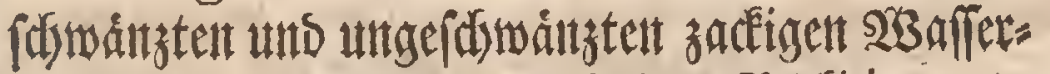
flofert; und von einer befondert atrt Elecinet wsafferante.

\section{(Ertiter Ibidnitt.}

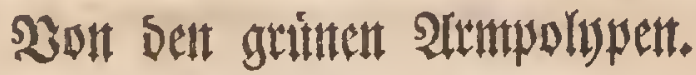

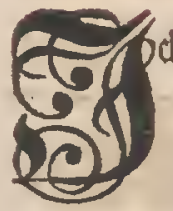

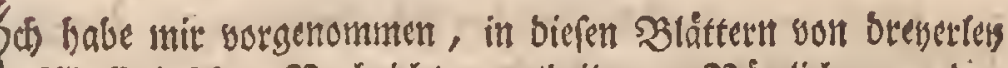

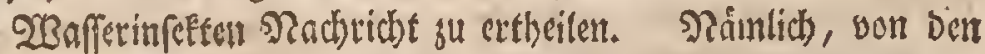
geinen 21tmpolypen; von oen gefobsoánztent unto unges

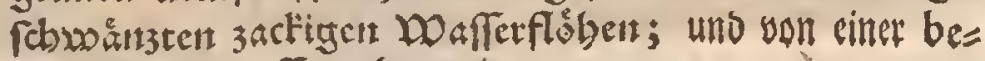
fontorit Zut Hleiter Doaferate.

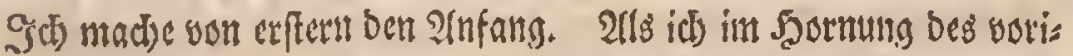

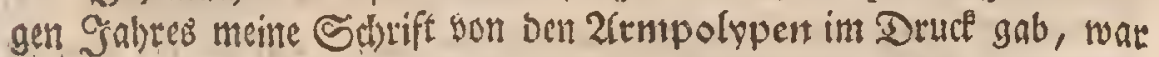
mir bie strune Gartung Derfelben noch nie in biefigen Bicgenden zu (Bes: fichte gefommen; uno id stweifelte ben nabe, Dafi es wirflid) sine fold)e $\therefore ?$ 


\section{(2) (2)}

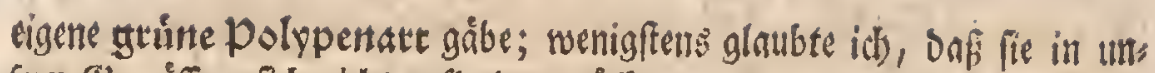

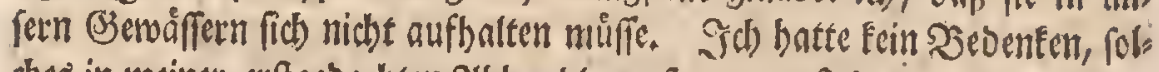
ches in meiner erftgebachten 2 lobandlung frẹn $3 u$ geftehen; indern aller: bings, nach Sxoanmetoants bơdffbilliget Evinnerung, Doabrbeir unb Gexoifenbaftigkeit altch in ber taturlicben Gefebidbte fatt baben mur.

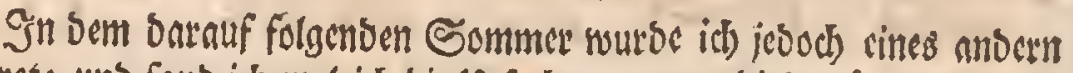
belebret; und fanb id) sugleids bie Lrfactse, warum biefe grtumen झolupen fo lange Zeit meiner Entbeckung entgangen waren. S(d) batte fie bišbero nie an Dem red)ten Orte gefucbet. Da id) Die andern Đodipen nod) alles zeit in fliefenden $23 a$ fern angetroffen batte; Diefer Lumftand nuch inzges mein als notbwendig angegeben witb: (o (abc id) mich) nach biefen grtuten

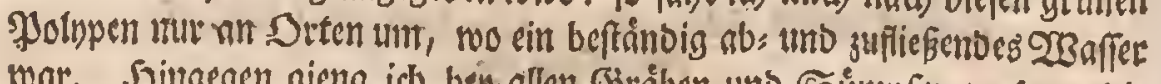
swar. Sgingegen gieng idl) bey allen Eitriben uno Símpfen vorbey, bie

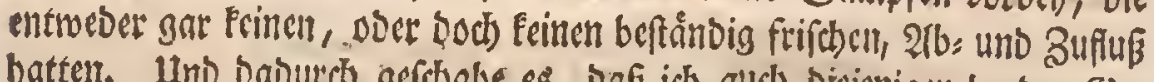

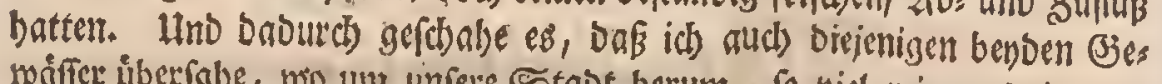

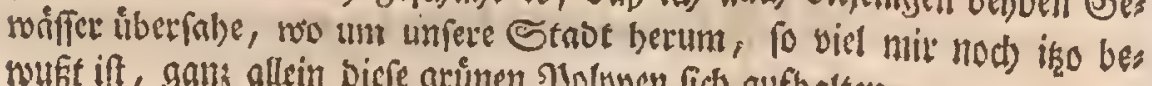
wubt ift, gants allein bicfe grunen Đolypen. fíb aufbalten:

Diefe stuen) Bewáfiet befinten fid obntweit hiefiger Stast unmittels bar vor bem fo genamten priffeninger $23 a b$ b. Dab eine if oben in Der Inbóbe neben Der 2labacberftraffe; Das andere unten im Örunbe,

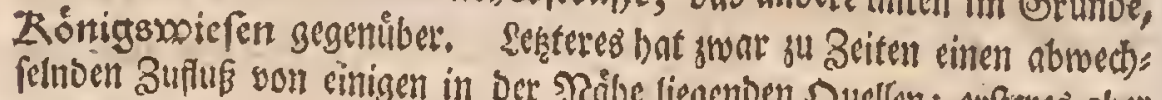

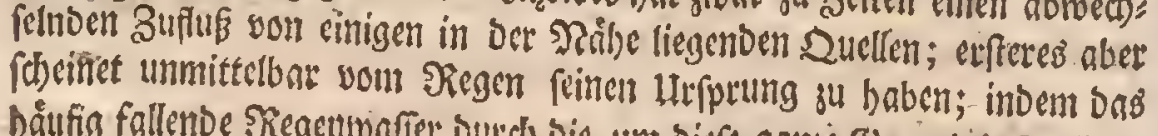
háufig fallente siegentrafier butch bie, tunt biefe ganje (segend befindlide,

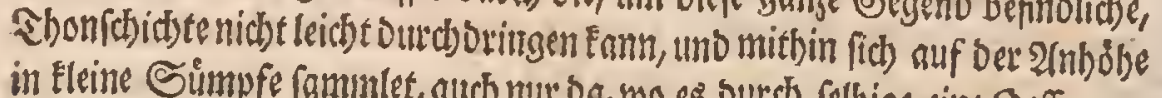
in Eleine Simpfe fammlet, auch mur ba, wo es burd) felbige eine Deffnung, ober Spalte, finoet, fits in einigen Eleinen Quellen unten im Brunbe geis 


\section{(3)}

aef. Daber ift auds enftgeonater Sumpf oen gangen Sommer ůber bes

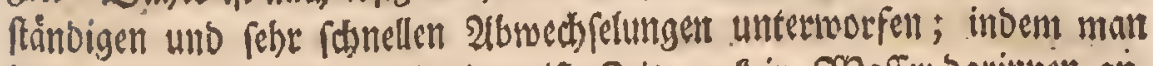
balo wernig, balo viel, und bie meiffe Beit gar fein, $23 a$ afer barimnen ane trifft.

Daidh eintonnle, in einet anbern abficht, aus bicfen benben Simpfent

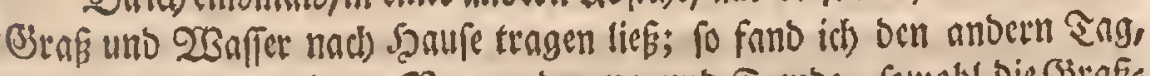

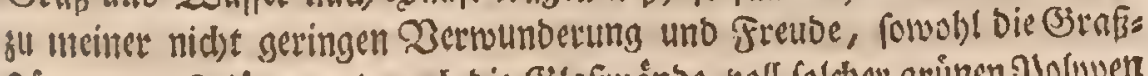

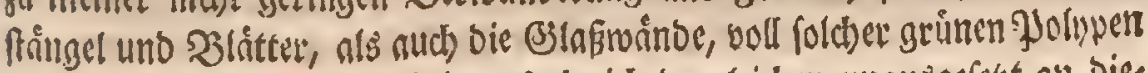
bo̊ngen. Hnto ven biefer Beit an babe id) bergleichen umausgeferegt an bies fen Srten angetroffen; fo oft nur einiges 23 affer in felbigen vorthanden War. Saieber) Ean id) fogleid) nicht unangenterfet laffen, Daf es nir noch

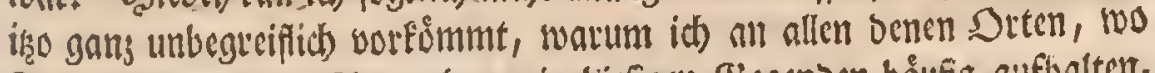
fich fonft bie anoern 21 tmipolnpen in biefigen - Begenden båunis aufhalten, nie cine srune; lind warum ich bingegen on, wo bie gruimen ihse 250 bnumg

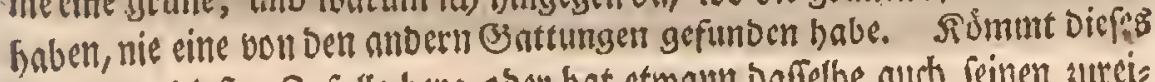
son einem blofen Bufalle ber; ober hat etroan onfelbe nuch feinen zuret:

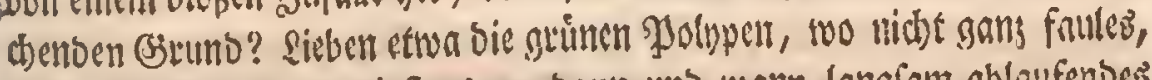

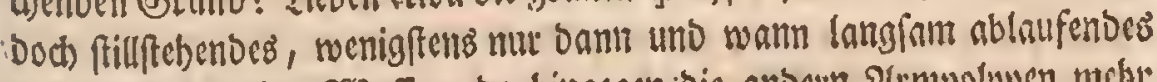
uno Durdsfrigenbes Waffer; on bingegen bie anbern 2(rmpolupen melfyreines, ober bod) in gróferer 3ervegung fethendes, bnben wollen?. D: Der finben bieleidst jene, weldies wobl am natirlidbften zu folgen fdscinet,

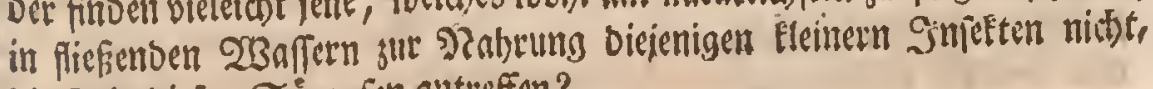
Die fie in biefen Sulmpfen antreffen?

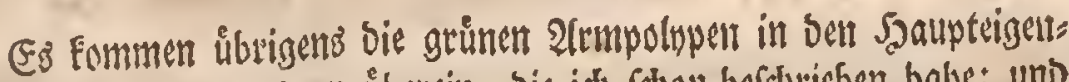

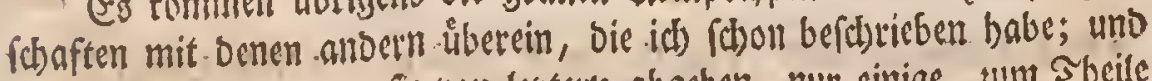
betrifft $D a b$, worinnen fie voll lestern abgeben, nur einige, sunt Sheile

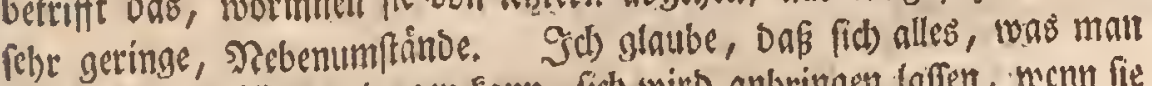
won ibnen su wiffen berlangen famm, fich wirb anbringen taffen, necnn fie If 2 


\section{(4) (4)}

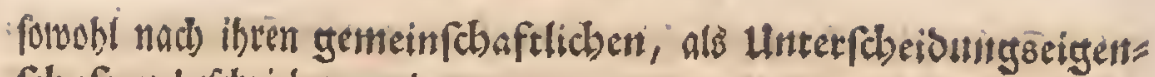
fibaften befdyricben werber.

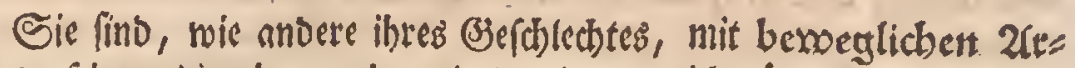
men verfeben; Dic aber auch, mie ben jenen, nidbt überall von gleidber

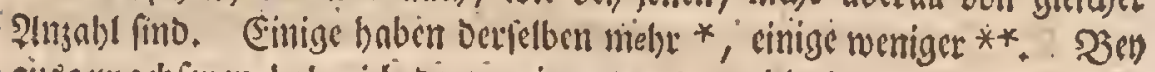
nusgemadjenen habe idl oeren nie unter 6 , mobl aber 9,12 , uno bey

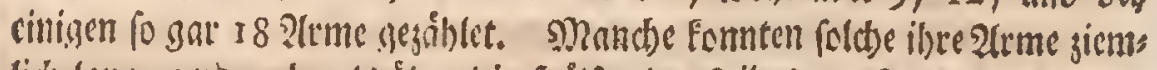

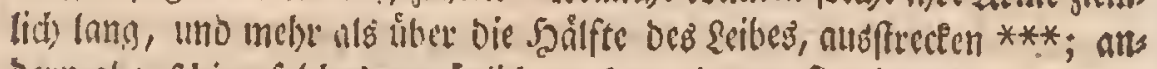

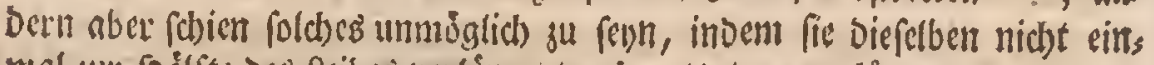

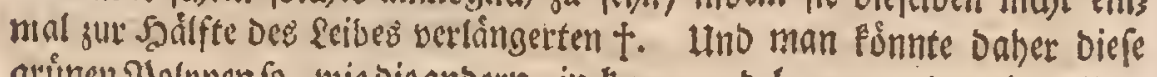
grimengolnpen fo, wie oic anocrn, in Eur 3 = uno langatmige sintbeiten.

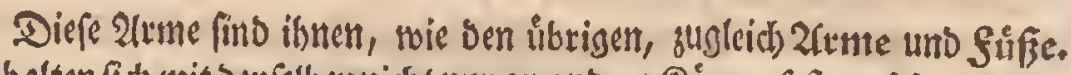

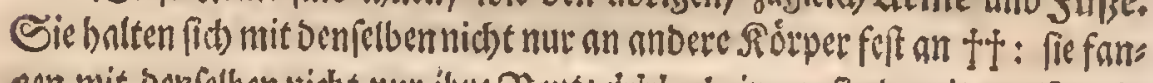
gen mit benfelben nidbt nur ibre Deute ttt, bringen fie ormit zur \$2) unD:

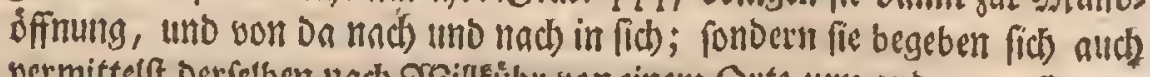

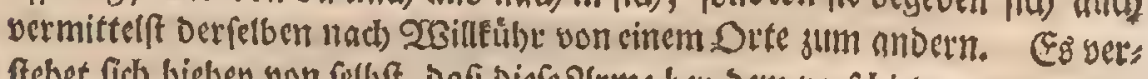

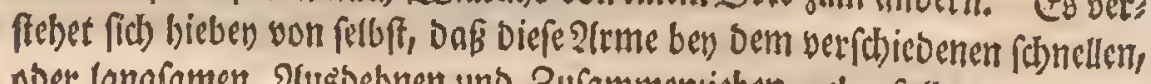

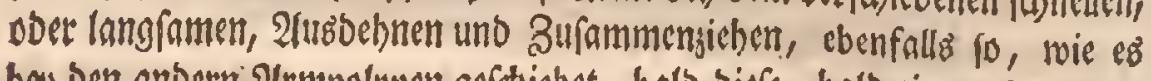

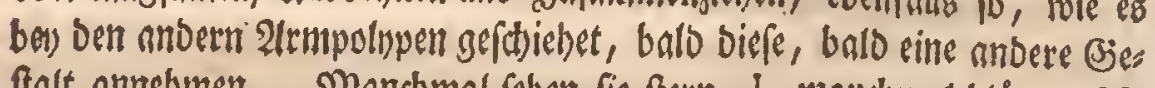

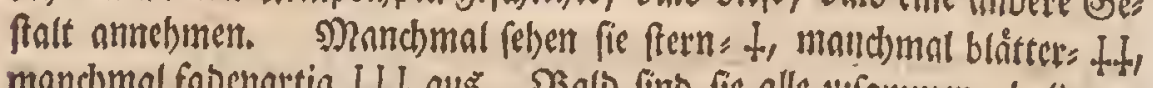
mand)mal fabenartig $4+4$ nuE. Salo fino fie alle sufaummen, balo nur einer unb ber anbere von ihnen, ausagebeljnet ${ }_{*}$; uno nehmen úberbief ats lerband ecfige **, bogen = foblangen= ober ringartige *** నrum: mun: * Tab. I. Fig. XI. XIV. Tab. It. Fig. X. XI. XII. ** Tab. I. Fig. X. XII.
XII. XV. XV. Tab. It. Fig. X. XII. Tab. III. Fig. IV. It Tab. II. Fig. XI. ttt Tab. I. Fig. XIV. + Tab. lli. Fig. IV. VIII. It Tab. I. Fig.

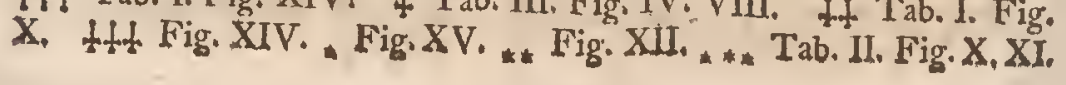




\section{(5)}

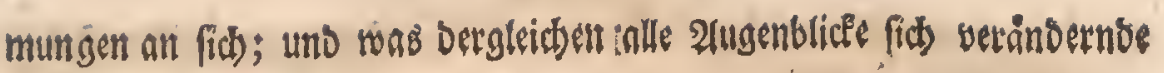
Stellungen mebr find.

Der Leib biefer grinen झolnpen ift faft allein in ber beftỉnoig grǔs

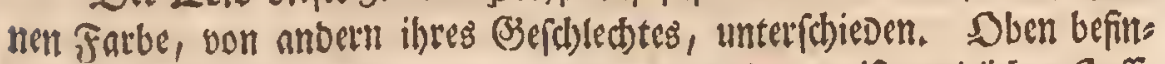

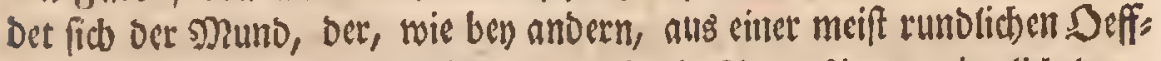
nung * beftelset, uno ben fie nuch, wie ein Đane Eippen, siemlidb lang,

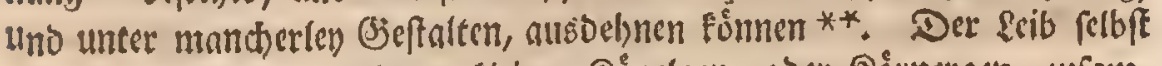

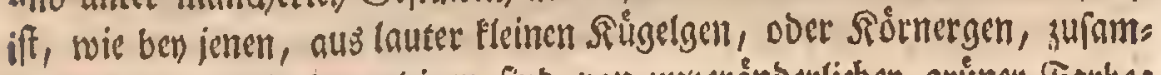

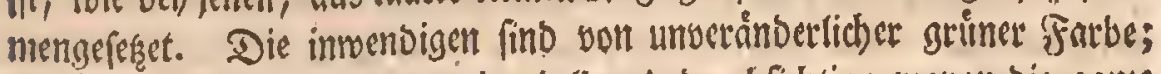

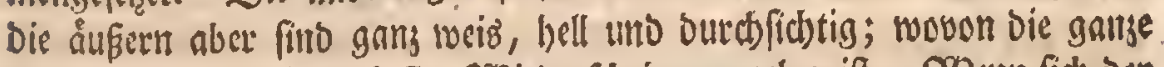
Jolnpe, wie mit cinenl bellen 2 bieberfheime umgeben iff. 2Yenn fid) ber seib biefer grimen \$olnpen in bie \&inge ausbehnet, fo ift Derfelbe ordents licher 2 seife surd)aus gleid) bick, obne boßs man an ihm, wic ben ciner

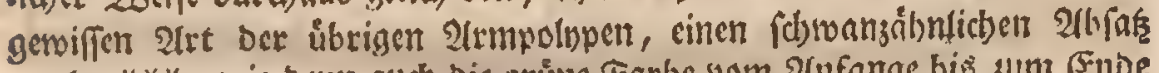
merfte ***; mie benn aud) bie grủne Farbe yom 2(nfange bio zun Enoe Durd) ben ganjen seib fortlíuft. Dood bleibt ber \&eib unten, womit bie:

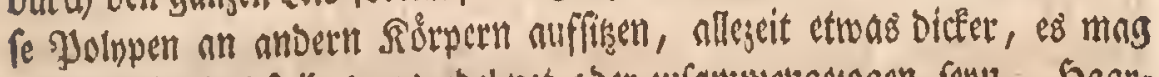
Das llebrige bes seibes nusgebehnet, ober zufammengejogen, fenn. Shaar,

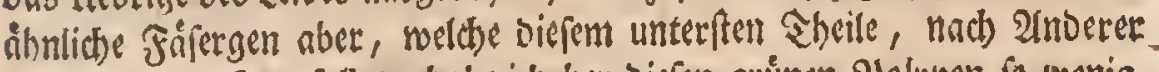

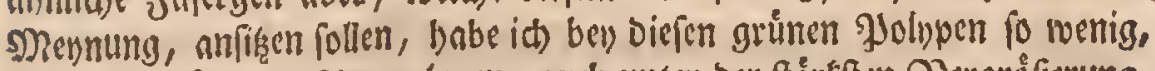
als ben Den ủbrigen 2(rmpolnpen, aud) unter ber ftátffen 2ergrớfertung,

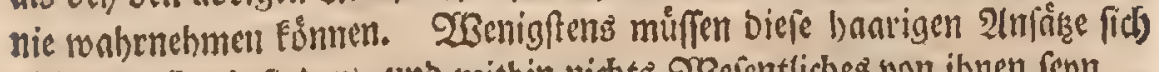

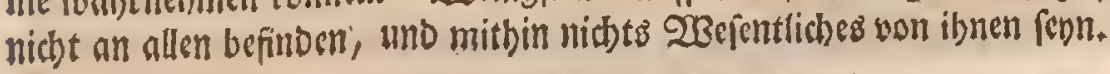

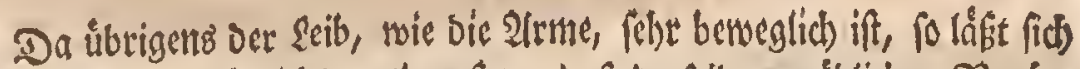

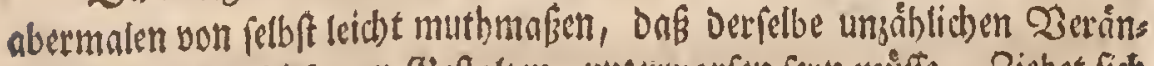
berungen, und feltfamen Bseftalten, uncerworfen fenn muiffe. Biebet fich $\mathfrak{A}_{3}$

Die

* Tab. 1. Fig. X. ** Tab. I. Fig. Xiv. Tab. It, Fig. X. Tab, III, Fig. IV. *** Tab. II, Fig. XII. 


\section{(6)}

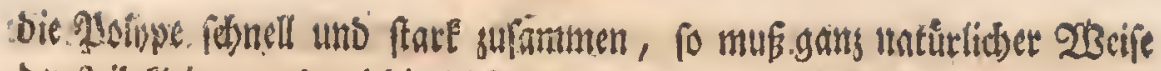
Der Eeib Eleiner, unt mithin bicket, toerben, or er benn balb walsen:, balo Eegets, ballo fpindels, bald Enopfs, balb feulenartig, balo oben, Galo unten, balo in ber Mitte, mehr uno reeniger bict iff *. Dehnet fich Der seib in bie sånge aub, fo fehet er entrveber gerno vor fich bin **,

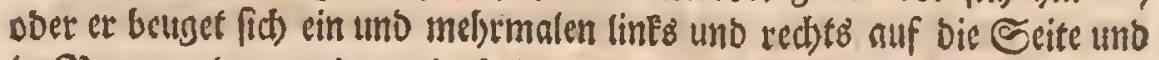
im 23ogen, ober el nimmt fonft eine andere ibm beliebige Stellung an ***. Dasu foimmit noch, baß auch bie veridhludêten Gureften, uno ijere ver: fchiebente \&age, bent \&eib auf mannisfaltige $\mathfrak{2}$ (nt auseinantoertreiben une weruuffalten. WBie Den, wenn 3 oocr 4 Eleine runblicbe SnfeEten fonell auf = unb bintereinanber in ben Reib gu liegen formmen, Derfelbe bócferig, unb als fo sielmal abgefeckt, ober unferbunben, ausfichet t. Lleberhaupt

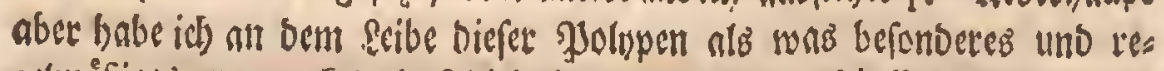
gelmåfiges angemertet, Daßs Diejenigen unter ibnen, Die ihte 2trme wenig verlangern fontern, fold)es befto mebr mit iljem Eeibe thaten; uno swat gefthabe biefes bon manden fo ftare, baf fie anberthalb zoll lang wut: ben It; bingegen wat biefes bel) benen anbern, bie ibre 2(rme ftare aus: Defnen fonnten, umbefefser, inbem fie ibren scib felse wenig, und faum Den britten Sbeil po feht, als die vorigen, ju verlángern vermogten.

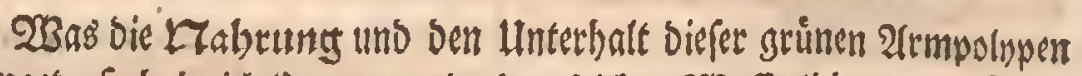
anlanget, fo babe id lie swar mit eben foldhen .23afferthiergen ernabthet, als bie andern 2(rmpolippen zu freffen plesen. Destuegen mógte id) aber

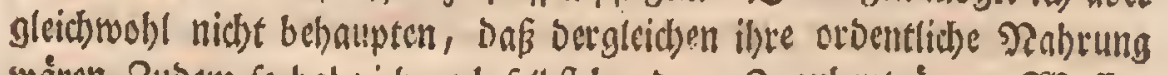
poàren. Subem, fo babe id), aucb felbft bey Denen Sraubentrågern, 2Bafer:

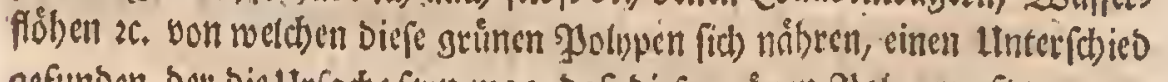

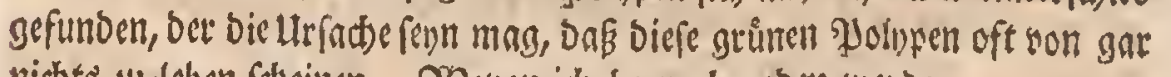

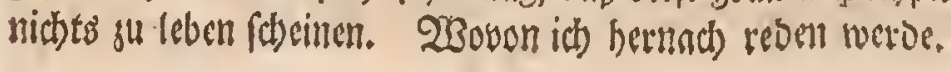

*Tab. I. Fig. X. XI. Tab. III. Fig. V.VI. IX. ** Tab. II. Fig. XII.Tab.

III. Fig. VII. "** Tab. I. Fig. XII.XIV. Tab. II. Fig, X, XI. + Tab. I. Fig. XllI. tI Tab. II. Fig. XII. 


\section{( 7$)$ )}

Gut 2(bficbt ibter Beugung, Fortplimsung und Detmehtung, ift biefelbe, wie ben ben anoern, theils eine ordentlicbe und naturticbe, theils cine aufierorbentliche und getunftelte.

Jente beftebet barimt, Dak auch bey biefent grument Joltypen ibet Gungen yon felbft nus und an bent Reibe gum 2 orfheine Eommen *. Es fint berfelbert ber 2(mabl nad) balo viele, batb reenige, oft auds nur eine unb bic anbere gugleidb beneitranber. Sidh babe झolopenmutter angetrof: fen, am weldser $\sigma$ unt 7 Sungen zugleich waren, unb yon benen matúte

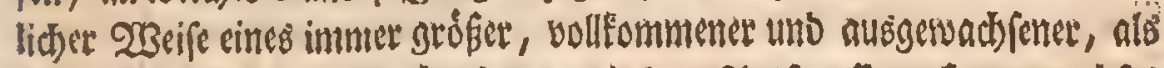

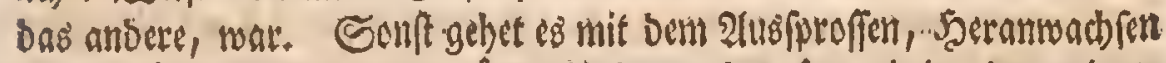

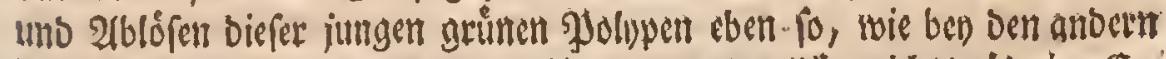

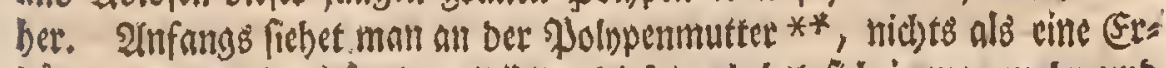
boibung, wie ein Şügslgen ***; bicfes erbebet fict inmer mebr uns meht, unb poirb in reniger, als einer Stunte, fu sinem Eleinen walfents

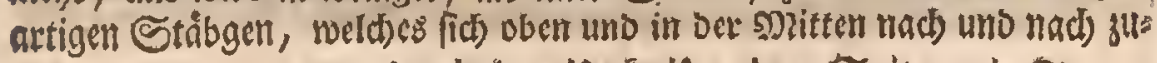

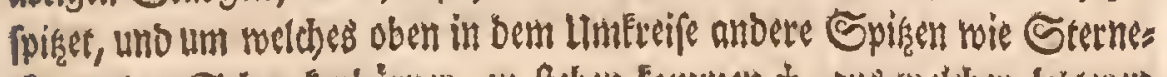

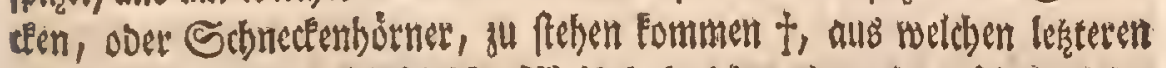

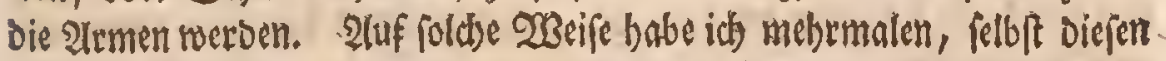
2Sinter biber, binnen weniger, als einem ₹age, cine junge \$olupe entfebent austwadfen uno fid) ablofen, gefehen. Crsentigftens, weis id) fein cintiges

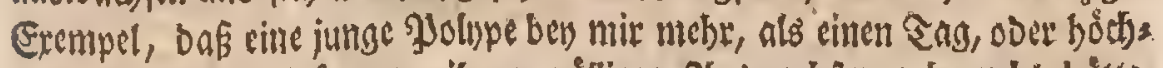

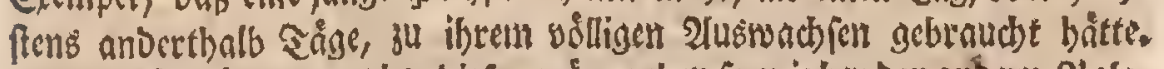

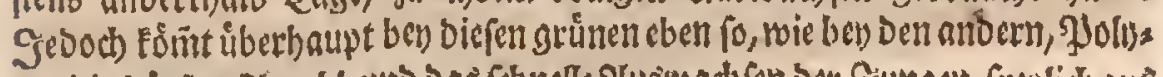

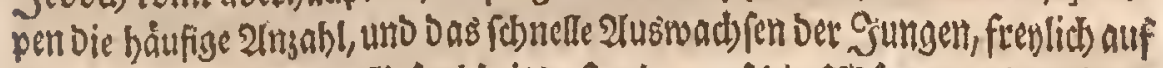

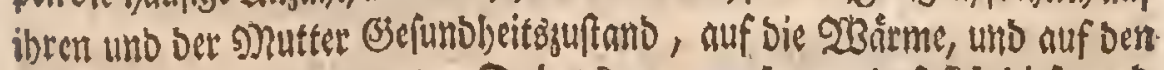

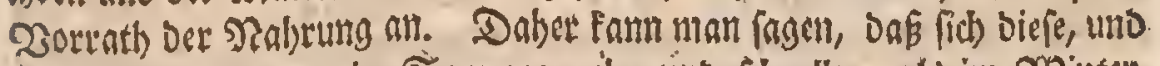
alle andere, Đolypen im Sommer mebr uno haneller, als im 2winter, oct:

* Tab. I. Fig.X. XI. XIV.XV. Tab.III. Fig.IV, a. "* Tab.I. Fig. XV.a, *** b. t c, di e. Fig.XIV.a.b. . 


\section{5 (8)}

bermehtet. Wenm man aber ben פ) ter ourd) eine beftánbige Stubenhize elfeket; und balleben feine Jolnpent nut mit notbigem Unterbalte vereben fann, fo wiro faft alles fo, wie int Sammter, fich feigen. WSenigftens bnbe ich biefen SBinter nicht bie ge: ringfte Derónberung, ober Derminberung, in ber 2(ngahl uno in ber Zeit

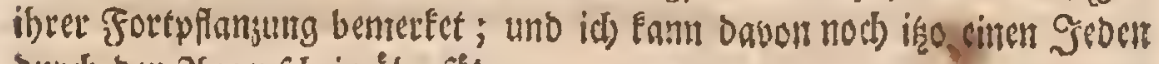
Durch ben \&ugenfobein thberfübrert.

Die auffetordenticbe und gekintfelte Fortpfingung Diefer grünet Solnpen gefdiebet nidst weniger, wie bey Den übrigen, Durch willeủhrliches 3erfesnciben uns Zertbeilen berfelben. Uno bier laffen fid) elle biejenigen gansen uno balben, cinfadben uno sielmaligen, Betftummelungen unter ges wiffen Vorfidstigfeiten unb Şanogrifen anbringen, bie id) in meinet

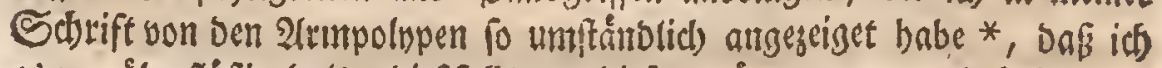
es vot uberflufig balte, bieff falls von biefen grünen neue, uno befonocre,

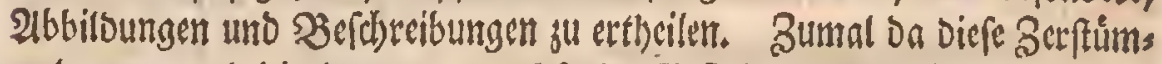
melungen, und bic baraus ermacb fende bieftalten uno Unformen, auf fo mannigfaltige Itten ficb felbft abinbern, uno abgeandert werben Eơnen, Dafi Durch alle Sbbilbungen boch ber wenigfte Ilyeil Derfelben fann oor: geftellet soetoen.

Sc) will bobato nut nod) eires einjigentunftandes gebenten, ben bies re gruñe \$olnpenart mit anoern semein bat. Man finoet nåmtich aud)

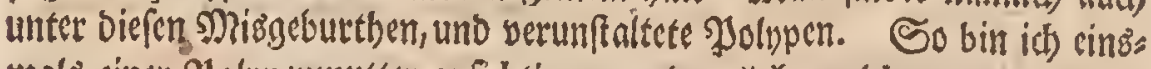
mals einet jolopenmutter anfichtig getoorben $* *$, weldser, auser cinem Sungen an bem gerwơbnlidben Drte ***, nod ein anderes ganj oben,

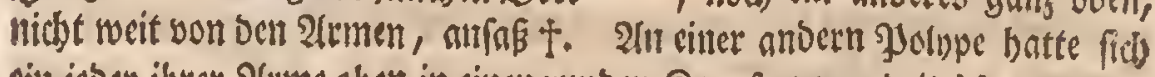
eit jeber ibter 2 (rme oben in einen runben finopf werwandelt $t+$. Es blieb biefe ஒolype in ber Stellung, wie fie bie 2lbbiloung seiget, ben fed) 230 . d)en unberweglid auf einem flecte. Sie fhien toot zu feyn. So oft * Seit. 48.u.f. ** Tab.III. Fig.IV. a. P* b. + c. It Tab.III. Fig. IX. 


\section{(9)}

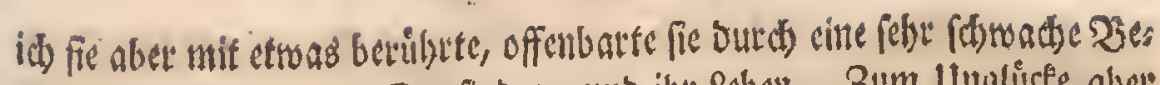

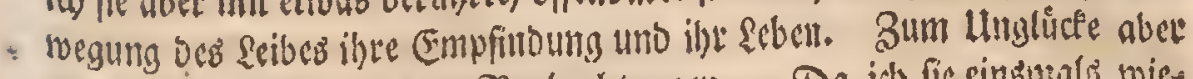

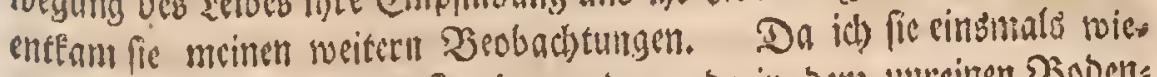
Der angerúblest batte, finl fie ab, und wotroc in bem unreinen 2300 ent

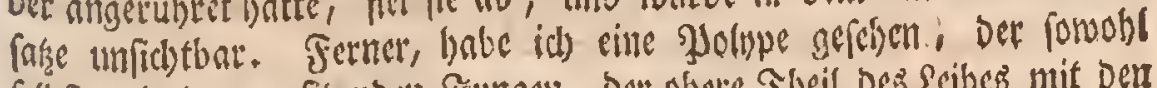

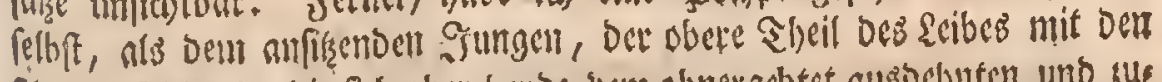

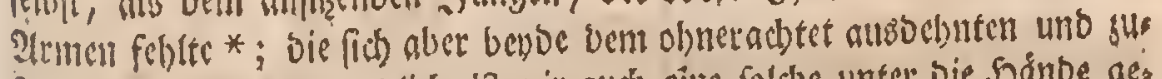
fanmentiogen. Uno errolich, if mir such) cine foldbe uneer bie Sagande ges

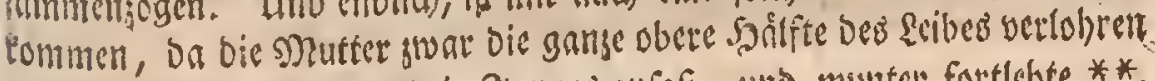

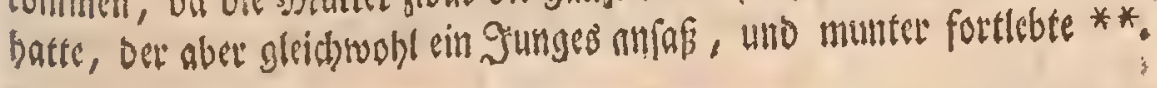

Diefer fen genug von bem, wab bicfe griment Alempolypen mit ams Sern gentcir babert. Gid) formme num auf Dicienigen Uutrerfebeiountys

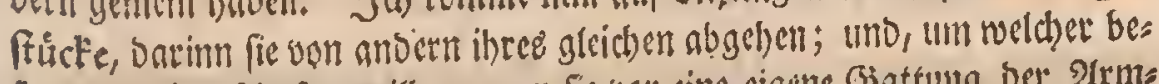

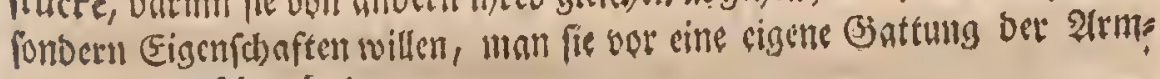
poloper ansuretsen bat.

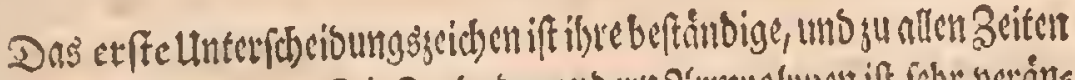

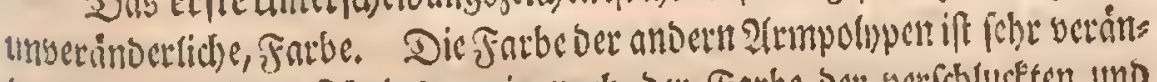

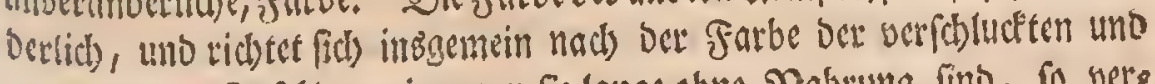
ausgciogenen Sureetten; ia weenn fic lange obne Palfeumg fino, fo vers

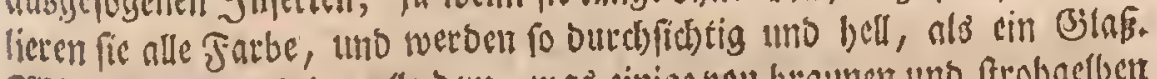

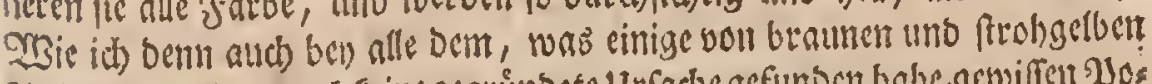

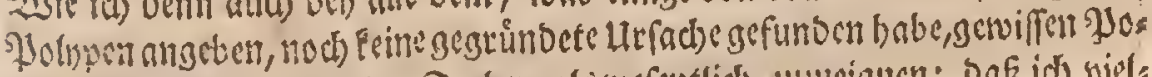

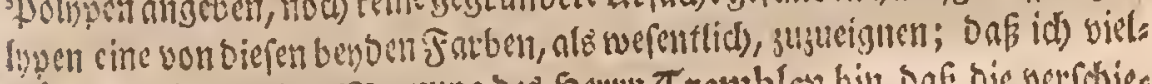

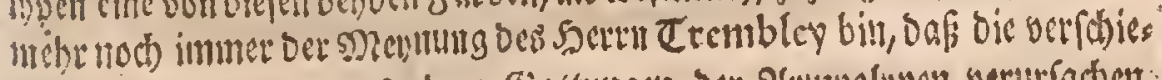

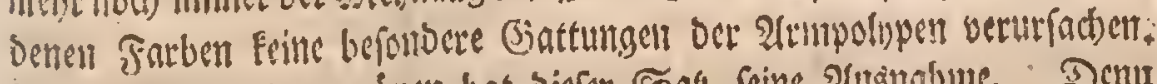

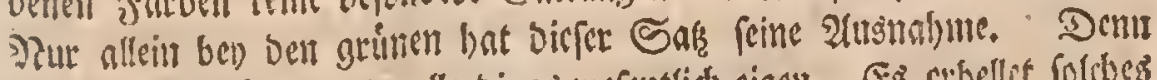

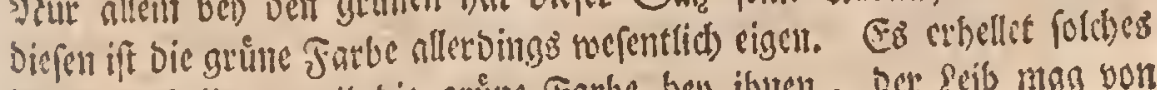
babcr; theils, wcil bic sriute Farbe bey iburen, ber scib mag yon * Tab. III. Fig. VII. "Fig. VIII. 


\section{(10) ) 彩}

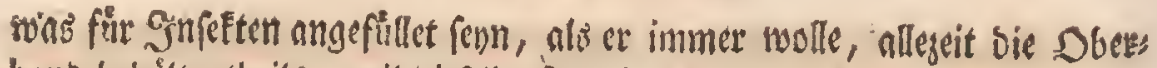
bano bebålt; theils, weil dieferlbe fids nidbt verlieret, wenn man fie auds noch fo lang ausibungert, uno obne alle ’a abrung léfit; unto enolich, weil, wenn man fie in 2seingcif, Salswaffer, ooer Eauge roirft, fie auds bier lange 8 .it ithe grime faltue bebalten.

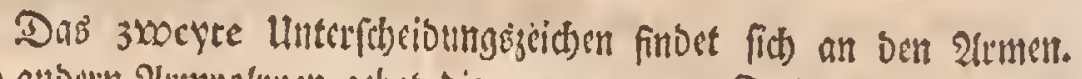

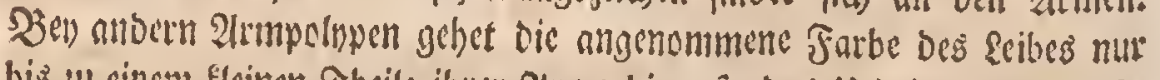
bis ju cincm fleinen Sheile ibrer ?ltme binauf; Das Ulebrige uno meife

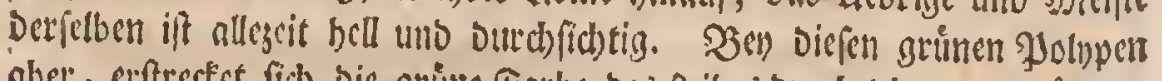
aber, erftectet fid bie grune farbe bes seibes burd) bie gantse vólligen

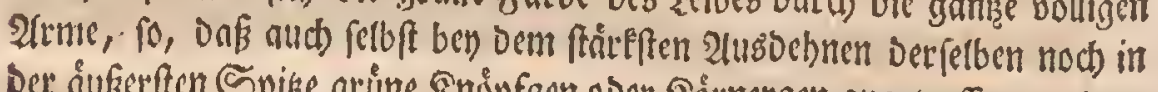

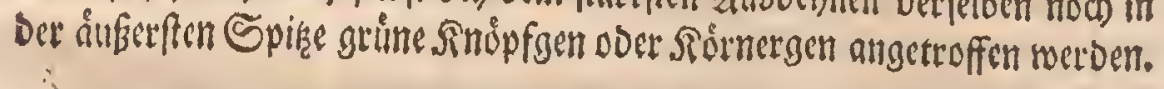

Del Ort, mo ben Diefert grůnen Jolnpen bie Gungen orbentlicher

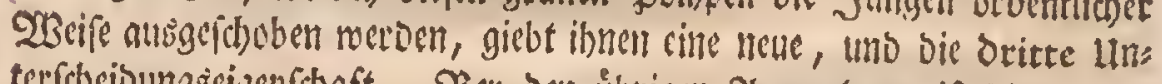

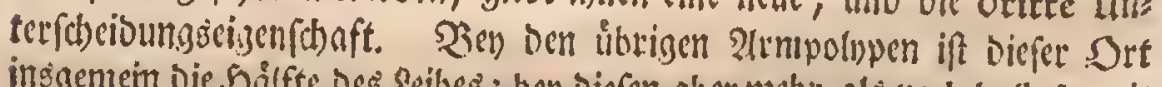
insgemein bie Sailfte Des seibes; ben Dicfen aber meble, als nods balb fo weif unten *. Eie mogen einzclne, wenige ober vicle, Jungen zugleich sus: folieben, fo mito man fie oroentlicher 28 cie alligeit ganj weit unten antreffen.

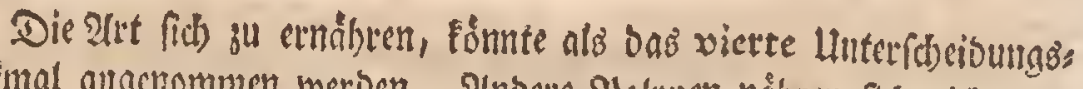

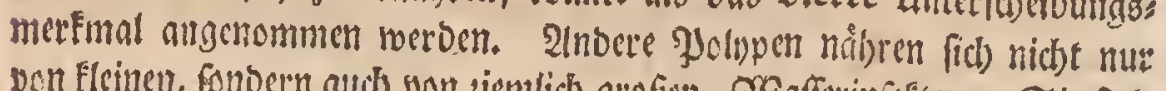
von fleinen, fonbern aud) yon jientid) grosen, 2 affering feten. Sie finb

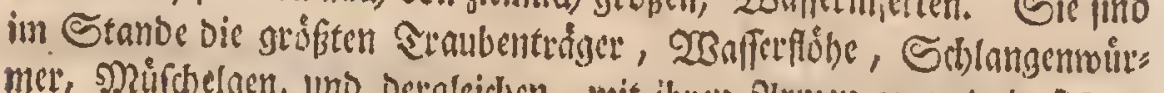
mer, Muirchelgen, uno Dergleid)en, mit ibren 2lemen an und it fich zu bringen. Dirfes Eỏmen biefe grinten \$olnyen nidbt betwerfftelligen. "Sie

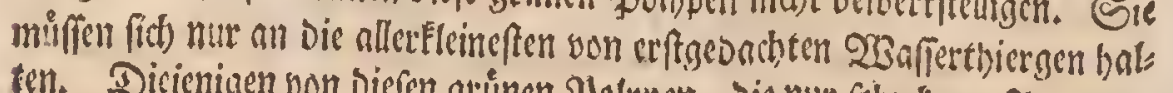

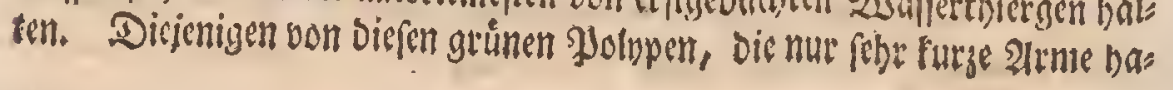

Tab, I. Fig. XIV. XV. Tab. III. Fig. IV. b。

berl, 


\section{(II) ( I )}

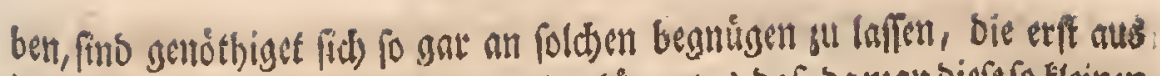
ibren Evycrn gefommen find; und Daber fömunt es, on

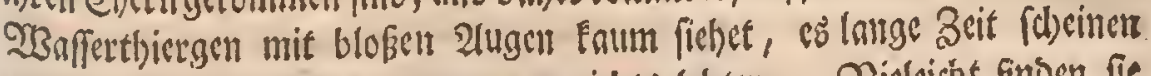

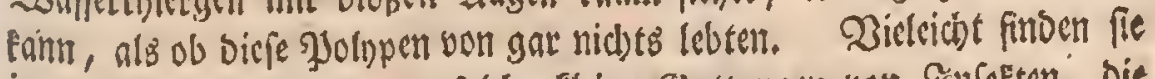

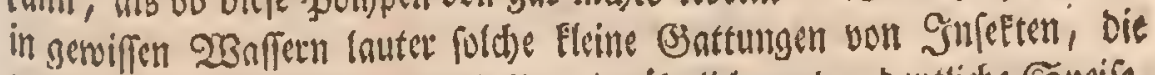

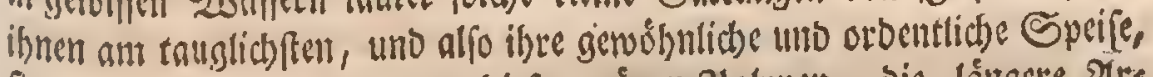

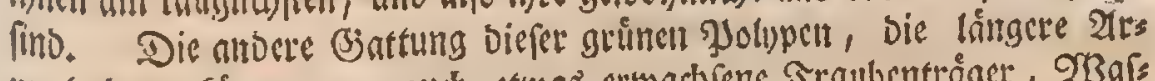

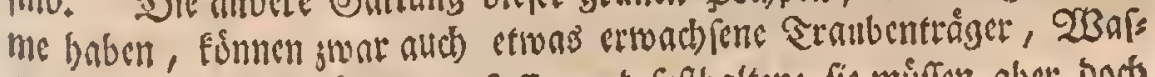

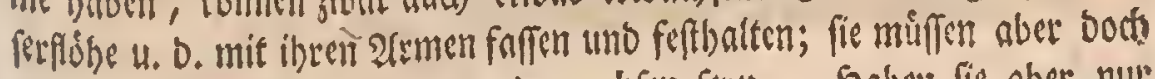

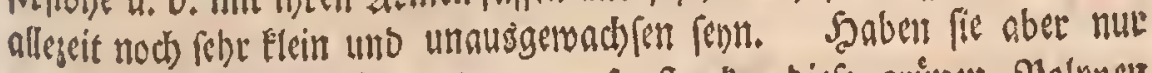

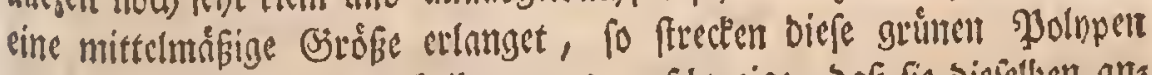

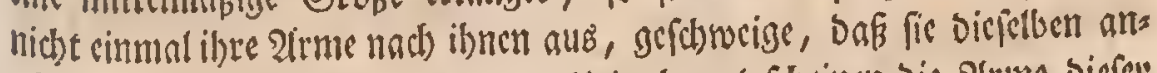
båfell und an fid) ziefen follten. Heberbaupt fobeinen bie arme biefer

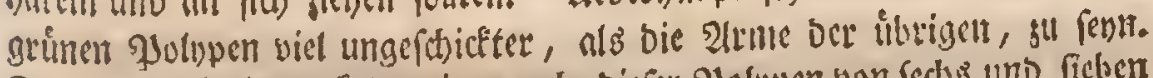

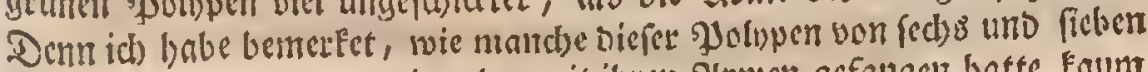

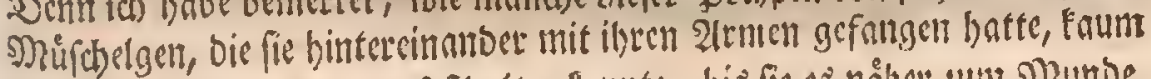

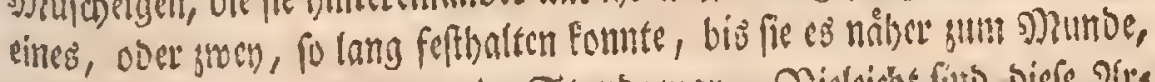

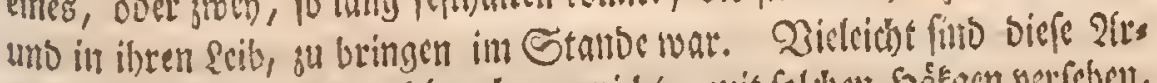

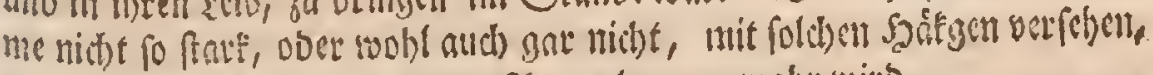
Dergleid)en unan bey ben andern 2irmpolnpen gewaht wirb.

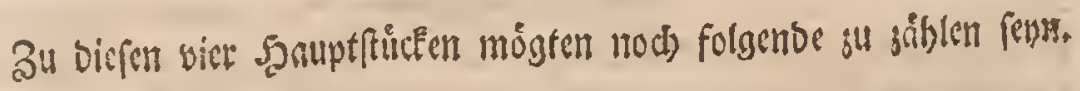

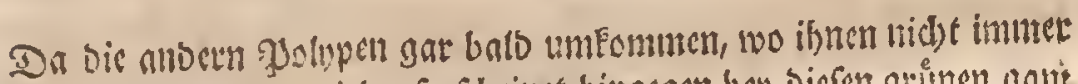

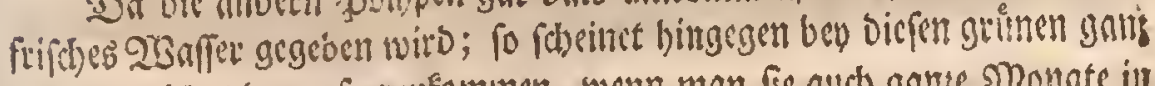
uno gar nictsts barauf angufommen, wenn man fie aud) games Monte in

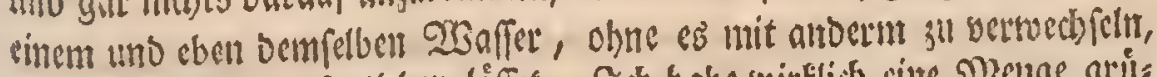

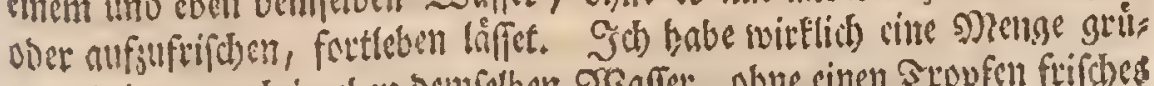

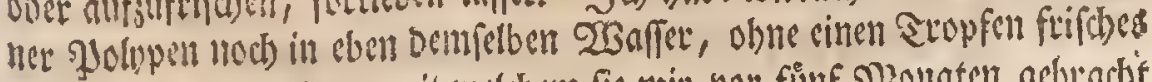

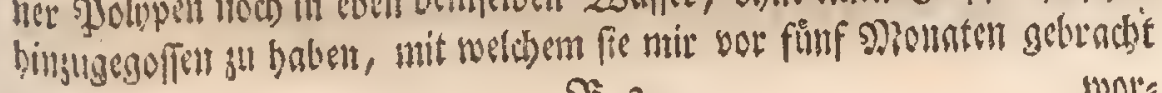




\section{( I2) (3)}

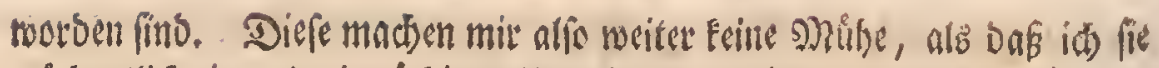

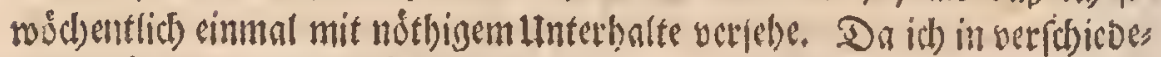

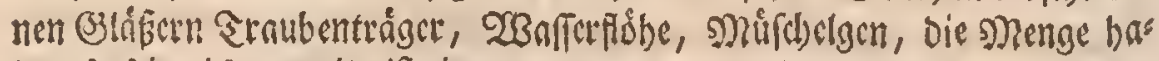

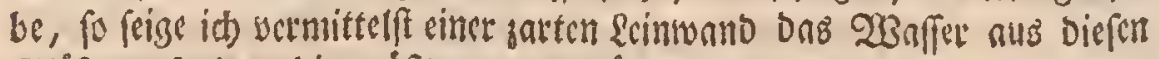

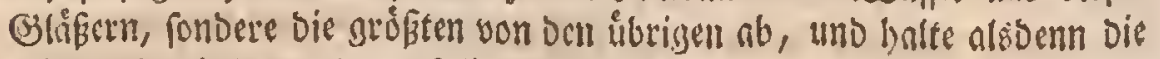

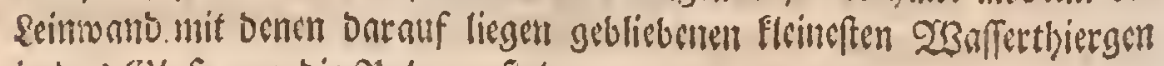
in ons (3) laf, mo bie Wolipen finto.

Es befthéftiget aber überbaupt biefe SImntrefung, was ich oben son

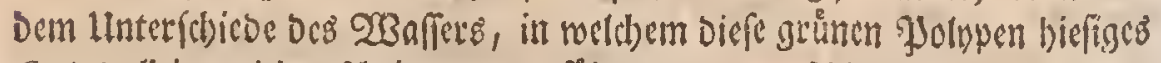

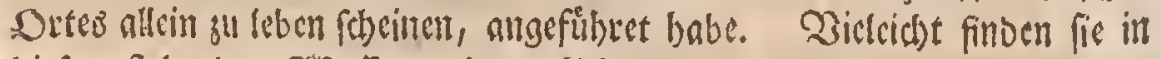

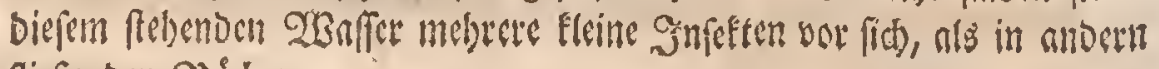
flięenoen פ̉ídlen.

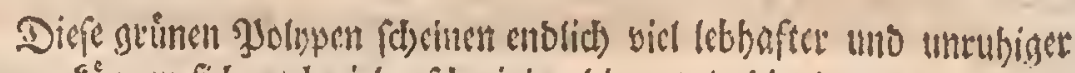

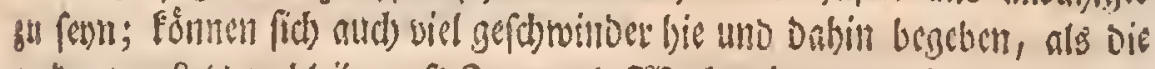
andern. Seretere bleiben oft Eage und 260 den immer auf cinem Fleclis,

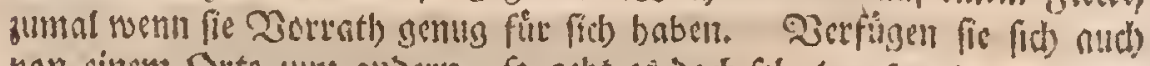
yon cinems Oete sum alloern, fo geht es Dodb feht (angfam ber.

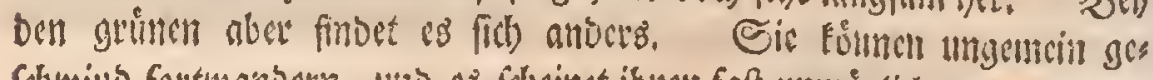
Chbwillo fortwanbern, who es id)einet ifnen faft unmogiglich su fonn, nuds

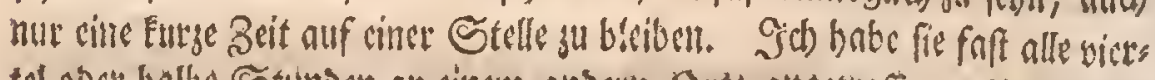

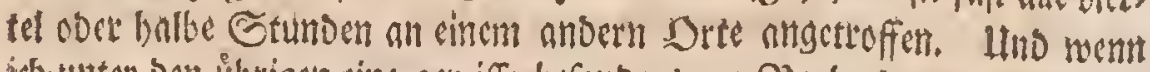

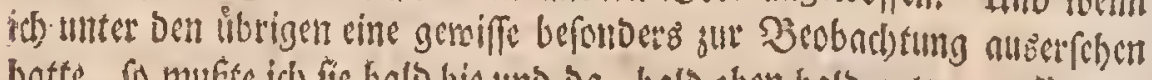
batte, fo muste ids fie balo bie und ba, balo oben bald unten, auffucber.

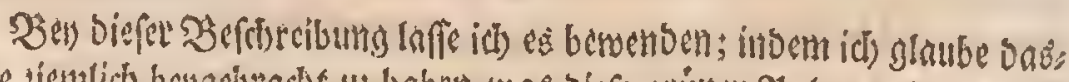

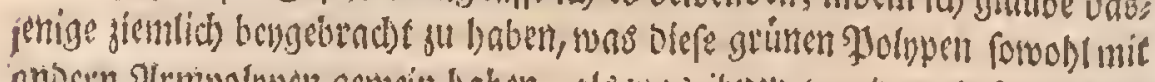

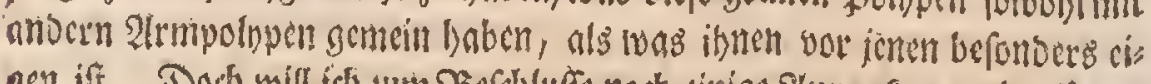

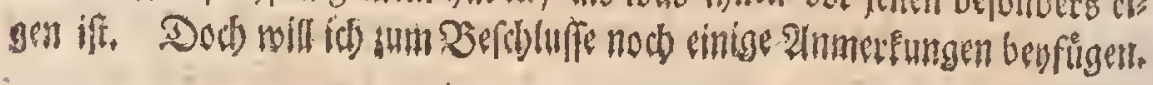




\section{( 13 ) 称}

Es ift oben erinmert morben, Doß id biefe grumen \$olypen itt cinemt fumprigten Srunbe gefunden babe, Der unmittelbar vom SRegenmaffer

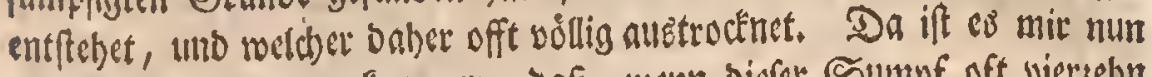
als was feltentes vorgefommen, oaf, menn bicfer Sumpf oft vierselyn

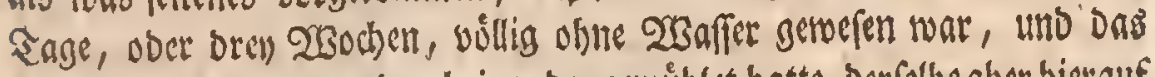
Qiel bie Eroe Darinnen burcheinanoer gewuiblet batte, Derfelbe aber bierauf

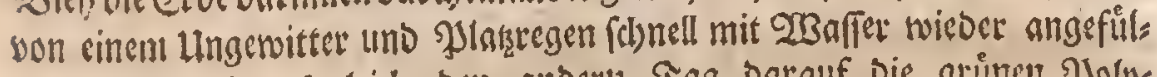

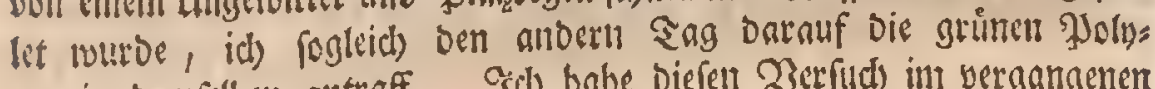
pelt in bemielben antraff. Sich habe Diefen Derfud) int vergangenen

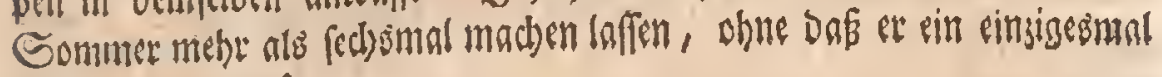
feblgerblagent whire?.

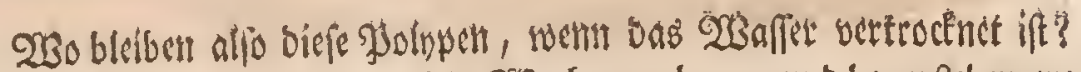

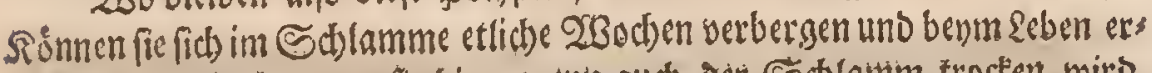

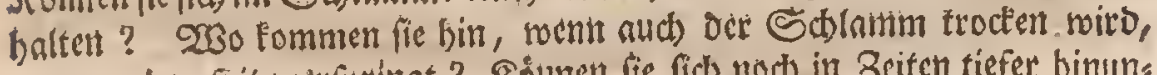

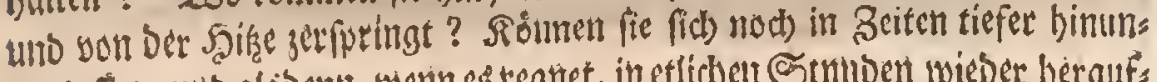
ter laffen; unb alebennt, wernes esegnet, in etlichen Strilloen wieber bernufs

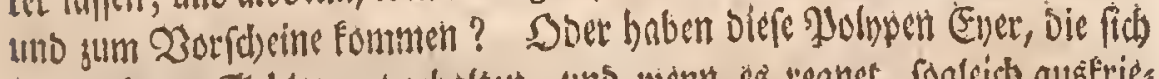

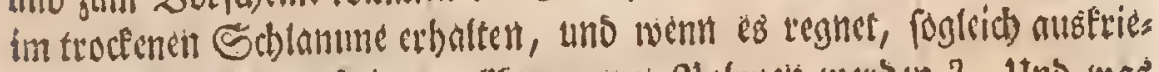
d)en, unb in turger Zeit zubollfummenten JJolypen werben? Itno was

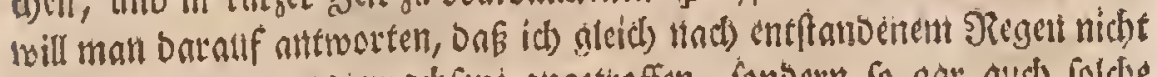
nur fleine und unausgerwadb fene angettoffen, forbern fo gar aud foldse

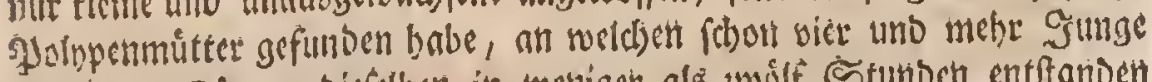

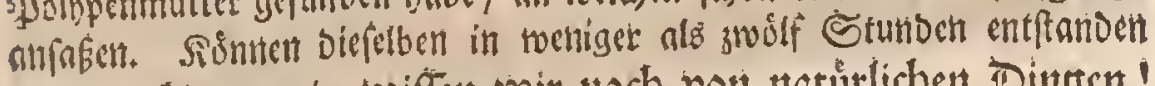
fern? So boenig wifien woir noch bon naturlichen Dingen!

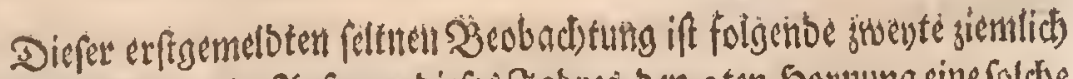

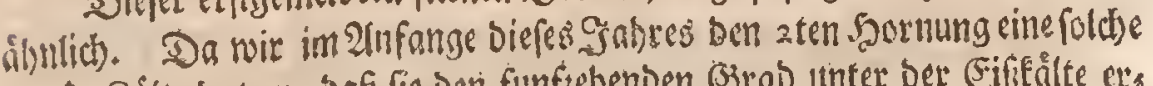

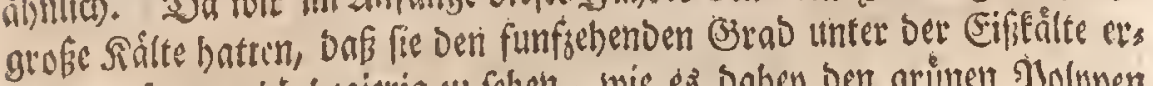

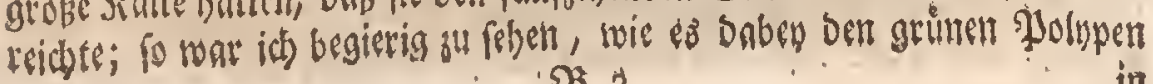
'शु 


\section{- ( I4)}

in eitrem berienigen Simpfe, wo ich fie am Enve bes vorigen Gafieb,

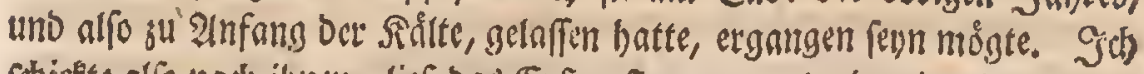

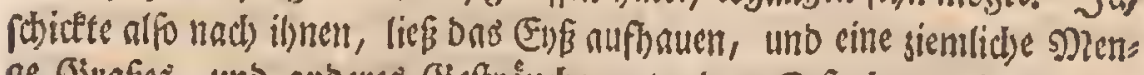

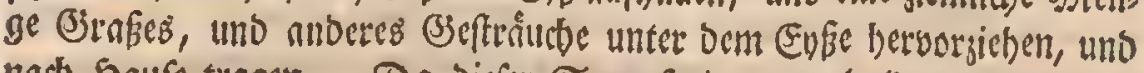
nach) Şaufe tringen. Da biefer Sumipf cine gute balbe Stumbe von unferer Stabt liegct; fo war natirlicher 23 eife bey Der fo grofen Sảlte

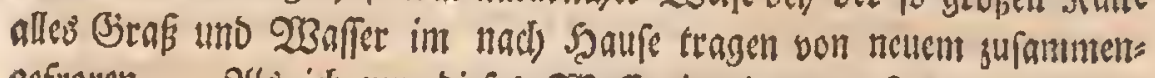

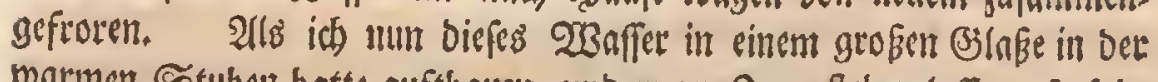
roarmen Stuben batte aufthauen, uno zween ₹age fethen laffen; fo fabe id) biersuf in meinem (stafe alles voll grúnter Jolypert, bie san!s munter lebten, uno bie fich nach uno nach auch fortpfiansten. 2Bie fonberbar

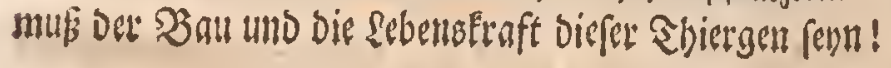

Sollte es inbeffen crlaubt fenn, cine s)utbmafung benbringen gu

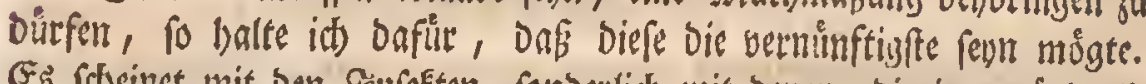

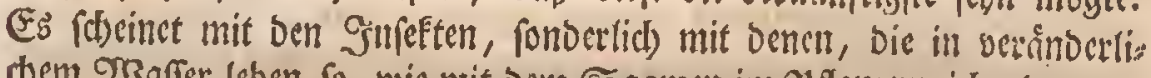
them 228 affer leben fo, nie nit Deur Saamen im gyfanzenteidbe, bersuges ben. Der allmád)tige unb weife Schơpfer mag gleid) im 2(nfange gewiffe Arten won Shiergen erfhaffen baben, Dercin Seben Eann surite ge:

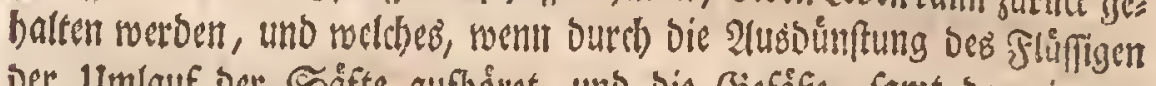
Der llmlauf ber Saifte aufboret, und bie Biefápe, famt bent imern

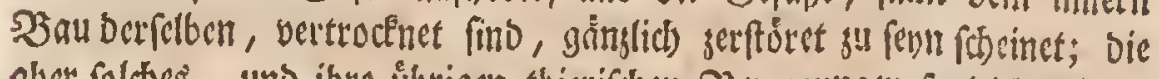

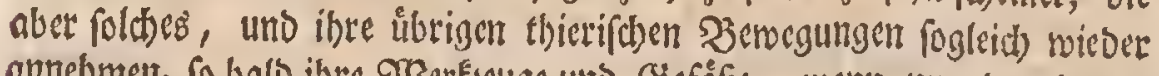

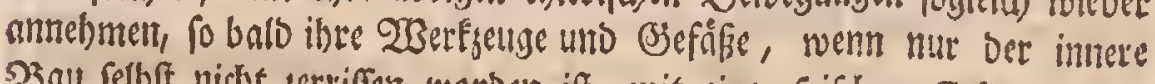
23aul felbft nidbt zerriffen worben ift, mit ciner frifdsen Erfeçung bcs Flufiligen etfúllet meroen.

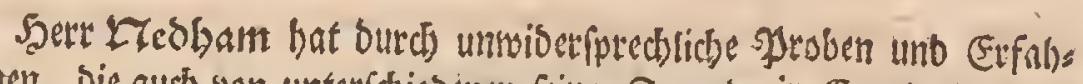

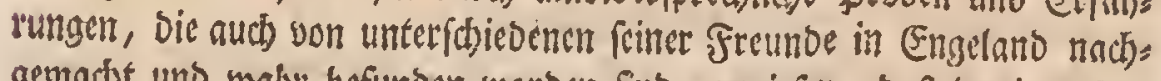
gemadst und wabs befunben worben fino, etroiefen, baf in einer 2 (nt 


\section{(15)}

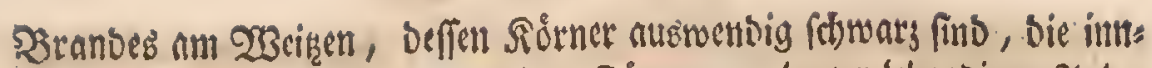
wendigen weidsen, werisen uno flcinen Fåjergen zu lauter lebendigen 2halen

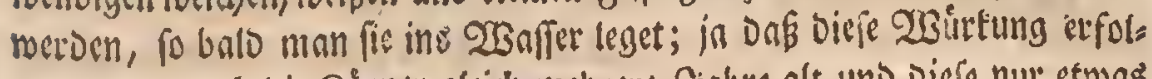
get, remn aud) bie Sơrner gleids inebrere Gahlece alt, uno Diefe nur etwas

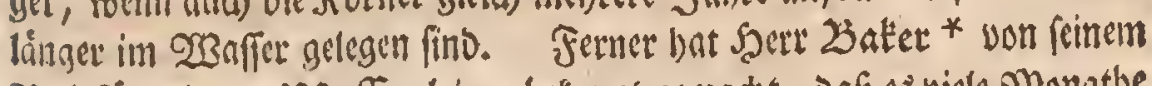

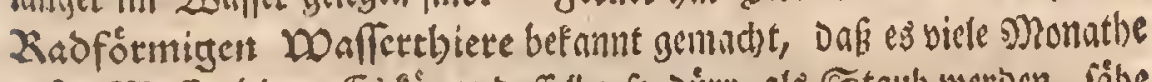

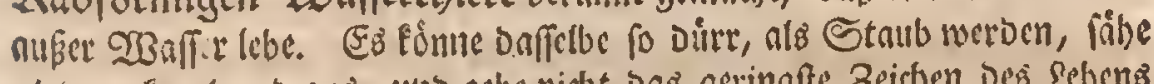

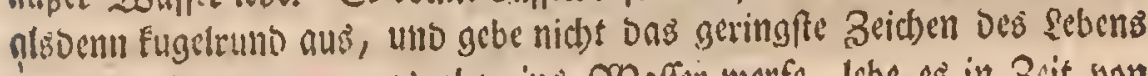
ben fidt; fo balo man es aber ins 23 affer werfe, lebe es in Sait won riner balben Stunde wieder auf. Es zeige alötenn feine Fioed wie jubor, tino fange von neuem an anbere Sinfeften ful fangen und sil freffen. Noun

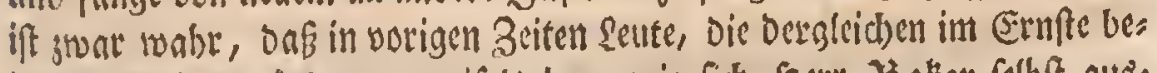

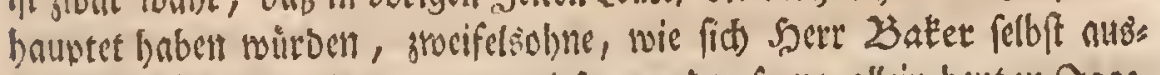

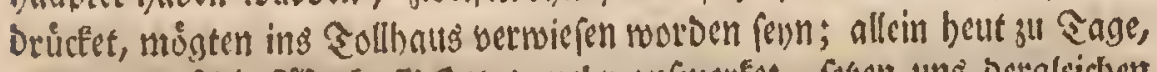

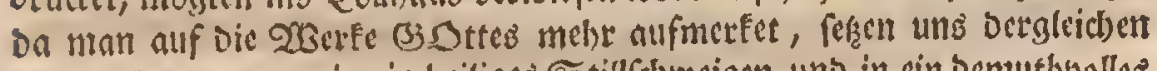
Deobachtungen nur in ein heiliges Stilldymaigen, uno in ein bemuthoolles Enftament. Sind aber biefe Erfahrungen wabr; fo fehe id nicht, wars

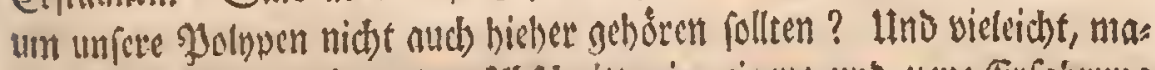
d): id) Filbf in Dem folgentoen s(bichnitte cine cigene und treue Erfabrung

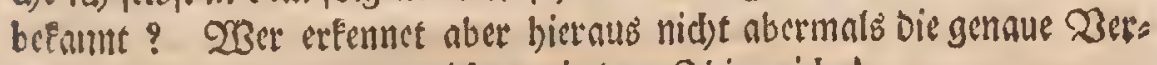
mandrfbafft Des Yyfanzenteides mit Dem Sbierreidbe!

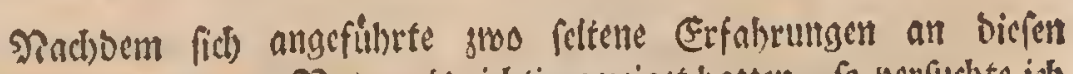

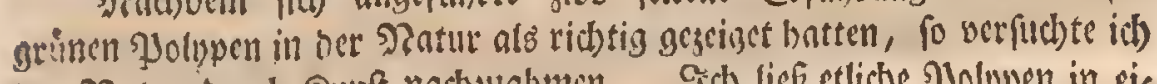

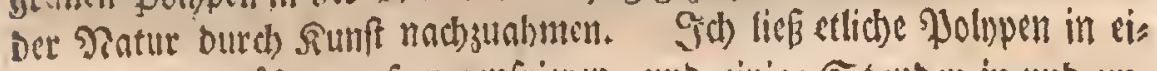
nen Fleinen Blípigen jufammenfrieten, uno einige Stunben in unb un, ter bem Ense. 2lls fie mieber aufgethautet waren, fo fobienen fic, Dem 2leuferlident nach, feille grofe Jerninberung erlitten zu baben. Sis

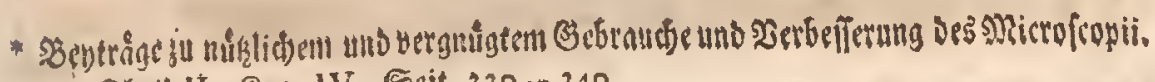

Sheil II. Sâp. 1V. Esit. $330 \cdots 340$. 


\section{(16)}

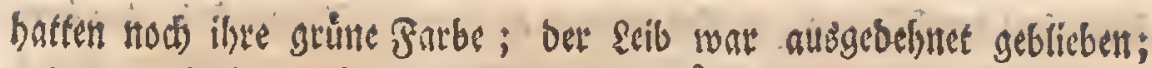
uno nut bic 2ame fabe man etwas verkin'st uno sufantmentsejogent.

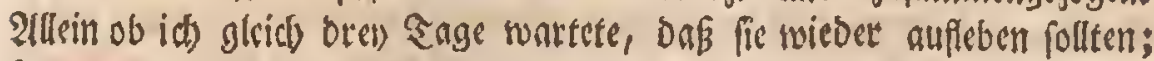
To warkete id) boch vergebent. Sie blieben obne alle 23 eroegung,

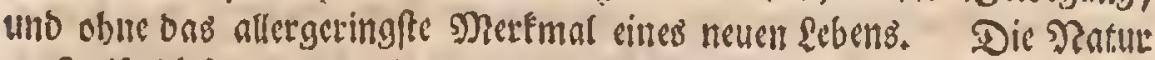

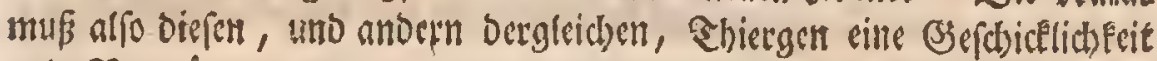
und Dermógen ertheilet baben, fich in ber grósten Sålte uno im Enpe

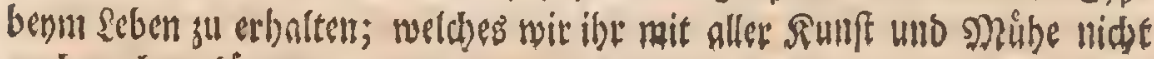
nad)machen finmen.

9)is(unge es mil ben biefen ceften Sunftgriffe; fo wat id) ben

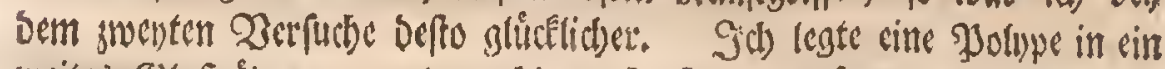

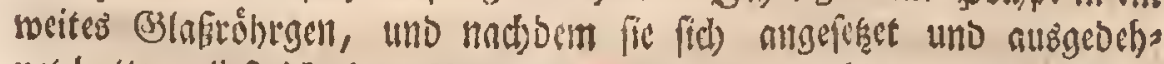

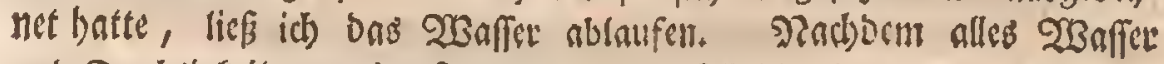

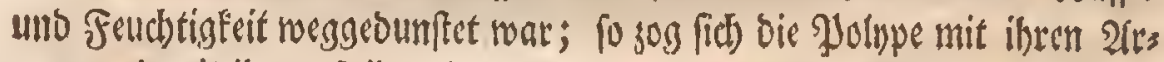

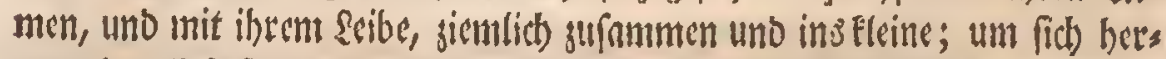
unt aber lies fie cinen beflen weifen burdfidjtijen Sdanum, ber bem Sd)aume ber Sdba!mwirmer vollfommen gleid) fabe, nur bap et biet

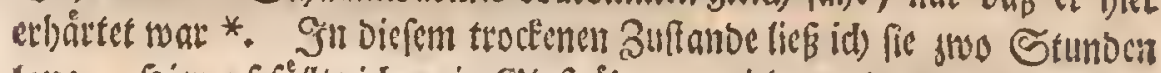

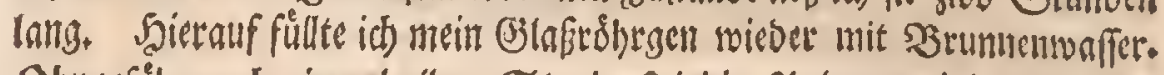

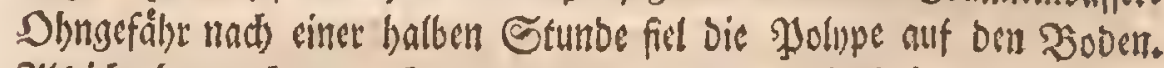
2l(b id) aber nad) sween ₹agen wieber nadjabe, fano id) fie lebenbig,

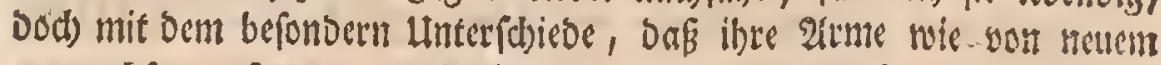
su wadsen anferngen; uno bie alfo bey) bem 2astrocinen sweifelsolyne mogen Sdbaben gelitten baben.

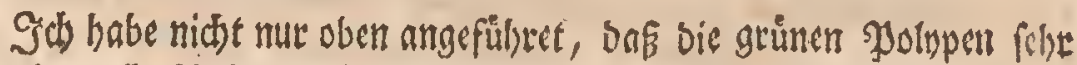

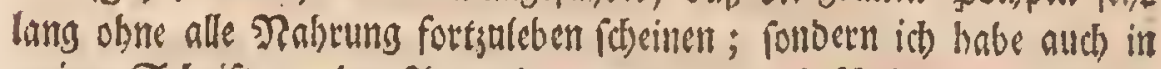
meiner Schrift von ben 2(rmpolypen, als febr wabricheinlid, angegeben, Das fie úberbaupt vermittelft ibrer Rớrnergen, unb berrelben Saunen, * Tab. III. Fig. V. einis 


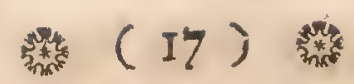

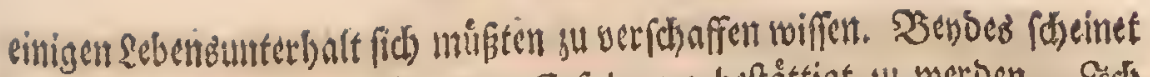

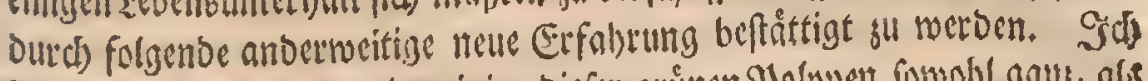

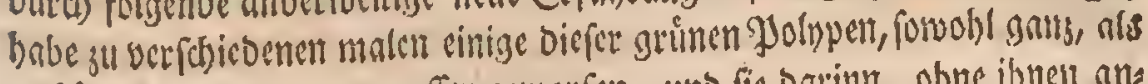
serfticfelt, in Srunnenwaffer geworfen, uno fie oarinm, obne ibnens ans.

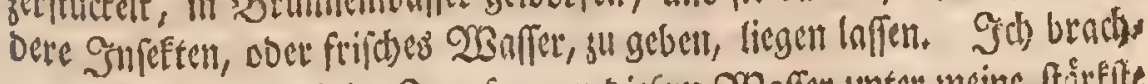

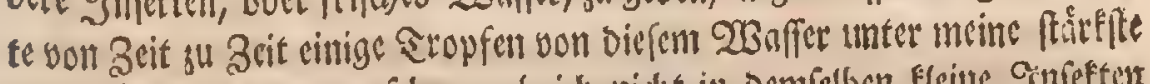

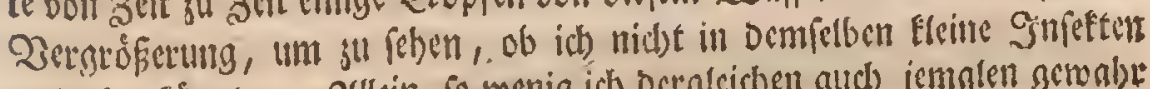

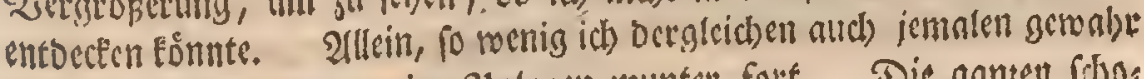

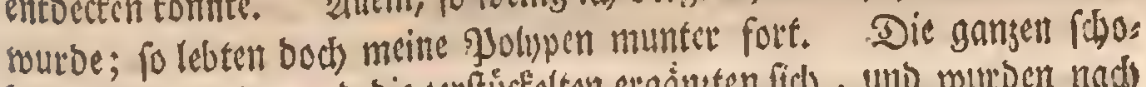

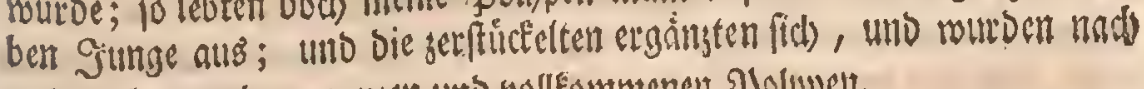

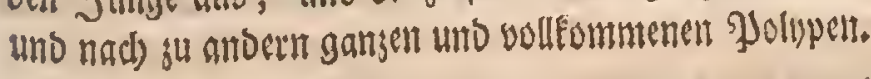

Soun etwas neue Sheile erbalten, obne von aufen cinen Zulatis zu

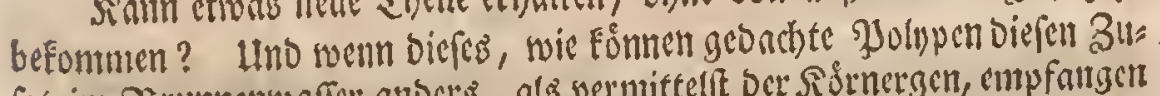

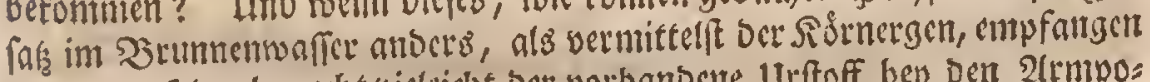
haben? Doer brnudtet victeicl)t ber vorhandene Irftoff bey Den 2(rmpos

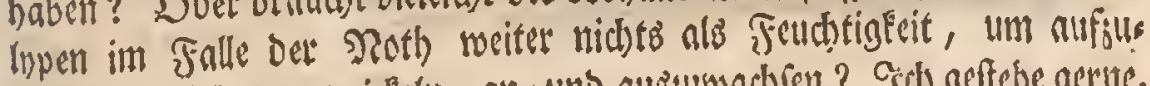

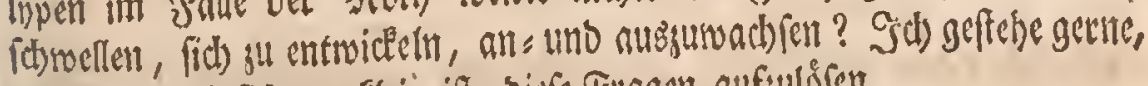

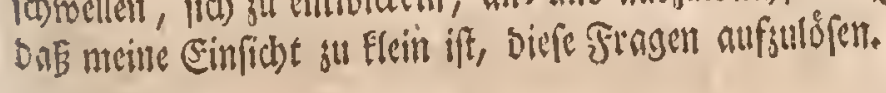

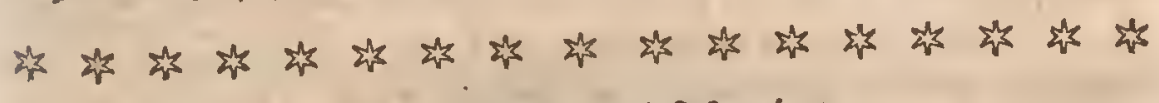

\section{Swet)ter Sifordinitt.}

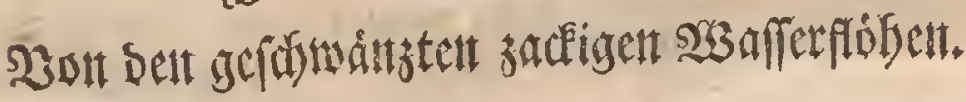

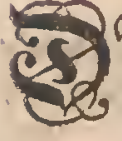

a biejenigen. 23afferthirrgen, benen gegenwaittiger uno folgender:

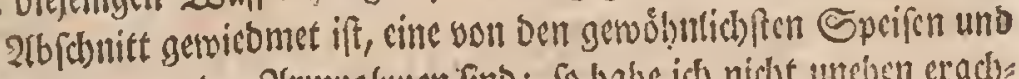
গabrungen der 2(rmpolypen fino; fo babe id nicht unteben erad): tet, aud) biefe nuf bas gennuefe uno porgfíltigfte zu unterfucten. Lino es (d) 


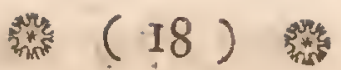

Det. Ess ift mir unter meinen Seobad)tungen nid)t mut cine gans neue uno feltfame (3)attung berfelben befannt morden*; fonoern id) babe aud)

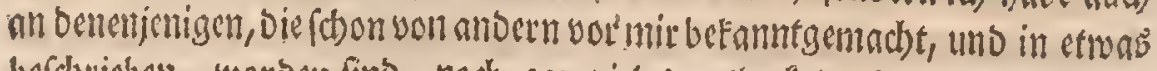

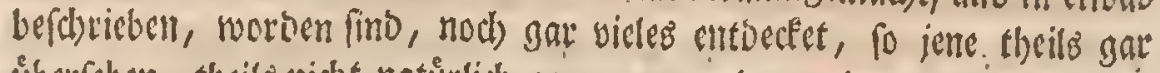
überéten, theils nicht naturllich genug angegeben uno abgebilbet baben.

Daв Bjefhlecht biefer 2 Baffertbiergen bat, nus utfachen, bie ich

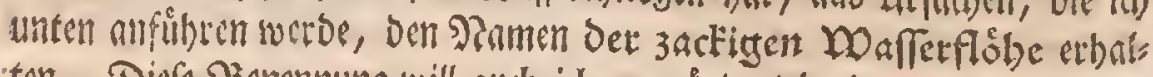
ten. Diefe $\mathfrak{3}$ enenmung will auch ich ungeảnoert benbel)alten. Nidht,

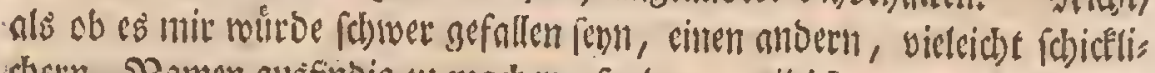

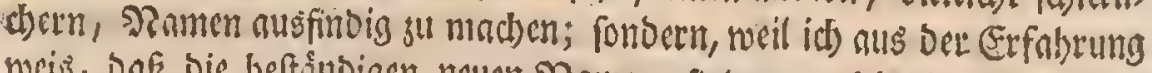

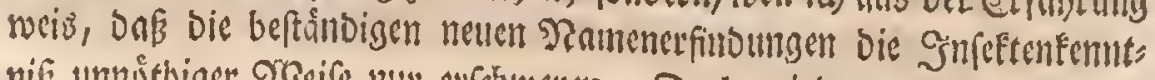
nis unnuthiger 23 eife nur erfetweren. Dod) wiro man ntir erlauben,

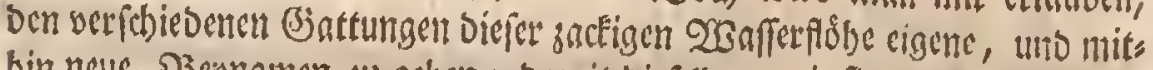
bin neue, Jesnamen zu geben; bamit bicfelben, wie fie an fich felbft vets

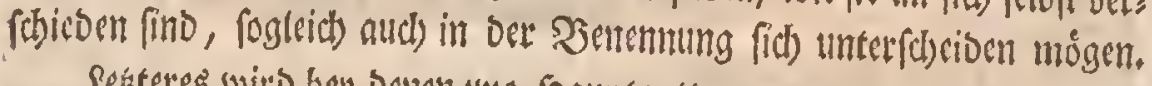

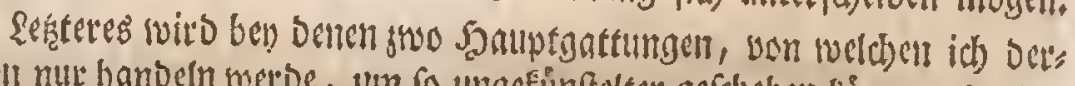
malen nut banbeln werbe, um to ungefúnftelter gefdachen fơnnen, ba be:

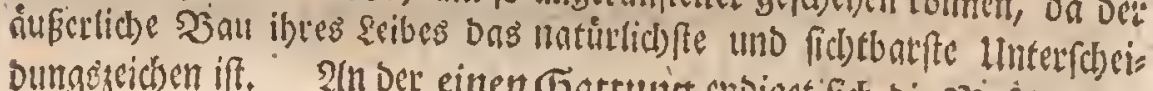

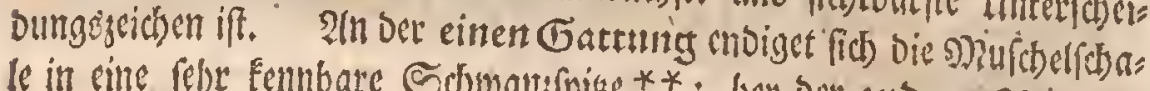

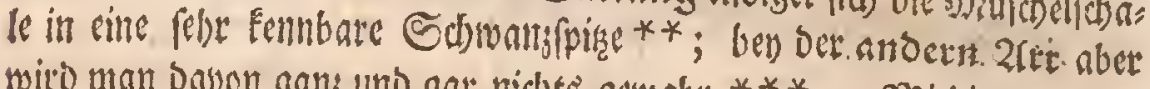

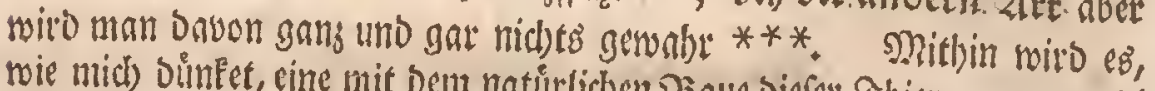
roie mid) binmet, cine mit bem naturtlid)

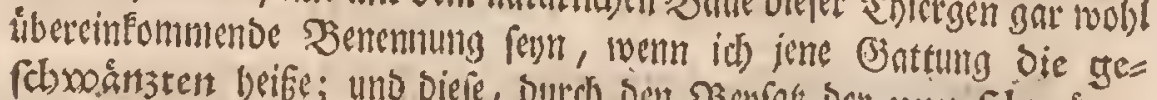

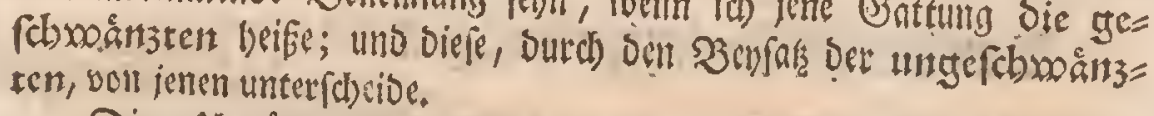

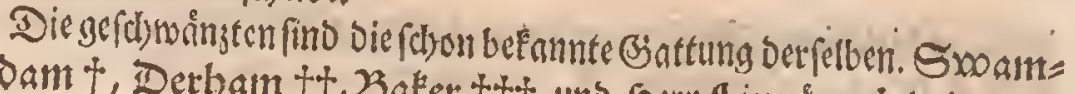
merdamt, Derban tt, 2 aker tt', und Sacr Lima:Hs t, laben uns

* Tab. I. Fig. IX. ** Tab. I. Fig. VI f. VII, VIU "Da

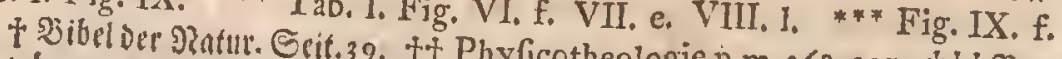

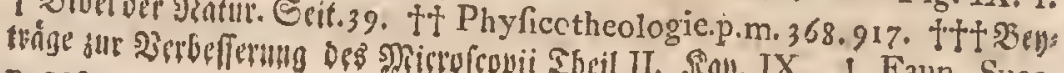
A. II\$2. 


\section{(19) (19)}

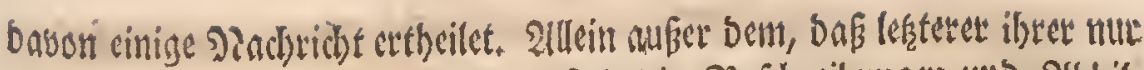

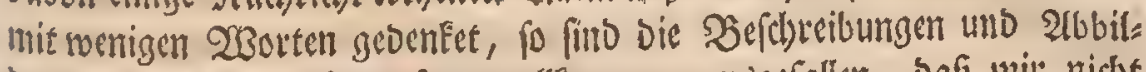

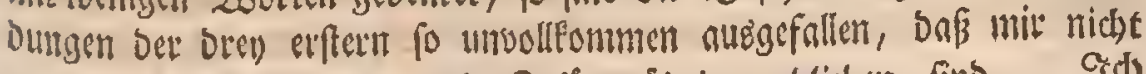

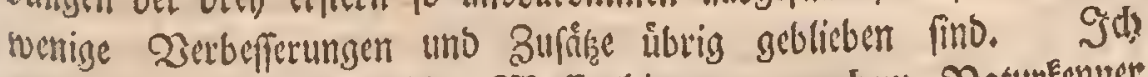

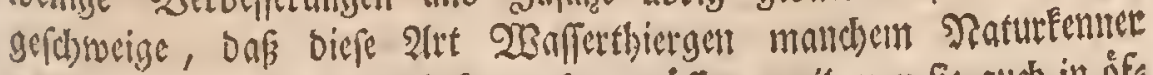

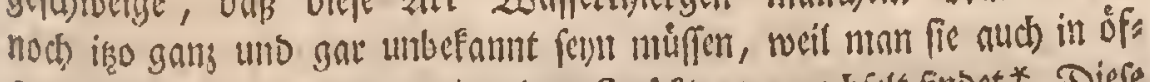

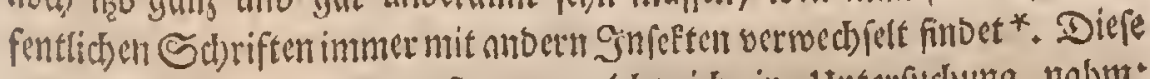

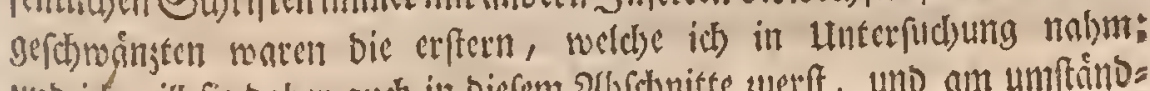

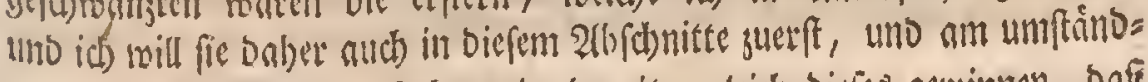

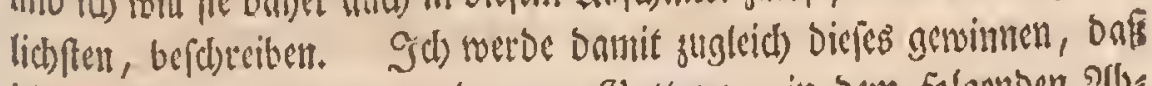
id) mid) bel) ber anberin und neuen (3attung, in bem folgenden 2 (bs

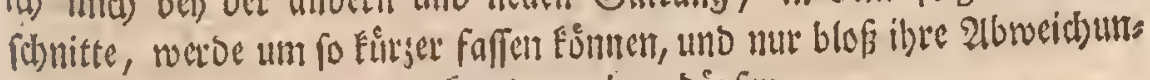
gen unb LunterficheibungsmertEmale anseigen birforn.

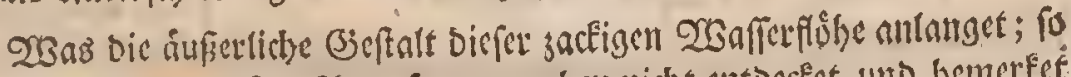

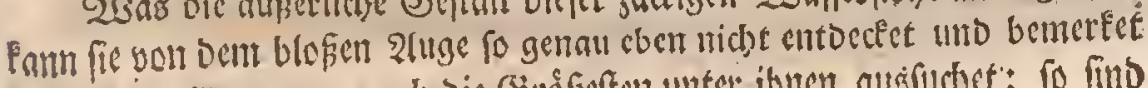

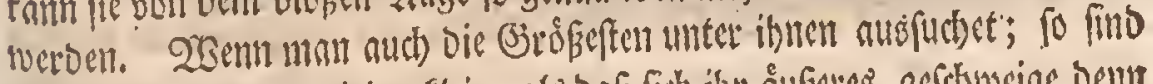

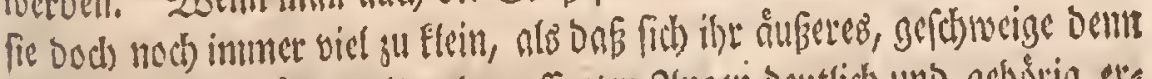

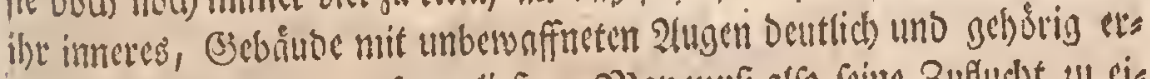

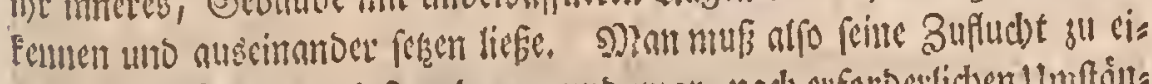

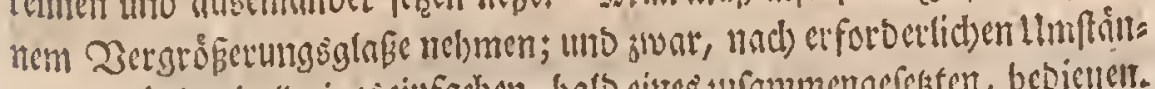

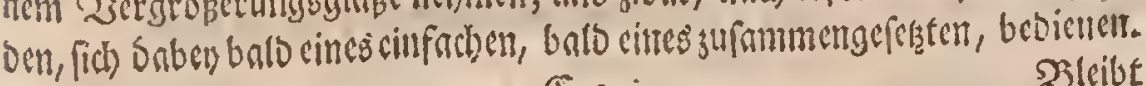

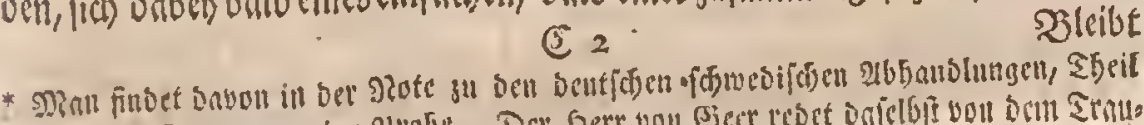

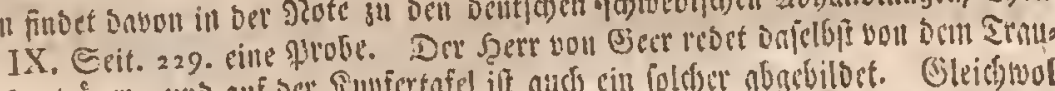

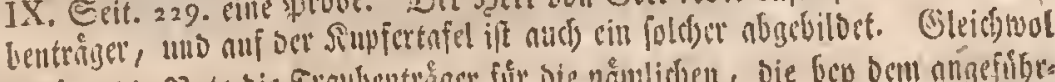

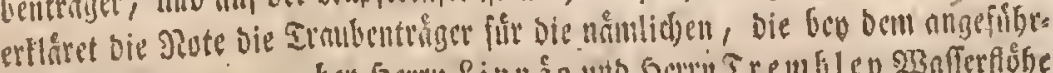

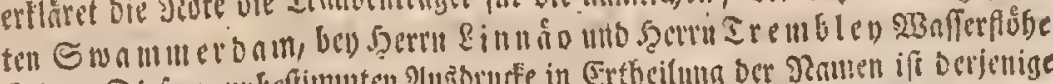

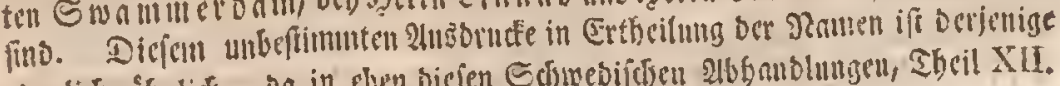

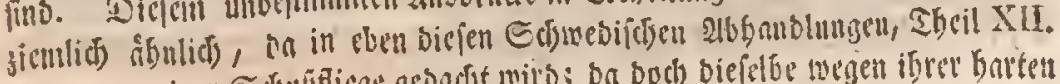

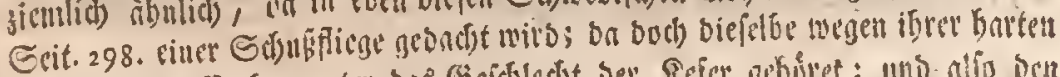

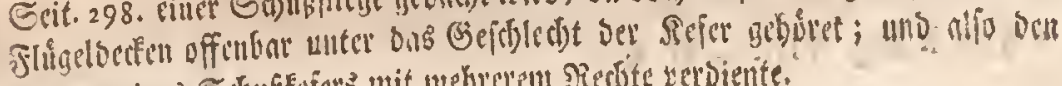

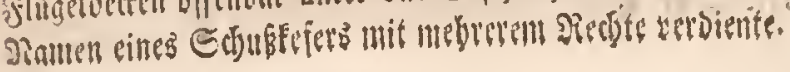




\section{(20)}

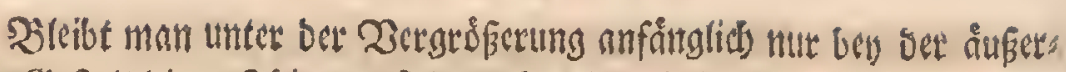
ficbert (Beffalt Dieler Shiergen fethen, fo gehet bie Seobadstung Derfelbers nocl) fo sientich (eicht von fraften. Na an Darf nut in ein sumbs uno bobls

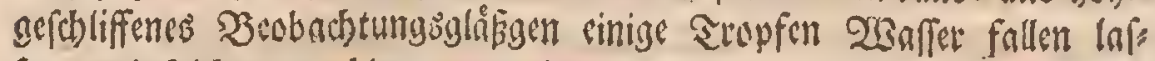
fen, uno foldbes, nacboem man cinen ven diffen zactigen 23 afferfibsen bineingeleget bat, unter bic sufaummengsfeşte Bergróserumg bringen;

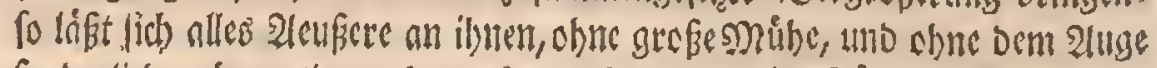

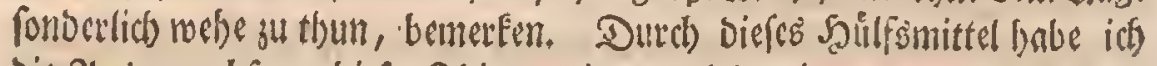
Dic 2lusgewadbenen biefer Shiergen jebesmal fo gebnuct uno geffaltet ges funoen, wie idh fie abbilben laffen, und fie nun befobrciben meroe.

Der ZRopf mit feinent langen fortyange; bic 2lume; bie truts rebelfchale mit ibrer bintern Sdbroansfipize, fint bicicnigen Saupts theile, Derèn man yon nußen gewabre wito, uno Deren jebes insbefondere zu beleudben iff.

Der Žopf * fabe an allen bencrienigen, mit welden idb im sorigen Eommer meinc 3 bobadbtumgen angeffellet babe, im Banjen betractet,

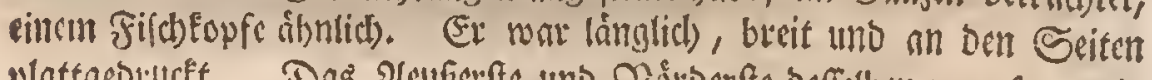

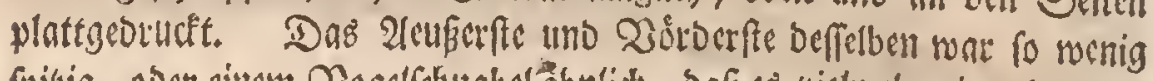

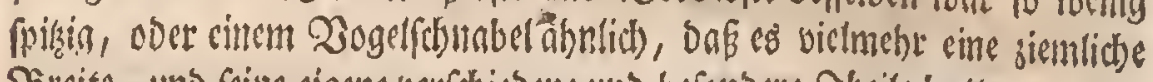

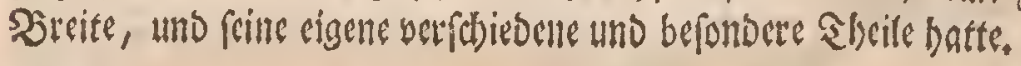

Diefe Bilbung madhte mich sicmilich berlegen, inbem Sxoammet= Oam, baket, uno pelbft dic 2(bbildung bey Setrn Trembley, Diefan

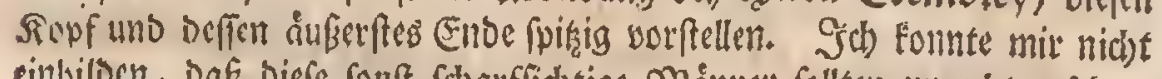
einbilben, Das biefe fonf fdareffichtige Moinner follten unred)t sefefen,

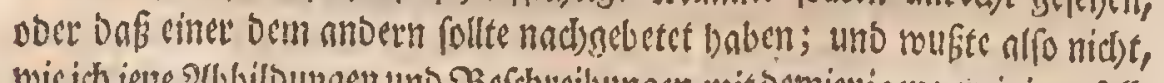

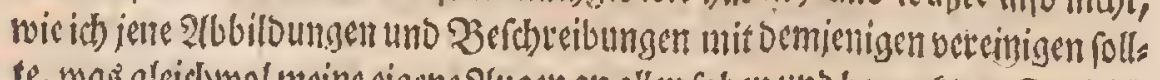

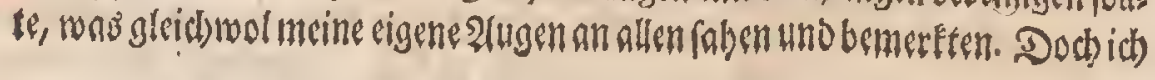

Tab. I. Fig. Vul, b. Il- ai toet: 


\section{(2I)}

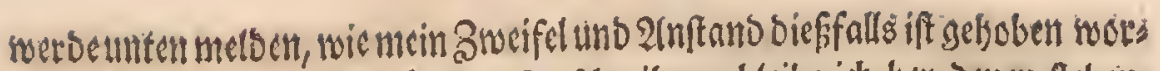

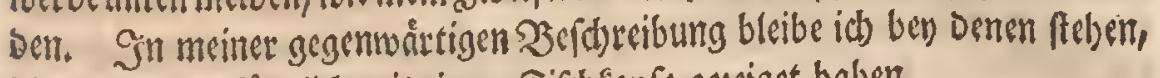
Die fid) mir anfônglid mit cinem firdsfopfe gçageiget baben.

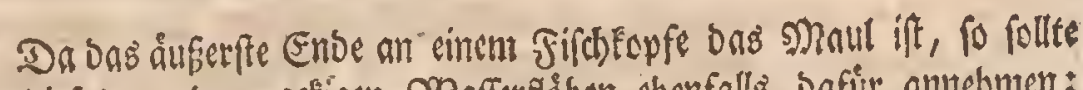

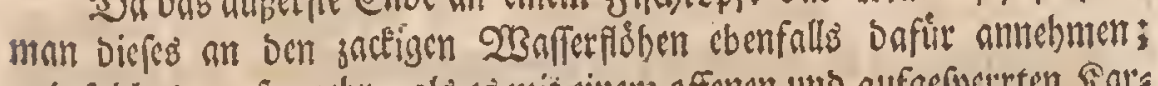
uno fold)es un fo mebt), als es mit einem offenen und aufsefpecten siar:

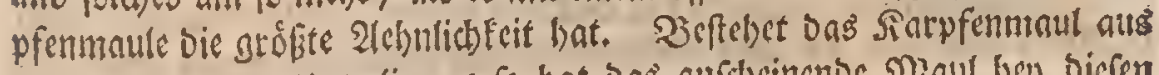
ciner Sber: uno Ulntertippe; fo bat Das allicheinende Piaul ben bicfen 23affertbiergen ebenfolls feime zueen bejonoere Slyeife. Der obere*. iff rebr breit, läuft (chereg nach vorne su, ullo enbiget fich in cine breite Echårfe, bie bey einigen meht, bey einigen weniger **, frumm und in bie

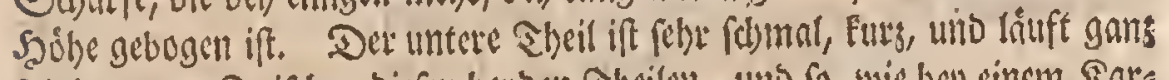

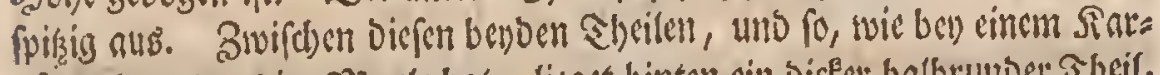
pfor, Der etwas im \$2 ?aule bat, lieget binten cin bicket balbrunder Sbeil,

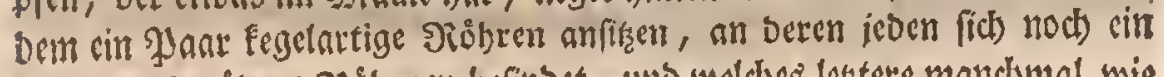

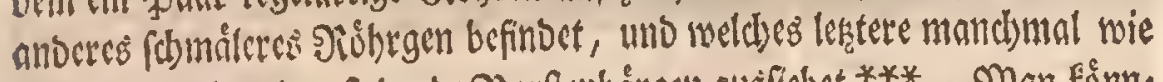

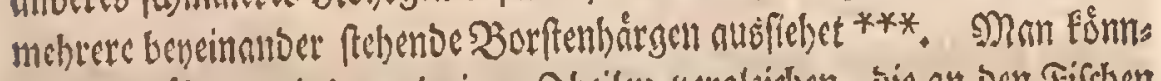

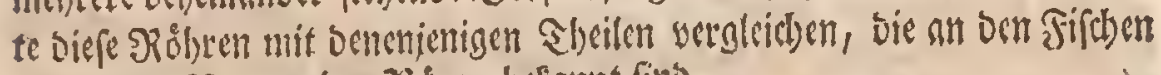
unter Dem Ramen ber 23 étere beEant fint.

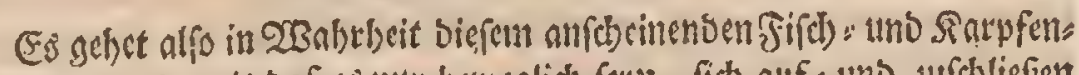
maule nichts $a b$, als baf es nur berweglic) fenn, fich auf = uno surchliefent follte. Doch eben Dae feblet ibm. Dirfes Maul bleibt bey biefem 2Baf ferthiergen je uno zu allen aciten wie anfgefpertet uno offen; uno nimt

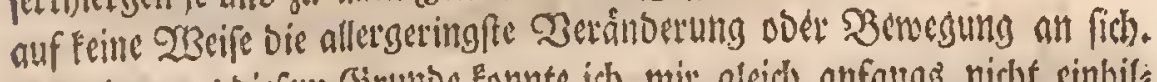
Lino eben nus biefem (jruntoe fonnte id) mir gleid) anfantgo nicbet cinbits

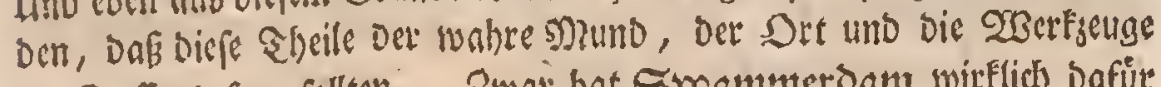

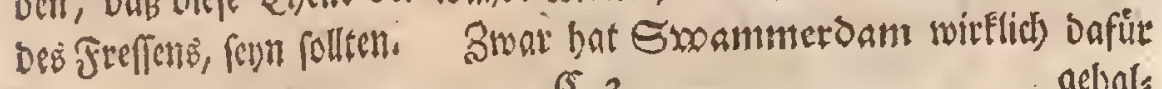
ह 3 gelyals

* Tab. II. Fig. II.'d. **b. *** Tab. I, Fig. VIII. † Tab. Fig. II e. It ce. 


\section{称}

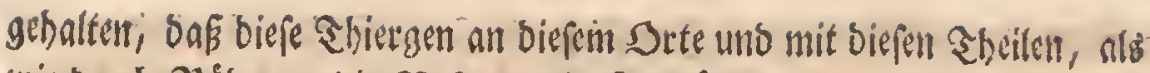

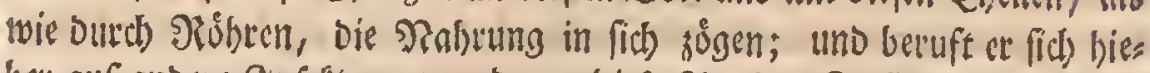

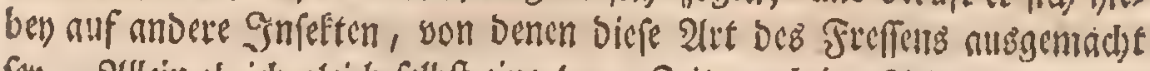
(et). 2(llein ob id) gleid) felbft cine lange Beit, nad) Der 2(el)nlids feit uno

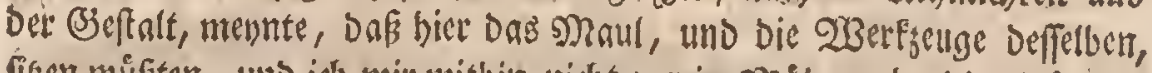

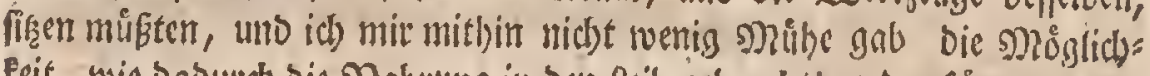

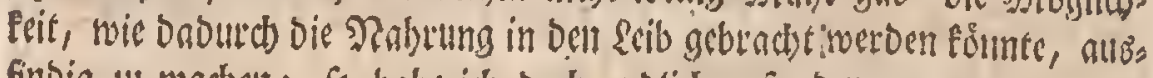
finbig su machen; fo babe idh Dod) endich sefunden, was vor cine fchlippfrige Gache es ift, noent mant mit Dorurtlycilent des 2fn=

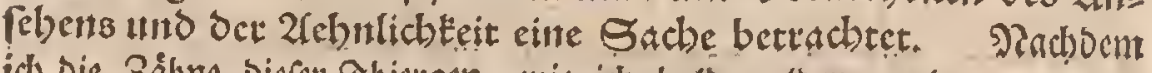
id) Die Sålbne Dicfer Sbietgen, wic ich balo meloen werbe, sn cinent sans anoern, uno gang ungewóbnlich fdicinenoen, Sorte entbecfet batte; fo nullere idb mothwendig Den Bscoanten, Das Das Man! bicr aur Fopfe

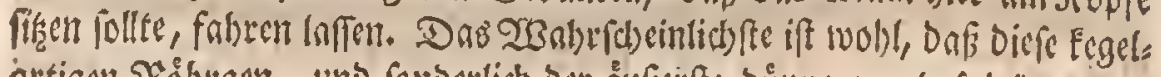

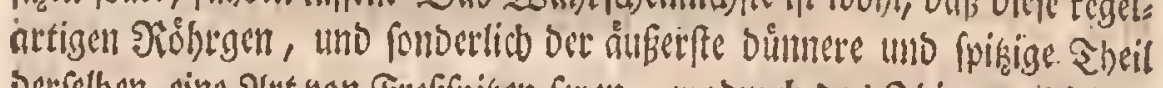

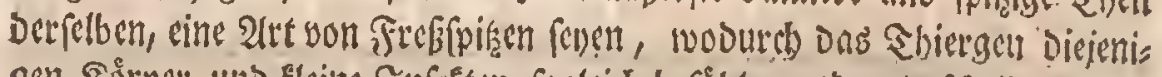

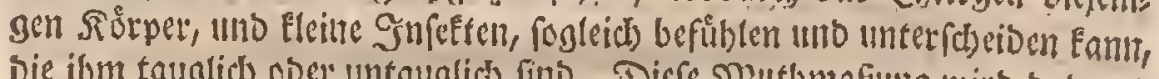

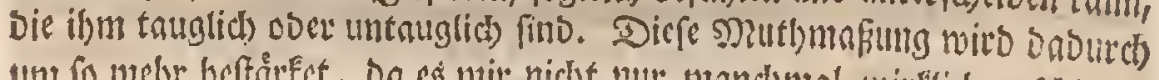

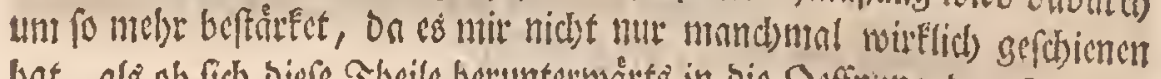

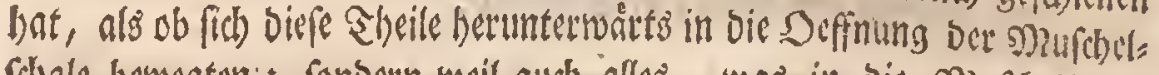
(d) ale berwegten; fonbern rweil audb alles, was in bie Nzurchelf(b)ale Eomme uno gebradbe wiro, unter und gans nabe an diefen Jiobrgen, obet Frefspitsen, vorbey gehet.

Zon ba, wo fich bas anf deinende Maul endiget, nimt ber Ziopf,

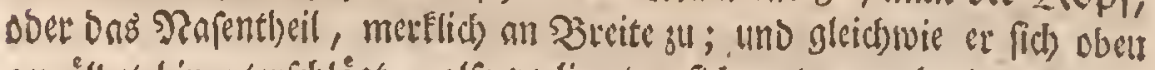
gerwoflbet himunterfdeliggt, alfo serlictet er fid) unten, nad) sincr fleinen

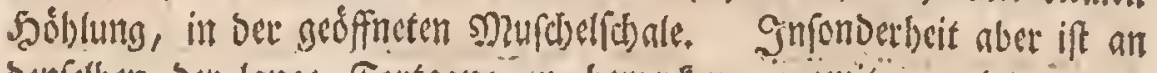
Denfelben ber lange Fortgang ful bemetfer, woomit ar obeit, und ein gutes Sheil ber bintern Nurcbellabale, als wie mit sinem Sdbilbe, 


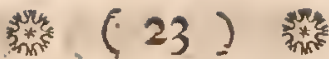

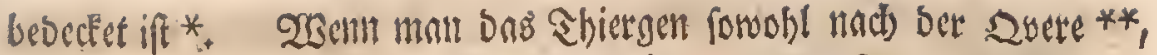

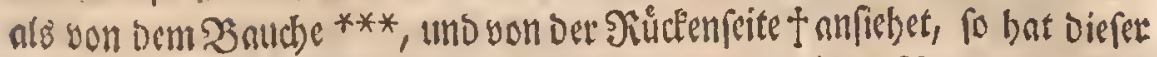

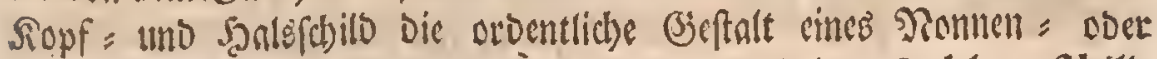

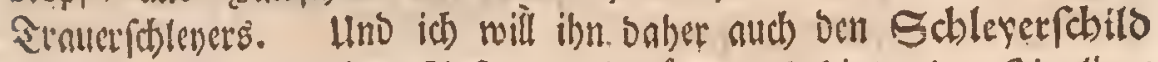
nennen. Er nintt feinen 2 (nfong gleid) liber und binter ber Sberlippe

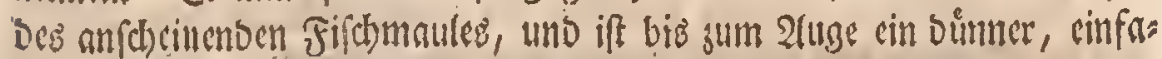
d)er, erbabener unb oben fidarfsulaufenber Strcif, weld)er, ba er ges

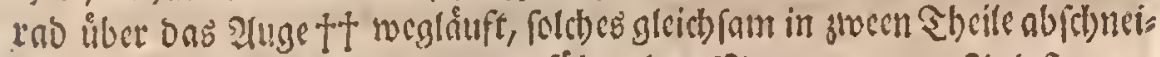

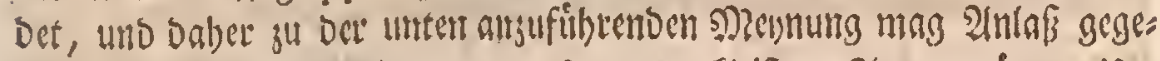

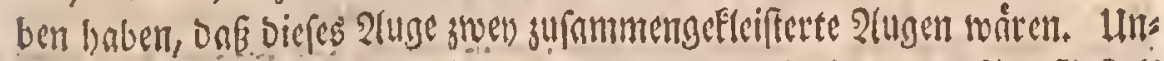

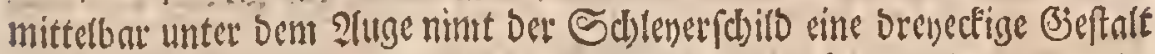

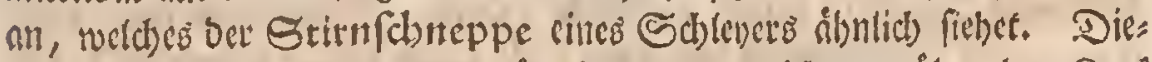

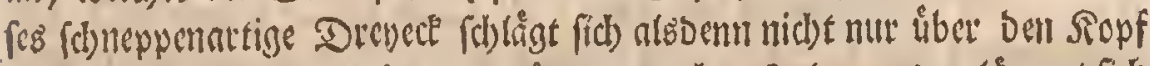
binúber, wo es cine gewólbte Evbóbung mad)t; , rondern es verlaingert fich aud) úber bie 2(ente auf bie Seiten binaus, wo es benen Seitencelent ets

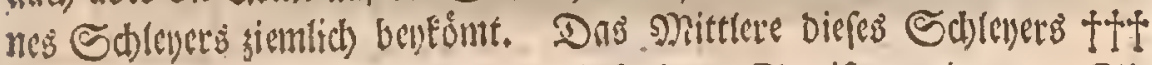
ift etruas erbaben, uno mit brenen befonoern Streifen gejieter. Sie entfeben yorne über Der Stirnfthneppe aus bem geond)ten einfacben

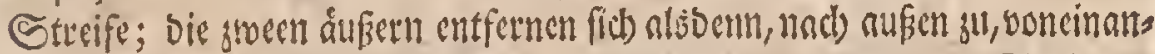

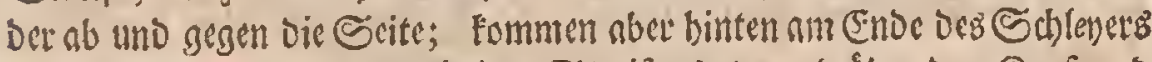
rwieber sufarmmen. Der mittlere Streif gebet gerno kiber Den Fiopf uno

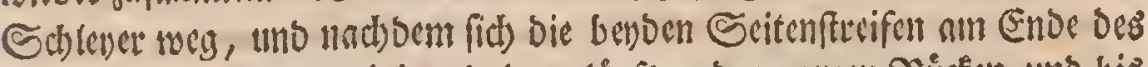

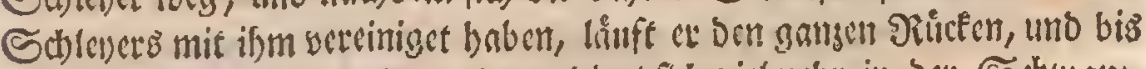

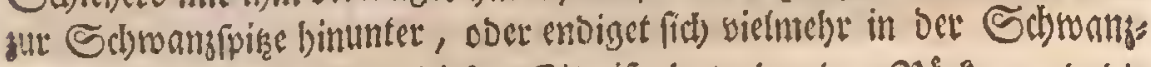

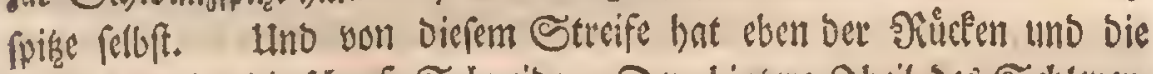

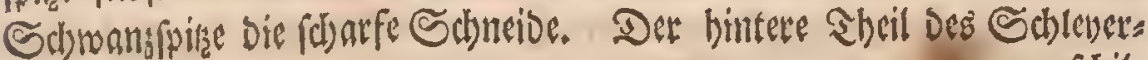
Thits

"Tab. I. Fig. VI, a. VII, a.b.b. VIII. U. e.f. Tab.11. Fig.II. h. "* Tab. I. Fig. VIII. ${ }^{* *}$ Fig. VI. + Fig. VII. It Tab. II. Fig. II.f. VII, a. tIf Tab. I. Fig. VI, a. VII. a, 


\section{邹 $(24 \overline{3})$}

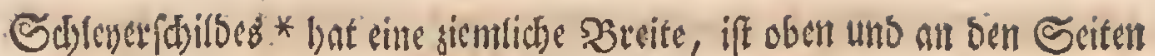

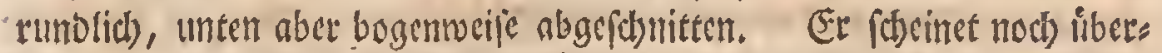

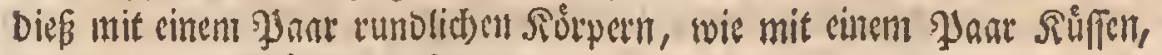
unterlegt oocr gefuttert gu jegn **.

Da man bicfe Shiergen beftindig mit bim Sispfe auf bem $\mathfrak{B}$ oben, und alt andere in Dem $2 B$ affer liegenden Siober auffabren und amfofich

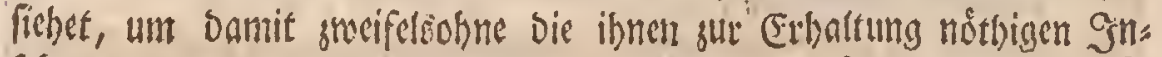

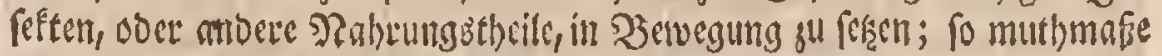

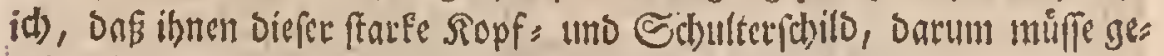
geben fenn, bamit die intern uno felje sarten Sbcile bes sopfes yon bem

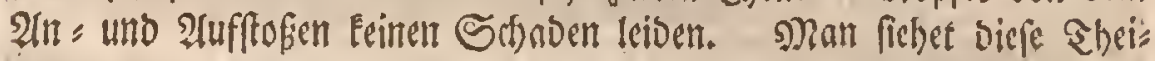

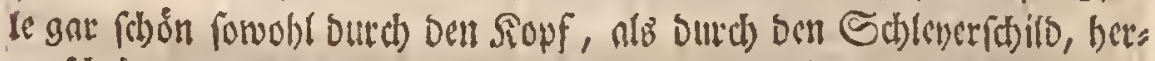

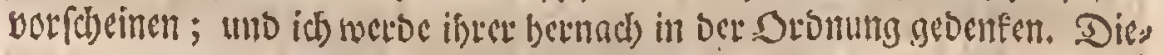
(ess mus id) nods anmerten, dap ber fiopf und Sd) lever zwar cben fo,

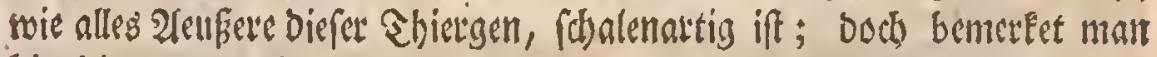

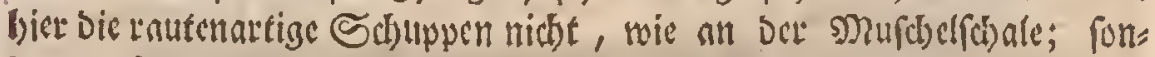

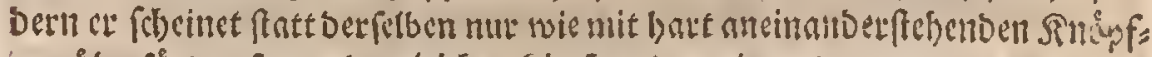

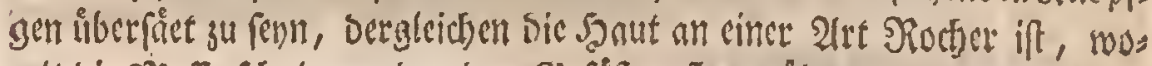

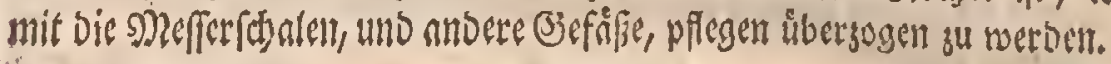

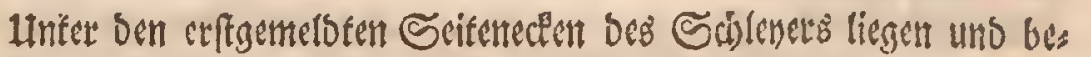

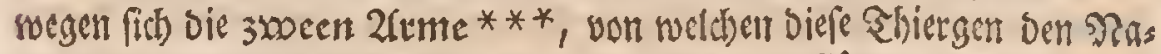
men ber baumatrigen oder gezaclten Doaffetfébe etbalten babed. Sie fint mit stween ober oren ringformigen 2 db fîfen dem Eeibe angeglies

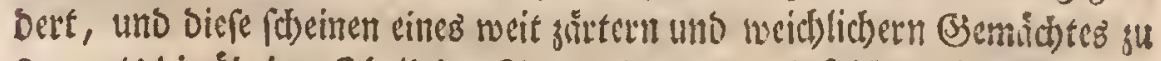

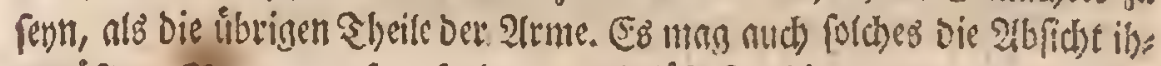

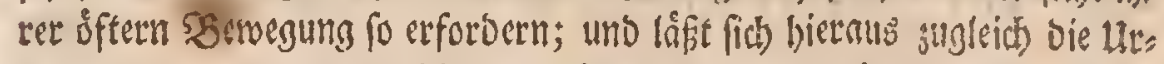

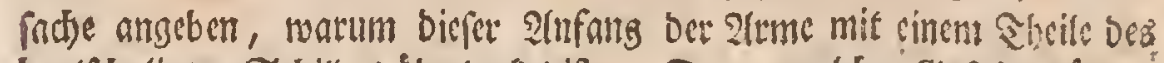

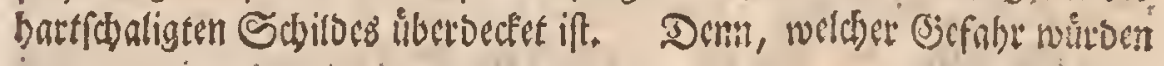
* Tab. I. Fig. VIL, b. " c. Tab. II. Fig. II. i. ar Tab. li Fig. g. giefe 


\section{(25) 紫}

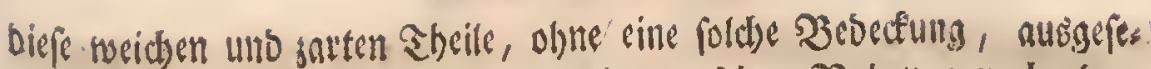
Ģet fenn? Uno wie fờnte Das Shiergen feiner Pabrung nadbegenen,

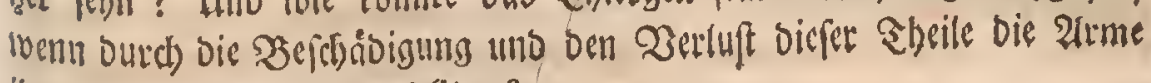
ibse $\mathfrak{B}$ cwegung verlieren follten?

Die 2utme felbft betreffento, fo folget auf bie ringförmigen 2 b fảge

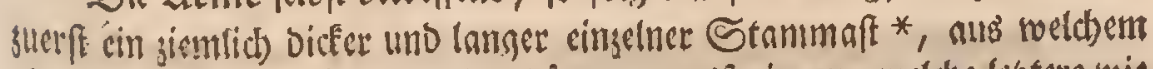

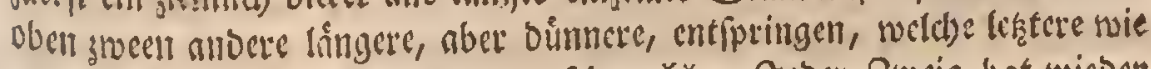
suseen Bweige an cinem Saume ausfchen **. Seoer Smein hat wieber

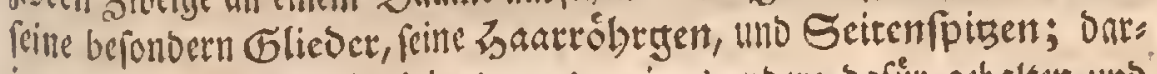
intren fie aber benberfeitz feinesineges, wie eB andere onfü gehalten uno aubgegeben baben, cinnuber bóllig gleich fenen.

Der untere, ooer innere bon biejen Bweigen, ber, wenn bns Shiers

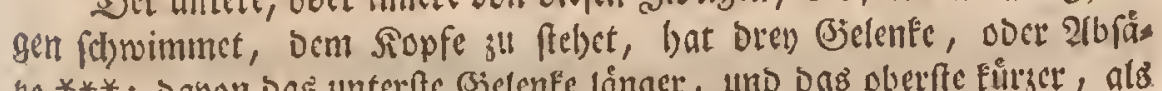

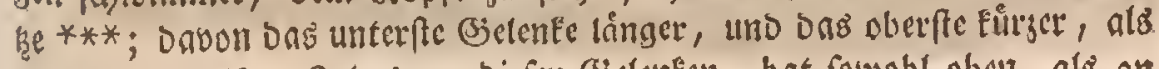
ons nittlere, ift. Geocż uon biejen bielenten, bat fowobl oben, als an

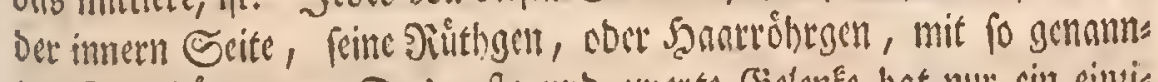

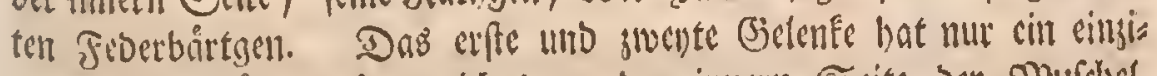
ger folcher Silthgen $t$, weldses an ber imern Erite ber \$Nufdel, Thale zu fethet; uno gegen ibm uiber auf ber andern Ecite fiebet man,

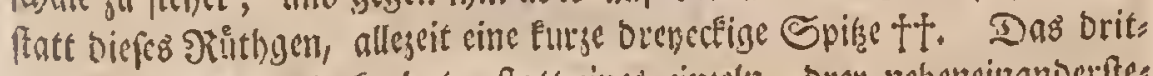
te uno oberfie Bselenfe bat, ftatt cines cimzeln, oret nebencinanocrftes

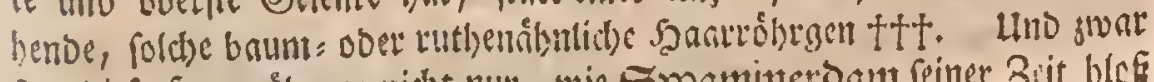

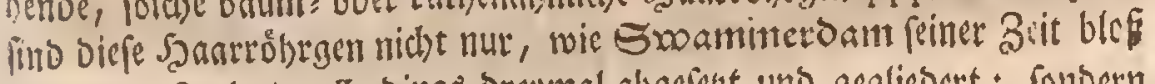
Bemulthma fet bat, allerbings breumal abgefest und gegliebert; fonoern

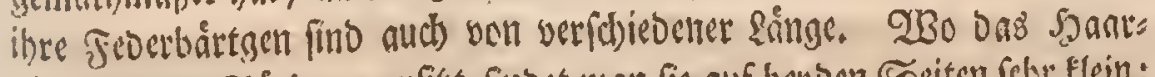

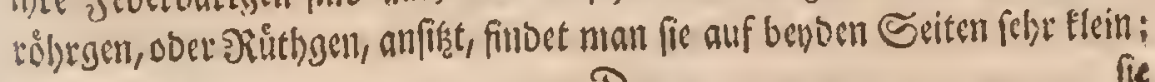

"Fig. VIII. I. ** Fig. VI. I. 2. *** Fig. VI. 2. VIll. 2. 3. 4. Tab. II. Fig. VI. a.b.c. t Tab. II. Fig Vl.e, f. tt d. d. tht g.h.i. 


\section{(26)}

fie werben nber gegen bie s)itte inmer långer und gro̊ker; uno alsbenm

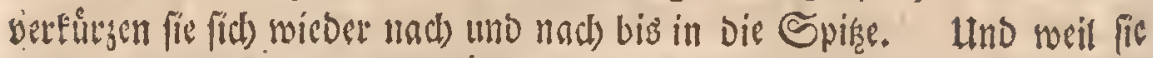

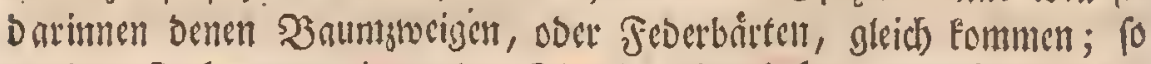

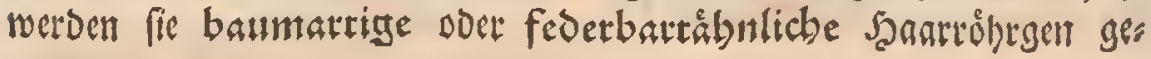
mennet.

Zen bieferm untern uno inner"n Blveige gehet ber obere, coer åußete,

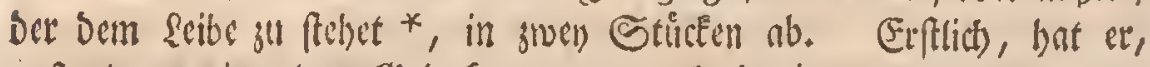
nufer Den sorigen orei) Bselenfen, unten noch cin viertes Elcince, Das aber felse mertlich iff. Bwentens, follt bem Darauf folgenden Bslieve

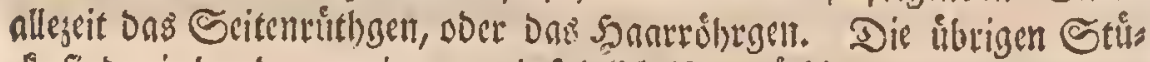
ule fino wie ben bem vorigen, uno folglit) ift unnetlsig fie su wicberbolent.

Diefe Orme fint, fowobl in 2tnferumg Des Stammaftes, als

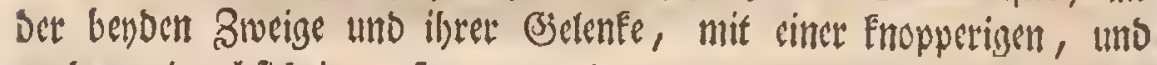

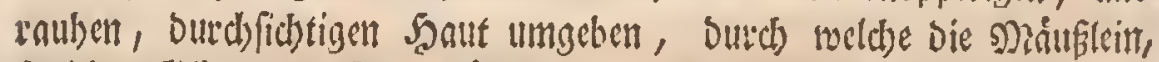

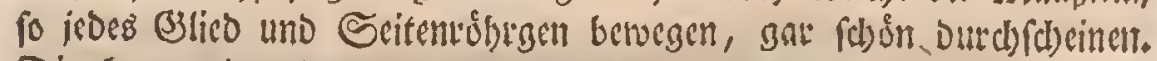
Dic Enopperige Saut gicbt vernutblict) Den 2 armen eine Dauerbafte

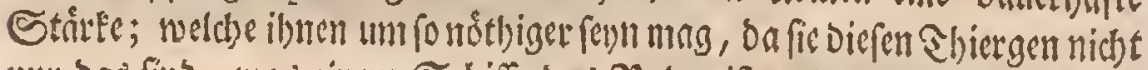

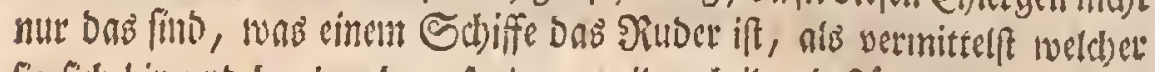
fie fid bin umo ber begeben; fonbern weil nud) ibre beftånbige Bewegung

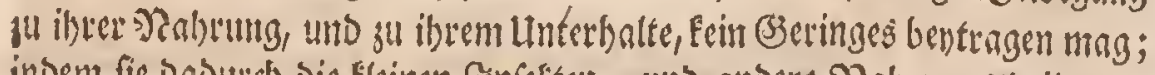

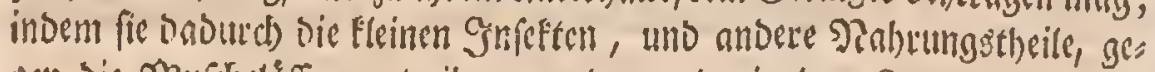
gen bic Sourcheloffnumg treiben, uno son ba in bas Sinnere berfelben, uno fo nach und nad in ibecen \&cib, ju bringen wiffen.

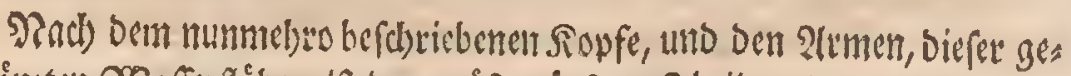

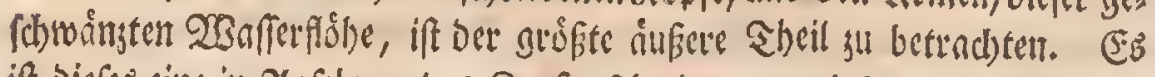

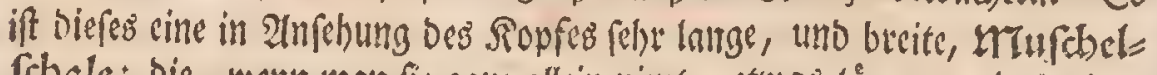
fobale; bie, wenn man fie gall allein nimt, etwas länger, als breiter, * Tab. I. Fig. VI, $x_{\text {, }}$ folg: 


\section{被 $(27)$ )}

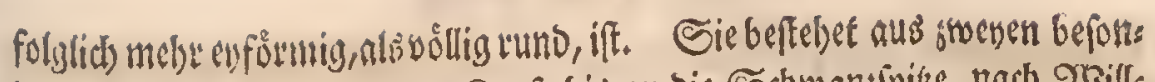

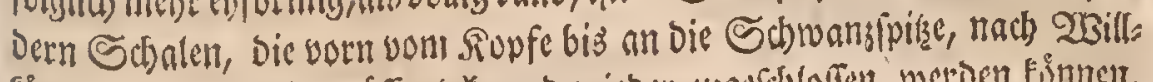

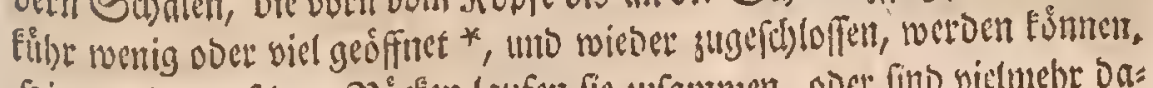

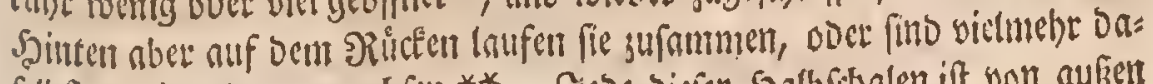
felloft an eimanoer gewadbjen **. Sebe biejer Salbidtalen if bon aufen

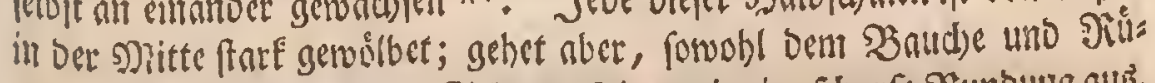

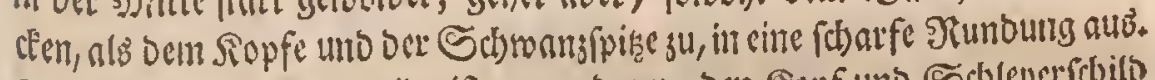

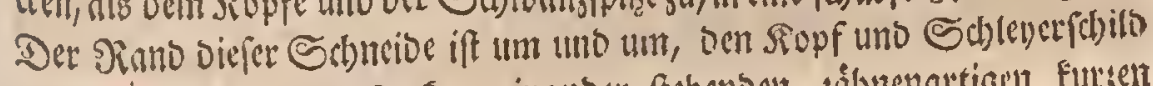

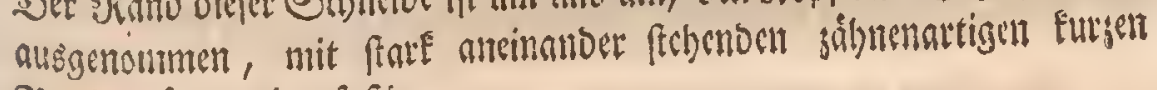
Doorfenhärgen eingefafit.

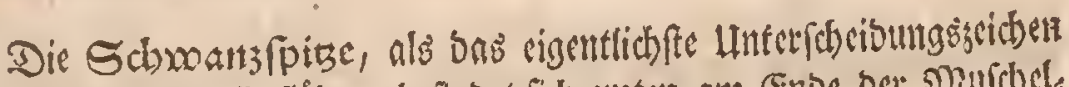

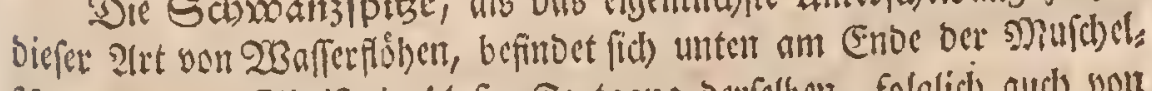
(c) ale ***. Sie iff cin bloser Fortgang oerfellent, folglid) auds woir

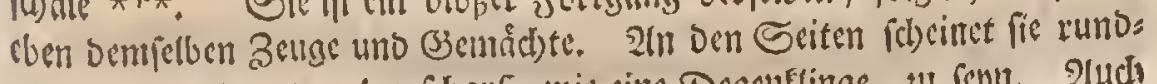
lich, oben umb unten aber fd) nef, wie cine Degenflinge, gu fenn. 2ud,

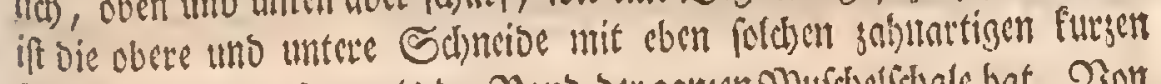

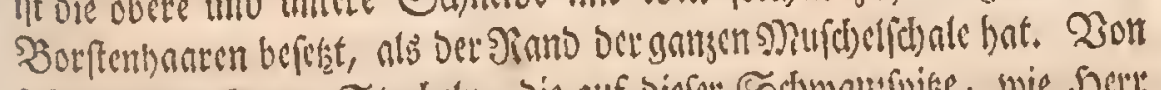

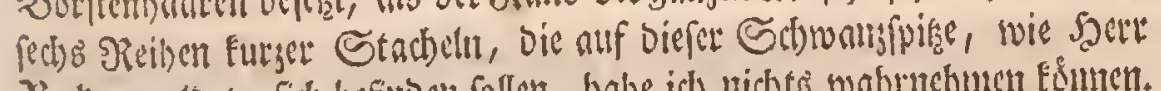

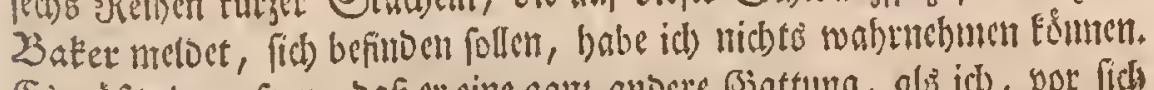

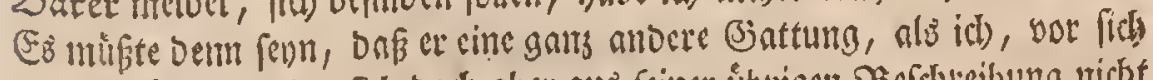

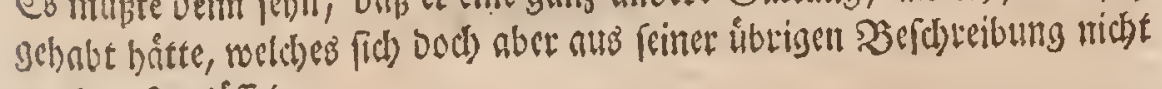
nutbmaken loffet.

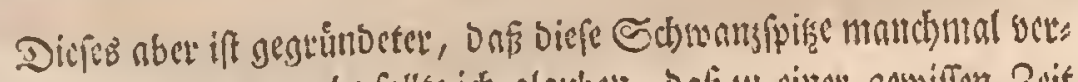

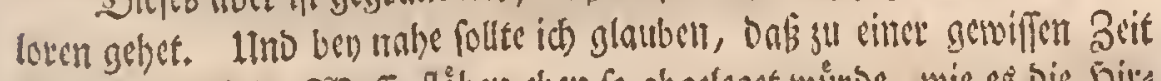

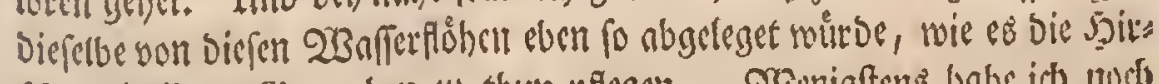

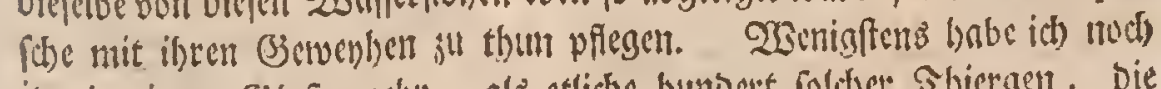

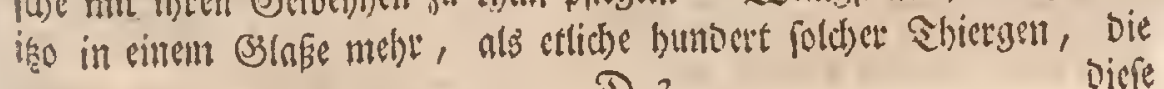
D 2
Tab. I. Fig. VI. ** Fig. VII. VIII. *** Tab. I. Fig. VI. E. VII. e.
VIII. I. 


\section{(28)}

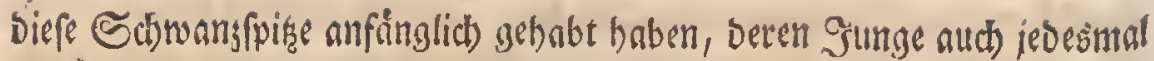
nit Derfetben verefeben fino, Denen felleft aber fie Dermalen insigefamt, uno whne 2fusnalyme, mangelt. WBenigftens lápt fid) bicraus biefes abnebmen,

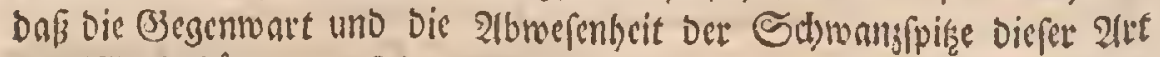

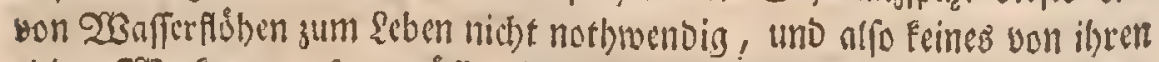

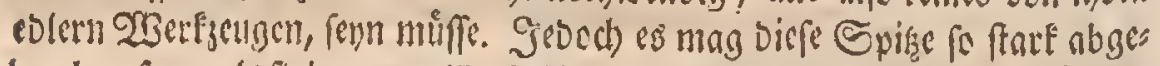

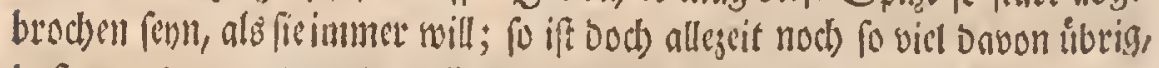
Dás man Daraus das elhemalize Daferyn Derferben abinebmen Faum.

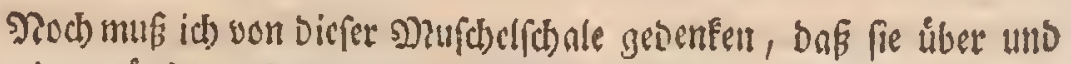
über mit gervinfelten Sdjuppen fabeinet bebectet ju feun*; und oaf wenn

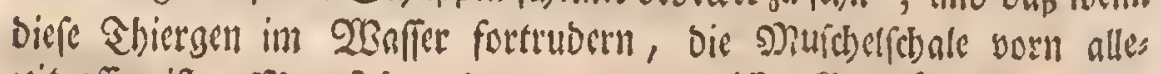
geit offen ift. Man fielet alöbenn einen gewiffen flauenåbnticben $\mathfrak{F} u \beta_{\text {, }}$ ben ich balo inåber befchteeiben weroe, beftånoig aus: uno cinfchlagen **.

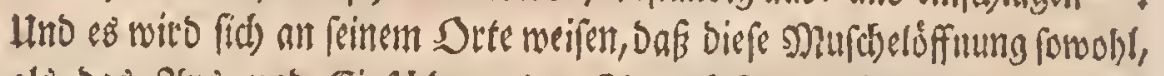

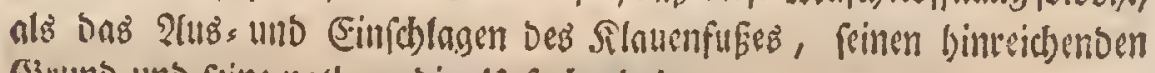
(3)

Scl) fonme nummefre yon ben ånfern auf bie inttetn sbeile biefer ja tigen Wafferfithe. Sie liegen theils oben im Siopfe, umb unter Dem

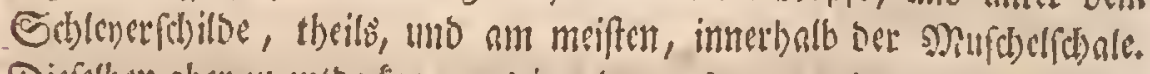

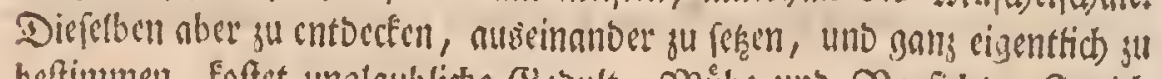
beftimmen, foftet unglaublicte Beiult, shibe und Dorfidst. Ja ich

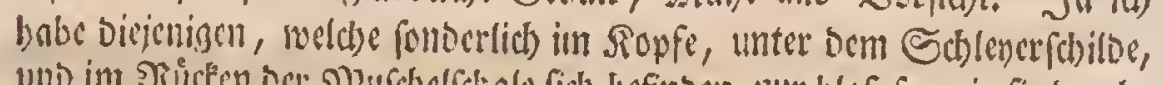

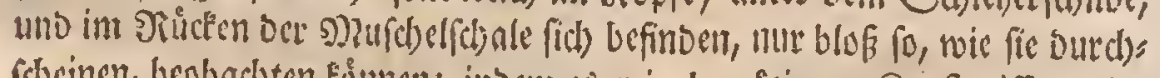

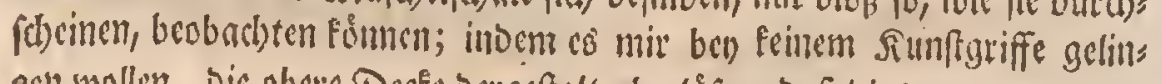
gen wollen, Die obere Decfe Dergeftalt absulofen, Dá Die Darunter liegen,

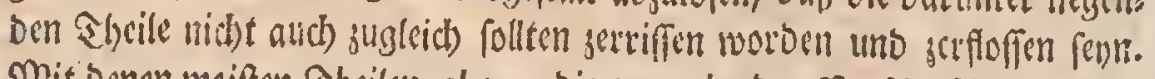
Mit Denen meiffen Sbeilen aber, bic born in Der Murchelichale gefuns

* Tab. II. Fig.II. ** Tab. I. Fig. VI. d. VIII. q, Den 


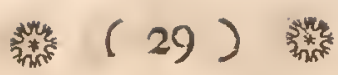

ben werben, babe id Deffer gurechte fommen fornnen; fintemal ich foldse nuf folgenbe 23 sife niach uno nad) getermet babe unverleset von Der Sdba: le absujondern uno berauşun

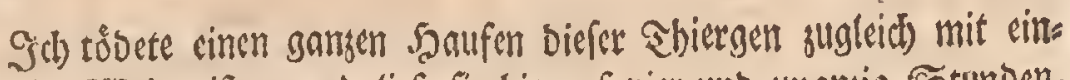

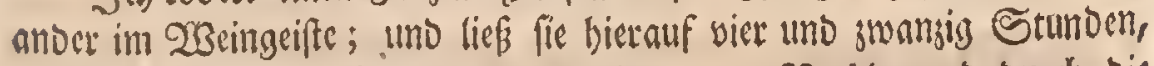

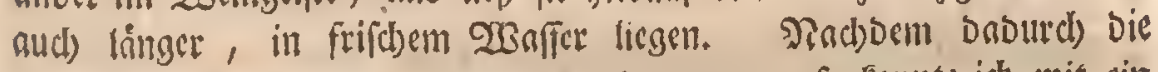
Schale gams meid) uno (d)lapp gewarden war ; fo fonnte idh mit ein

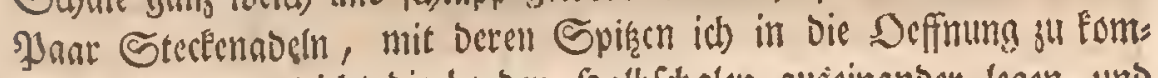

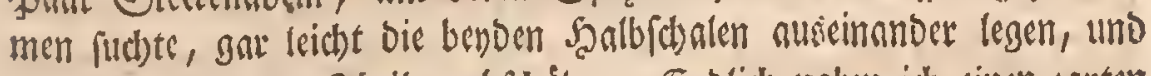

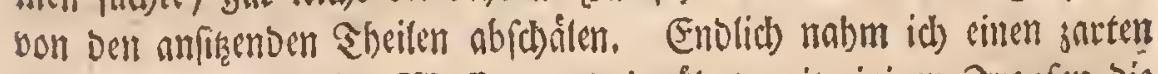
Binjel, taucl)te ibn ins $28 a f(e r$, uno berill)rte mit einigen Sropfen bie abscfonderten, und freen Daliegenden, Slbcile fo fang, bis fie fid) auscimans

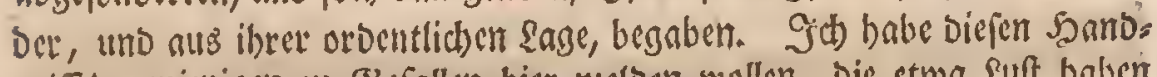
griff Denenjenigen zu Befallen bier meloen wollen, bic etwa Euft baben

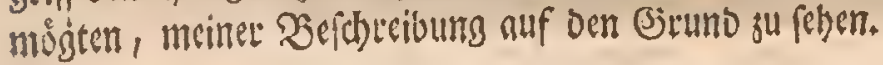

$23 a s$ bie inmern Sheile felbft anlanget, fo follte ich sware billig son ben eblern ben 2Anfang maden; allein ich wetbe Diesmal nads eiter andern Sronumg berfabten. Sad) werbe guerft bicienigen ges nau befimmen, bie fich glcids beynt erfen Inblick seigen, unt auch olne Dergresserumg sefehen meroch. Ltno Do ift Denn gleich Das erffe, fo

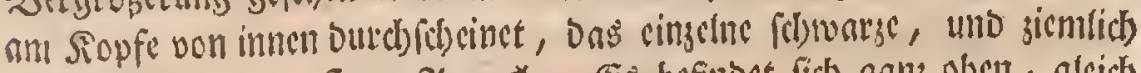
grope zufanmmentgefeste s(uge *. Es befinbet fich ganz oben, gleich

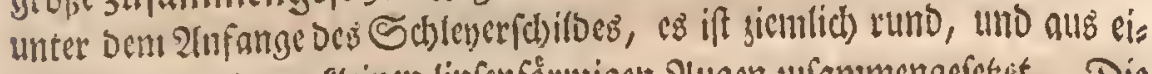

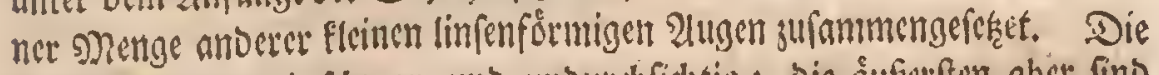

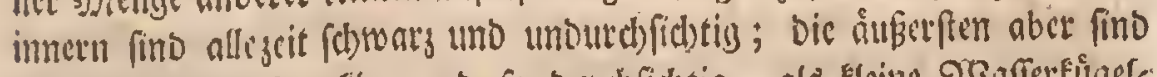
rund unther weis, Flat und to burchfid)tig, als Elcime 23 affertiget: gen. Şedes diefer linfenförnigen '2lugen bat peine befonbere Sebenersen, D 3 Die

"Tab. I. Fig.VIII, c. Tab. II. Fig.II, f. 


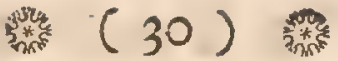

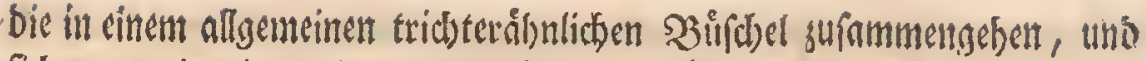

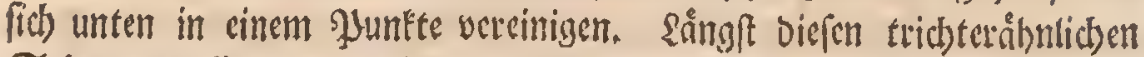

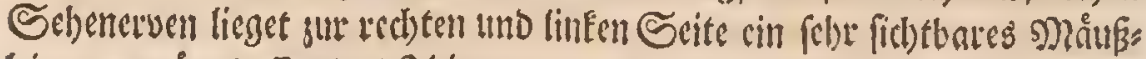

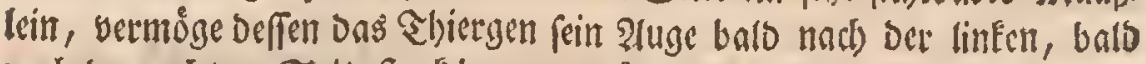

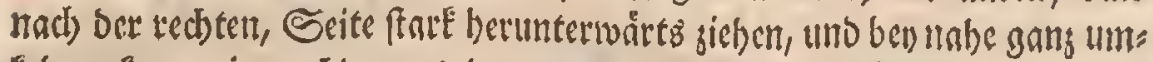

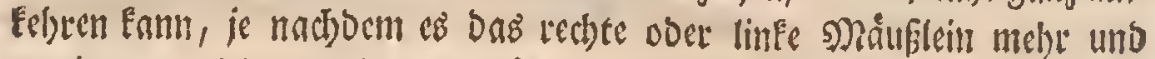

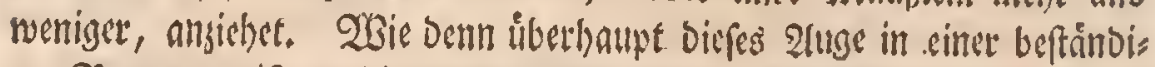

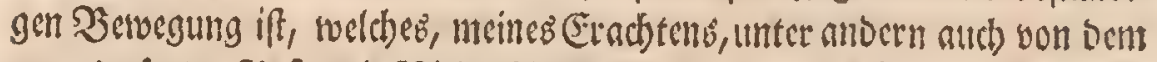

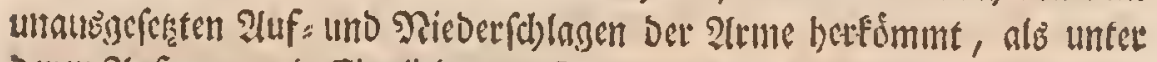

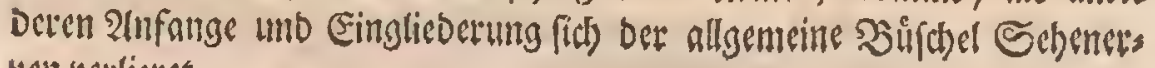
ven verlietet.

Sid) weis swar, bas Swammetdam, 23aket, uno anocre mit ib:

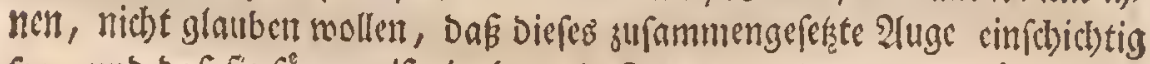

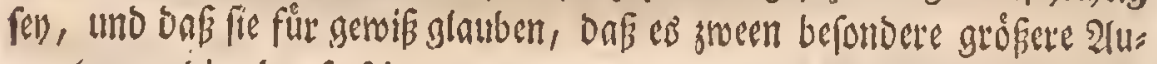
sen fenen, bie aber fo febr uno genau antimander geflebt wären, daß fie

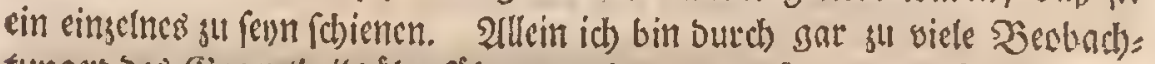

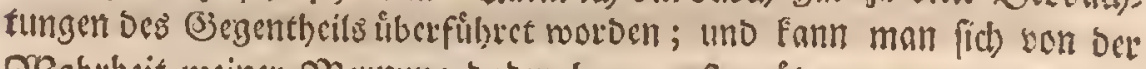

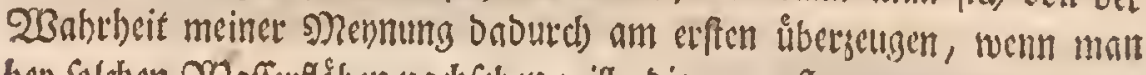

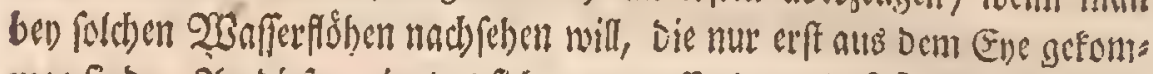

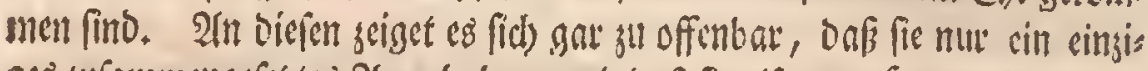

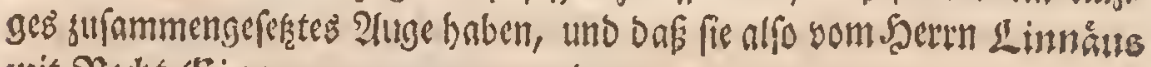
mit Red)t 佂inatugent genemet werben.

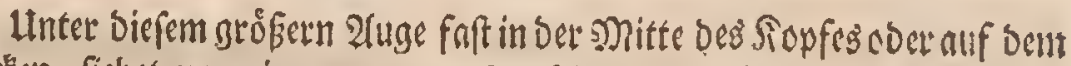

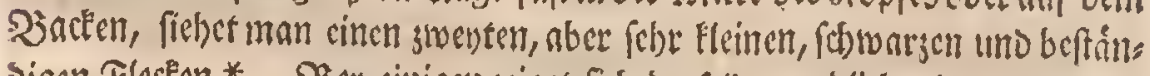
bigen flecen *. Ben einigen jeiget fich berfelbe runblid), bey antoerti es cfig, und nod) bey andern wic brey orbentlidse, in eimem Dreycele bey eins

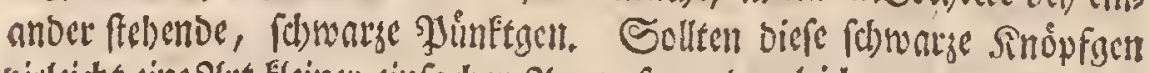

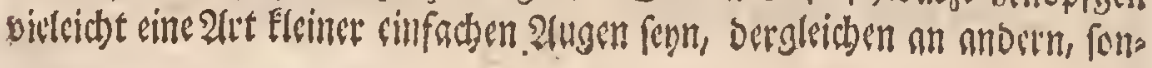

* Tab. II. Fig. II. g.

Ders 


\section{㤦 (3I)}

Derlich Erbinfekten, zuberláfing befannt fino. Weenigfens babe ich ben

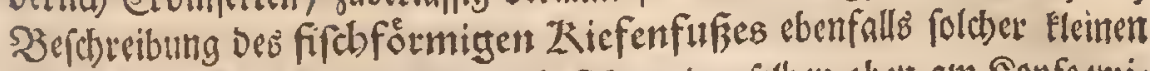

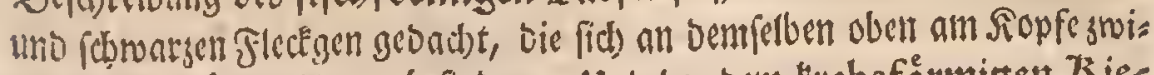

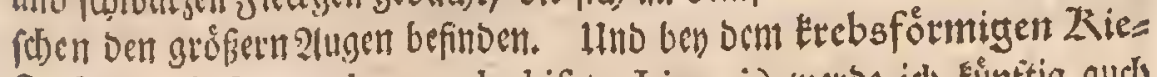
fenfusc; (Monoculus cauda bifeta Linnæi) werbe id) funjtig nucl) Dergleichen etwab zcigen Eônnen. Dod) mus id geftebsn, bafich auf

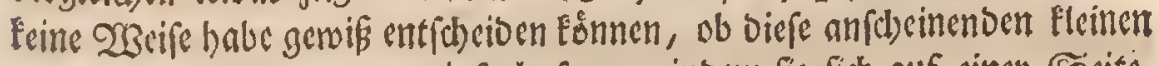
2(ugen boppelt, ooer null cinfach) feyen; indocm fie fich auf einer Seite, soie all Det anbern, gestiget baben.

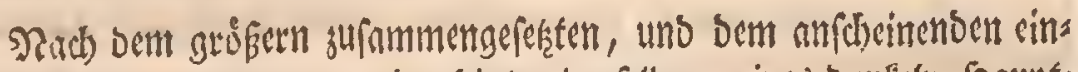
fadjen 2luge, wiro man weiter binter benfelben, eincs Dunfeln Sanupts

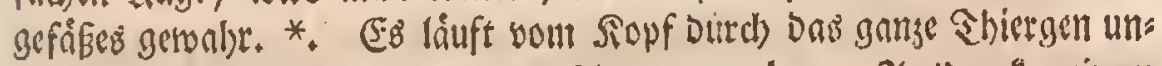

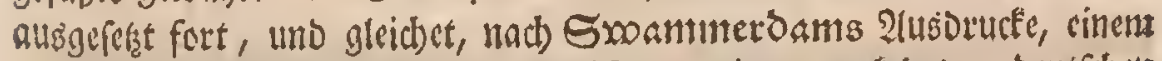
rómifchen $S$, odcr, ned eigentlicher, sincr vertebreten beutfdben

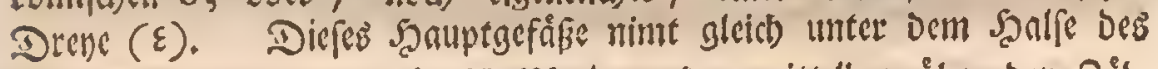

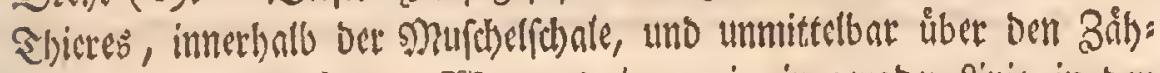

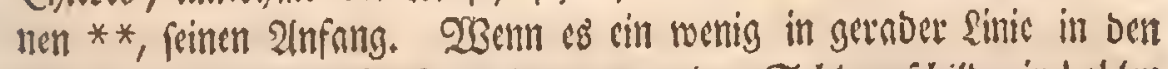

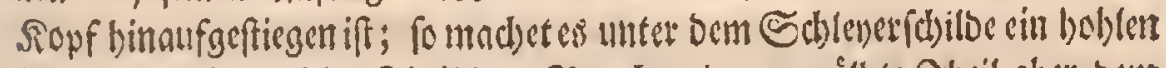

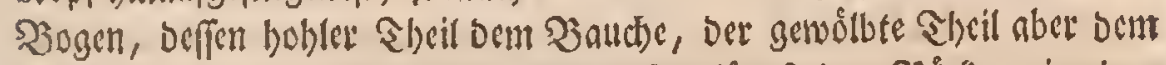

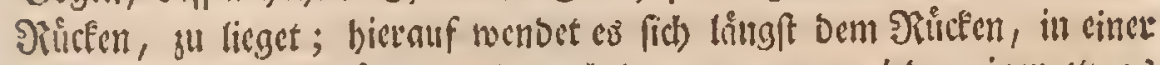
Sd)langenlinie, abroiets; und nad) Dem es unten sweber cinen ctwas

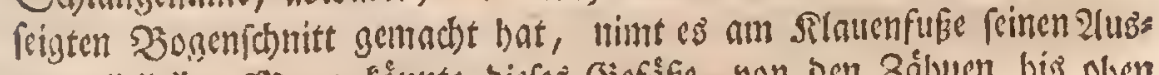
gang ***. Jiann fónnte biefes (jefăfe, von ben Bál)uen bis oben

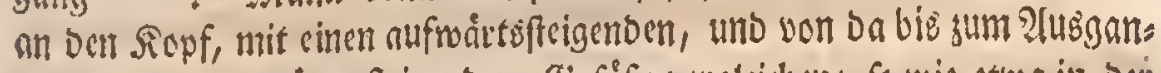
ge mit einen abmatrts fecigenden, Gefáfe verglecthen; fo wie etwa in bec

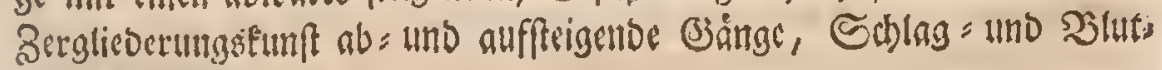
noerth, borfonmen.

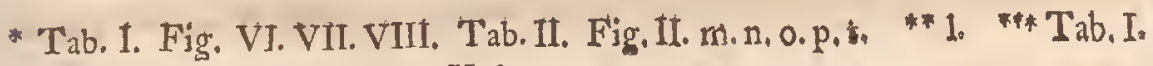
Fig. VIII, o. Tab.II. Fig. V.k. 


\section{(32) 32}

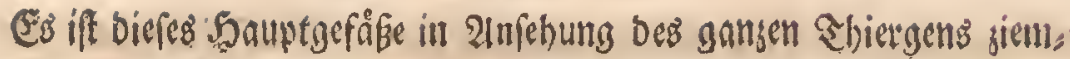
lid) weit uno gros, uno mit eitrem meift braunrothen uno gruinlidben Safs

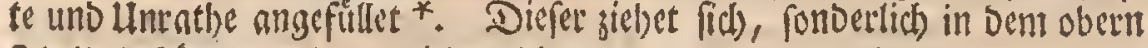

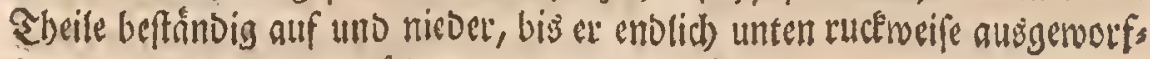

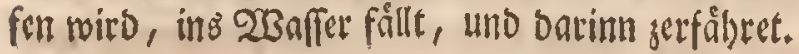

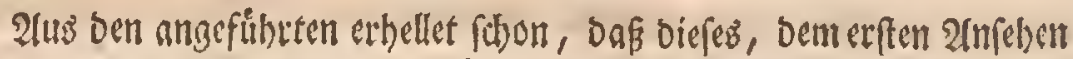

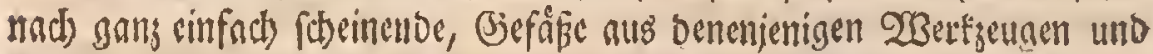
Theilen zufanmengefest fene, mit weld)en bes Shiergen feine salabrung

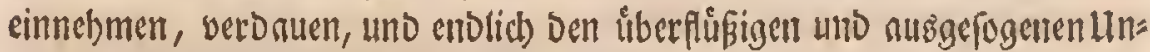

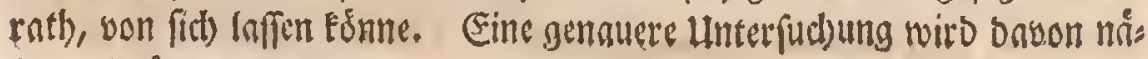
bere Ertáuterung geborn.

Die naturlichfte Dermuthung ift, bafi Die obere Seffnumg Diefes (3)

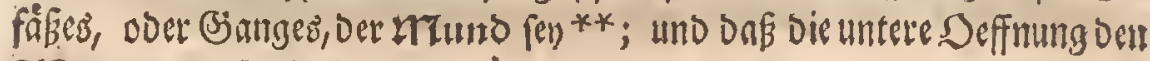
2ifter ausmad) ***.

Gene Munbffơnung befinoet fid) alfo, exft angegeigtermafen, inn. wentwendig swiften unio innerbalb ben benden Sd)nlen, gleidh obers

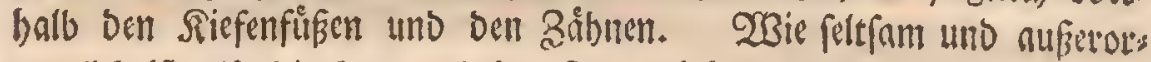

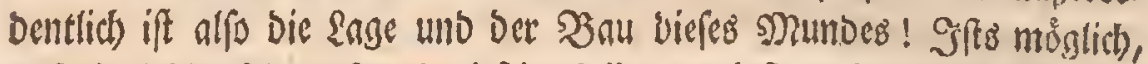
Daf ein Shier feinen \$nund tief im Eeibe, menigftens fehr weit unter Den

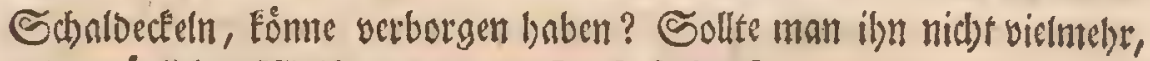
und natirlidjer 2 Beife, vorn aun Sopfe fucten?

Sid) babe midh bariber fdyon oben ertlaret uno begenget, wieviel es mir getoftet hat, bis id bieß 20 oruttheil überftiegen habe, onf ber Muns eines Shieres alleseit vorn an Sopfe fițen múffe. Hano wer weis, ob id) je bie 23 abrtheit wurbe gefunden babell, wenn nidbt ber befonoere $\mathfrak{B a u}$

und

* Tab. II. Fig. II. o. p. Tab. I. Fig. V. $m_{1}{ }^{* *}$ Tab. II. Fig. II. m, ${ }^{* * *}$ Tab. I. Fig. VIII. o. Tab. Il. Fig. V. k. 


\section{( 33 )}

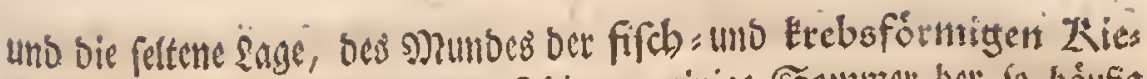

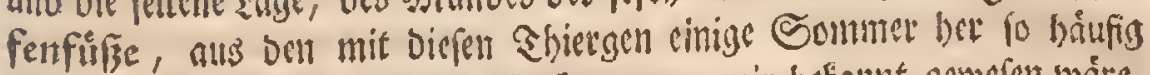

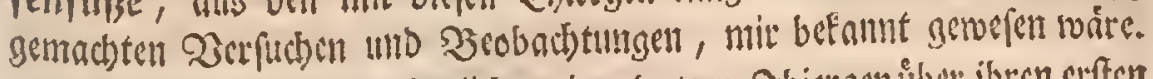

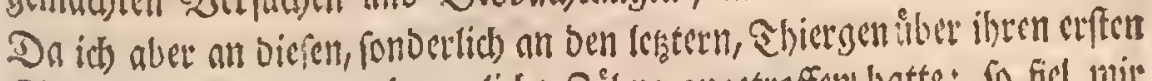

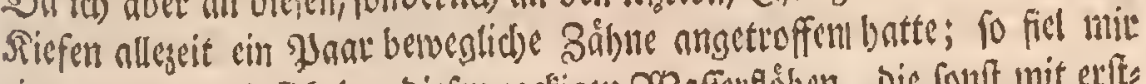

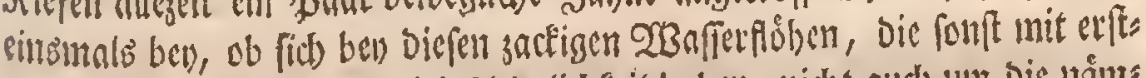

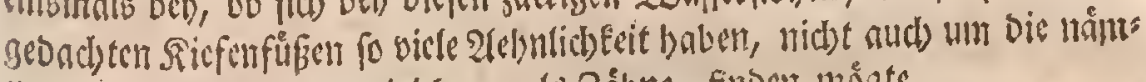

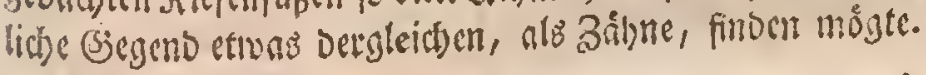

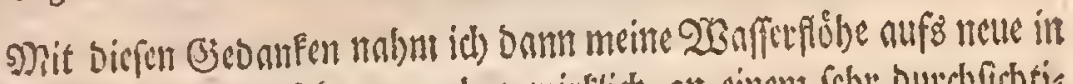

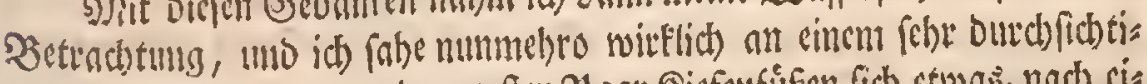
gen Diefer Shierger unter bem erffen Yant Siefoufusen fid ctwas, nad) cis net befondern 2irt, auf und nieberbewegen. Ltho waš bas s)ecife, fo

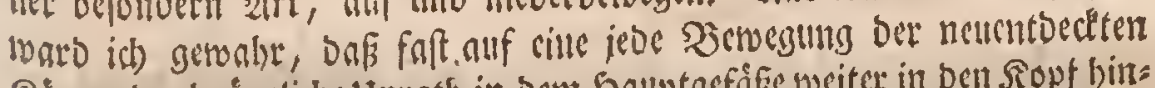

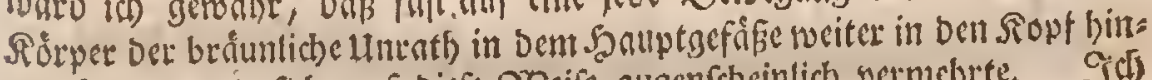

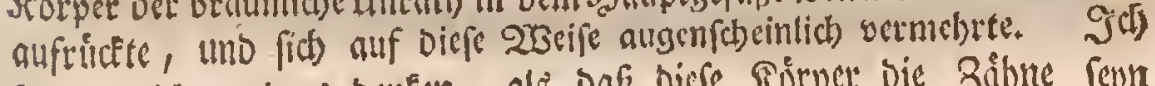

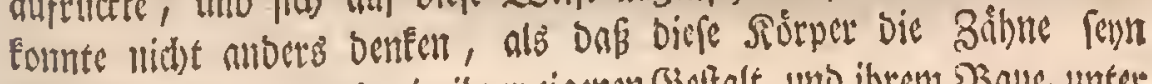

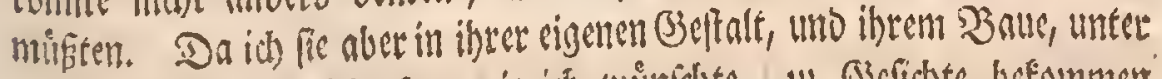

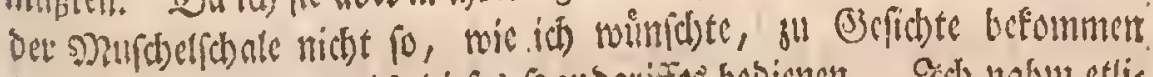

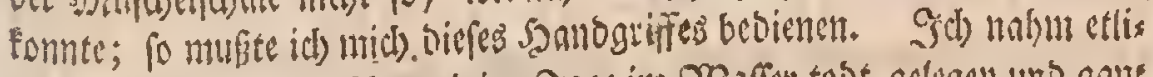

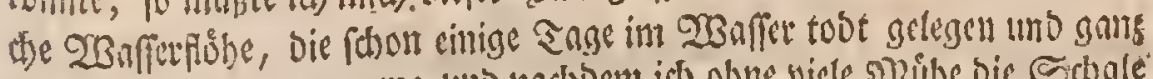

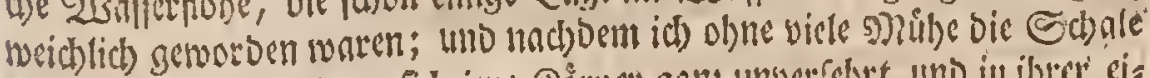

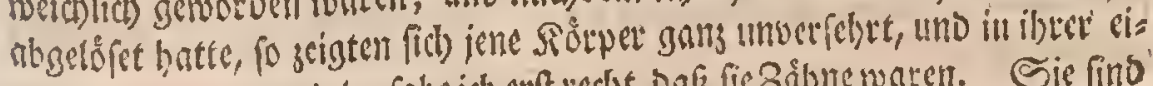

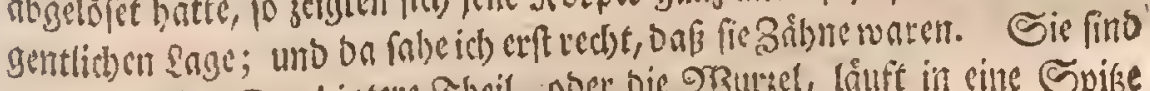

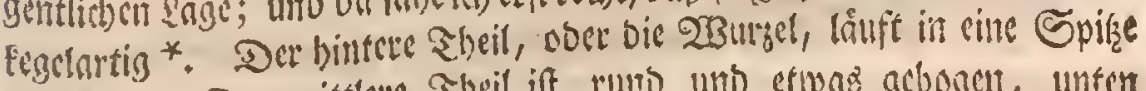
sus **. Der nittetere Sheil ift ruto und etwaz gebogen, unter

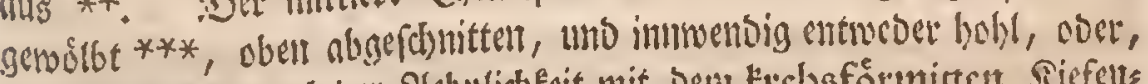

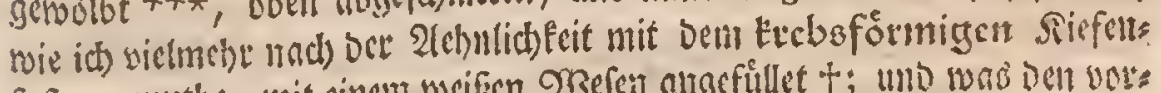
fufec sermuthe, mit einem weifon 2 Befen angefillet $t$; und was ben vos:

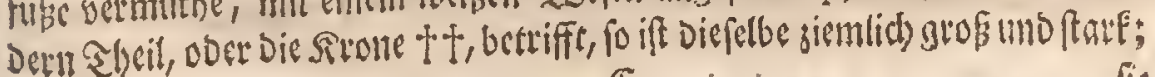
(E)

* Tab. II. Fig. II. " a. a. ***b. b. fc, c. tfd, d, 


\section{(34)}

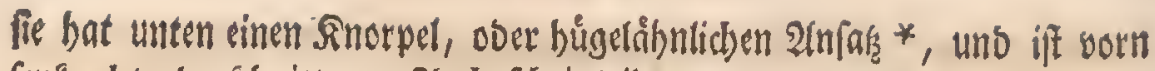

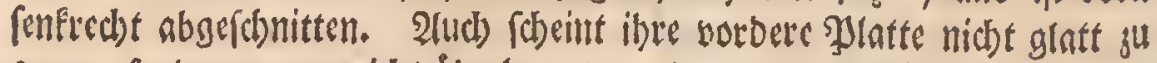

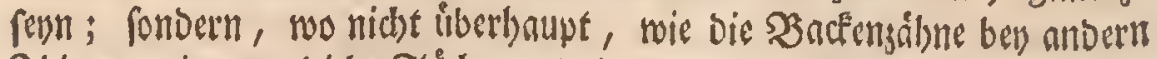

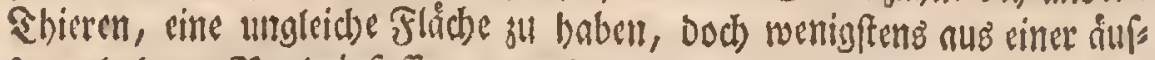
fernerbobenen Sandeciufaffung, und einer innern Sertiefung, zu befteben **.

Diefer Baibne fino zween, ouf jeber Scite einet. SMit ibret WSirjel fint fie binten angegliebert; nit ibrer firone aber, und Deren vorbern släb)e, fto und aneinanber. Int eben diefes ibr Bufammenteiben verurfacbet, bas

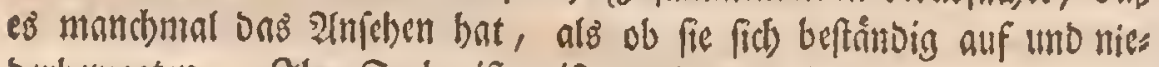

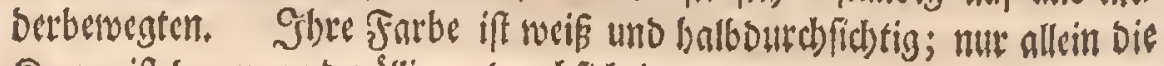
Frone if braun und vellig untourdfictrig.

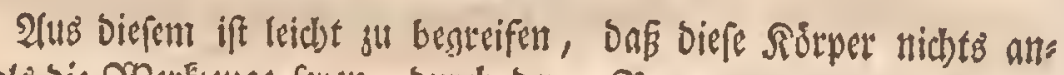

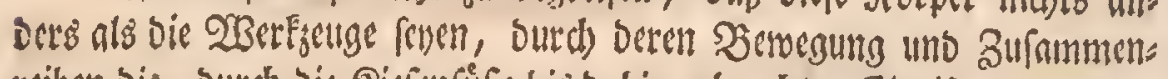

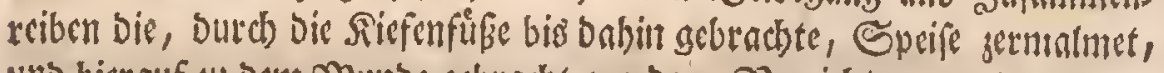

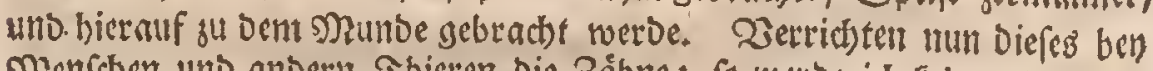

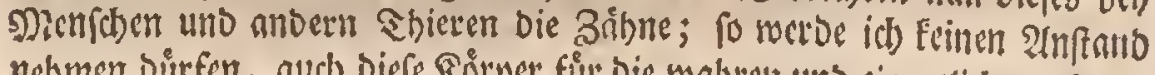

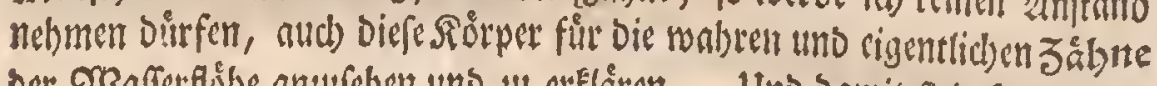

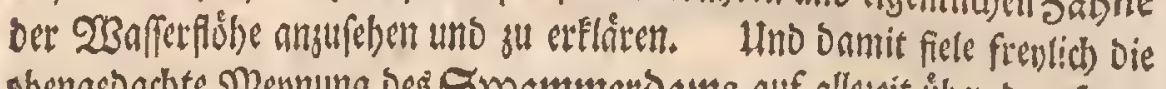
bengebad)te Mennung oes Sxoammerdams auf allescit über ben Şau

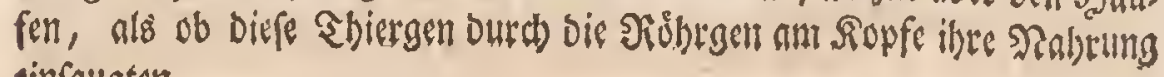
einfaugten.

Slltein, man mỏnte mir einuenben, wie bent bic Speife biefer

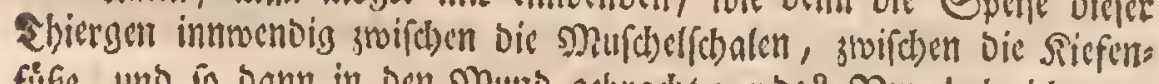

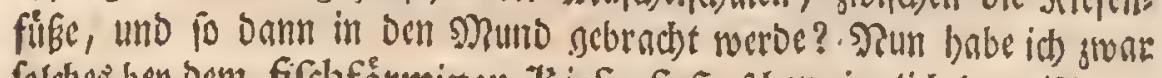

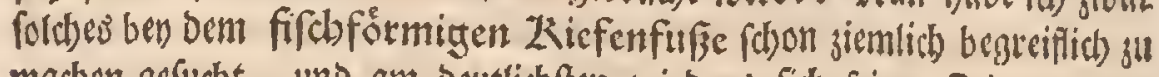
madben gefucht, und am Deutlidften wiro es fich (einer Beit an bem

* Tab, II. Fig. IUI, e. e. "*f,

trebs= 


\section{(35) (35)}

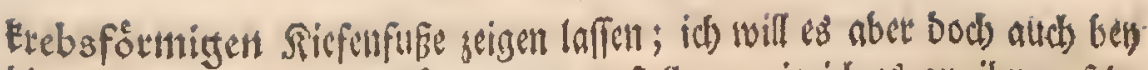

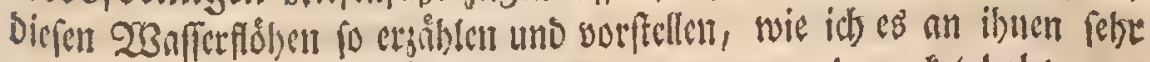
oft, uno nie obne Dergnugen und Derwumberung, bemertet babe.

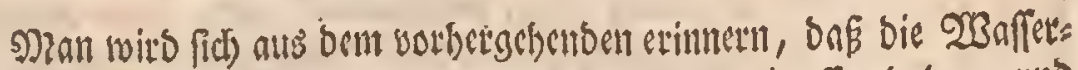

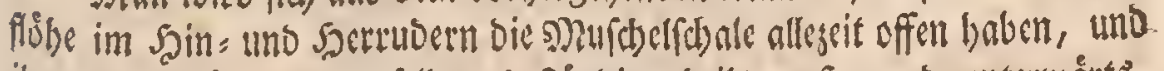
ibre Siefenfiffe in berfetlen beftåndig tbeils suf = แno unterwårtb.

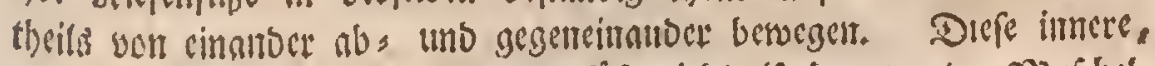

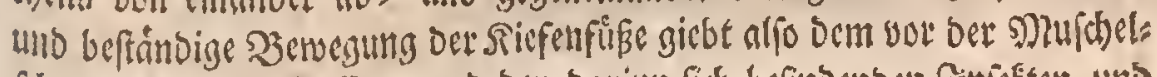

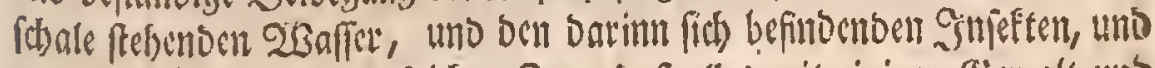

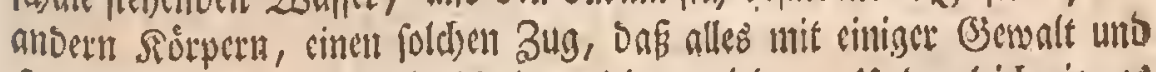

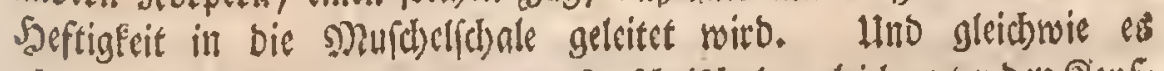

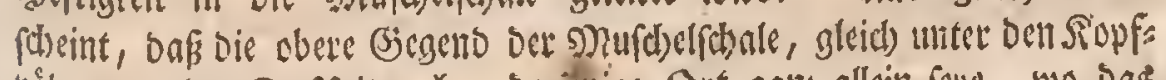

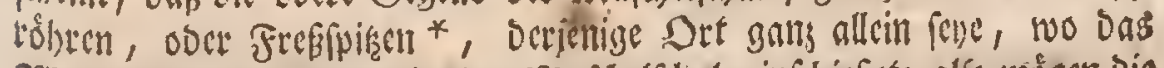

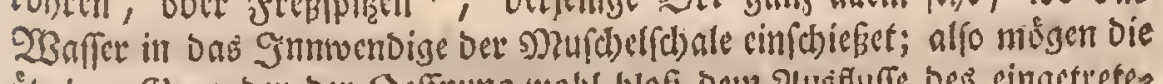
ủbrigen Bigenoen ber Deffinung mobl blofi Dem 2lusflufe bes cingettetes

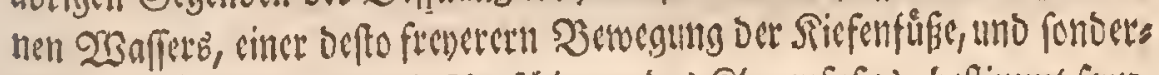

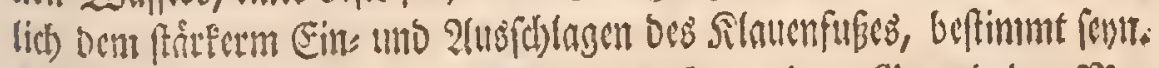

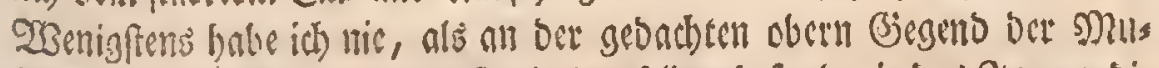

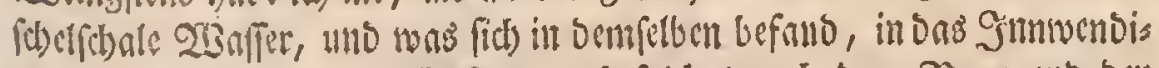

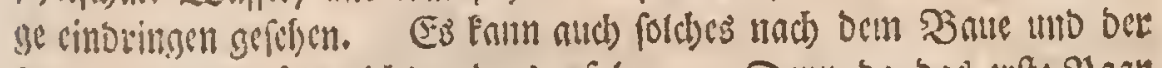

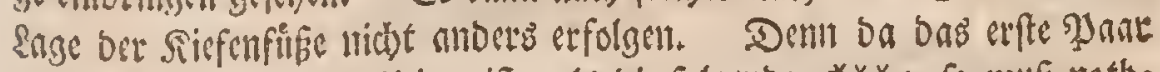

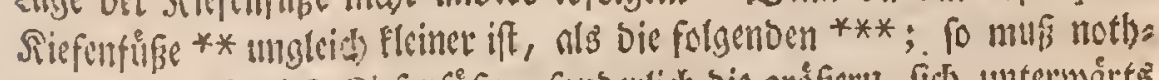

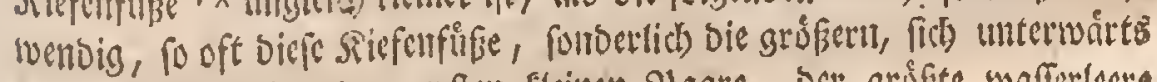
berwegell, buen bei) Dem erfen Eleinen Juare, ber groffte waffertecte

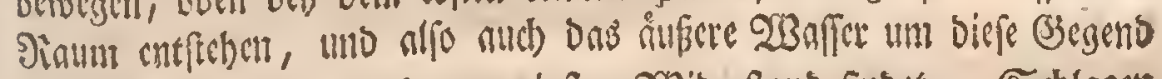

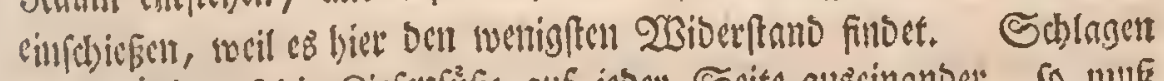
(iib) nut hierauf bic Sieferfülis auf jober Seite auscinanber, to mus ons oben eingettetene Orsafer zwifben biefelben fommen, und fich E્ 2 bicts * Tab. I. Fig. VIII. a. Tab.II. Fig.II, v. "** Tab. II. Fig. IV. I. *** 2.3.4.5. 


\section{称 $\left(3^{6}\right)$ )}

biernuf won einem siefenfupe zum andern berabfenfen. So bato das Weafer bis zu dem Icḩten Riefenfupe * berabgefommen ift; fo wertoen oic

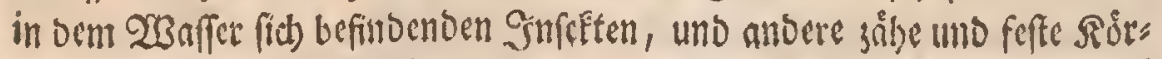

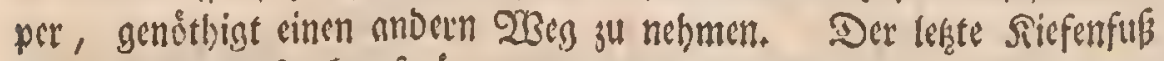

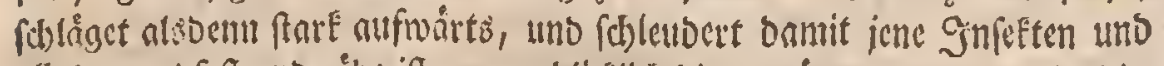
alles, was feft uno zaibe ift, augenblictlich binterwairts, uno znar in bies

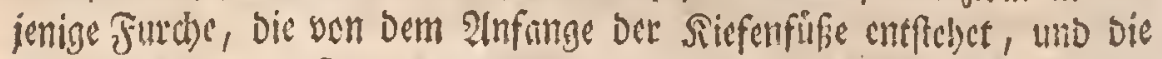
son bem 2luf: und zutbun berferlben balo weit, balo eng, ift. In bis;

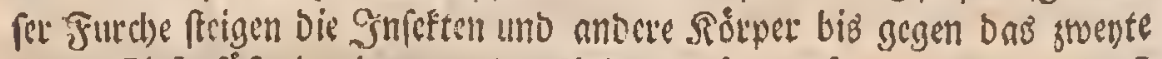

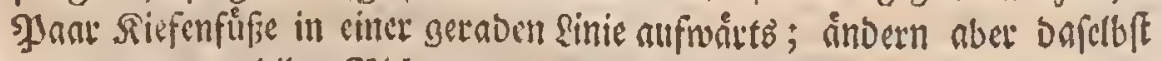

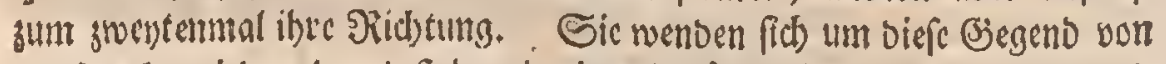

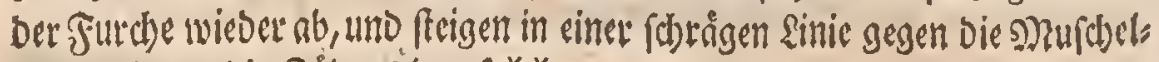
fchale bis an bie Bảbne binauf **.

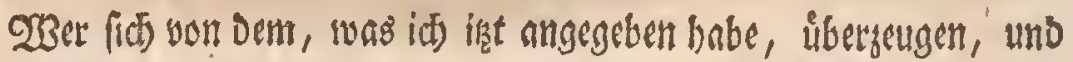

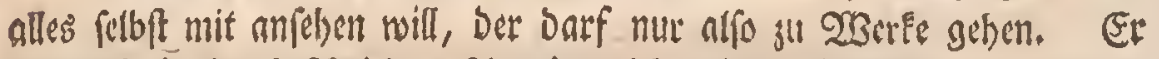

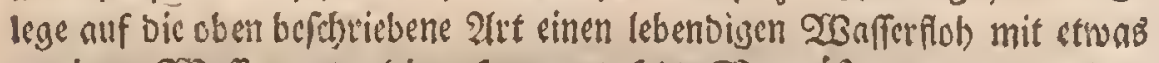
menigen 28 affer unter bie zufammengefelete Wergréferung; und bringe

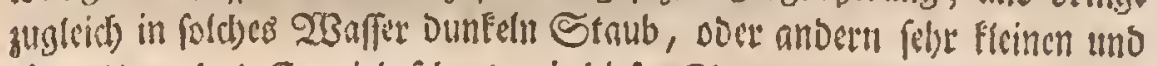

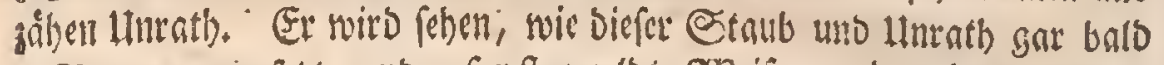

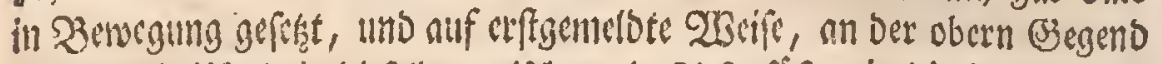

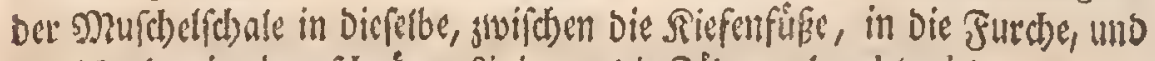

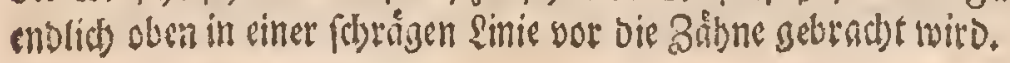

Sommen Dann aber GnfeFfen, doer anbere Sidrper, yor bie Bälne;

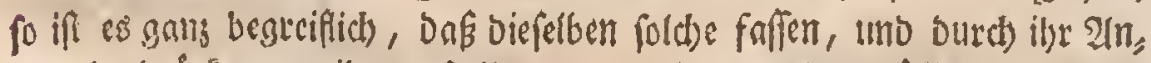

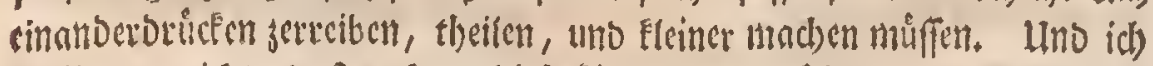

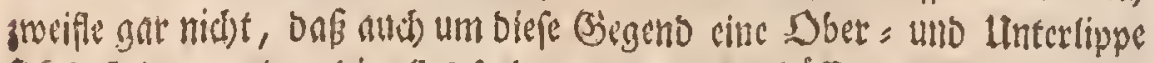
fict be finten werbe, bie alles folang an Der Ngunodffnung crbalten, bis Dab Shiergen bie Speije in ben 2(nfong bes Mnundes gebrad)t babe.

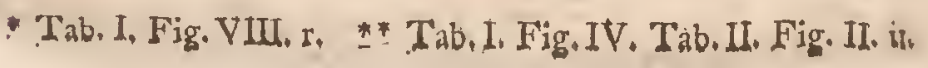
94) 


\section{(37) (3)}

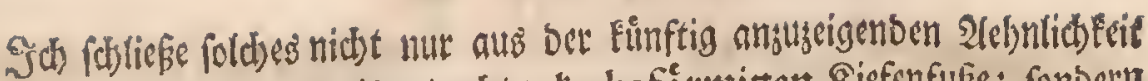

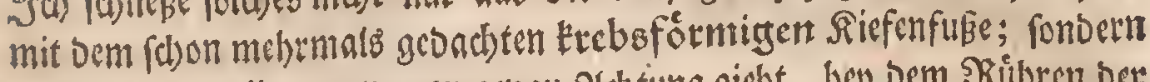

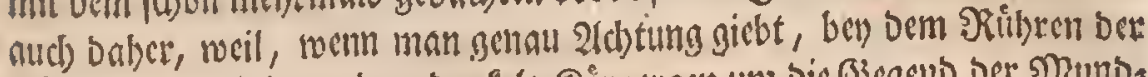

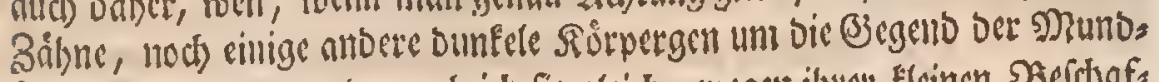

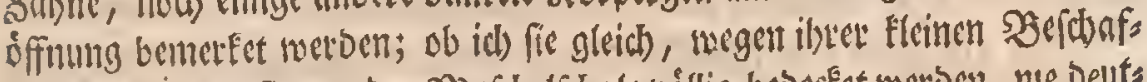

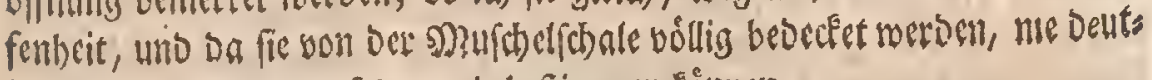

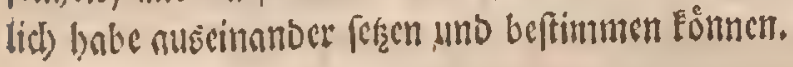

(3)leid) binter Dem Munde gethet ber Scbluno $\mathfrak{m}^{*}$. Er tnter

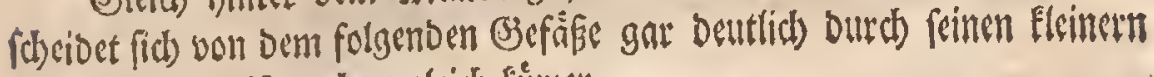
Durchichnitt; ift aud) ungleids furtzer.

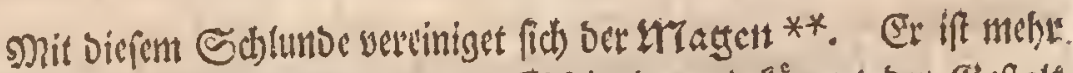

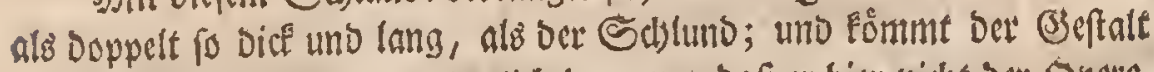

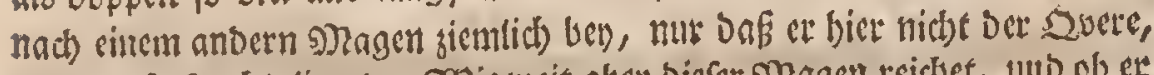

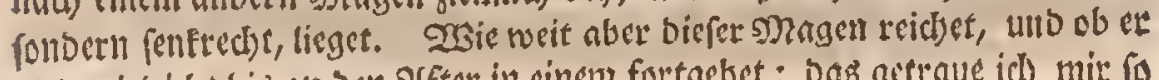
nicht vicleidst bis ant Den 2(fter in einem fortgebet; Das gettaue id) mir fo

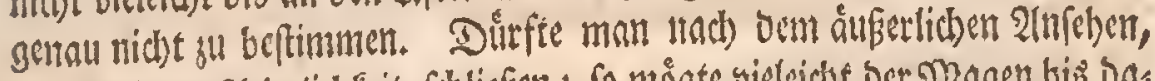

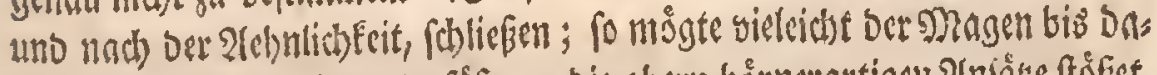

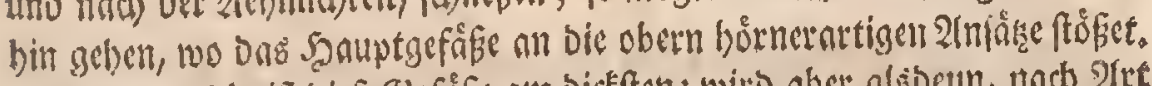

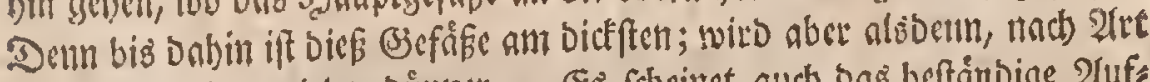

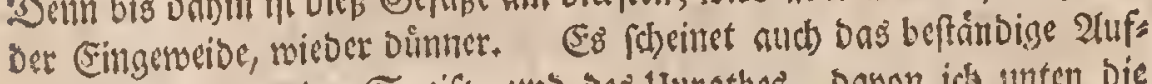

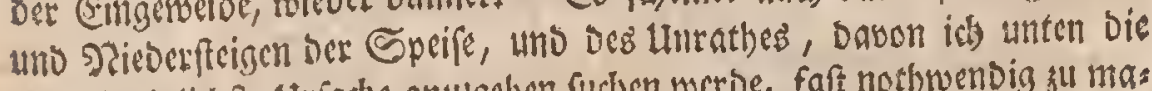

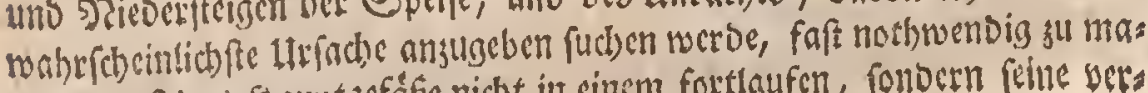

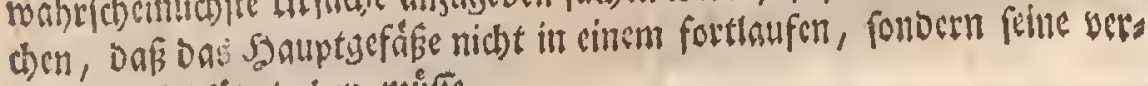

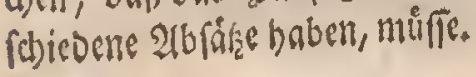

So grof und weit ibtigenb blefer sthagen, und ser ibrige sbeil

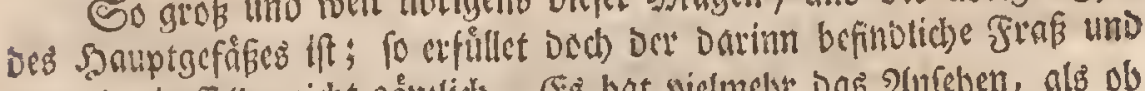

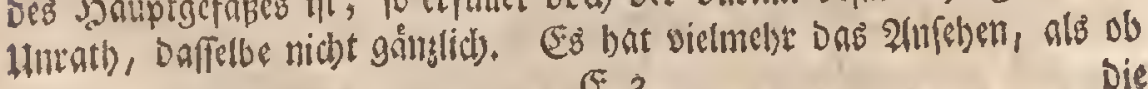

. Tab. Il. Fig. It.m. Fig. I. ** Fig, II, $\pi_{x}$ Fig. I. de 


\section{( 38$)$ )}

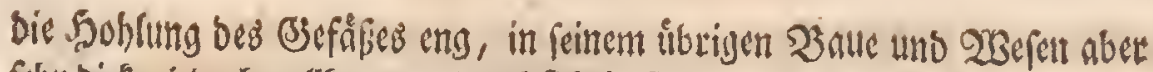

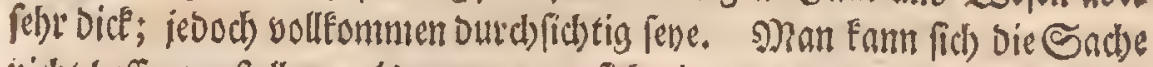

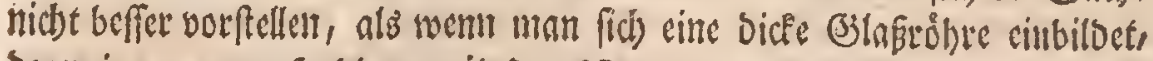

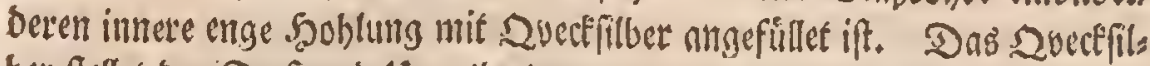

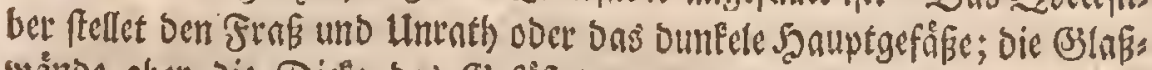

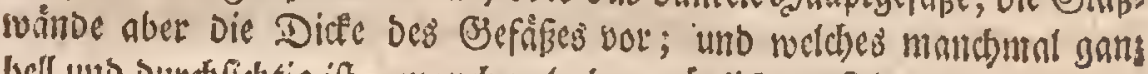

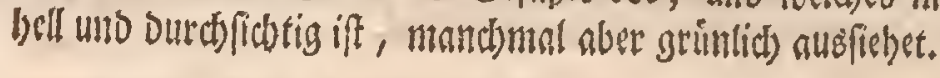

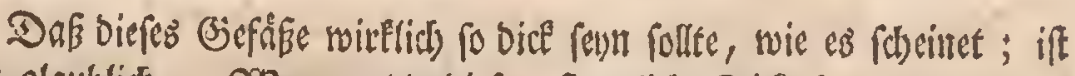

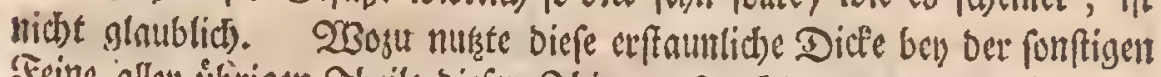
Feine aller ubbrigen Slyeile biefer Slbiergen? Soer, wenn es mit lnuter

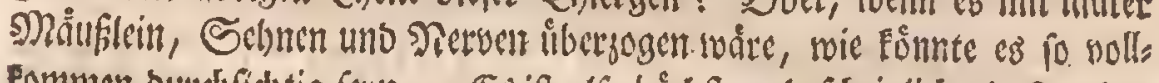

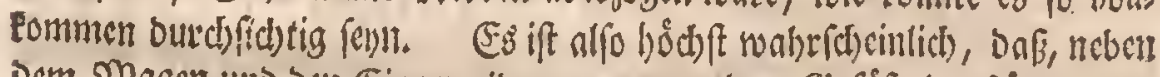
Dem Nagen uno Den Eingerweiden, sween andere Brefípe Der singe nach

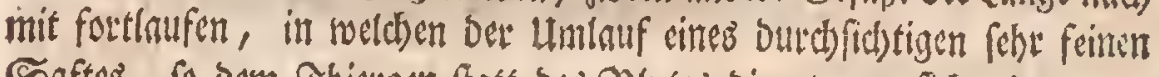
Safteb, fo bem Sbiergen ftatet bes Szlutes bienet, vor fich) geben nrag.

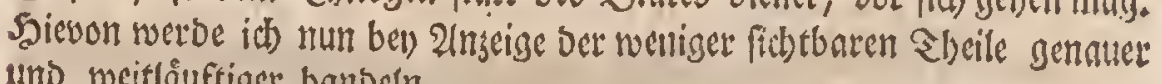
uno weitlåuftiger banoeln.

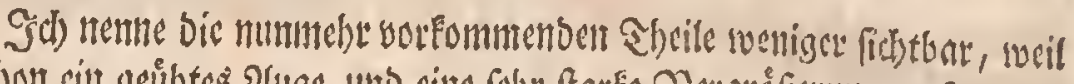

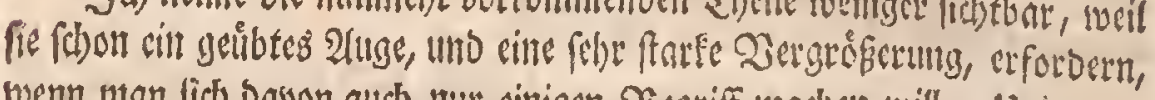
wenn man (id) bavon auch mur cinigen Siegriff mad)ent will. Llno auds

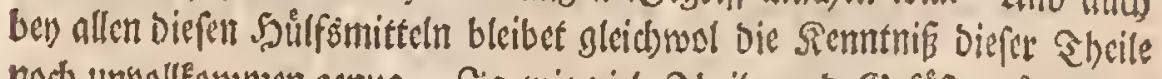

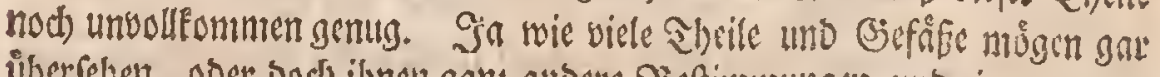

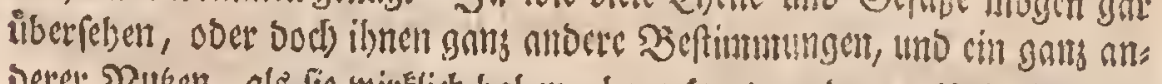

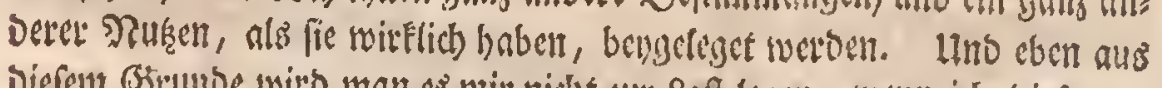
Diefent Grunbe wirb man es ntir nid)t jur Saft legen, wem idj bieje wes

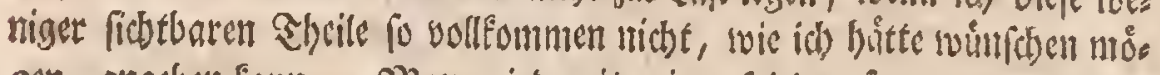
gen, angeben fann. Snan wiro nit mir zufrieben foun, wenn id fie

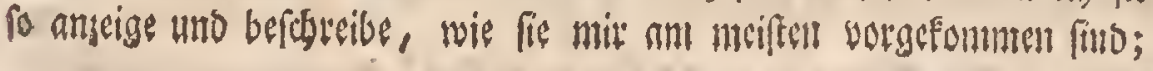




\section{(39)}

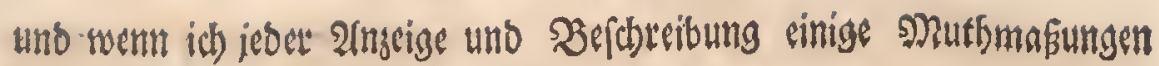
yon ibrem Endarmecte beyfugige.

Es firgen biefe eolern, uno zum seben ber Sbiergen nothwendigen,

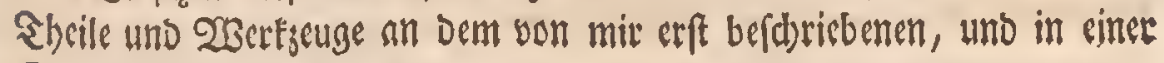
Ed)langenlinie burd) ben Sopf Den ganzen Seib heruntergebenden bun

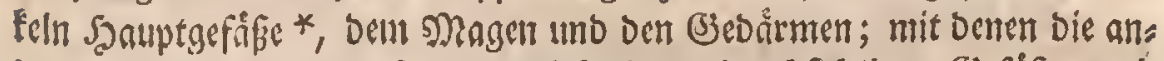

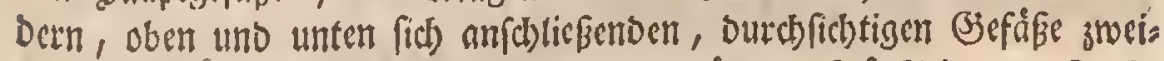

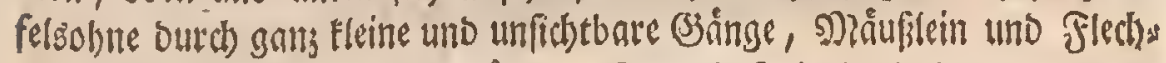

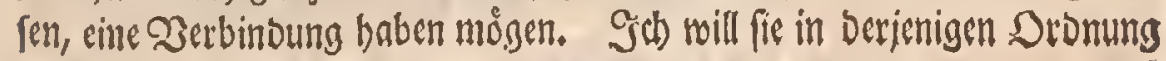
anfihteren, in weldjer fie mir su Beffidte getommen find.

Llnter bem Munbe, unmittellbar vor bem Magen nad) aufen zu, fies

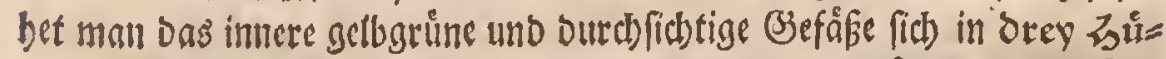

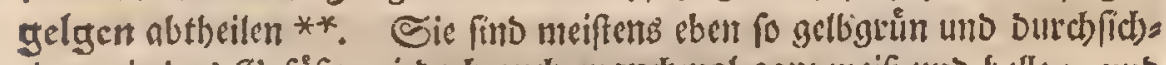
tig, wie Das (sefópe; jebod) audh mand) mal gans wei sund belle; uno

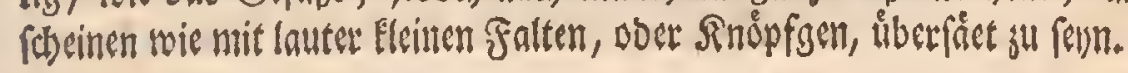

Das unterffe Zुligelgen *** lieget gleid) beu) Dem 2(nfange bes

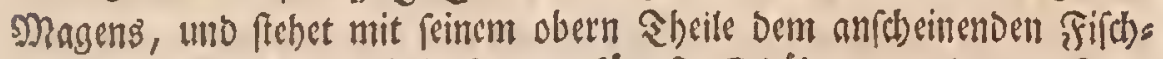

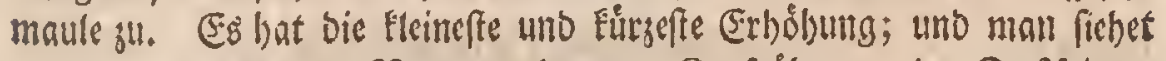

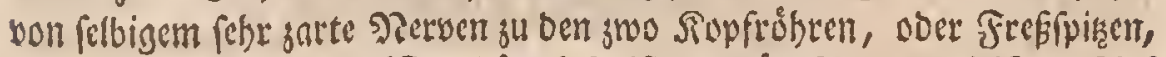

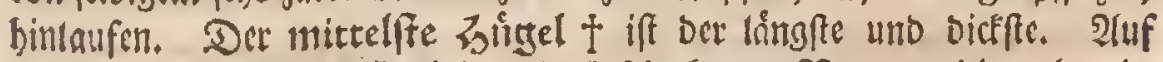

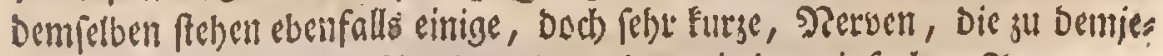

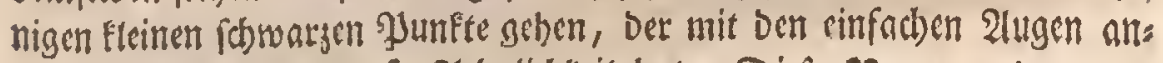

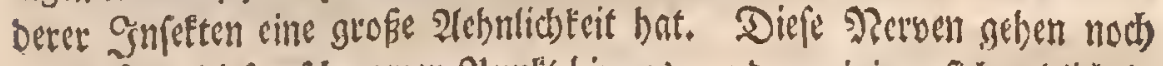

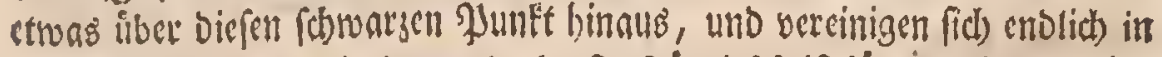

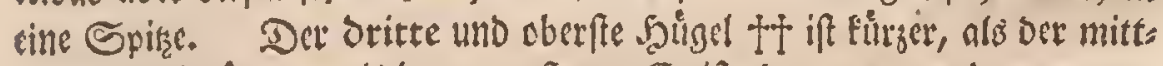
lere, jeboch länger, also ber unterfte. Er ift obell gants runo, wo man

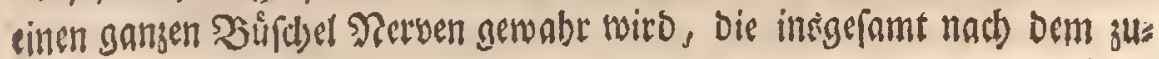

* Tab.II. Fig.II. kk, o. p. q.r.s.t. ** I, 2, 3, *** I, t2. tt

fnms 


\section{(40)}

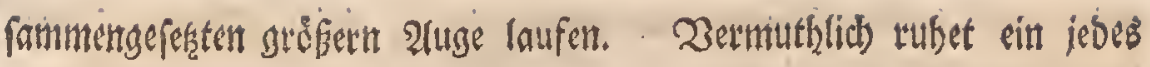

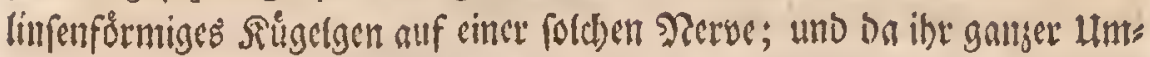

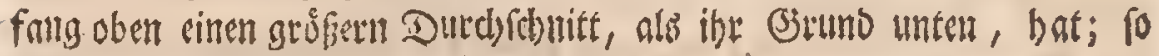
inelymen fie bie Bicftalt cines Sridjters' an.

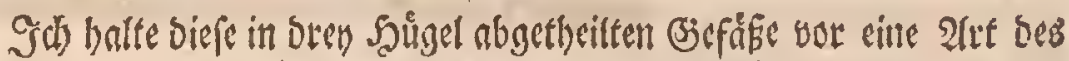
Gebirnes. Der Birfbel Nerven, ber bon bem grơfern Iuge nuf bem

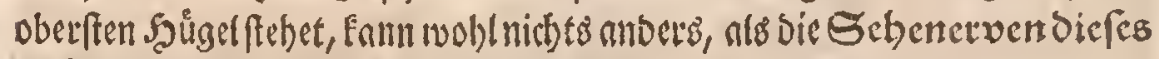
grof Betin 2lutges enthalten, weldbe fich bier nit bem Sieflirne verbindert,

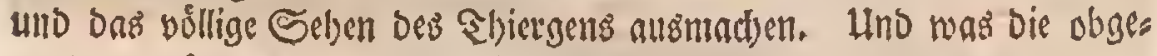
melbte beftainbige Bewergung biefes 2fuges betrifft; fo mag woht biefethe

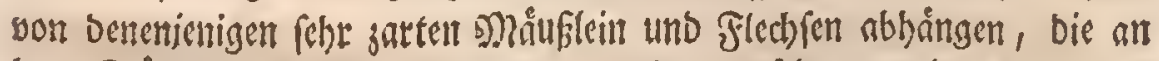

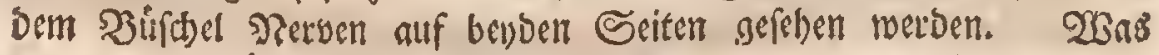
ber mittlere Shigel bor einen Zluect babe, getraue id mir richt ans

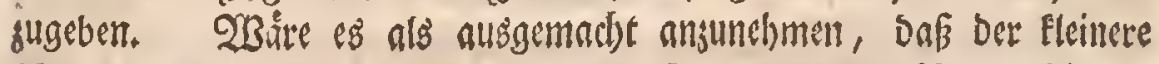

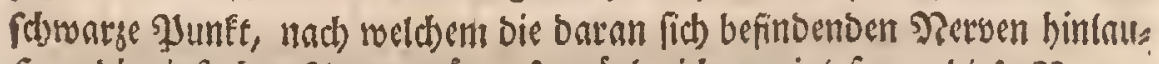
fen, bic cinfadben 2ugen woirc; fo wirbe id) geneigt fenn, biefe Nerben fïr bie Sebenetven ber cinfaeben Zurgen su erEtåren, bie fibi) benn

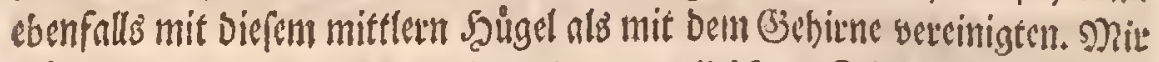
múfte biefes um fo viefmefle einfeuchten, weil id) 34 Beiten biefe Niersen

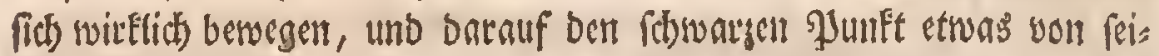
net Stelle fich babe begeben felsen. Die aus benz lestert wno unterften

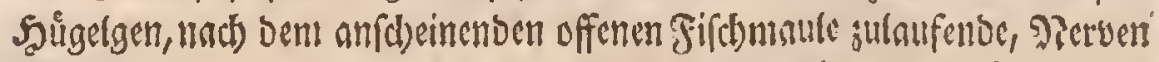

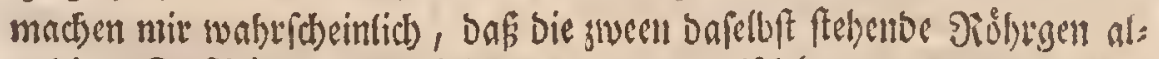

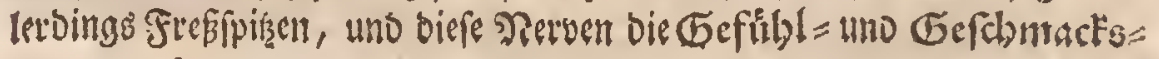
netven, feven.

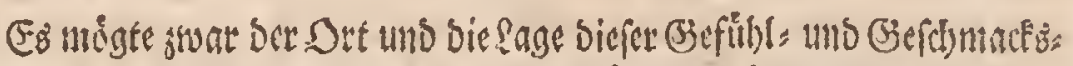

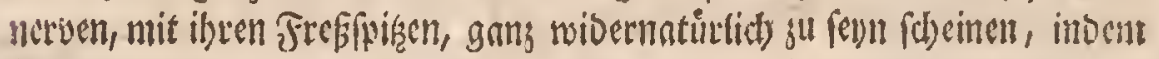

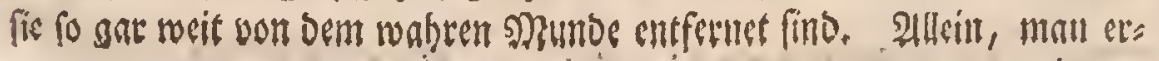




\section{(4I)}

inmere fids nut beffen, was ids) oben gefagt babe; fo nuire allet biobfalfiget

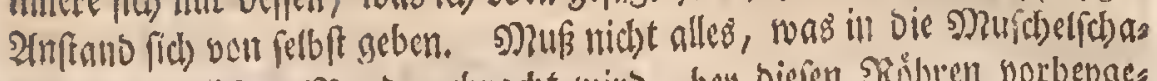

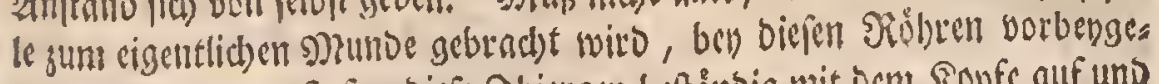
ben? Ilno roarum frofen diefe Shiergen beftindig mit ocm Sippec auf uns

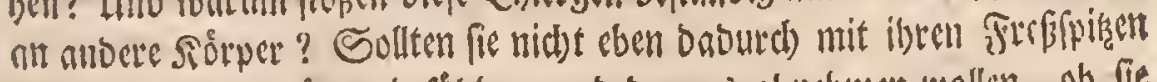

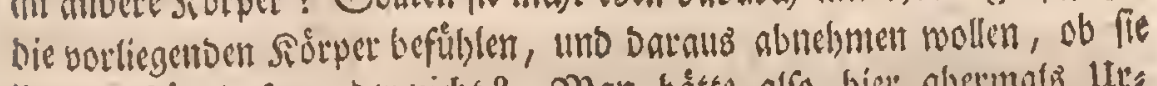

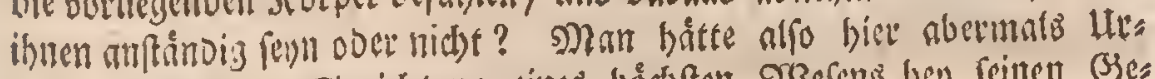

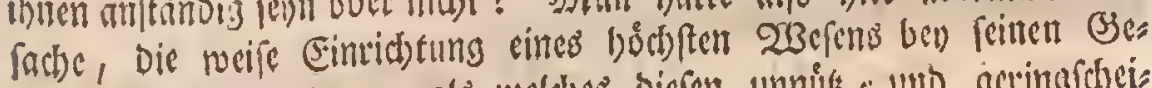

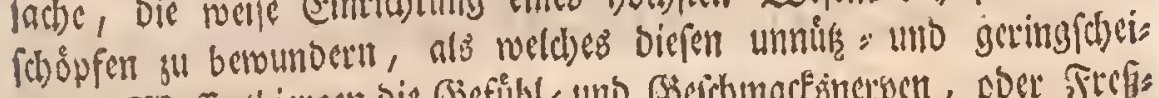

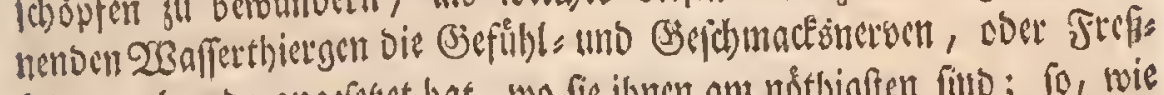
fpisen, cbent Da angreferget bat, wo fie ilbnen am noftligften firto; fo, wie

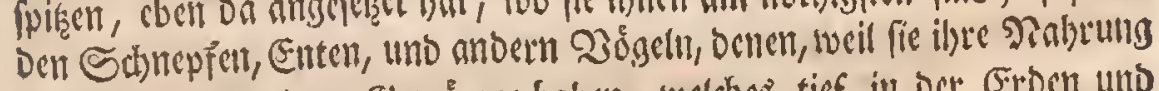

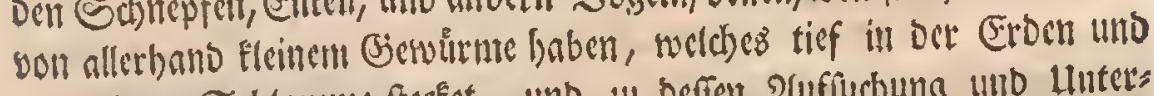
unter Dem Schlanmte ftecfet, und zu beffert 2(uffuchung und lluter:

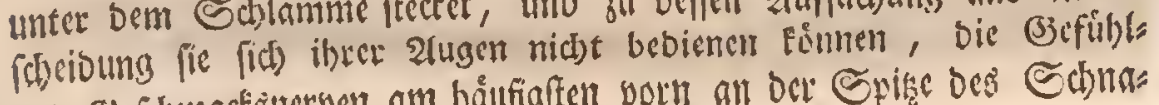

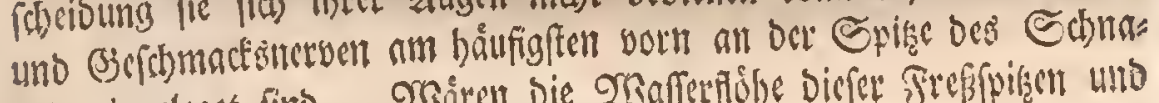

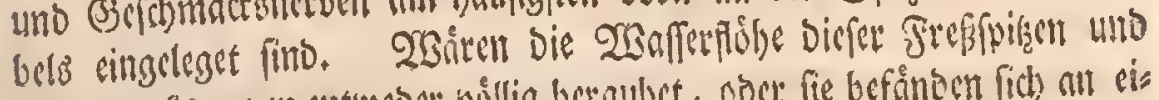

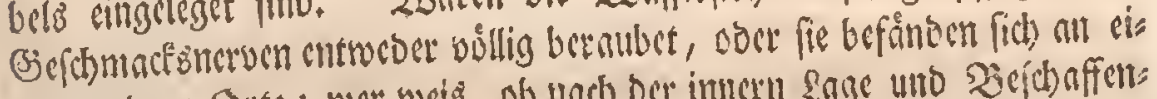

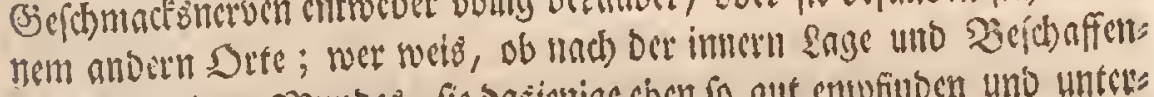

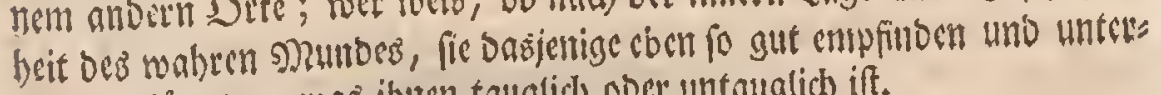
fiseiben foonten, was iburen tauglid) ober untauglid ift.

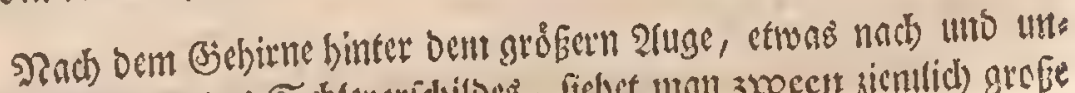

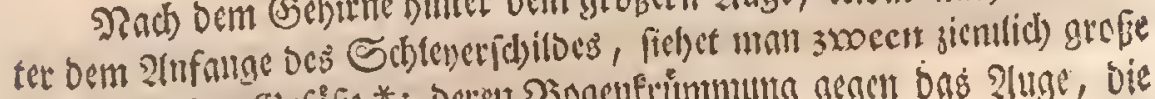

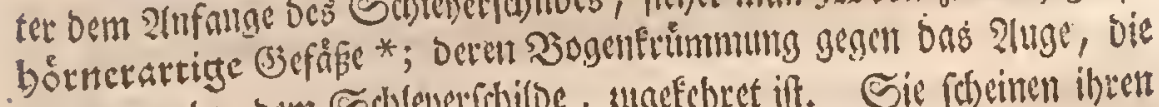

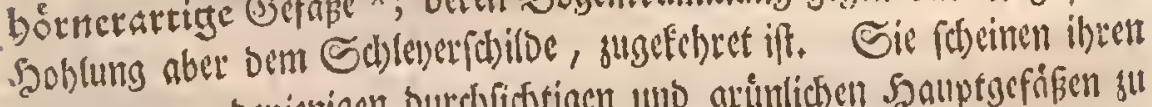

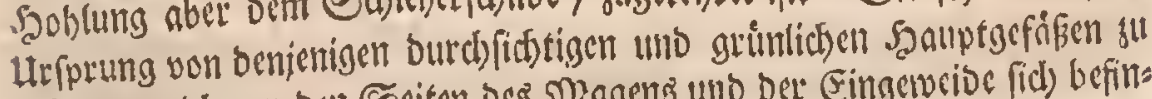

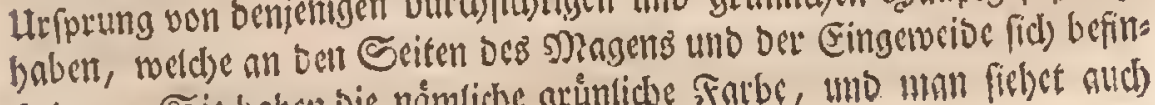

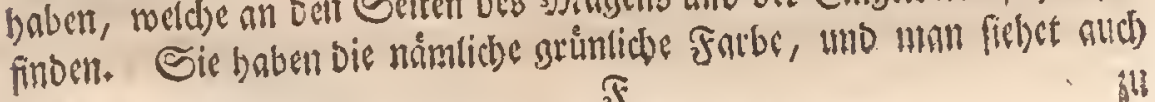

* Tab.I. Fig. VIII, d, Tab, II. Fig. II, k.k. 


\section{(42)}

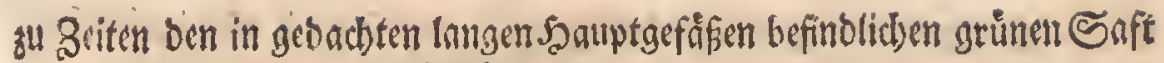

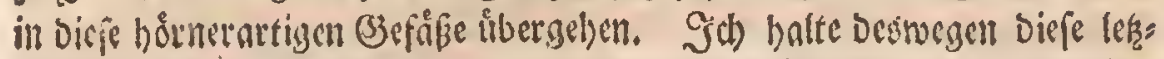

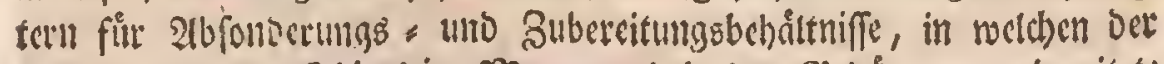

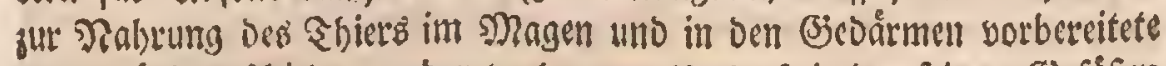

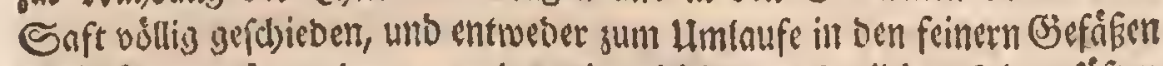

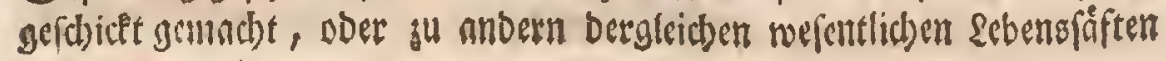
verbraudet wiro.

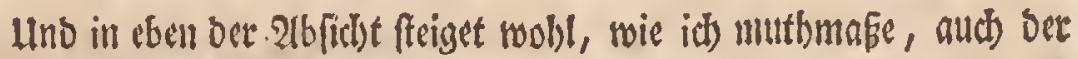

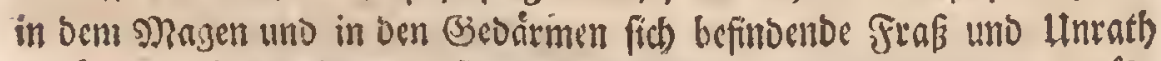

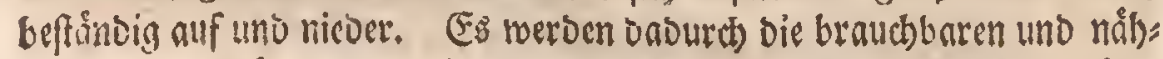

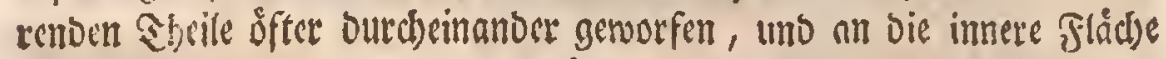

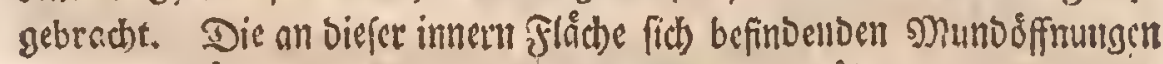

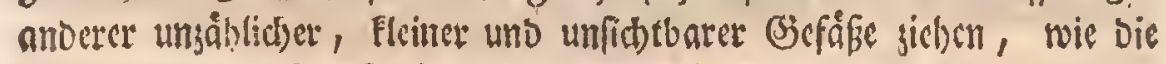
Mildhavern (vafa lactea) bey) ben Menfden uno Shicren, zucifelb: shne Den bünneften Saft aus uno an fich; und fihbren ibn burd) anbe:

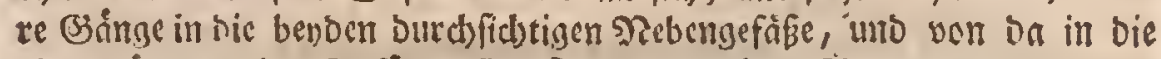

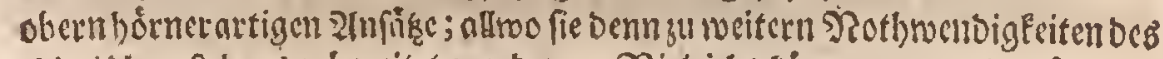

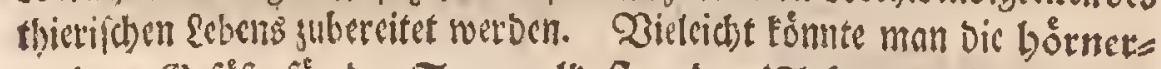

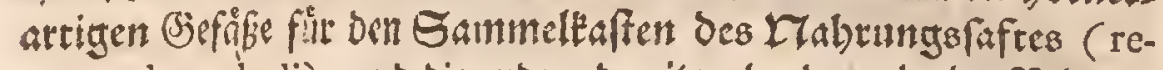
ceptaculum chyli); und Die anbern bamit verbundenen benden शiebenges fö́be vor eine 2let der MTilebbruffader (ductus thoracicus) anfeben.

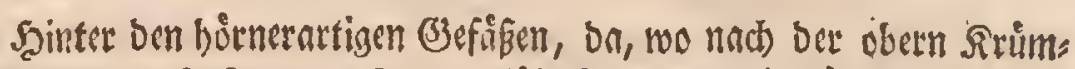

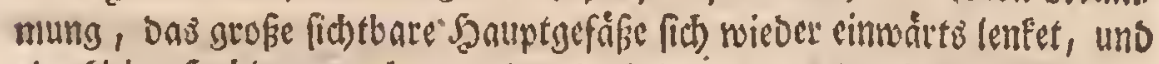
cine fleine Sabblung madbet, gelset ein fleiner (Bams berab *, Der in ber

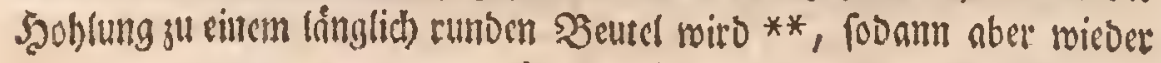

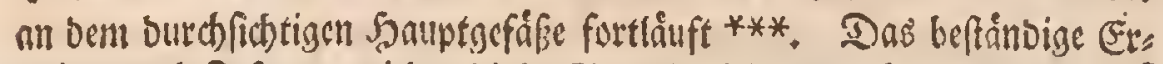

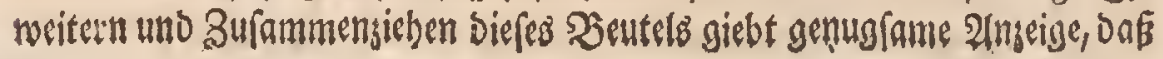

* Tab. II. Fig. II. p. ${ }^{* *}$ q. ${ }^{* * *}$, so

Der: 


\section{(43)}

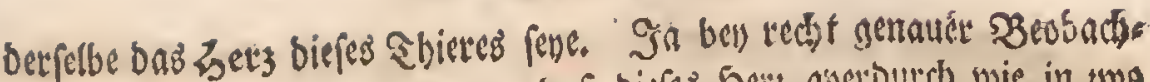

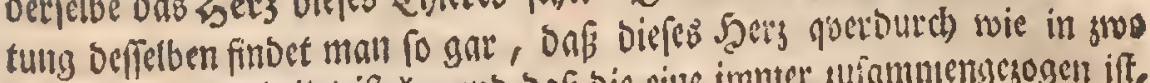

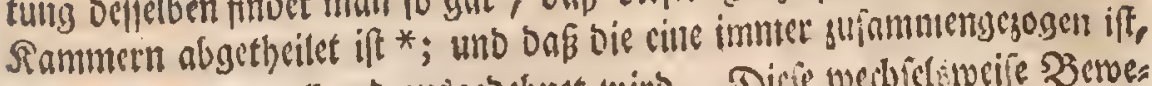

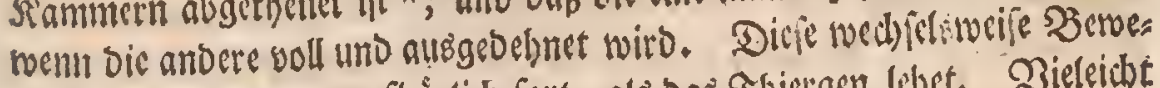

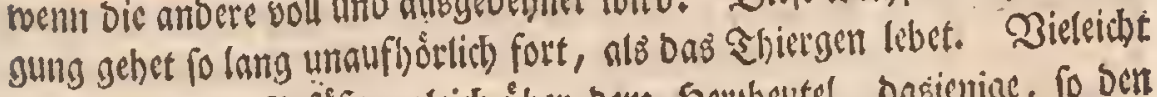

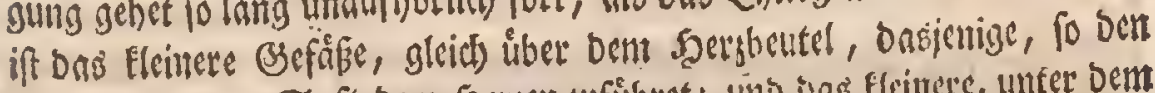

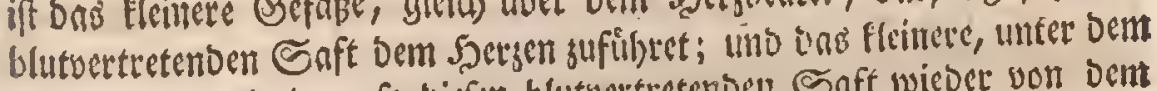
Sacrjbentel Dasjemige " To biefen blutvertectenden Saft wieber von Dent

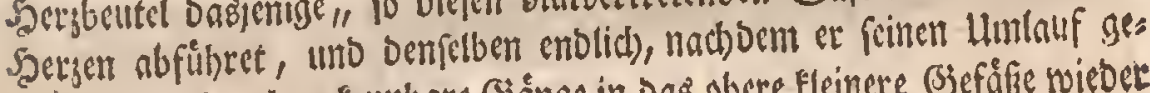

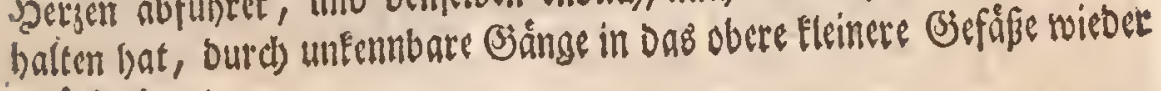
zuruectbringet.

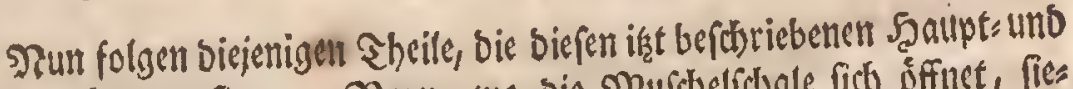

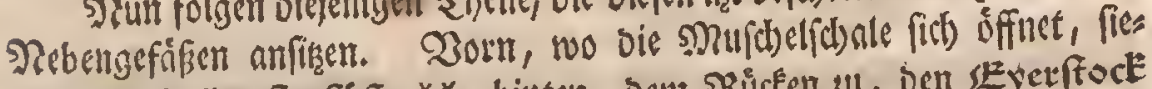

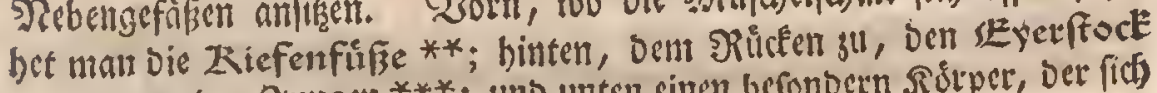
mit Evern ober Gungen ***; und unten cinen befondern soitper, Der fich

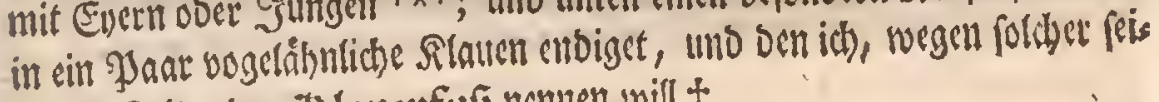
net Beffalt, Den Klaulenfuris nemnen woil t.

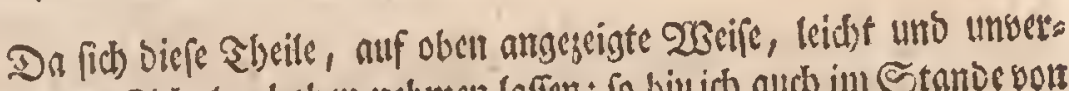

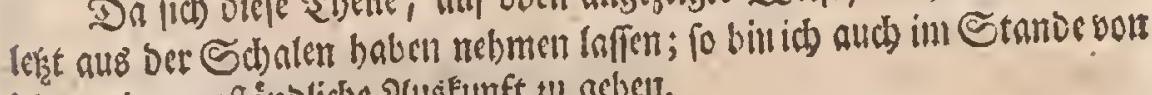

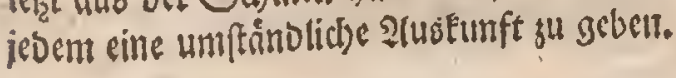

Der Ziefenfuife tt fino nuf jeber Geite vier, obct, wernt utams red)t genau nimt, funfe. Sic find alle, fo vid ids babe entoection foót: uen, binten fowobl felbft mit einanber verbunben, nlb audb bent Sants gefáfic titt angeglicbert.

$$
\mathfrak{F}_{2}
$$

()ด

* Tab.II. Fig.11. r. " Tab. I. Fig. VI. Fìg. VIII. Fig. IV. "* Tab. I. Fig. VIII. i. +T Fig. VI. d. VII. g. VIII, o. p. r. Tab. II, Fig. V. tI Tab. II. Fig. IV. 3. 2. 3. 4. s. Itt 2. 


\section{(44)}

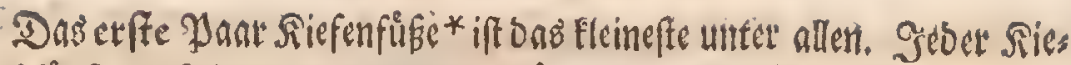

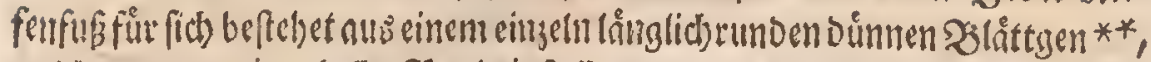

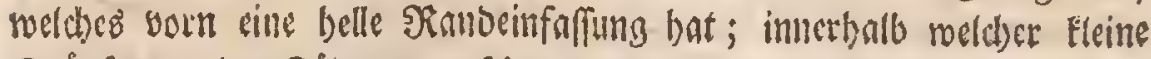

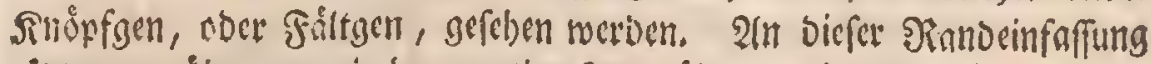

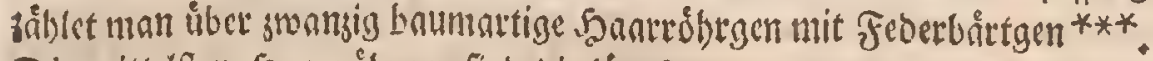
Die mittelfen Sagarrơbrgen fino bie lángften, icoes aber if brevmal ges glicbert.

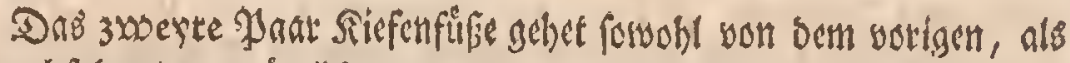

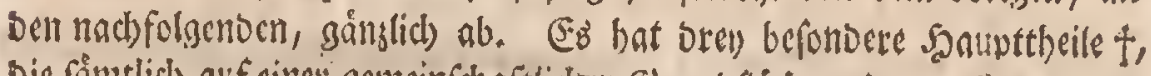

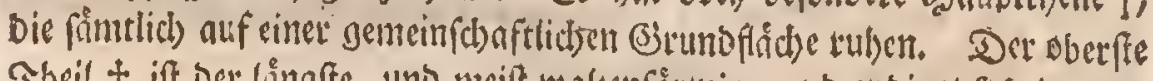
Sheil t ift Der lingfte, uno meift walzenformig; und entoiget fid) in zween

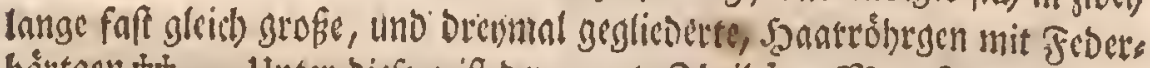

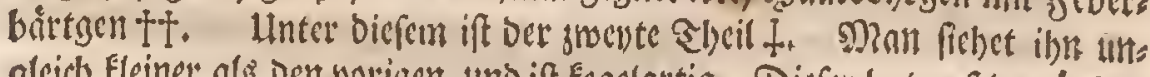
gleid) Eleiner als Den worisen, und iff Ecgelartig. Dicfer bat nuf Der neuscrs

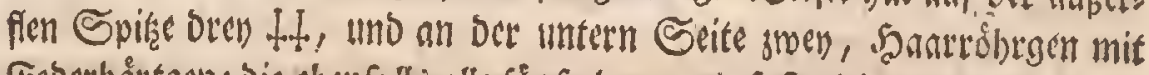
Feberbårttgen; bic ebenfalls alle fünfe lang, unto faft glcich grob finto +4 t. Der britte Elycil * bônget an Dem erff berchtiebenen fegelartigen Sbeile.

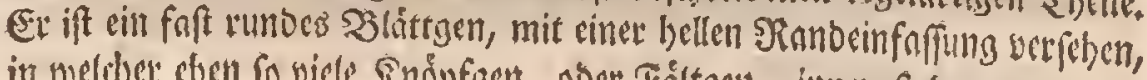

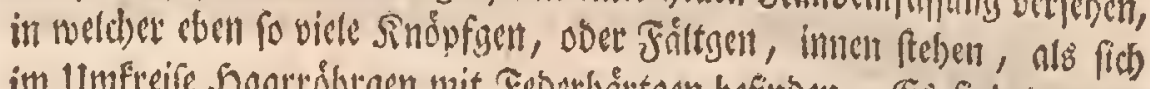

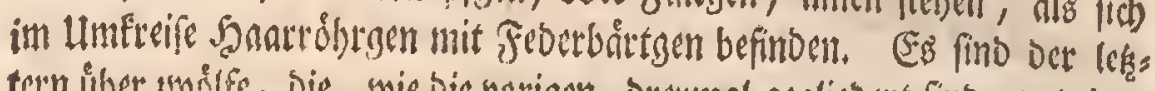
tern iber swodfe, bie, wie bie vorigen, breymal geglievert fiut, uno bets unterwårta bången.

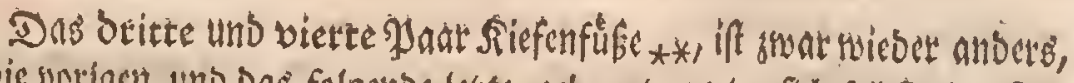
als bie voriget, uno ong folgende leferte, gebnutet; unter fich felbft aber fino

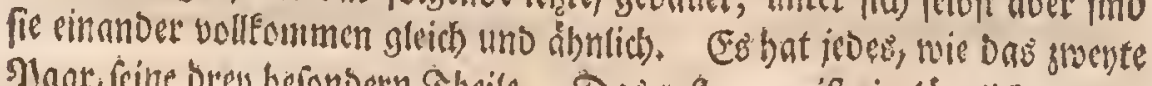

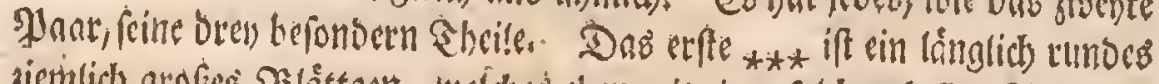

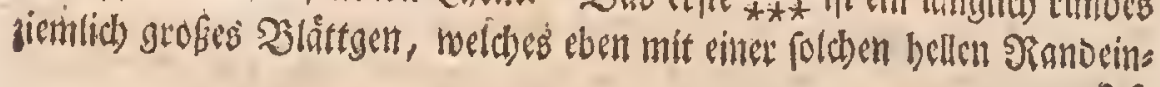

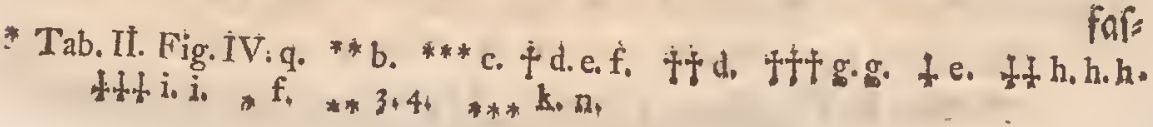




\section{(45) (4)}

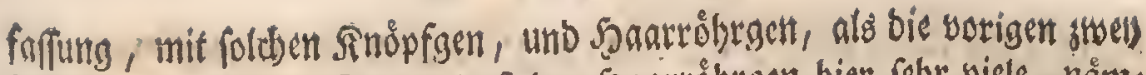

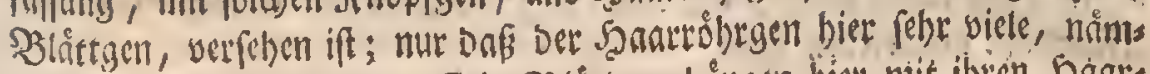

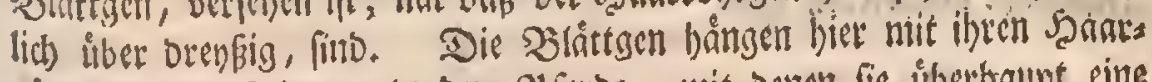

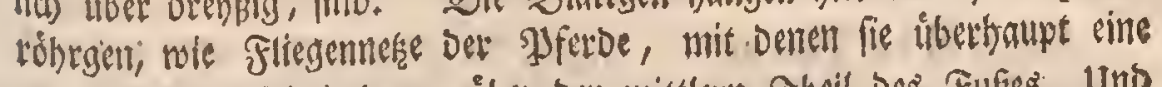

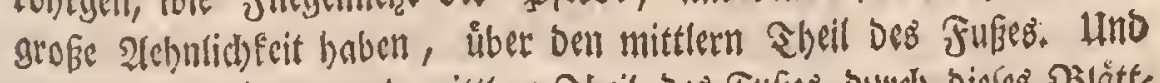

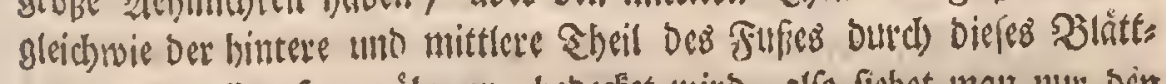
sen, uno Deffen Sanrrobbrgen, beberfet wirb, alfo fieffet man mur bin

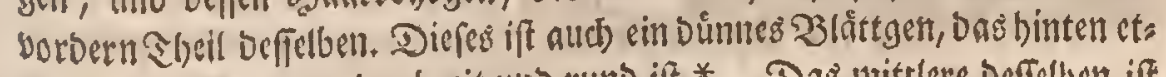
was fdymåler, yorn aber breit uno runo ift *. Das mittlere beffellen ift braun gebippelt, uno folglich balb burdefictitig; um uno um aber ift eine belle Durdsfidstige Janteintaffung, an weldser vorn vier, uno an Der uns

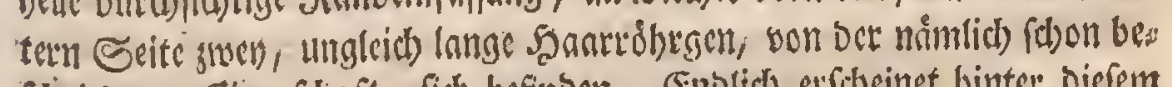

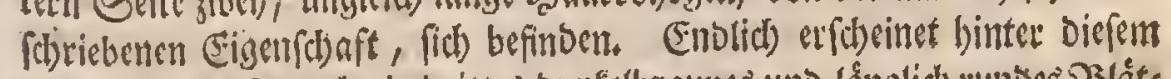

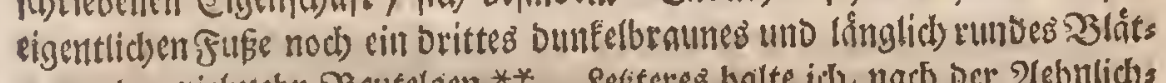

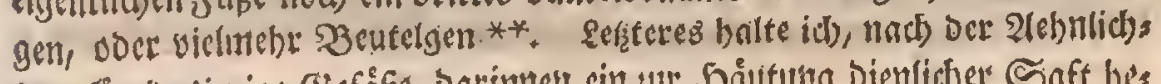

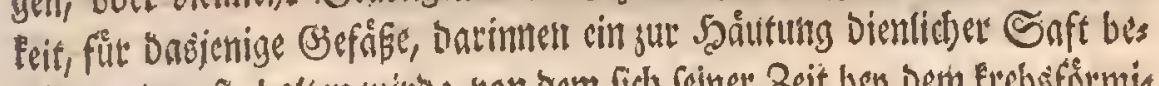
reitet usto aufbehalten witto; wen bem fich feinet Zeit ben Dem frebsformis gen Siefenfuf

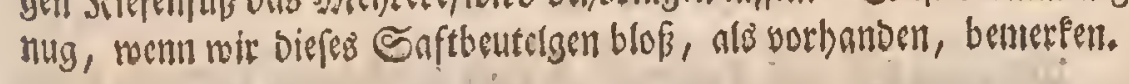

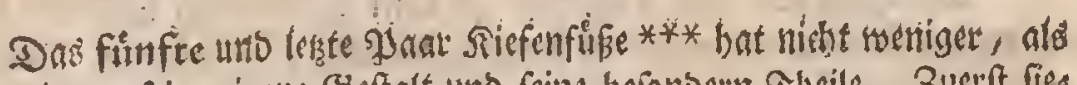
bie worigen, feine eigene Beftalt unb feine bejondern Sleile. Zuerft fies

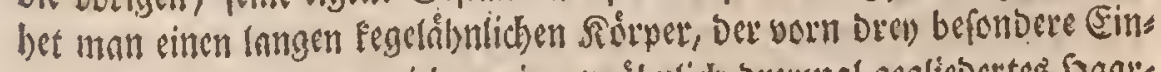

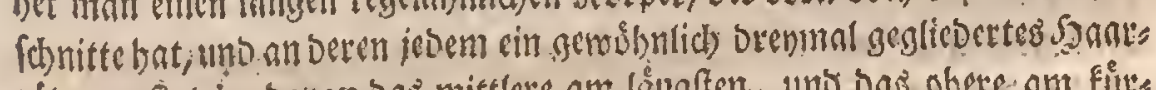

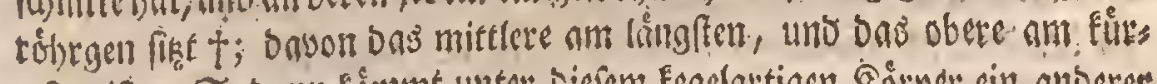

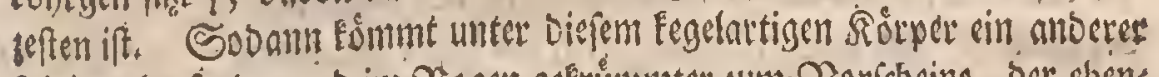

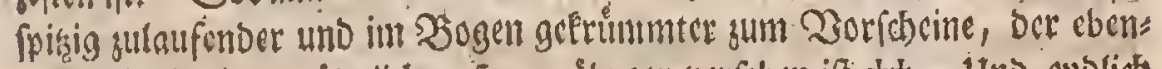

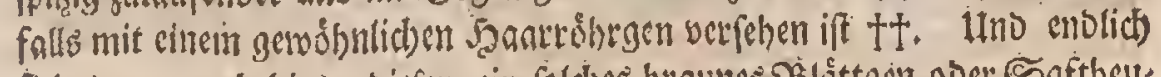

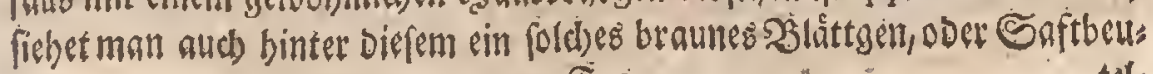
$\widetilde{5} 3$ t t

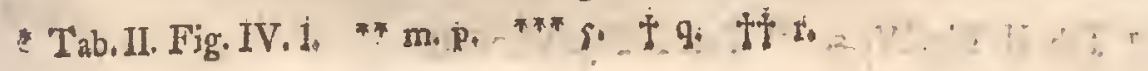




\section{$(46)$}

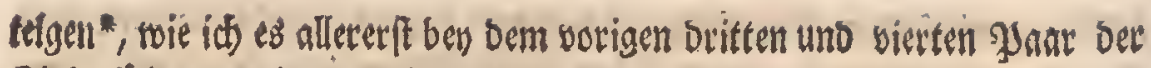
Siefenfufec berdrieben babe.

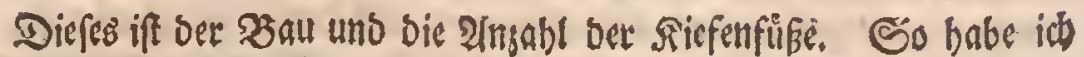
fie wenistens am offerfen gefehen uno bemertet; ob es gleich ben alle Dew fenn Eo̊nnte, Dafich mich bie und Da noogte geirret, doer micl) fonft

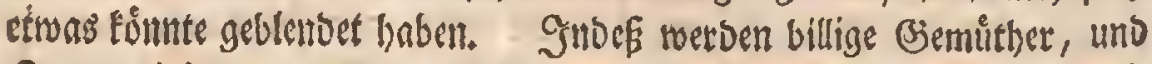

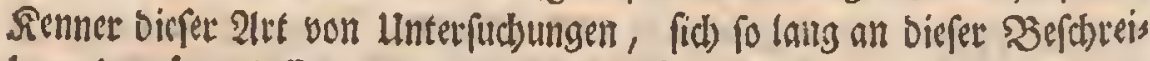
bung begnuggen loffen, bis ein anderer édmmt, ber es beffer su mad)en

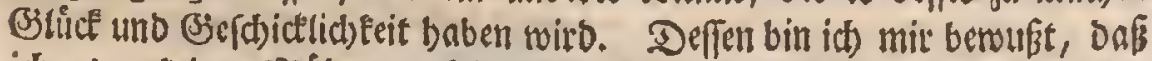

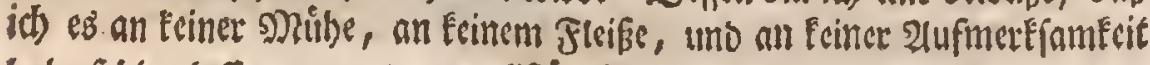

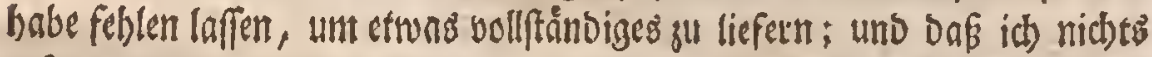

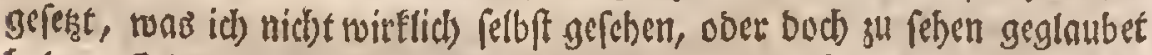

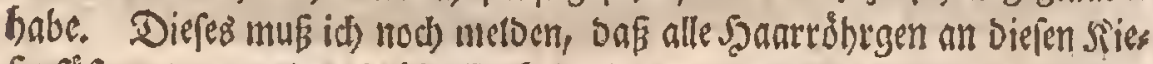

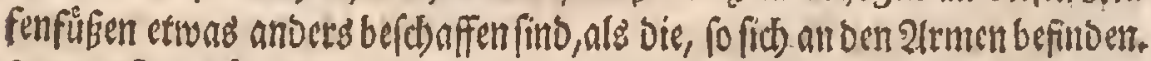

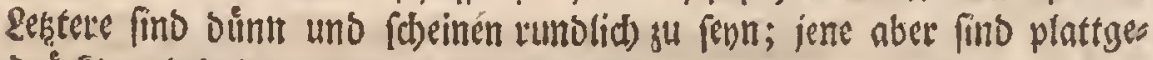

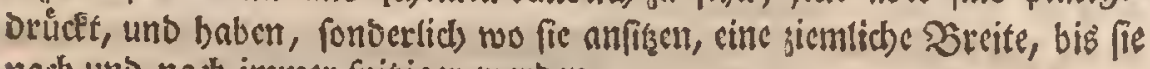
nach uno nads immer fpitiger werben.

Utebrigens find bicfe Riefenfufpe in ciner beftinbigen wellenfortunigen, ober; wie fie Stoammetdam nemnet, jitternoen 3 Jewegung. Ilno als's

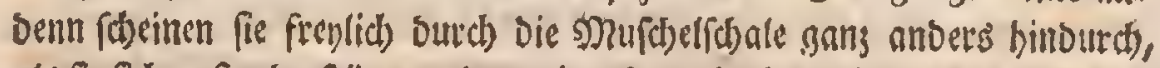

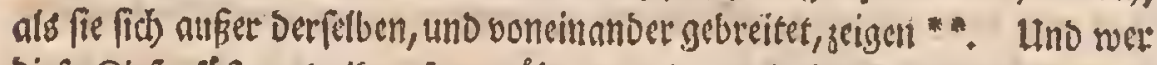

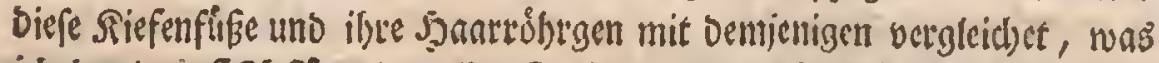
ich bey Deri fifchformigen Ziefenfuffe, uno Deffen Siefen, gefagt bahe,

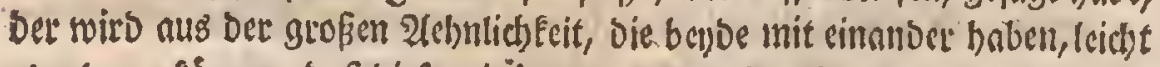
abnebmen Edonnen, Daß biefe mit ienen gleichen Zluect umb gleidbe Beftiun:

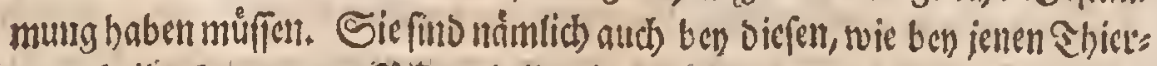

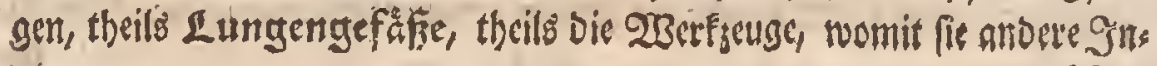

* Tab. II, Fig. IV. s. ** Tab. I. Fig. VI. VIII,

reften 


\section{静 $(47)$}

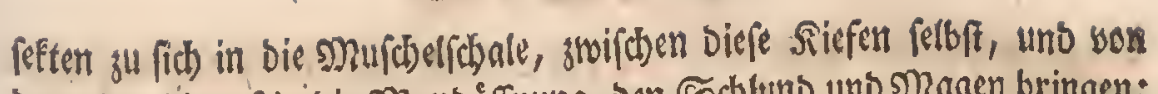
Da weiter binnuf in bie \$Rundeffnumg, ben Scthlumo uno Mngen bringen;

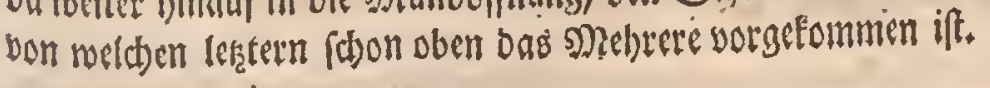

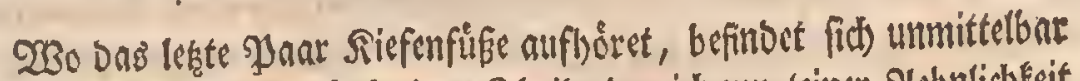

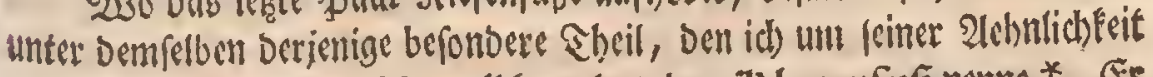

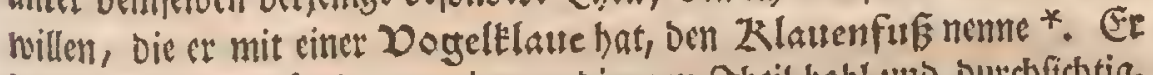
if gang tutb gar băutig, uno innwendig zum Sbcil bobl unb burchfictig.

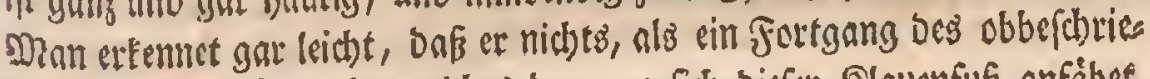
benen Sauptgefépes iff, weldes ba, wo fich biefer Silauenfus anfäbet, siemlich brcit wirto, binten einen 3 ogen madte, unb alsbenn unter bers

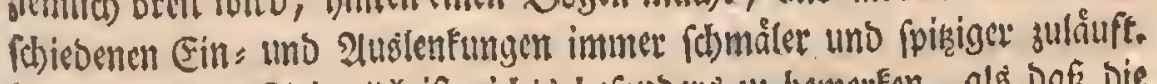

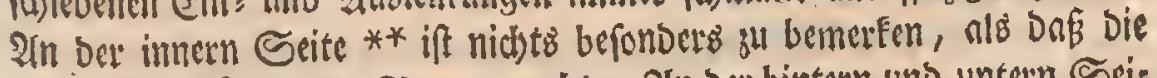
obere Fußsesflåche einen Şogen madt). IIn Der bintern uno untern Seis te abet fommen verfobiebene Stúcte sor.

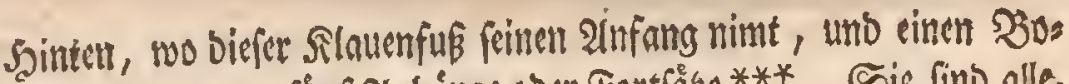

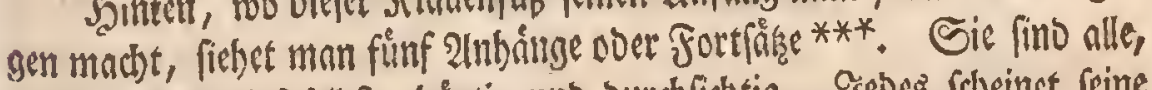

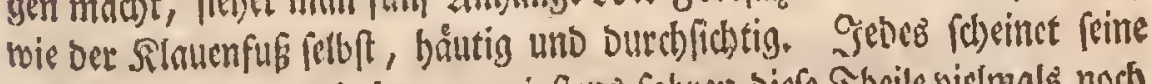
eigene 3 ervegung ju baben, wenigften faltren biefe Sheile vielmals noeh lang fort zu gittern, ween auch glcich alle fictbbare $\mathfrak{B}$ cwegung am saut

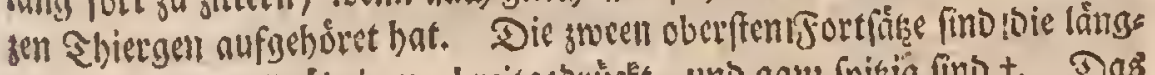

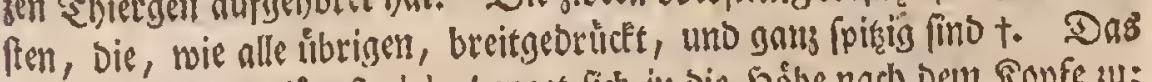

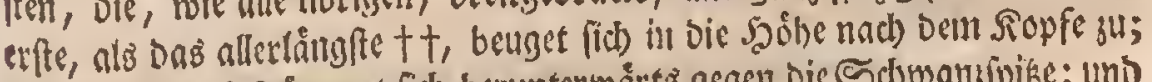

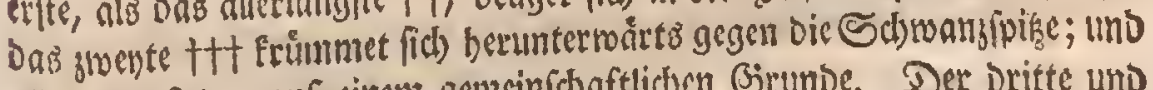
alle bende fethen auf cinems gemeinidaftliden Girunbe. Der Dritte und

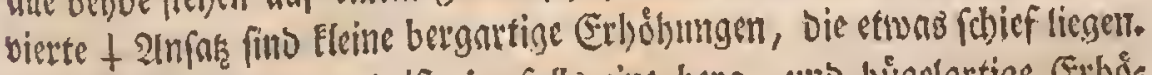

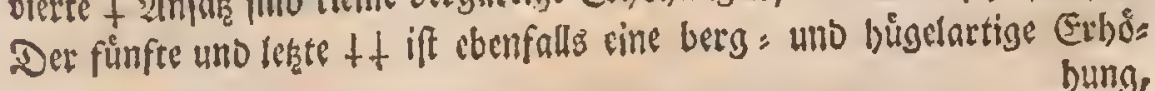
bung,

* Tab I. Fig.VI. d. VII.g. VIII. o. p. q. Tab. II. Fig. II. " * Tab.II.Fig.V.n. * Tab. II. Fig. V.c. d. e. f.g. te. d. tf c, tffd te.f. tf g. 


\section{触 $(48)$ )}

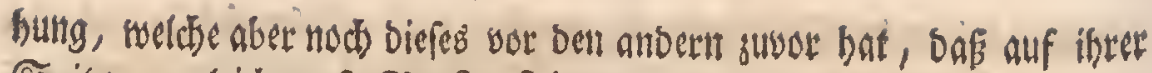
Spifse zno gleid) grope Sorften fichert.

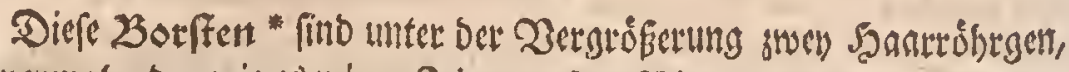

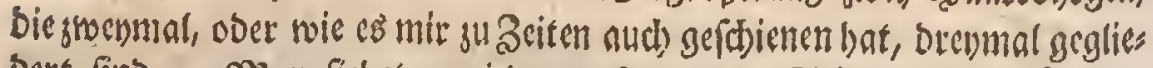
bert find. MRan fiel)et an jeoer auf benden Seiten Feoerbontrgen,

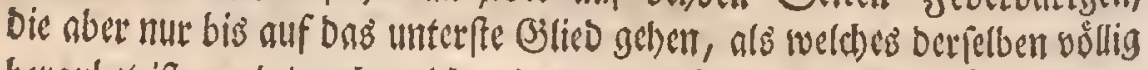
beraubet ift; uno burd) weld)en leetern Umftand biefe Saanerdbegen yon allen andern, bie man fo baiufig an biefem sbiergen finbet, abgeben.

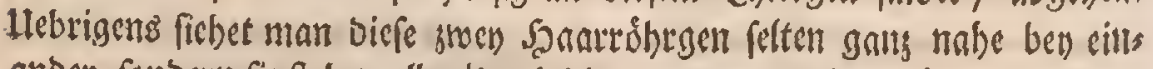
ander, fonbern fie ftehen alleseit, wie bie 2(rme eines mittelmáfigen Cirfects, alfo bon cinanoer ab, bafi fie oben, wo fie anfitisen, nabe ber cinanoer

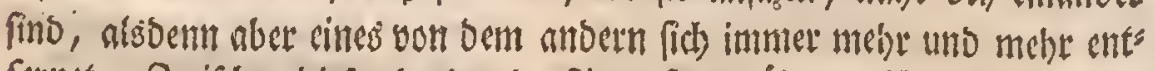

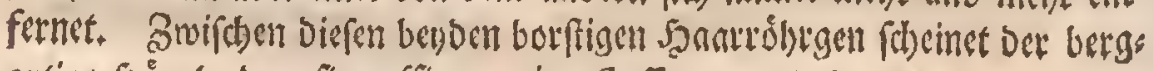

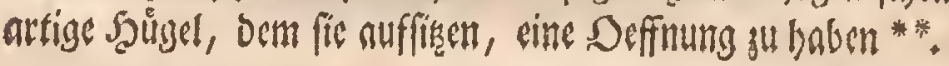

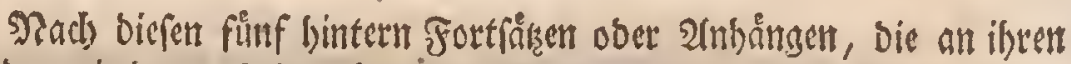

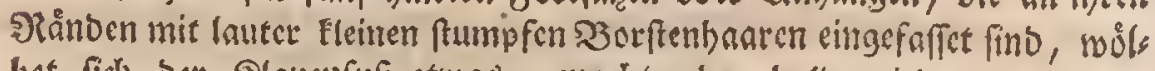
bet fid) bet Slauenfußs ctrong, madit abet bald wicber cine Saobs lung***. Diefer Sbeil, melcher offent ift, seigt fiel) vorn uno binten mit lauter Erummen Stact)eln beferset, beren obngefóbre in allent vier umb

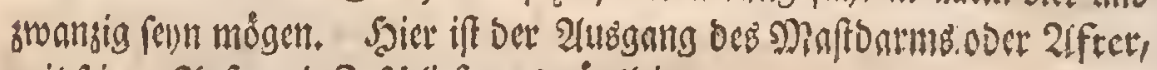

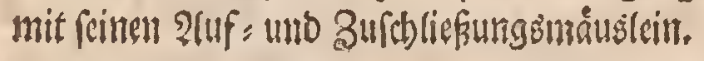

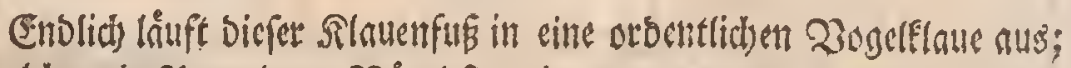

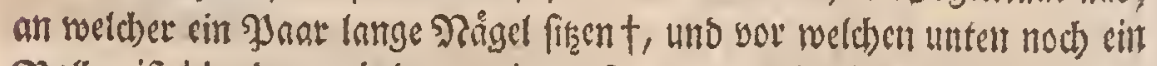
Ballen ift $\mathrm{t}$, Det, wie bet vorige erfe, born umb binten mit Stndeln bejectet iff.

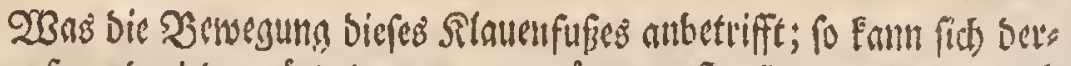

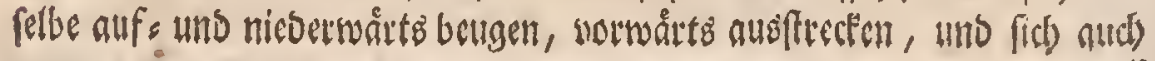
*'Tab. II. Fig. V. h. h. ** i. *** k. t m. tt 1 


\section{(49) (4)}

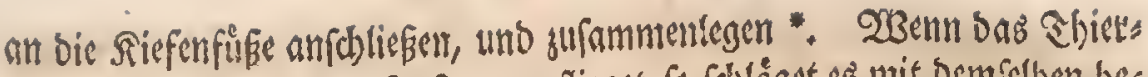

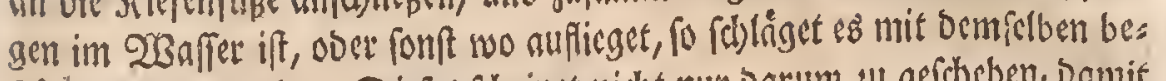

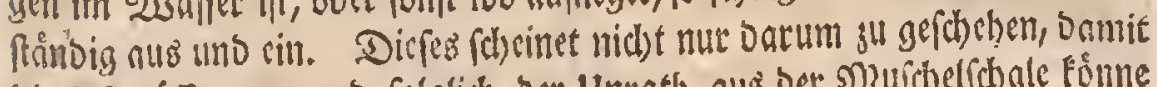

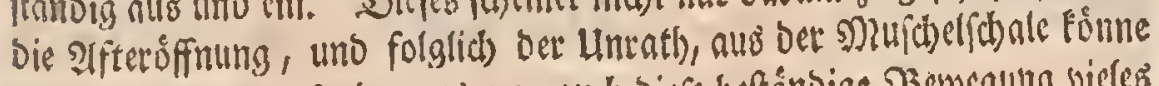
gebrache werben; fonbern es mag auch diefe beftánbige. Berwegully vielez

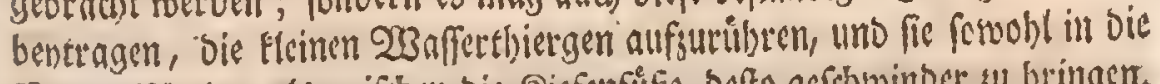

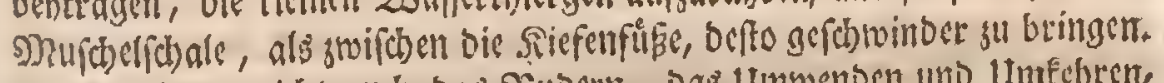

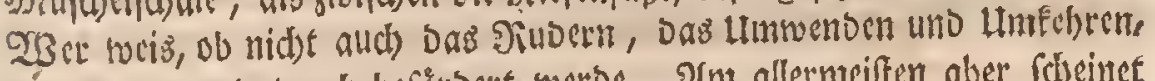

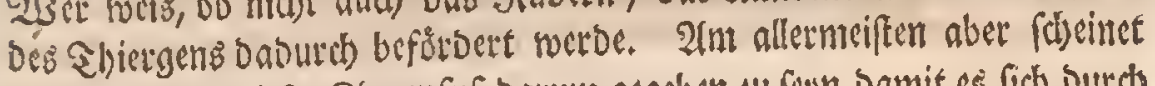
Dem Shiergen Diefer Sinuenfuf Darun gegeben zu fenn, Damit ef fich Durds Sallfe beffélbert nicht nur für andorre Junfeften, bie fich, wie an ibre åufern

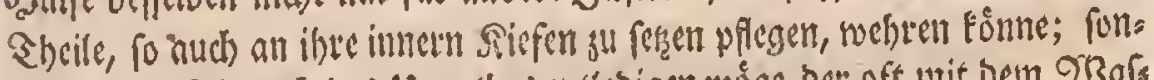

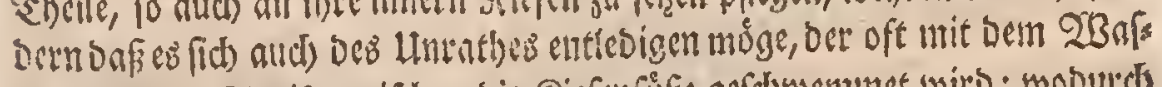

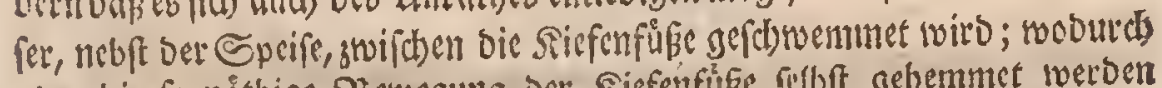

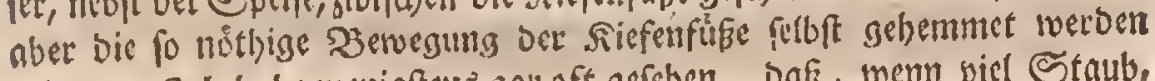

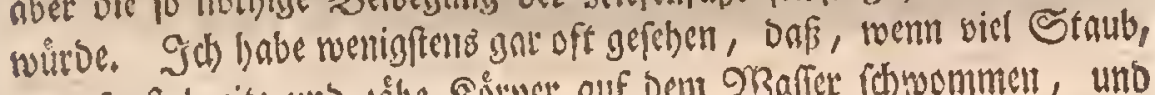

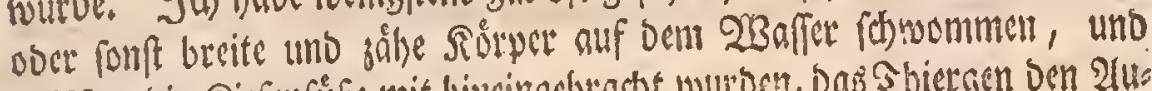

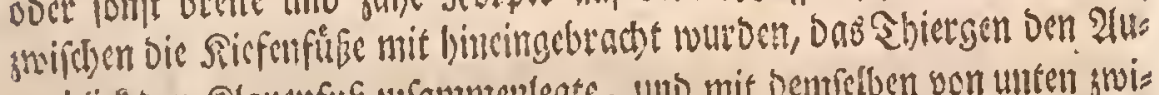

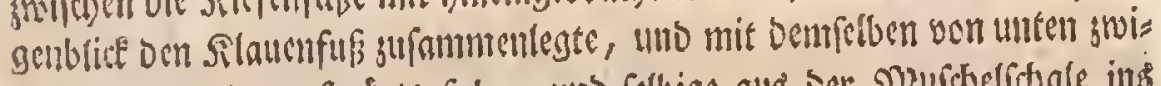

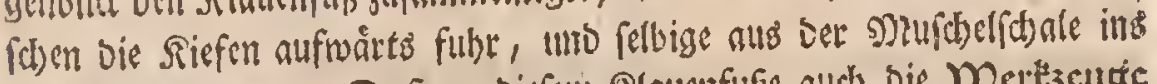

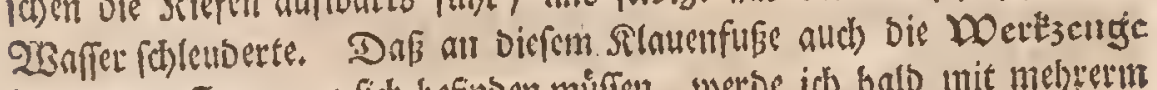
Der fortpflantsung (id) befinden múfen, wetbe id balb init melyeerm wabyifbcinlids zu madsen fuchen.

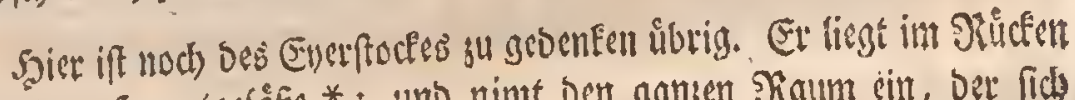

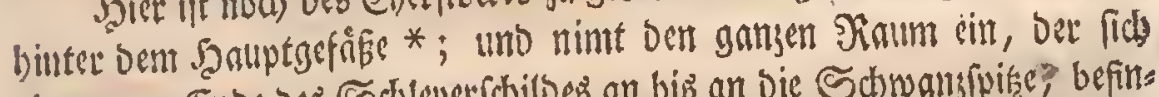

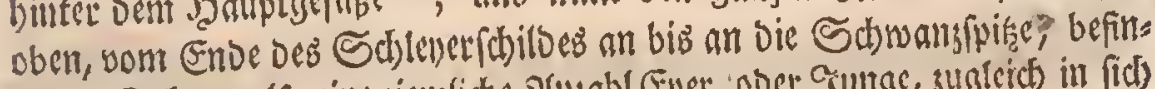
Det. Ere Eann alfo cine sientidye 2 (n)

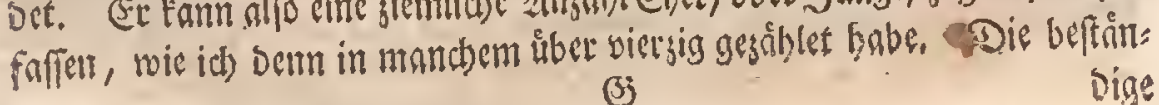

* Tab. I. Fig, VIII, i. 


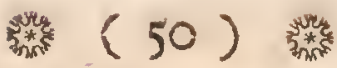

bige $\mathfrak{B}$ etuegung Deß Slauenfubes wirft Die Ener uno Sungen in biefent

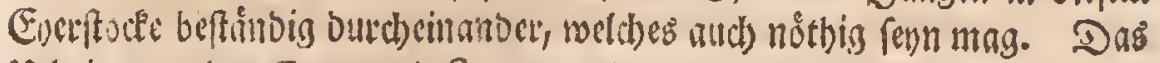
Hebrige von ben Evern uno Sungen foll bey Der Beschichte von Der Fort: phanzutitg volforinmin.

Diefe Nad)ridbt fowohl von ben innerlichen, als yon ben n̊ußerlichen,

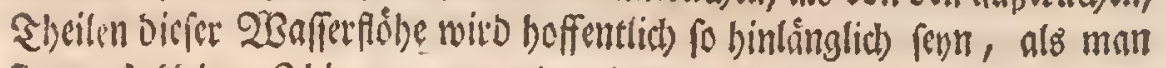
fie von io fletinen Shiergen vernuthen faitn. Sibl werbe nunmebro voll ibrent 2fufentbalte, von ibret Lebensate, Fabrung uno fort = pflanzung, Dab গiótbige anjuseigen baben.

Da fonft anbere 20 nferinfetten insgemein cin cigenes uno befonberce 233 affer licben; fo ift biefen 23 afferfióben bingegen jebes red)t und einer ley. Es ift genug, menu es nur 2 Sa affer ift, cs fen hermad ftebeno ooer fliefend, faul ooer frifib, bell ober trübe. Sie baben fich fo gar bey nit mit blosen SBrumnenmaffer erbalten laffen; fie baben in folchem munter fortgelebet, fich auci) Darimen fortgepflanset uno vermebret.

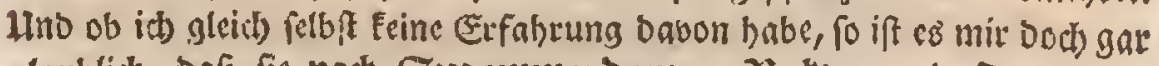
glaublich, Dáp fie nach Sxoammerdams, 23akèts uno Derbams 2tubiage, auth in 23 uffertrogen unb anbern $23 a f$ ferbebailtniffen ro

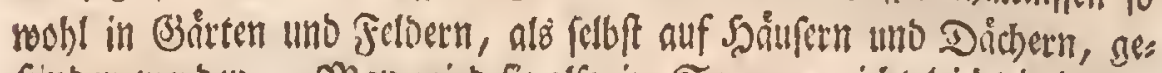
funben werben. SMan wiro fie alfo im Sonmeet nid)t leidht in irgeno einem freven 25 affer vergeblid fucben. Dod) if nir vorgeformmen, als

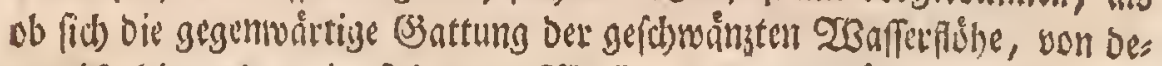
nen id) bier reoe, in febenden $23 a f f e r$ lieber und båufiget aufsubalten plege.

Sn biejen $23 a$ fern fiebet man fie nuf verfbbiebene $\mathfrak{T}$ rt unb 2 Beife obne Unteilab, uno obne auch nur cine fleine Beit rubis ju fent, fich bin uno ber begeben *. Exwammerdam fdbrånfer ibre Serwegungen in

- Tab. L. Fig. I. Dren 


\section{(5I)}

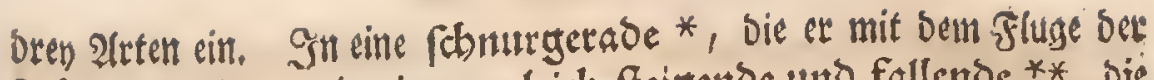
Zögel vergleid)et; in eine ungleich freigende tuto fallende **, bie

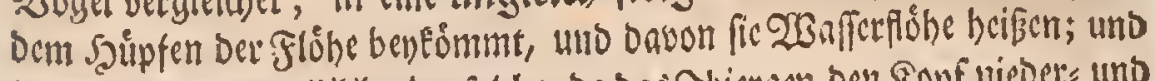

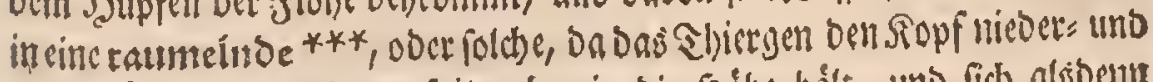

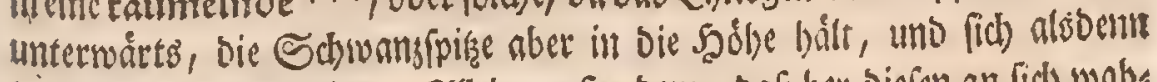

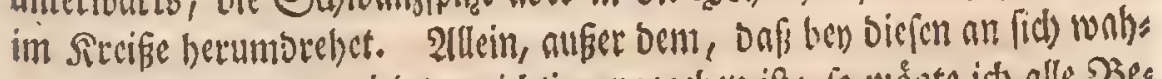

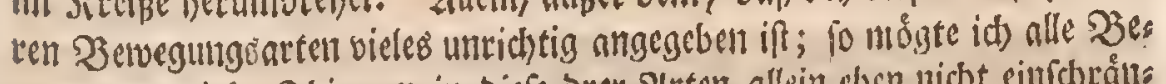
lvegungen biefer. Shiergen in biefe brev Plrten allein cben nicht eillfdbrån:

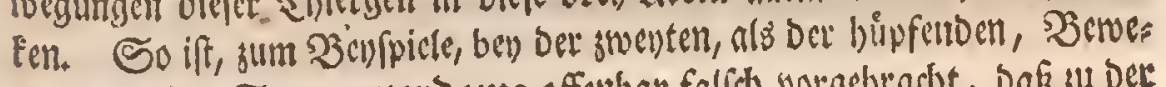
gungeart ocs Exoantnerdams offenbar fal(id) vorgebrad)t, baj ju Der Seit oer Siopf allçeit oben, und bir Sd)wambipige unten, fenn follte; indem man fie auf bie nåmlid) búpfende 23 eife aud nad) ber Socre, wageedt, und gerab binunter, burd) Das $2 \mathfrak{Z}$ affer fid beroegen fiebet, unb wo Der Fopf balo cben, balo unten, bald nuf cine andere Seite, luto abweds)s felno nad) ailen (jegenben, bingeridbet iff. So ift es ferner cine biefen

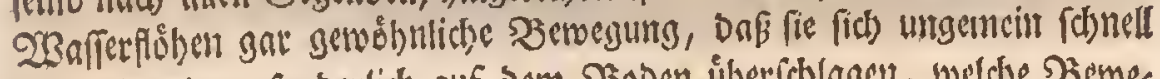
hintereinanoer, fonberlid) auf Dem 230 ben úberichlagen, weld)e $\mathfrak{B}$ erwes

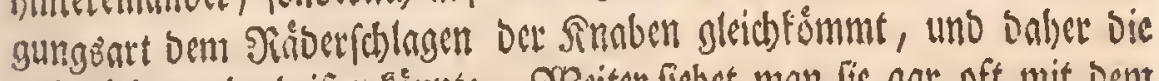

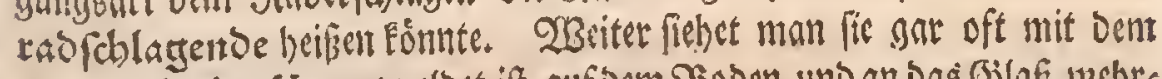

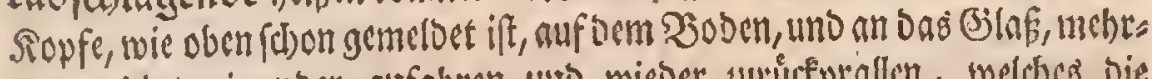

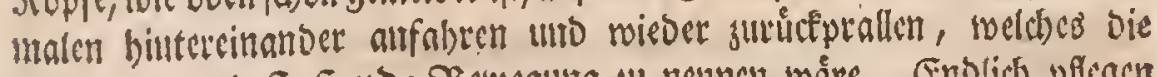

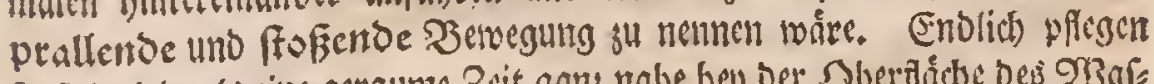

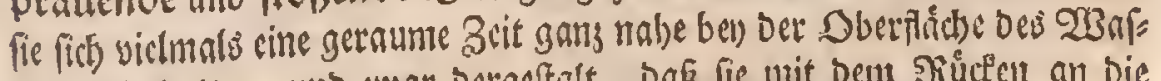

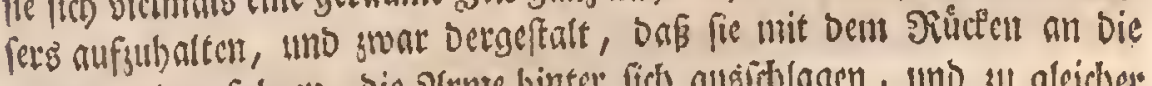
(3ilapruand anfabren, bie 2(rnte binter fid) ausid lagen, unt ful gleicher

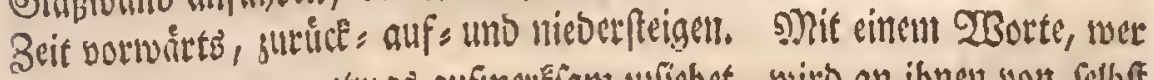

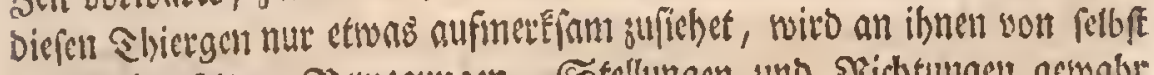

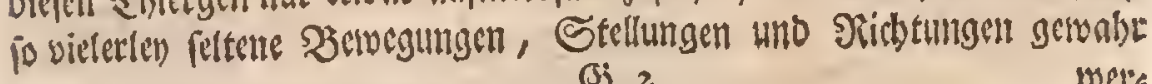
(B) 2 wels

* Tab. I. Fig.I. b.c.d. ** e.g. "** f. 


\section{( 52 )}

soerben, bafich) forge, man mơgete es mir verbenen, wenn id midh bey foldben Sleinigfeiten lánger aufbalten wollte.

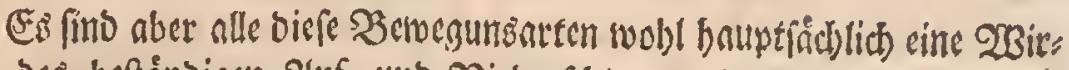
Fung Des beftåndigen 2luf = unb Nicoerfblagenb Der 2/rme, und mag

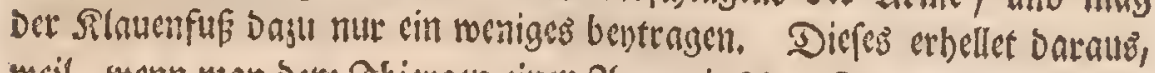

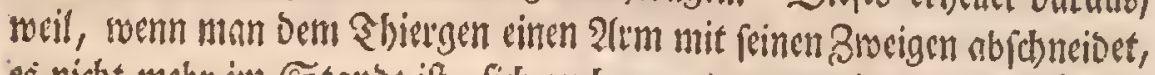
eś nicht mebr int Stande ift, fich aud) nur etwas weniges in bie Scóbe zu begeben. Es blcibt auf Dem Boben, und mad)t Dafelbft inbgemein bie

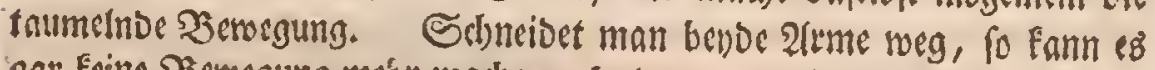

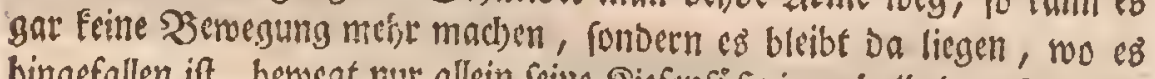
bingefallen ift, bervegt nut allein feinc Siefenfufe innerbalb Der Mufd)et:

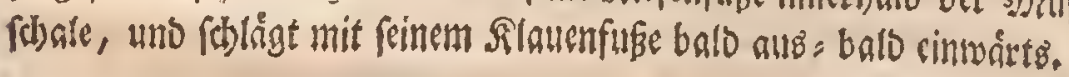

Diefe 2 Bafferfiobe foheinen ůbrigens, wie bie अolwsen, uno melle

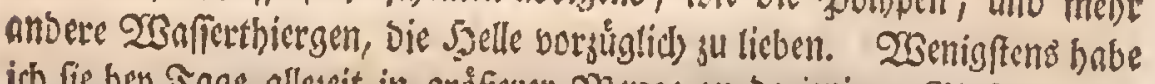
ich fie bey ₹age alleseit in sróserer Mzenge an berienigen Binffeite auf unb nicberfteigen gefehen, weld)e an Dem fenffer frund, und wo alfo Die

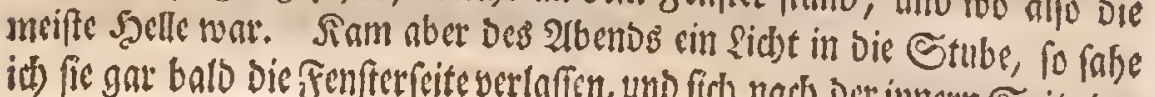
in fie gar balo bie Fenfferfite verlaffen, und fich nach) Der innern Eeite ber Stube binuenben. Sir folgen zweifflsobre benenienigen Eleinern ISnfeEten,

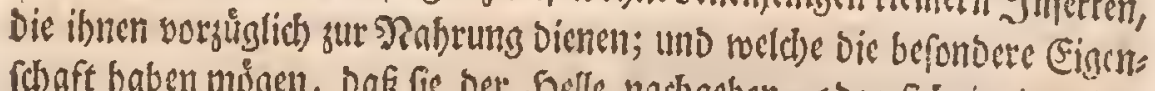

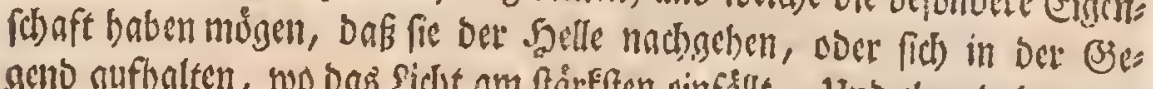

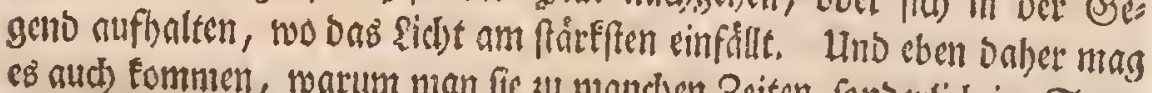
es aud) fommen, warum man fie su manchen Zeiten, fonberticl im Som.

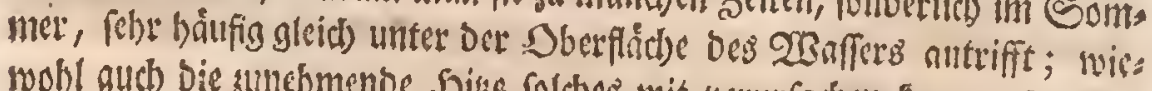

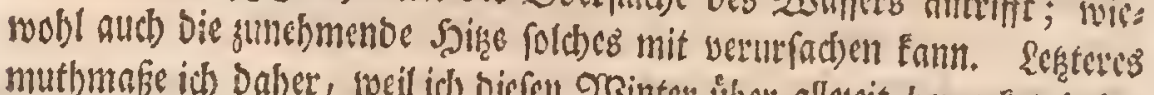

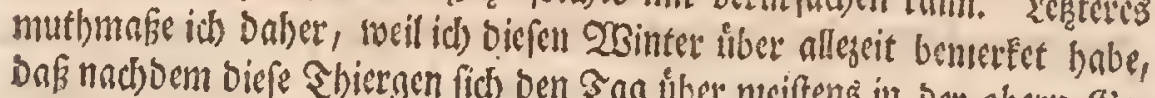

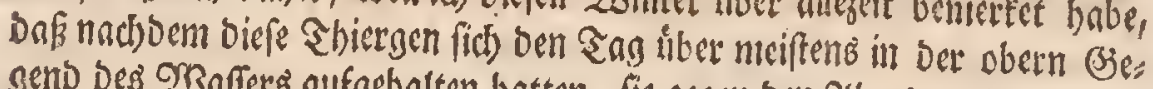

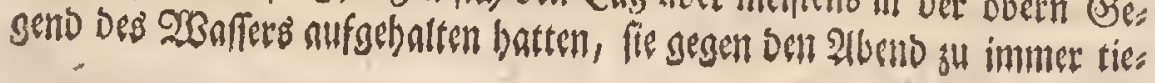




\section{幖 $(53)$}

fer berunterfunfen, ie nadboem bic 2 (3arme fich nad und nach vermin:

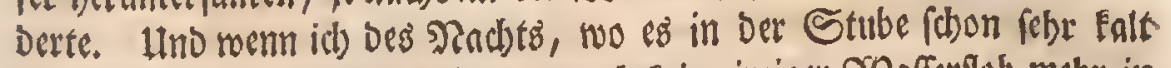

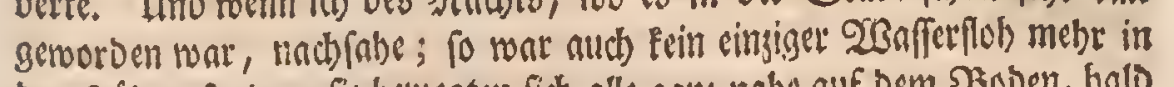

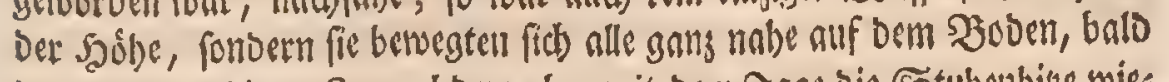
Da, balb borthin. Tie nachbem aber mit Dem Sage bie Stubenbize nies

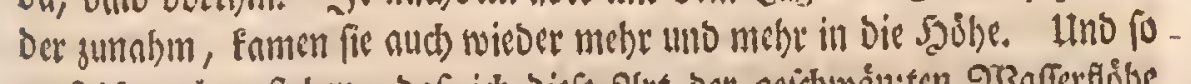

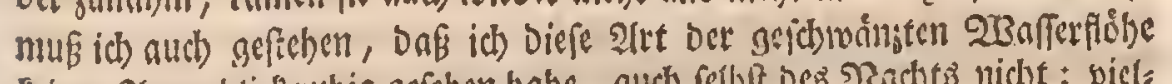

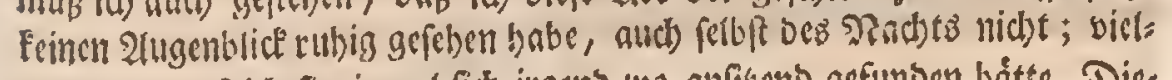

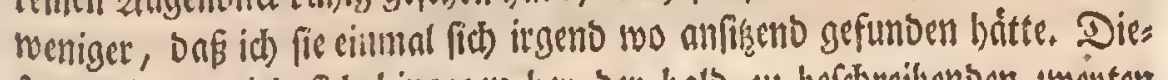

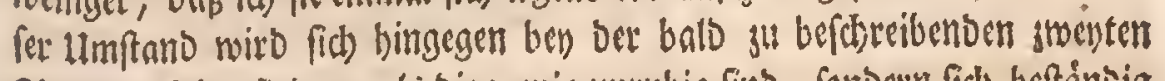
2rt ungefelyst findert, als bie wenig untuhig fint, fonbern fich befthindig suresen, uno lange Beit an einem Drte frill bleiben.

Sxoanmerdam und 23 ater fdreiben es biefen Shiergen und ibrer

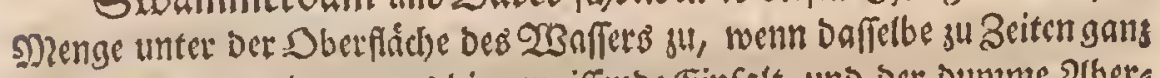
roth ansfiebet, uno moraus bie unwiffende Einfalt, und ber bumme afters glaube, wer weis was fure cin ulbel, yorberfagen will. Ee hat alld bies

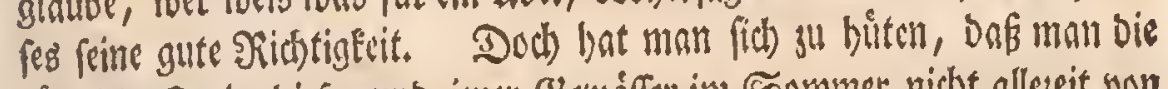
rottlidse Farbe biefer und jenct Bsenoffer im Sommer nidbt allegeit von

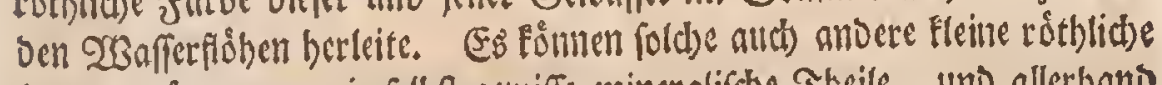
2 safferwirmergen, in felbft seniffe minernlifthe styeile, und allerhand

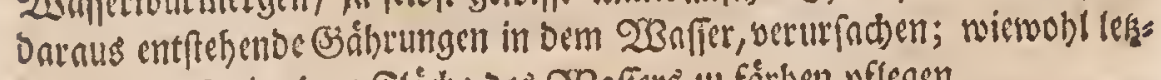

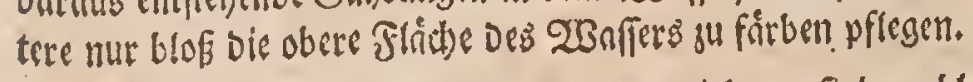

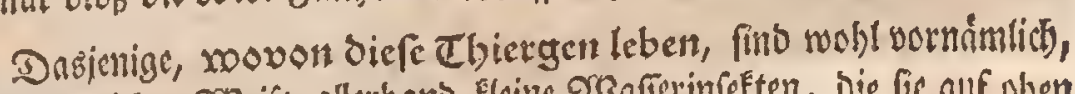

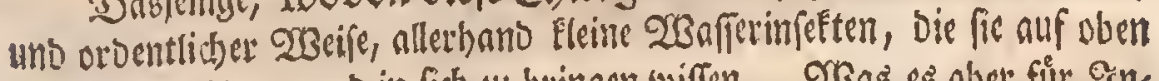

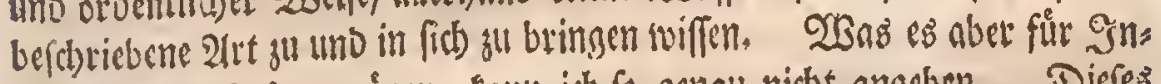
feften eigentlich fenn mogen, fann ich fo genau nicht angeben. Diefes

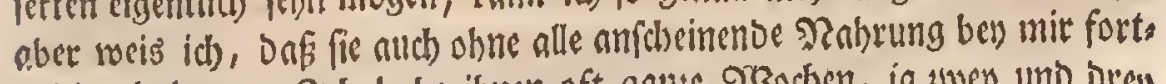
getebet baben. Jib babe ibuen oft gange 230 dsen, ia swen uno brey sonate bintereinamber nicbts als lauter $\mathfrak{B}$ rummenmaffer gegcben; unb 


\section{( 54 )}

bodf war ibe Magen und Şauptbarm immer nit ciner bunfel gefärbten

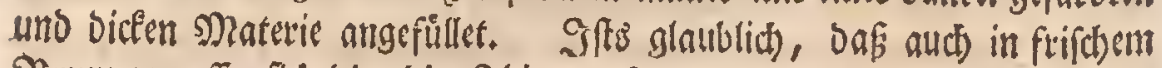

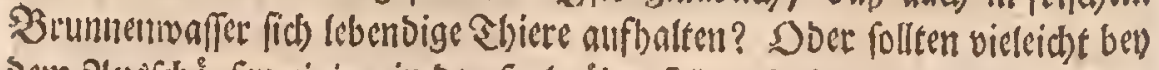

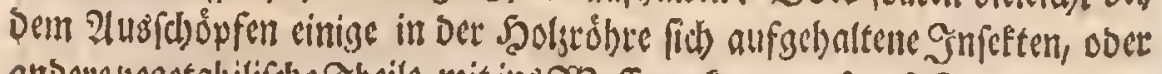
andere vegetabilifhe ?heile, mit ins 23 affer gefoumen fenn? Sumal oa man

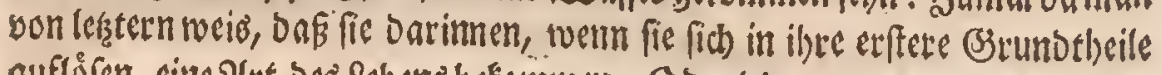
auflófen, eine Ant bes Sebens befommen. Soer leben etwannbiefe Stbiergen

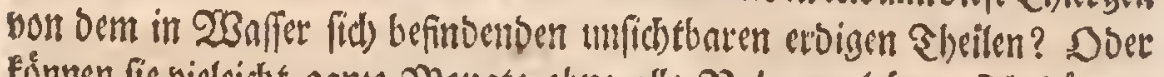
fơmen fie bieleid)t ganje Monate obne alle Mrabrumg leben, fidb båuten,

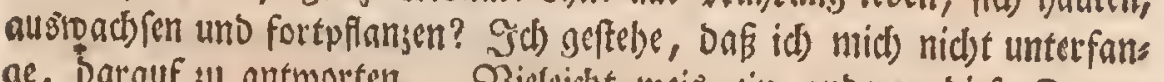
ge, barauf ju antworten. Diefcidbt weis ein anderer biefe fragen grünolich) su entfabcioen!

Die Sortpflantunty uno Detmebrunty betreffeno, fo if guforoerfit als eine, fhon von anbern 2 anferinfeften * befaunte und ridhtige Sache,

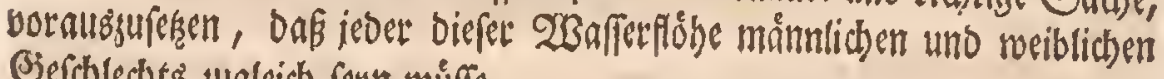
(3ephlect)ts zugleich fenn múffe.

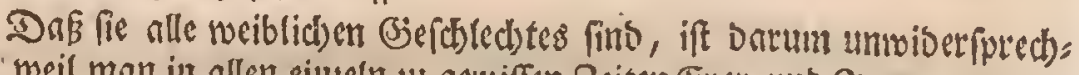
lich, weil man in allen eingeln ju gewiffen zeiten Ever uno gunge antrifft.

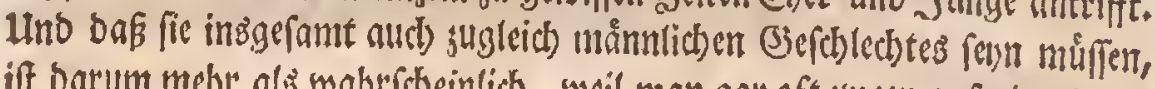
ift barum mebr als wabrf cheinlich, weil man gar oft sween auf eine foldse

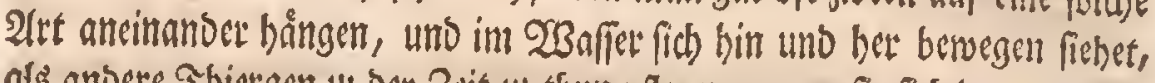

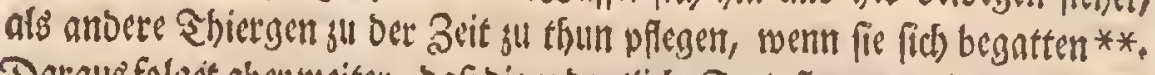
Daraus folget aber weiter, bas bic orountliche Torttpfanzung oiefer 23 affer

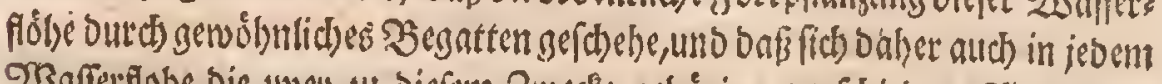

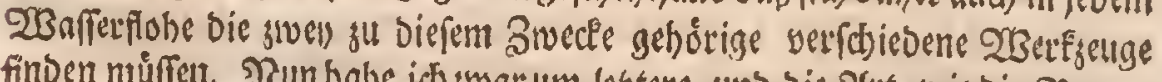

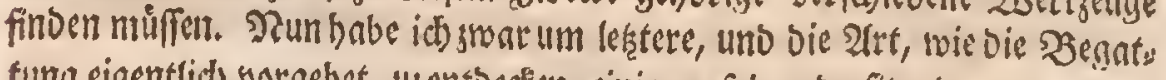
tung eigentlid) yorgebet, suentoedfen, einige oufeinanderficenoe uno jufam:

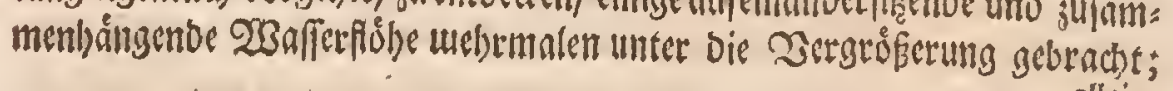
allciur,

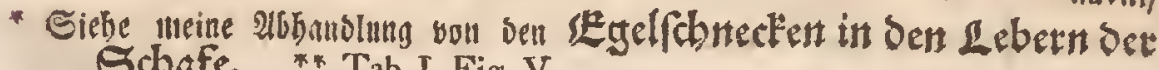
Sdbafe. ** Tab.I. Fig. V. 


\section{(55) 粼}

allein, fie babent jecesemmal ether cinnonber verlaffert, alş id fertig wertben

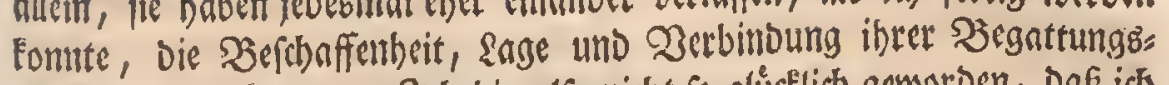

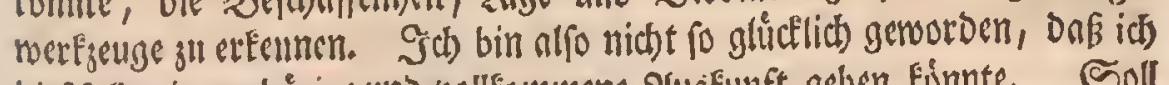
Dieffalls eine gebórige uno vollformmene 2uśtunft geben fúnnte. Soll

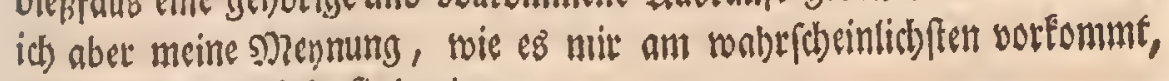
entoecten, fo befteltet fie barium.

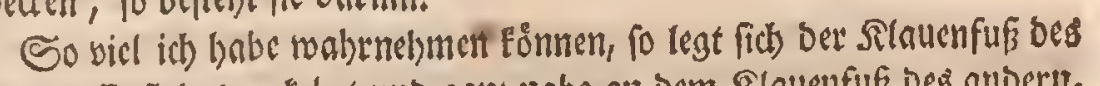

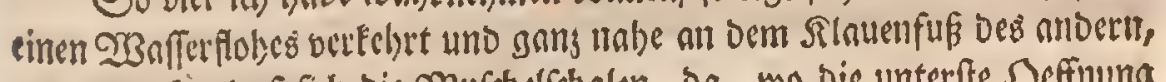

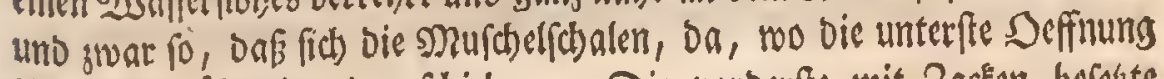

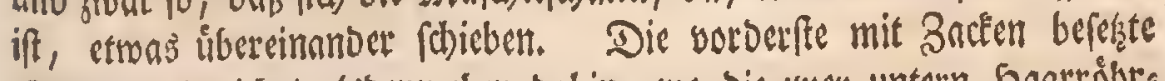

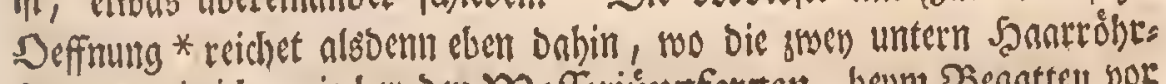
Sen**, Die ich, wie bell Den Do afferjüngfergen, beynn Deganten bor

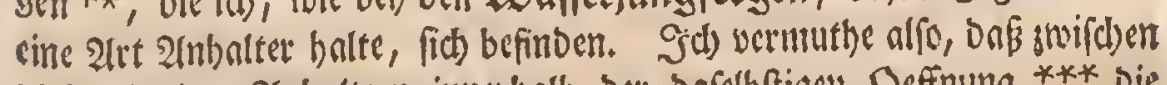

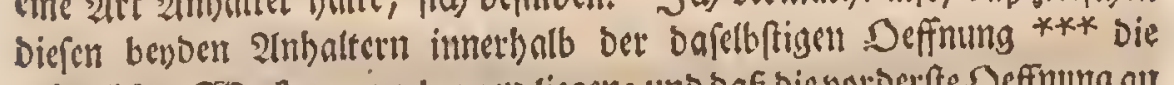

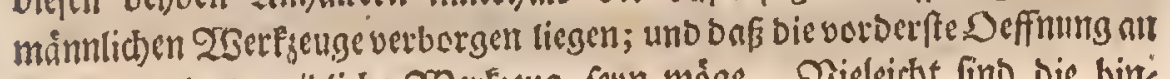

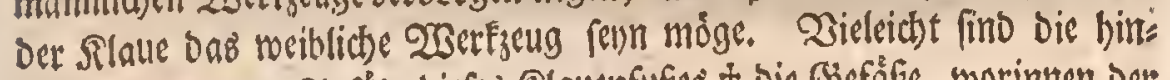

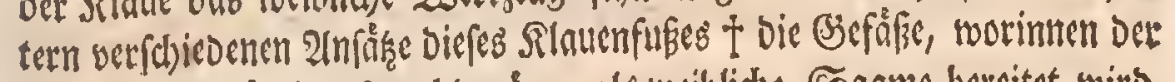

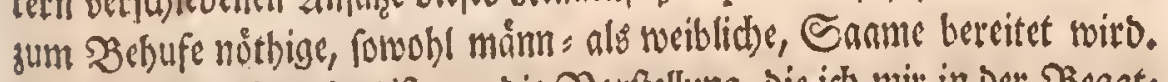

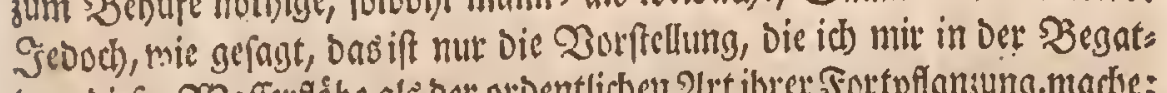

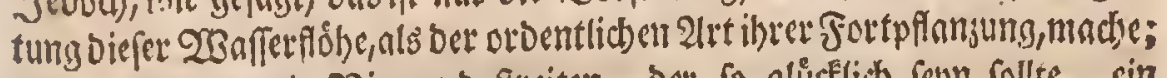

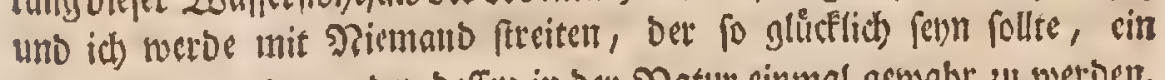

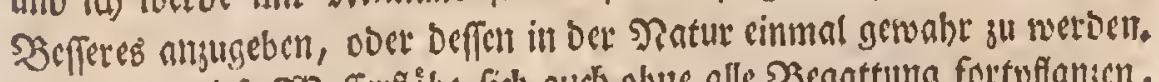

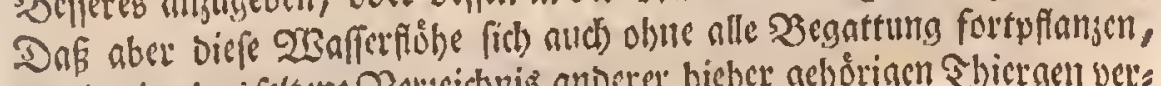

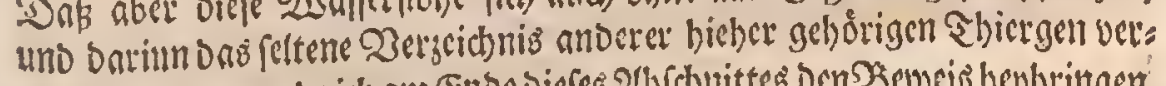

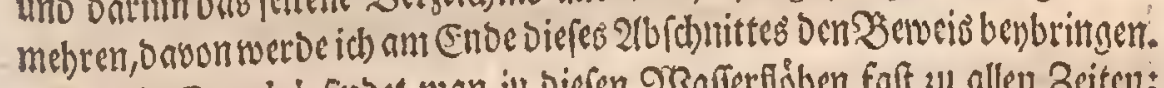

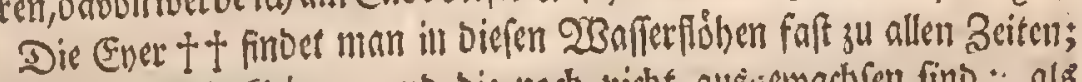

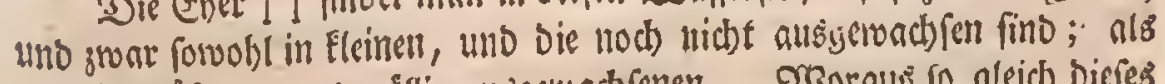

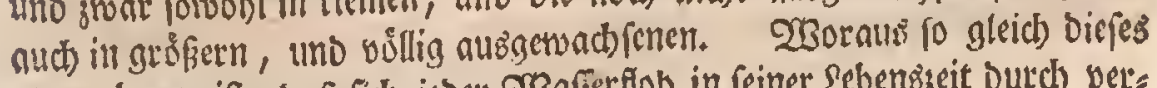

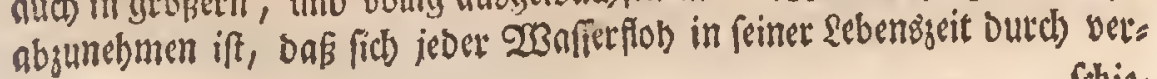

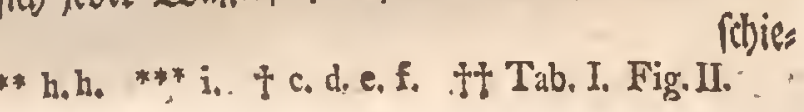




\section{(56)}

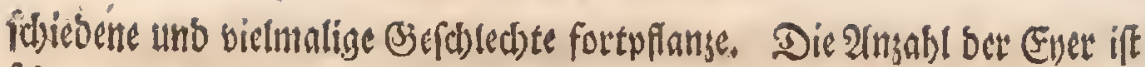

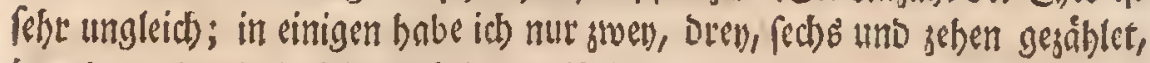

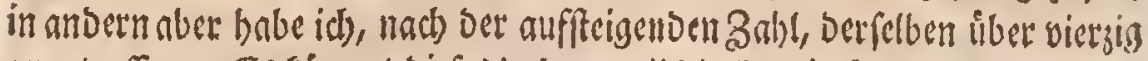

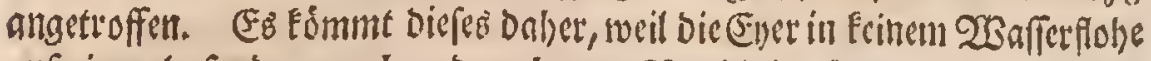

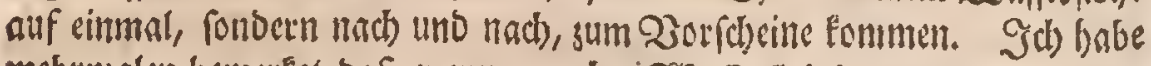

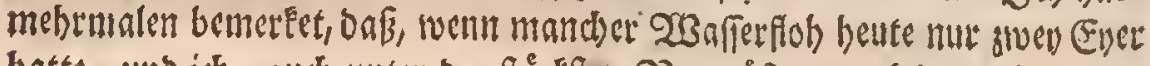
batte, uno idh, aud) unter Der ftårfften Zergróferung, Eeine neitere 2ll: lage su melbern anfichtig werden fonnte, gleid)wobl den andern Tang Dats

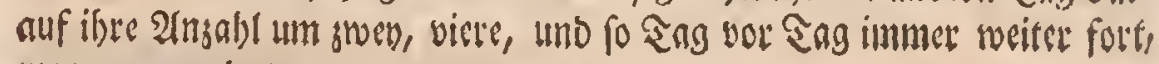
sugenommen batte.

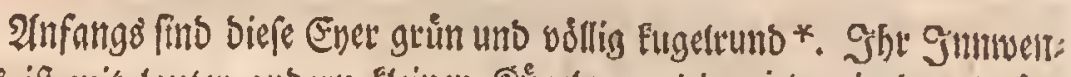

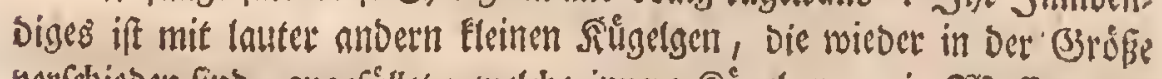
verfchicben fino, angefullet; weldse innere Siligelgen, twie 23 affet: uno Suftblafen, Durchftheinen. PRadh ciniger Beit nelymen bie Ener cine längs licisunde ober enformige (S)eftalt an **; Die Farbe aber bleibet grün, uno

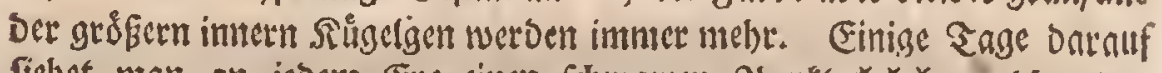
fieljet man an jeoem Eve einen fohwarsen glunft $* * *$, welcher bas grófere 2luge ifl. 3u Der 3cit wirb Die grime farbe immer blafs

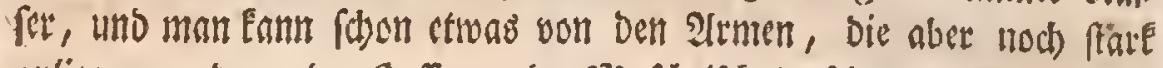

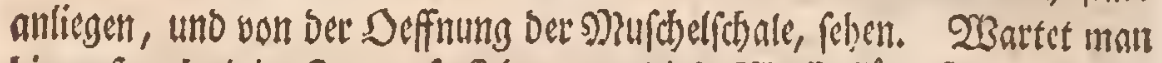

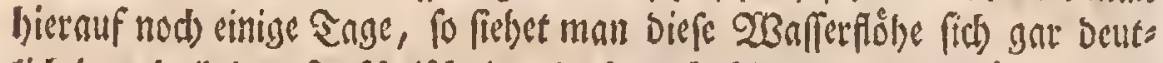

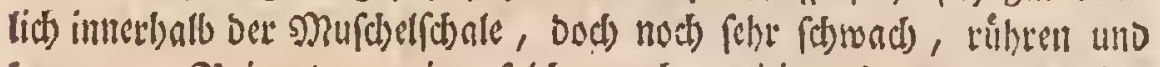

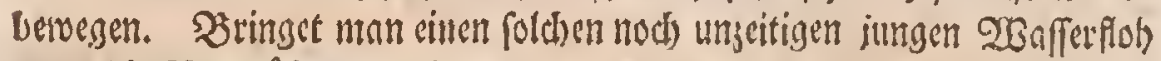

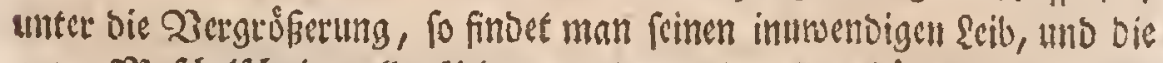
gange Mufdelfdate, voller fleinen runben und bellen Rígelgen $\uparrow$. Uno Der Sbcil, woraus in Der Folge bic Schwansfpige mito, liegt, wie ber bes

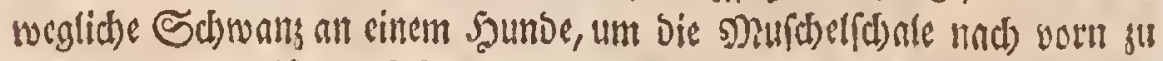
berungebogen, if won faft gleichrumber Dicfe, und vorit, wic flumpf alige:

- Tab.I. Fig.II, a.b.c. **d. ***e. † Tab.I. Fig.lI. a.b.c. 


\section{( 57$)$ 释}

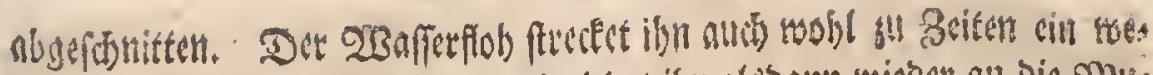

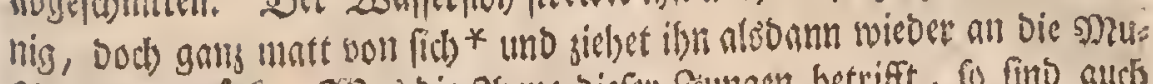

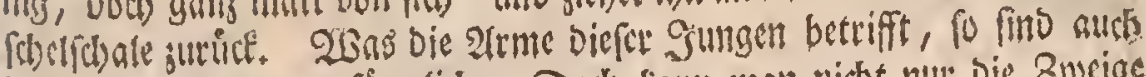

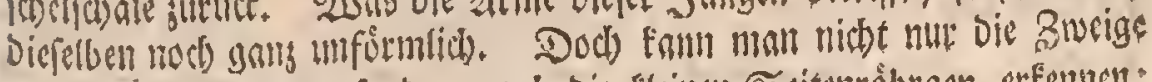

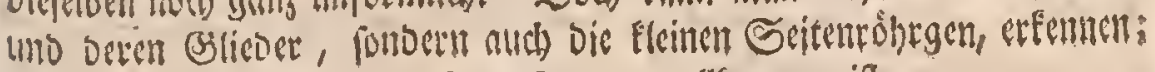
Dayon aber alles feht Euts, fumpe und undolffonmen iff.

Da biefe Jungen nicbe alle auf cintural, fontern nach uno nad), auds

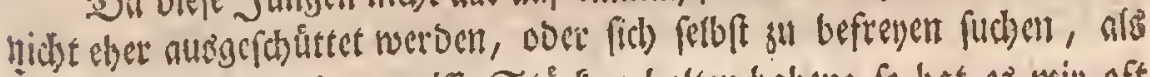
bis alle il)ee Slyeile cine gerwifie Stårfe entynlten baben; fo bat es mit oft

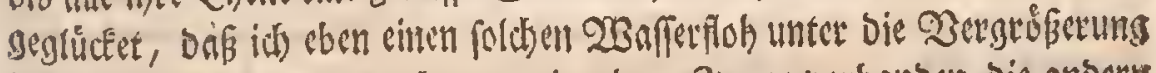
befant, in weldsent nur nod) groen ober been) Junge vothanocin, bie andern

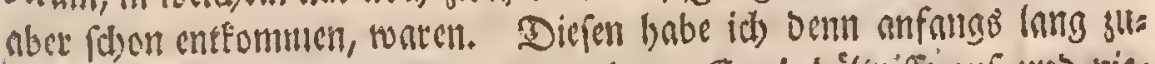

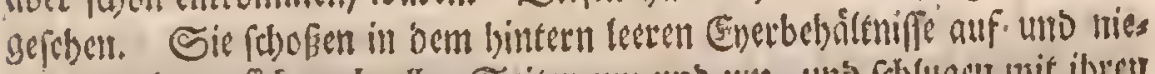

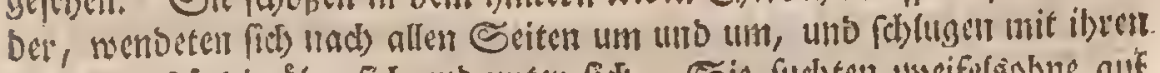

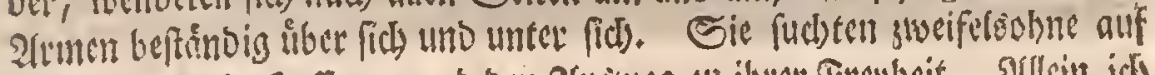

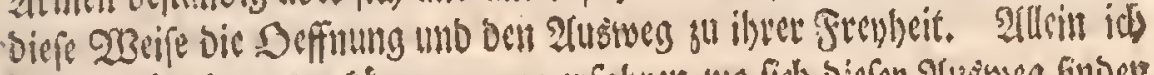

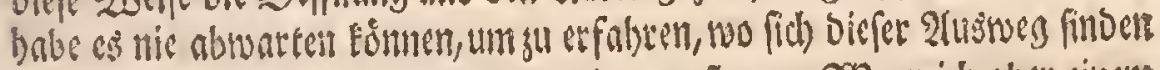

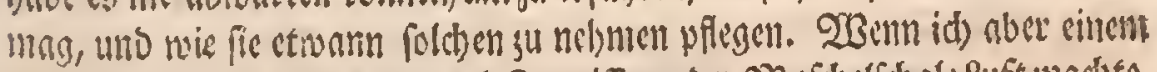

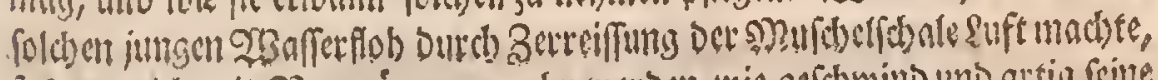

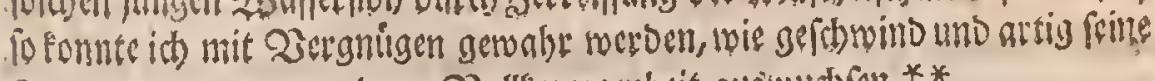

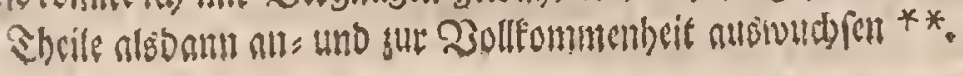

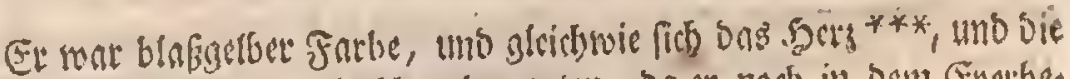

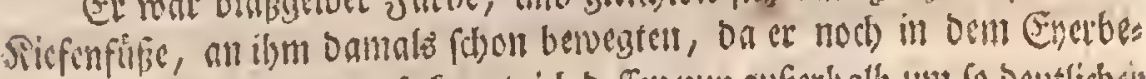

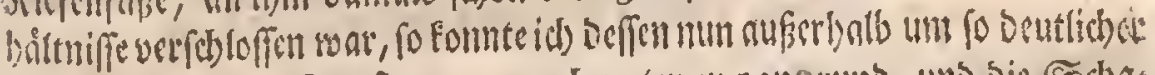

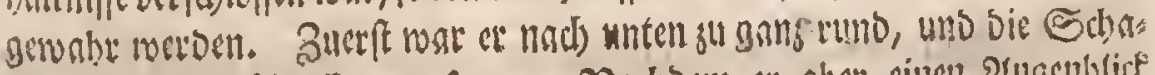

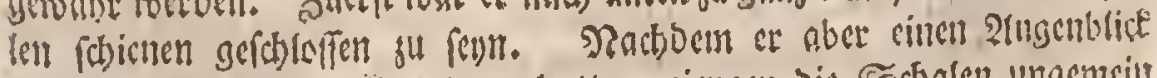
obne alle Bewegung ftill gelegen batte, giengen die Estbalen ungemrils

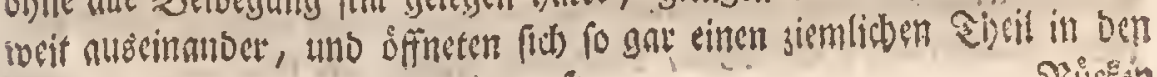

*Tab. I. Fig. III. * Tab. I. Fig, IV. "** a.

givicen 


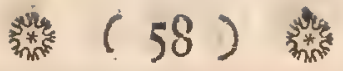

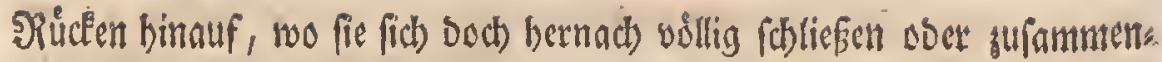

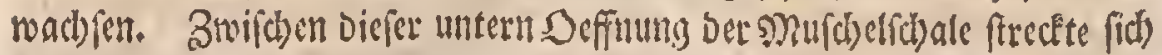

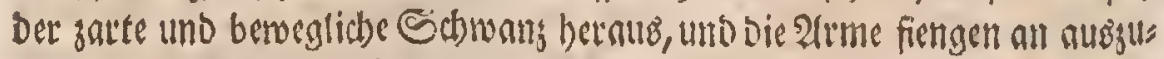

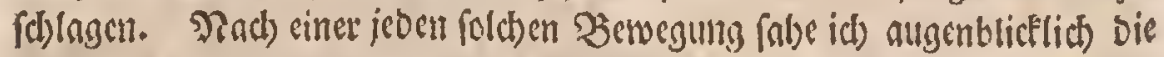

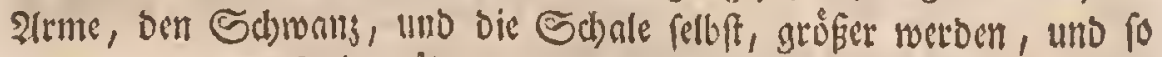
nabmen nucb bie Seitenrỏbrgen an ben atmen augenfucinlich an \&ånge

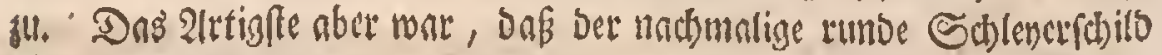
bier an ben Ssiten sam fpig̨ig wurbe. Shatte fich bet junge 2Baffer:

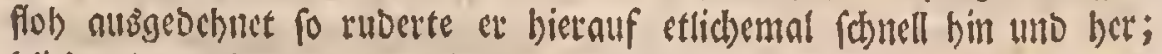
blieb aber gleich wieber liegen, zog firb abermalen zufanmen, uno vebnte fid) auf bie enft befdriebene $23 e i f e$ rvieber alls, ba alsocnn ber

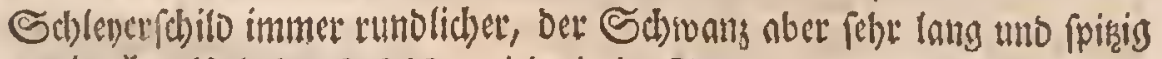
sourbe *. Lano burch folde wieberbolte $\mathfrak{B}$ ctwegungen wurbe ber junge

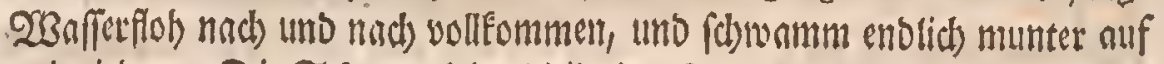

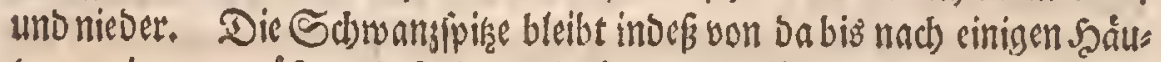
tungen immer sréfer, als fie hermach iff ; uno fo ifts auch was befonoers,

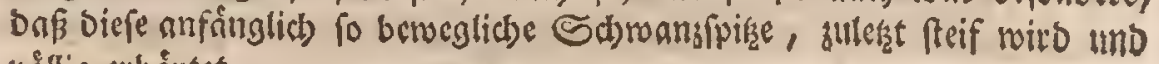
vơllis erbaำtet.

2(us biefer Befchreibung folget benn zuencetery. Einmal, bas ber

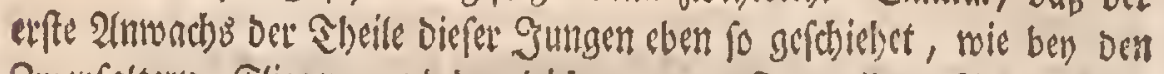
Swenfaltern, fliegen, und berbleidsen, wenn fie aus ibrer gluppe Fom:

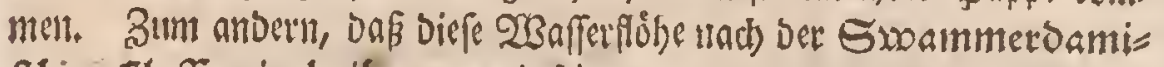
febent Claffentintbeilung, uno feinen gams ridtigen Sieobacbtungen, 3u Denenjenisen geboren, bic ibre Sungen tebendig susf hbüttent.

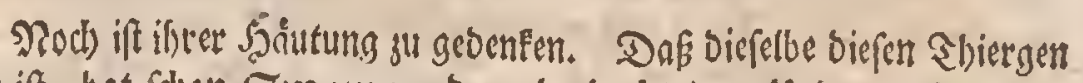
eigen ift, bat fdjon Groammetoam beobadstet. Uno man Famn bas yon gat leidbt ein 2 (ugensenge werben, wemn man fich gefallen laffen will,

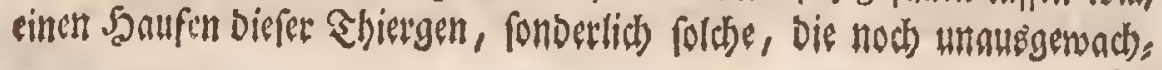

$*$ Tab. I. Fig. IV.o. 


\section{(59)}

fen find, in ein frifbes uno belleb Brumnenwaffer zull legen. Naan wirt nach einigen Sagen louter foldbe Saåute finden, Die Dent gansen Shiergen

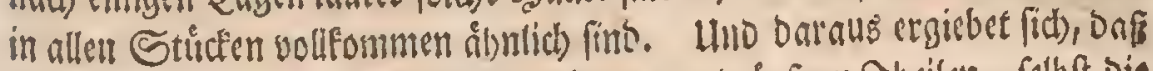
Das ganze Sbiergen mit allen feinen innern und åuscen Sbeilen, felbft die

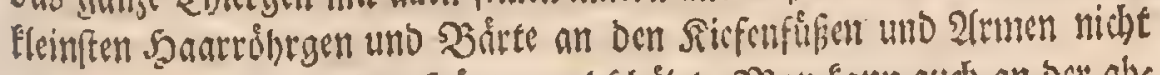

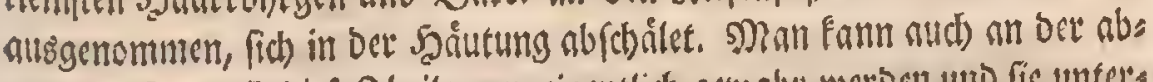

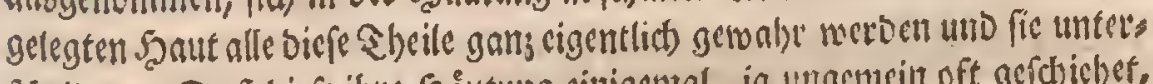

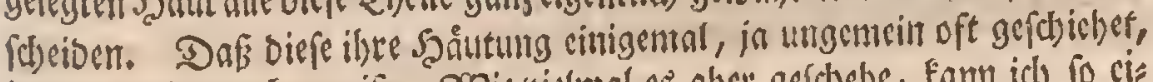

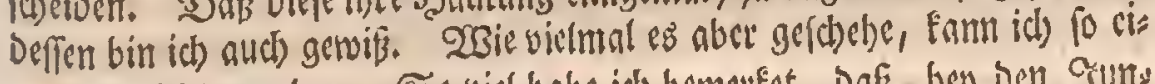
gentlich nidst angeben. So viel babe id bemerfer, Dafí, ben Den Sum:

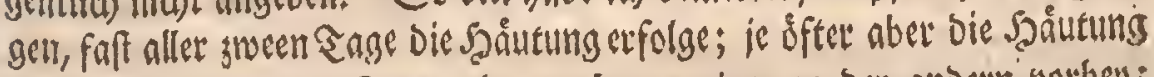

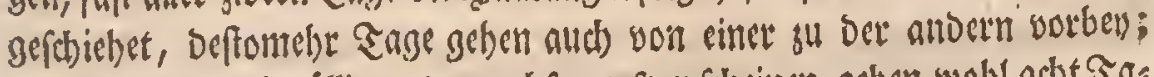

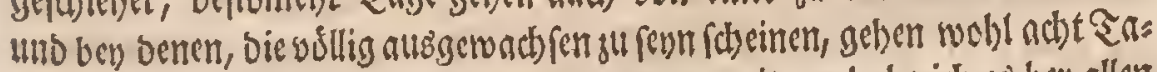

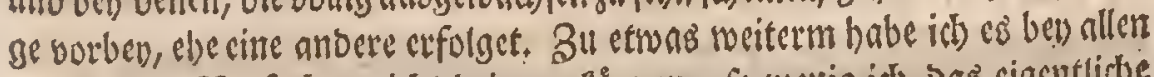

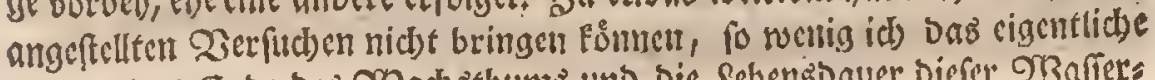

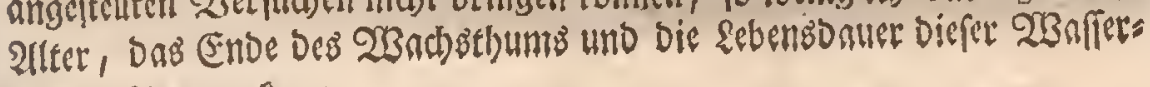
folble beftimmen Eam.

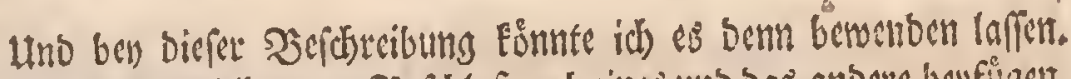

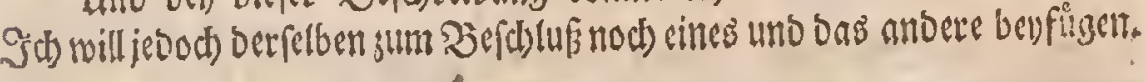

Das erfe betriffit biejetrige Brattung bet gefdhwingten zactigen 20 of

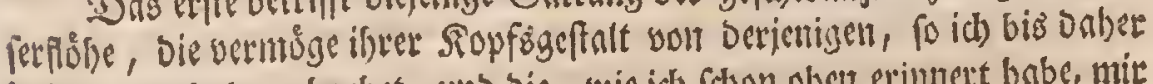
befchrieben habe, abgehet, und bie, wic idh f(b) on ober erinnert babe, mir

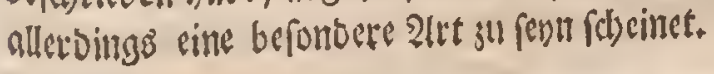

Damit malt fid) von Dar Beffalt biefes Siopfes cimen befto beffern Begriff machen Ésme; fo babe id Denfelbert audj befonbers nbbilben lafs

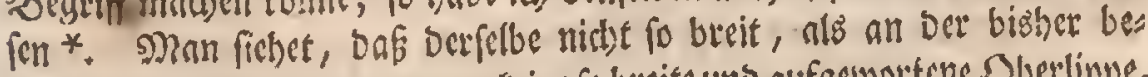

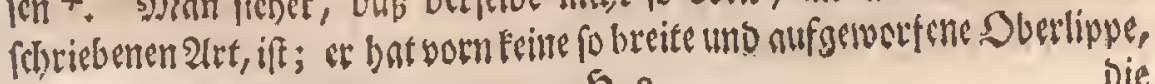
$\sqrt{3} 2$ Die

* Tab.II. Fig.I. 


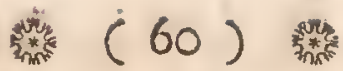

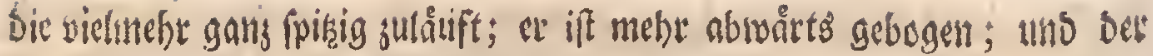

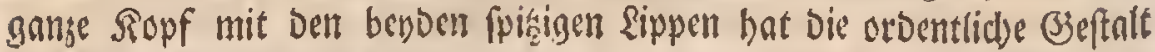

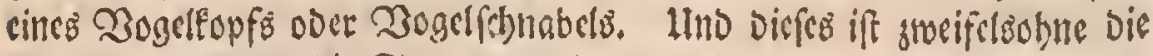
B3attung geveren, bie Sxoammerdam, 23 aker uns Syert Ttembley Befehen babert. Denn bende erferen befdreeiben nusibrietlid) Den Souf

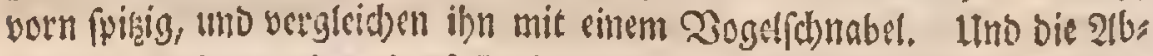

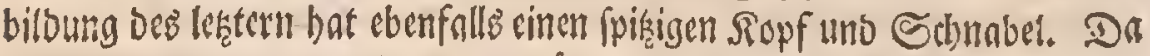
nuch biefe (s)attung burchgehenos róthlicher Tarbe ift; fo fcheinet von ibr Das $2 B$ affer um fo mebre eine rothe Farbe erbalten ju Eonnen. 23 as mid)

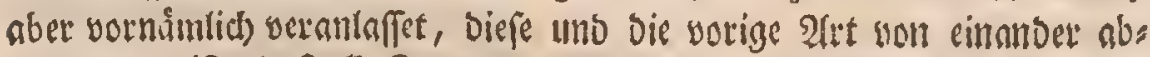
zufonderm, ift, bns alle Sungen, fo von ciner ieben slet entftanden find, ben ibnen sigenen, fpisigen ooer breiten, Ropf gebabt baben. So babe id) aud) jeoe itl befonoern 28 affern nur allein sefunben. Shan fómte

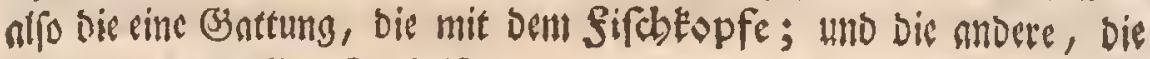
mir dem Dogelespfe, beisin.

Das 3ivente, befien id) nod zu gedenfen babe, betrifft Diejenigen

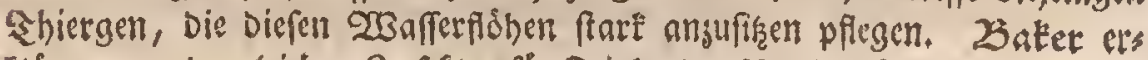

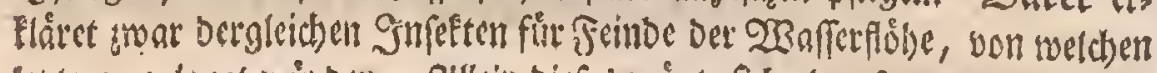

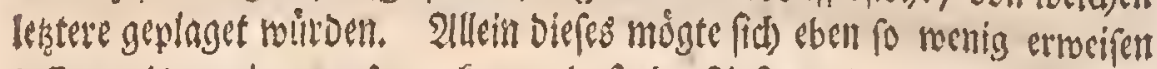

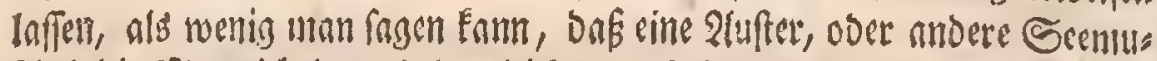
Fhel, bie slecercicheln, und bergleichen, ju Feinben habe, weil fich Diefe an jenen anbauen und feftrcten. Es thun biefes joldbe, uno bie. ibrigen, Ebiets

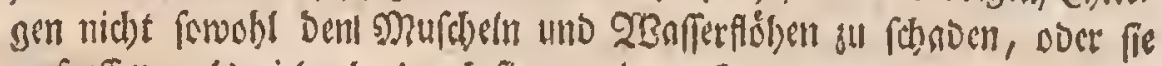

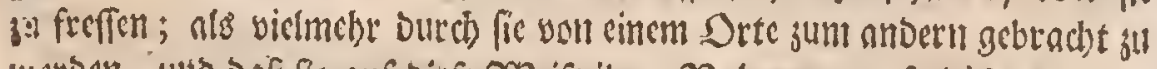

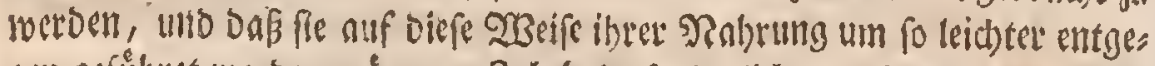

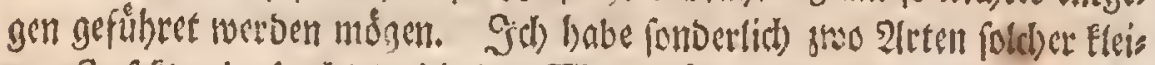

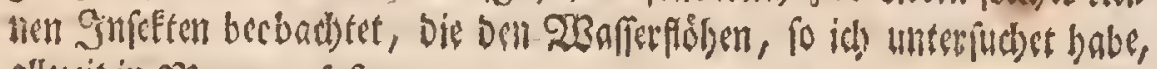
allegeit in wenge anfopen. 


\section{(6I) (6)}

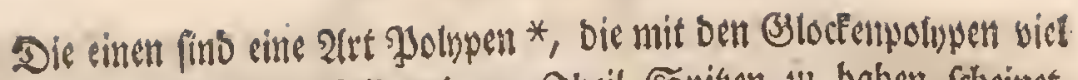
åthnlictes baben, nur Daf ibr oberer Theil Epiţen ful baben faheimet,

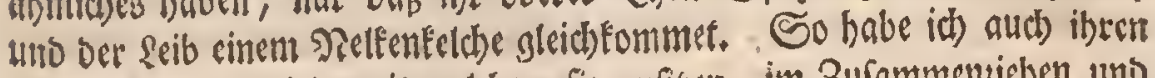
Stengel ooer Stid, mit welcbent fie anfigen, im Bufammenjielsen uno 2usobehnen, nic fo fobraubenartio geftalter gefimben, als bey ben orbentlis

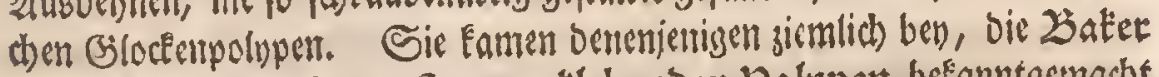

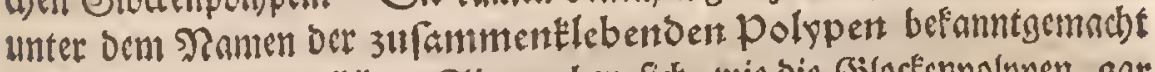
unto befdrieben bat ${ }^{* *}$. Sic madben fids), mie bie Biloctenpolypen, gat leid)e won ibeen Stielen loß, umo man farin fie alsogann ben bunoerten bin und berfobnimmen feben.

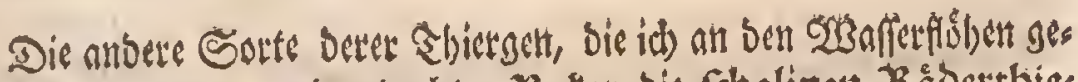
funden babe, nemnet mebrgeondber 2 atket bic fobaligent Ráberthte:

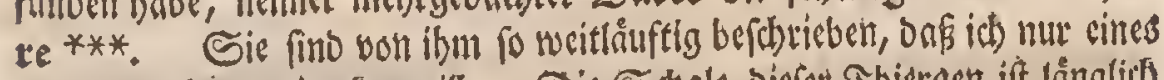
und bes andern geberfern noill. Die Sdjale bieper Shiergen ift långlit's

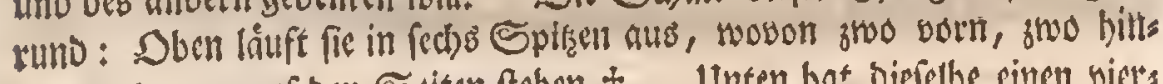
ten, und ztro auf ben Setten fteben t. Inten bat biefelbe cinen biets ecfigen Einfobnitt tT. Diefe obern Stracheln, uno ber untere Eimfohnitt, zeigen fich zu ber Beit am beutlicbfen, wemn bas Sbiergen toot iff, ober fich gans in Dic Sd)ale eingejogen bat. Da biefe Schale ungenein ourd): fidjetig ift, fo fiethet man zu Der Beit, wenn Das Thiergen obne alle Beewes

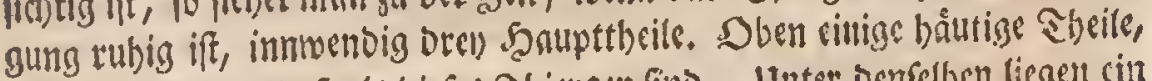

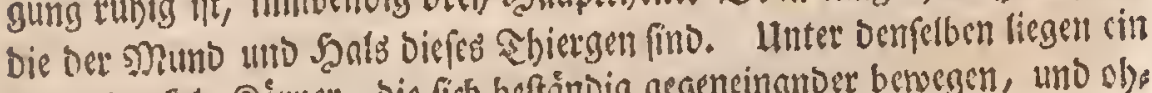

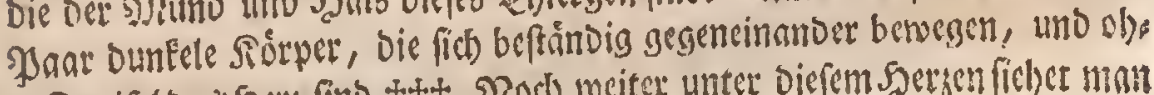

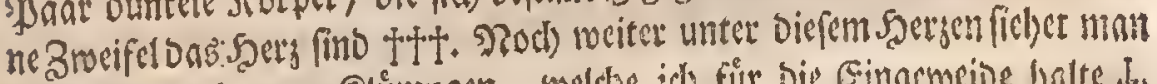

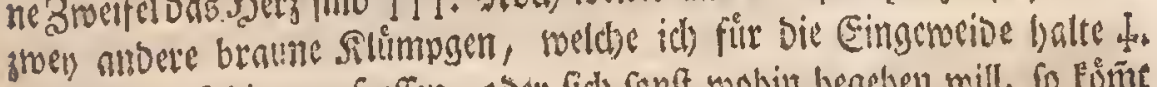
Wosm bas Shiergen freffen, doer fid) fonft rodbin begeben mill, fo füme SD 3

* Tab. I. Fig. VIII. h. ** Shat It. Sap. XV. Eeit. 433. Tab, XIII. No.IV. VI. X, us XIII. *** Tab. I. Fig. VIII, kk. Tab. Il. Fig, VII. VIII.IX.

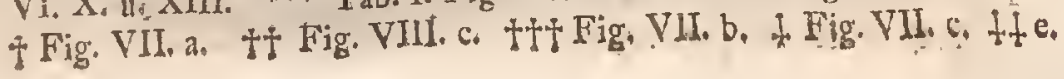




\section{(62)}

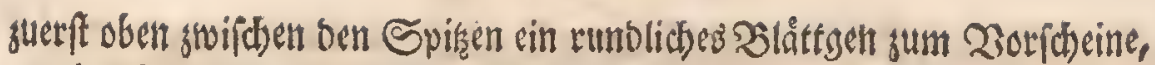
weldses fich) gar balo in given verthcilet, auf beren gansen Einfaflung laus

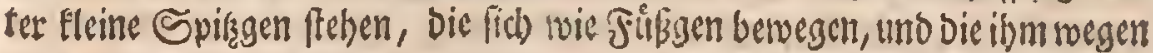

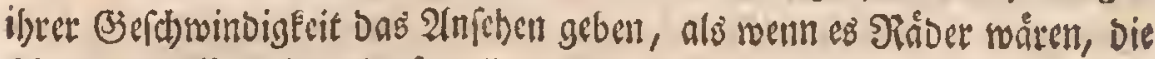

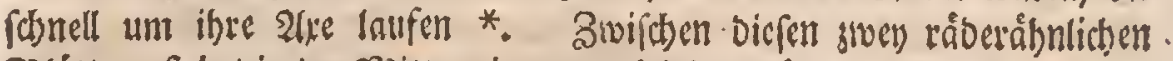

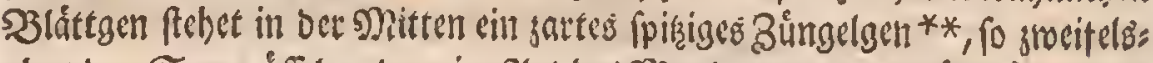

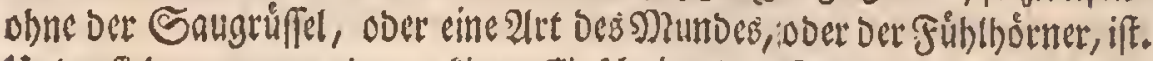
Unten fiebet matr aus dem ectigen (Einfdynitte Den Schwans auss, und cins geben ***. Diefen Eann Das Sbiergen mad) allen Seiten beewegen, und ibn, wic bie Şumbe, fo, ober anders, beugen. Das 2leuperfte bes Sdbwanjes

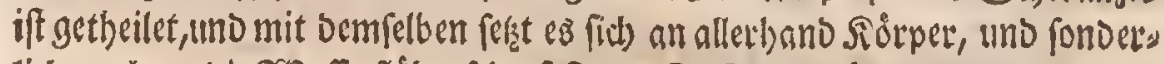

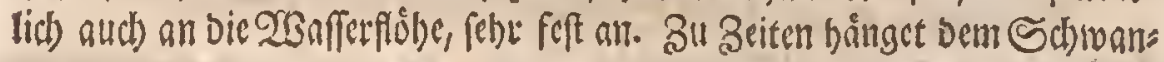

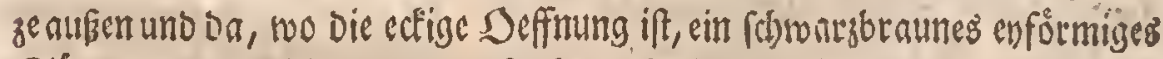

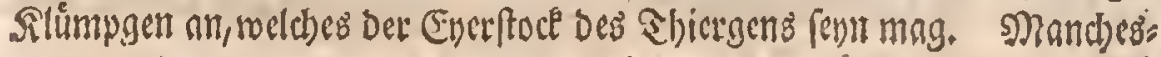
mal fieber man auch sween foldse Evarfticke an ibuent.

Da Serr Zaker yon sinem andern rabformigen Shiere, welthes er Den Radmacber nennet ft, Das Defondere, uno zum Sbeil Erftaunen=

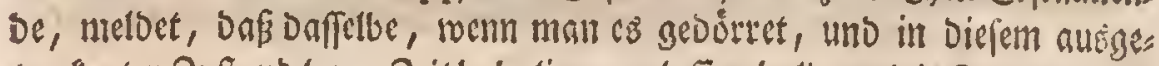
troceneten 3uffano lange Zeit babe fiegen gelaffen, balb, uno in 3eitvon eince balben Stunde, wieber lebendig werbe, wenn man 2 Baffer auf Daffelbe giefe; fo vermutfete ids, baf es aud) mit ber erftgebachten Sorte Der

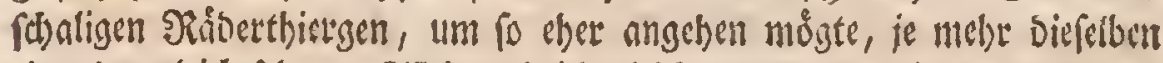
cinnnoer glcid) feben. 2(llein, ob ich gleich) mandbe nur eine balbe Stun, De ausgetrocenet babe; to bat mir glcid)wol Eein eingiges, wenn id) wieder Traffer aufgegoffen, son neuem lebendig tocrben wollen. 2Beil ids mids inbeffen gar wobl eriunere, and jenen Radmaber vor bem Sabre oft sefeben su baben; fo bin ids feht begierig, fo bald mir loldser mictoer zu

(3)

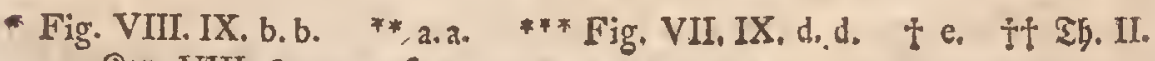
Siap. VHI. \&c. 384. Teq. 


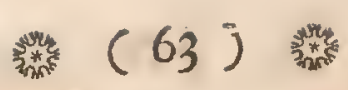

Befithte Eormmen wirb, mit ibm felbft bie Đrobe gu madien, und won jes ner feltnen Erfahrung cin 2lugenscuge ju werben.

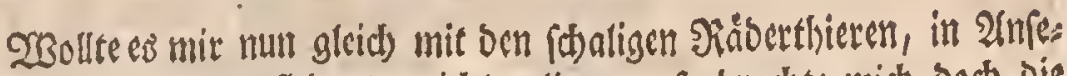
bung ibres 23 ieveraufebens, nidst gelingen; fo brad)te mich Doch bie Zbakerifbe 21nnectung, auf einen andern artigen Derfuch mit Denent

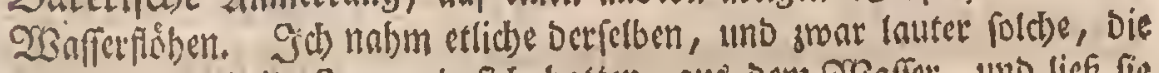

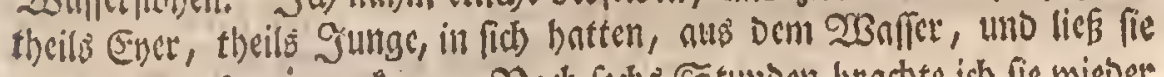

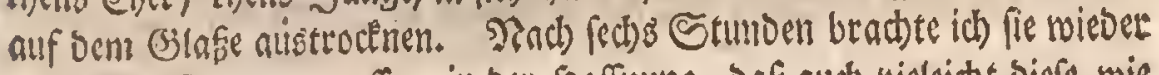

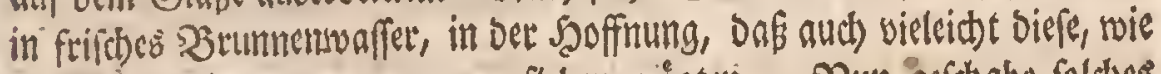

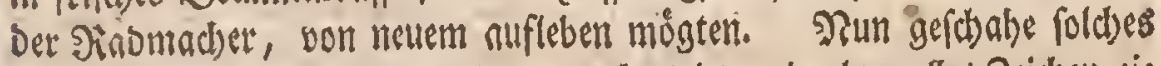

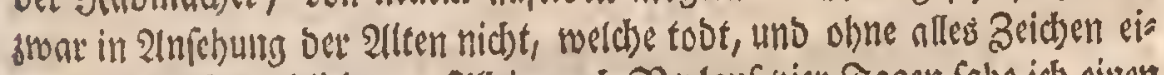

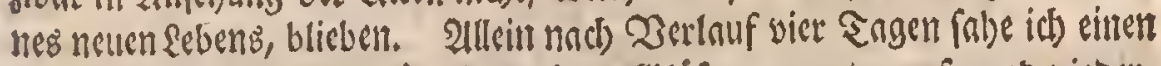

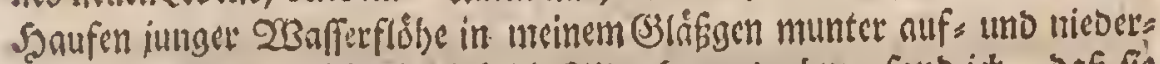

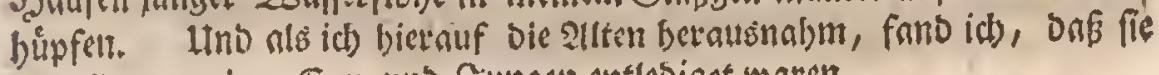
aller ibeer surigen Eyer und. Sungen entlediget waren.

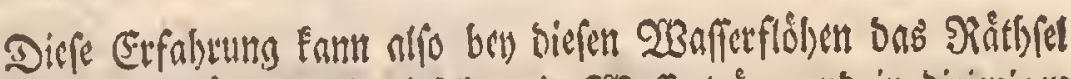
einigermaken auflosen, roie bicfélben in $23 a$ afertróge unb in biejenigen

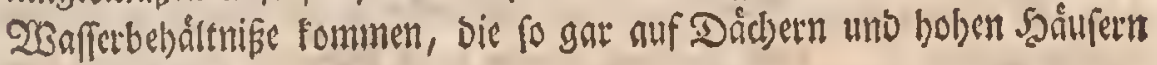
(iid) befinden.

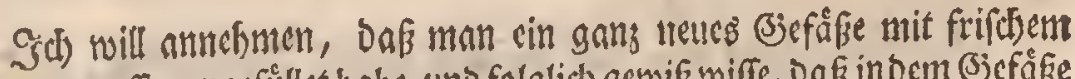

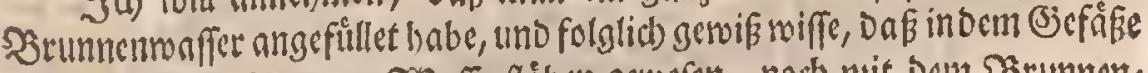

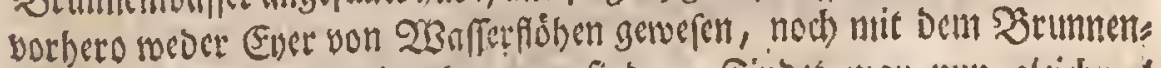
waffer Dergleichen bintingefommen finb. Ginbet man nun gleid)wot

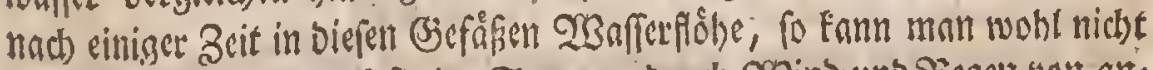

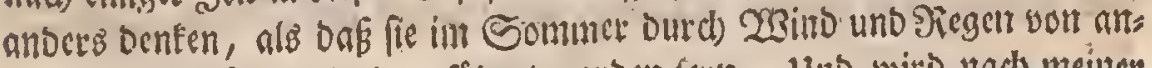
bern Srten múffen bincin geführet worocn fenll. Llub wiro nads meiner

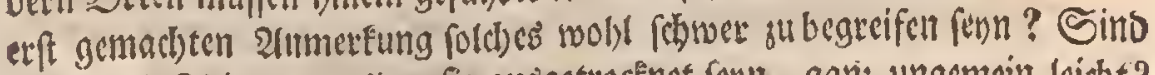
nidbt biefe Slbergen, wenn fie ausgetrocinet fenn, gania ungemein leicht? 


\section{(64) 留}

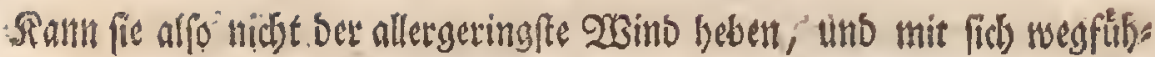
ren? Die Ener bleiben, wie id erwiefen babe, in Dertractuen unvers

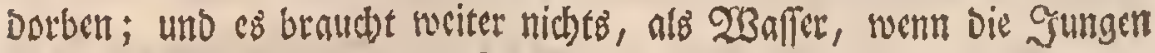

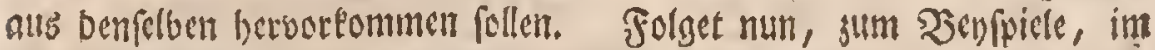

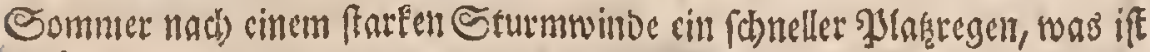
natirlicher, als Dap bergleichen mit ben Stanbe fortgefiburte, uno in ber

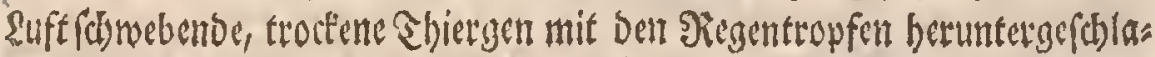

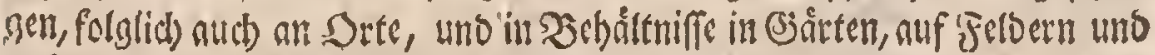
Déd)ent, gebrad)e toetben, wo man fie eben nidjt vermuthet båtte. So

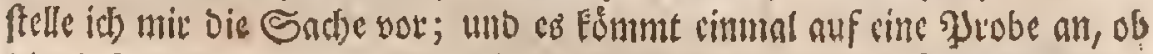

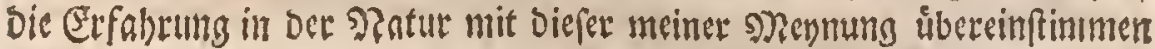
mógte. Nan bủffte, Davoll eine Wrobe zu macbers, im Sommer bel entfeflendem Sturmminde, und Darauf arfolgendem Siegen, olsmoeit fols

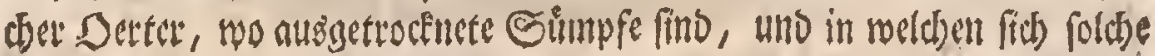

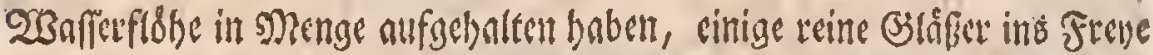

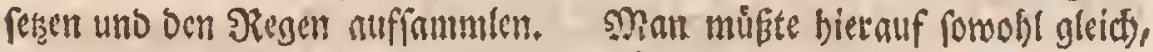

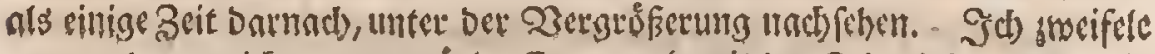

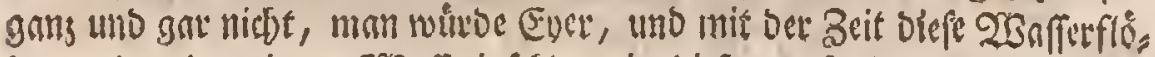

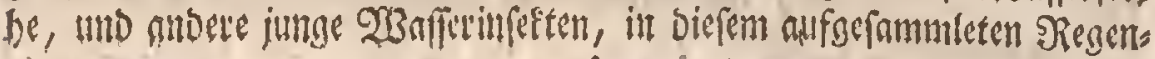

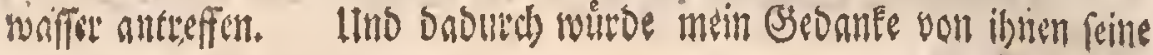
bollemontene StînEe erbaltent.

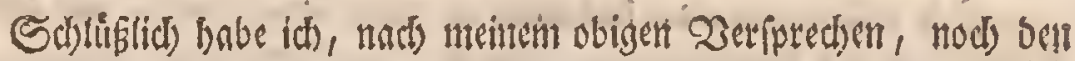

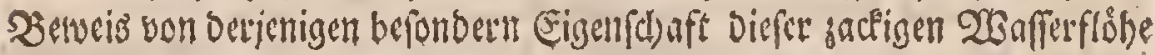

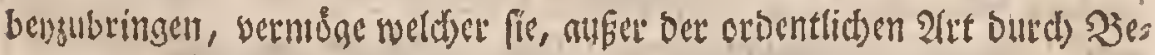

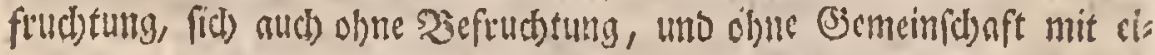
nem ambern ibles gleidben ju haben, foretpflanzen uno Sunge zengen Eơn nen.

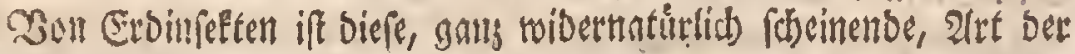

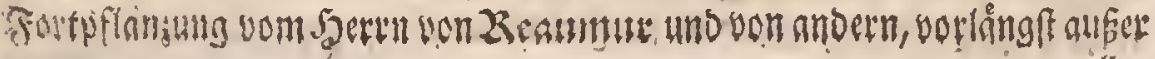




\section{(65)}

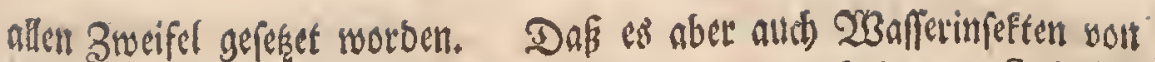

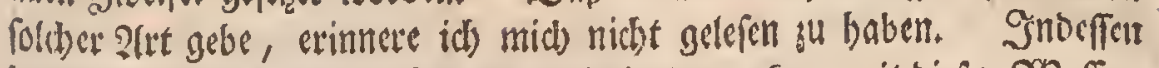

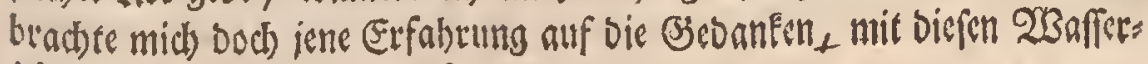
floblen sinen \erfudb su madien.

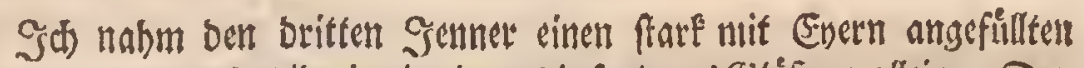

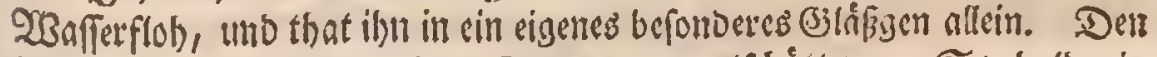

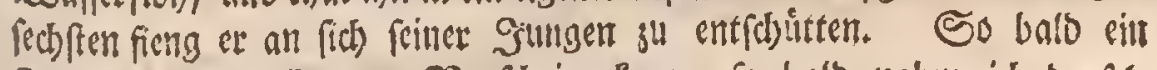

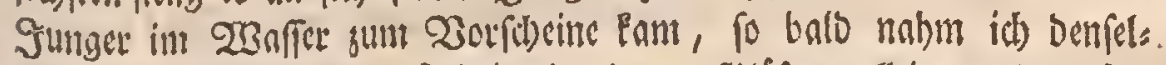
ben, uno brad)te ihn ebenfallò in cin eigenes șláfgen allein; uno madbte

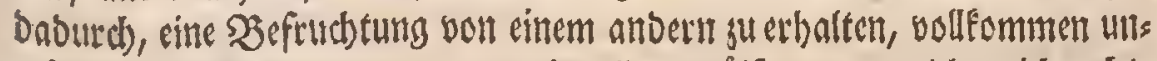

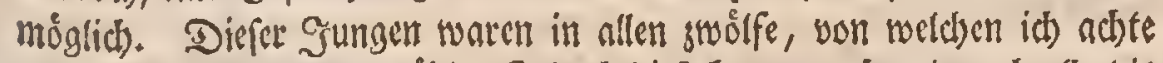
3u meinen Derfuchen erwáblte. Jeood) Diefe Eamen nad) uno nach) alle, bis

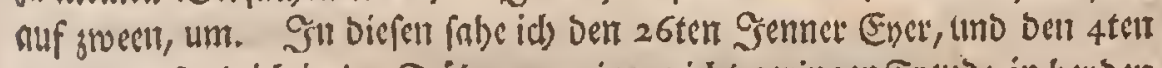
Saornung fallo ich in Der Frube, su meiner nid)t geringen Fretibe, in benden

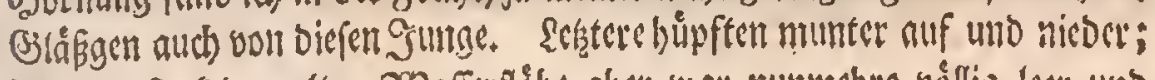

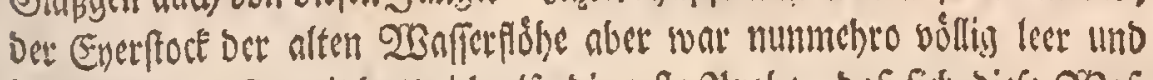

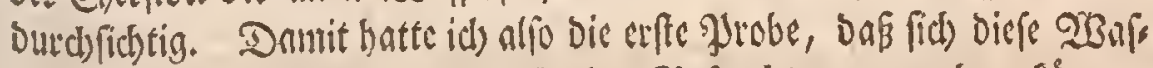

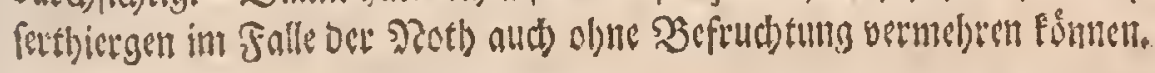

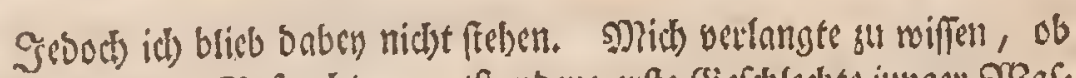

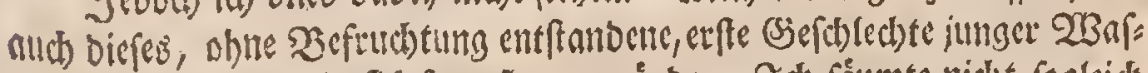

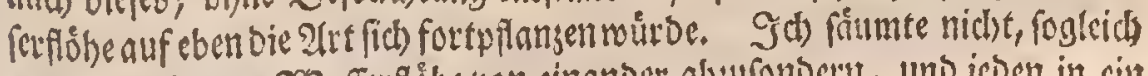

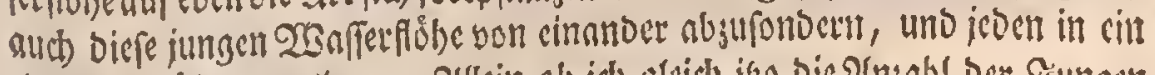

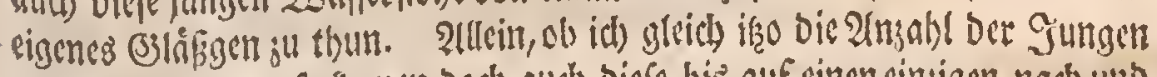
berosppelt batte; fo fannen ood) audb bicfe, bib auf einen sinjigen, nach unt

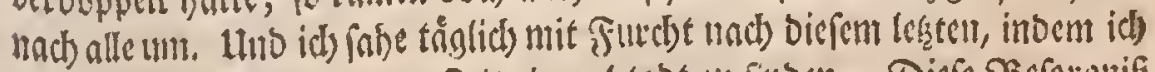

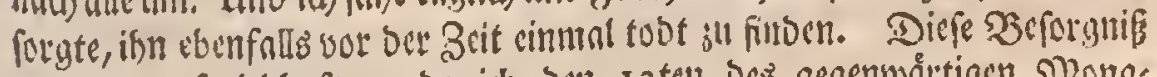

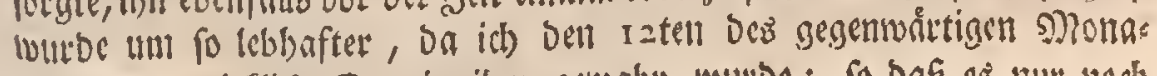

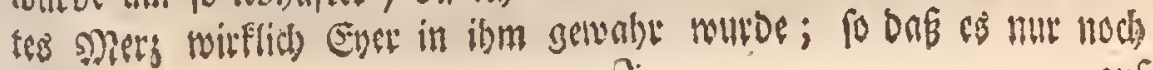
g

auf 


\section{(66)}

auf einige Sage anfäm, um zu crfabten, ob auch aub biefen unbefrudteteten

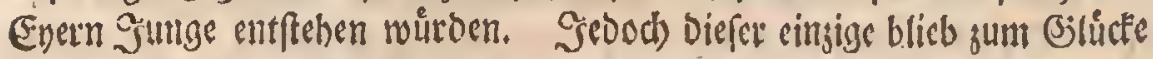

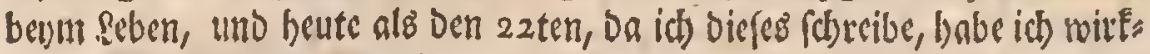

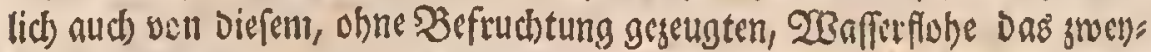

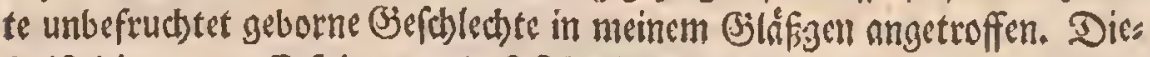

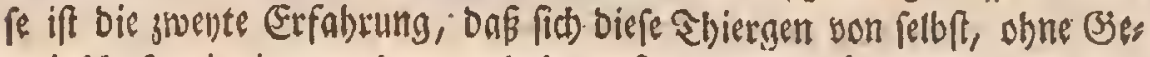
meinfdiaft mit einem andern zu baben, fortyflansen tơnnen.

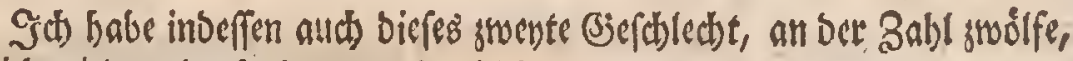

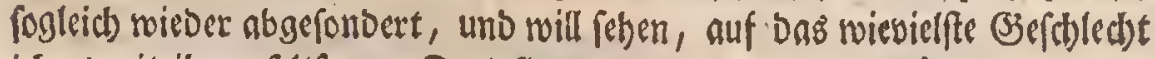

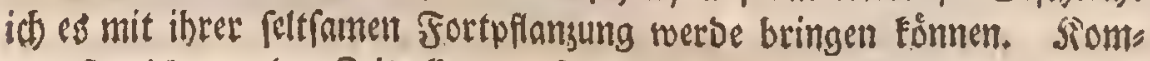
men fie nidts nor ber Zeit alle um, fo stocifele idh gar nid)t, id) werbe auds

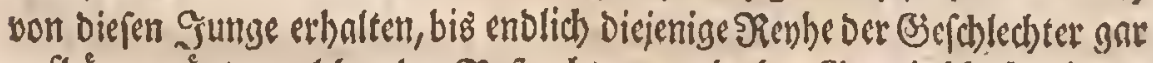

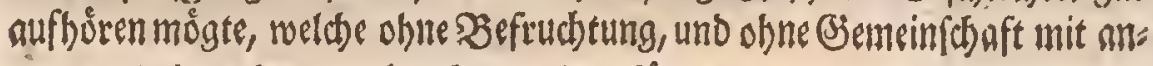
Dern gu baben, berworgebradt wetoen fónnen.

2Ber batte fich in ben åltern Beiten fo was tråumen laffen! uno múf fen wir bier nid)t abermal Die unumi(drinkte Macht bez Sdjöpfers bes

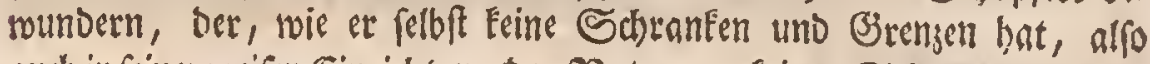

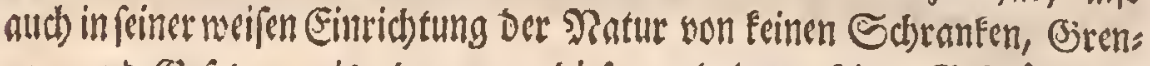

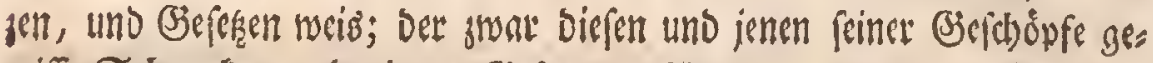
miffe @dranfen uno rigene Bieferge vorfdyreibet, biefelbe auch an for the nothroendig binbet; bey andern (Befditpfen aber jene Schranfen

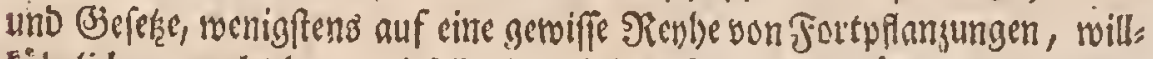

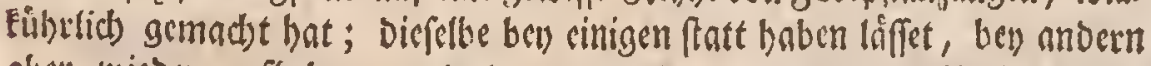
aber mieber aufbebet, und leştere nad) gang andern (Eintichtungen

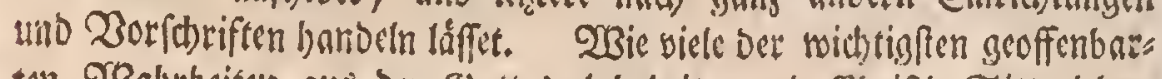

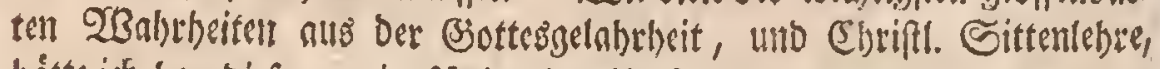
bitte ich bey biefen geringf(bscinenten umftande beyjubringen uno zu er:

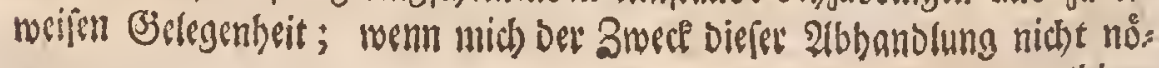




\section{(67.)}

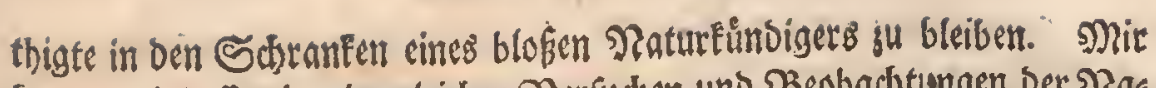

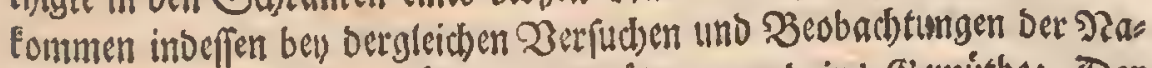

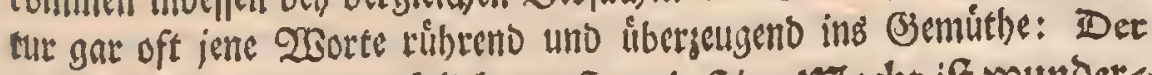

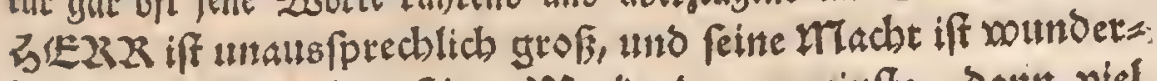
barlich. Doir Feben feiner Doerte das boentigfte, Dant piel gróf̧ere finto uns noch vecborgen! *

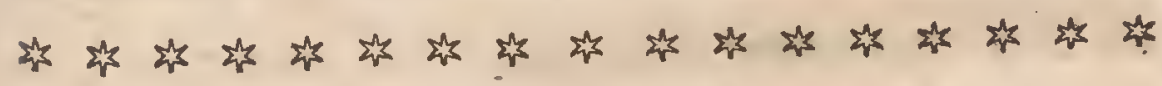

\section{Sritter 9 ([)}

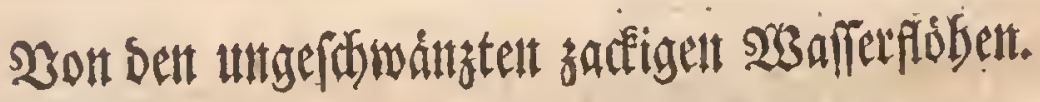

(Pad)oem id) in bem votigen 2 b fobnitte bie befamte, unb bev uns ges ses

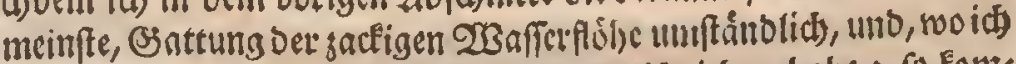
mir nicht ju viel fomeidsele, zurcidgento bejdricben babe; fo font: me id nin. ju einer anbern (Sattung berfelben, und von ber id, fut mein Stbil, noth nirgenos etwas geleeten babe.

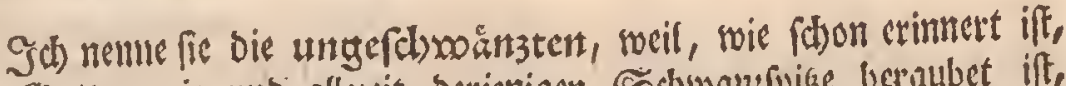

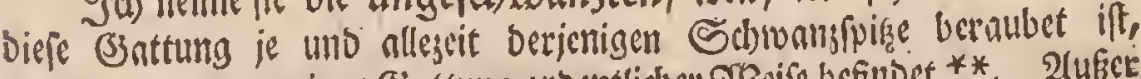

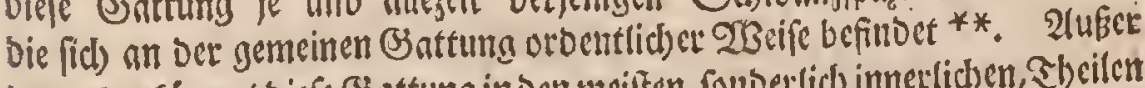

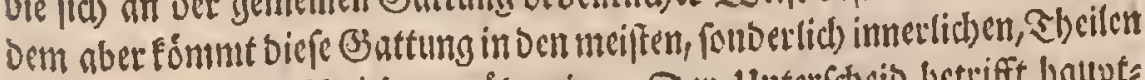

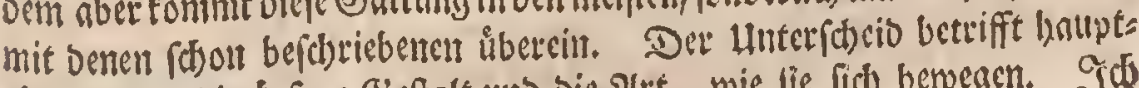

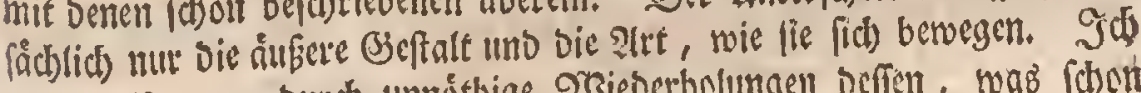
werbe alfo, un burch unuéthige 2 Bieberbolungen beffen, was fach

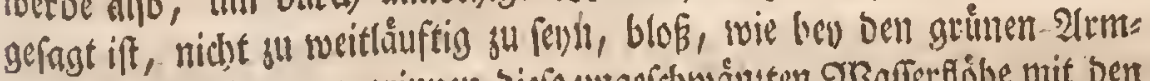
polnpen, angeigen, morinnen bieje ungefdwainten $2 B a f e r f i o b e$ mit ben

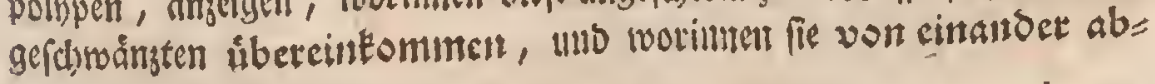
gebert.

$9=$ গn

* Sir. XLIII. 31. 36. "* Tab. I. Fig. IX. f. 


\section{(68)}

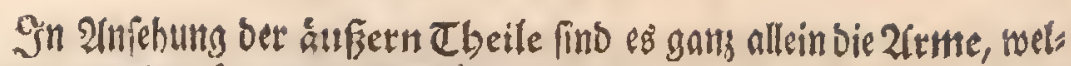

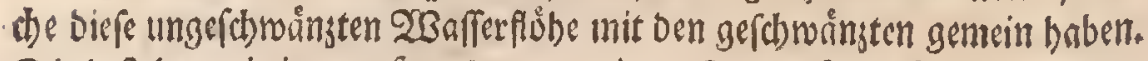

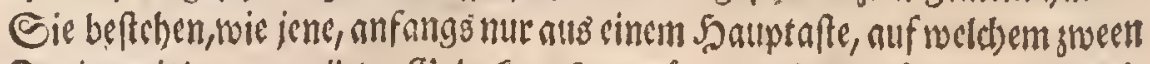

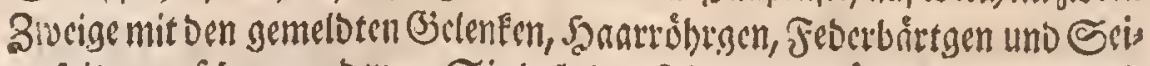
tenfpisen, gefehen tucroen. Sie befinoen fich an bem námliden Sorte; firto Durd) cben foldbe ringartige (slieber unit Dem \&cibe verbunden; uno werbern

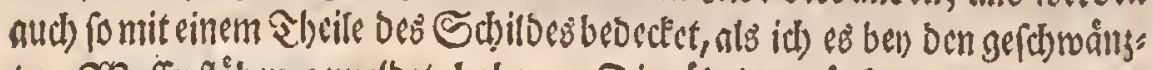
ten $23 n$ ferfióben gemreloet babe. Die úbrigen åusern Sheile gelsen

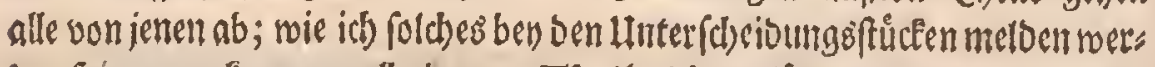

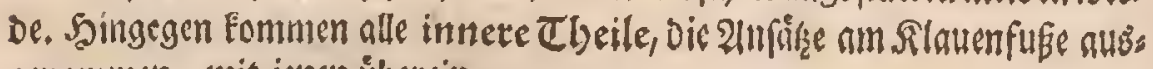
Benonmen, mit jenen ủbetein.

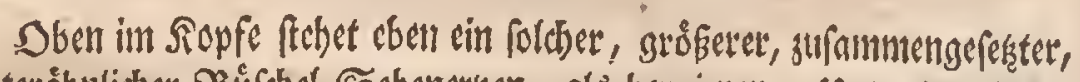

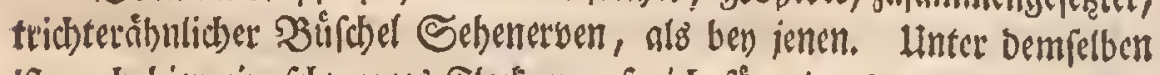

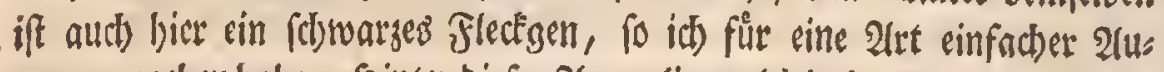
gen angegeben babe. Sinter Diefen 2 (ugen liegen biejenigen gemeloten bren

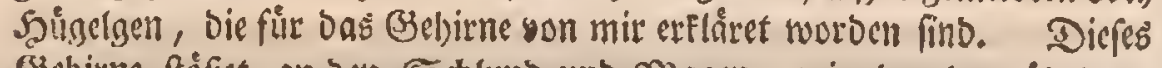
(3)ebiene fófiet an Den Echlunt und Magen, wie bey ben iubrigen.

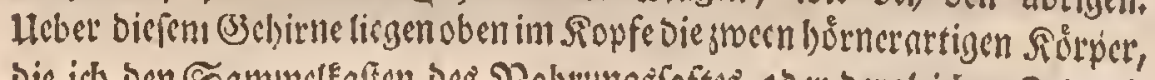

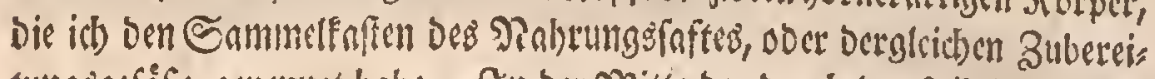

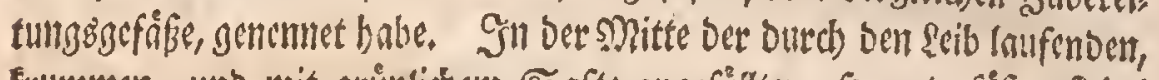
frummen, uno nit grintichem Safte angcfüuten, Şauptgefo̊ke, fiebet

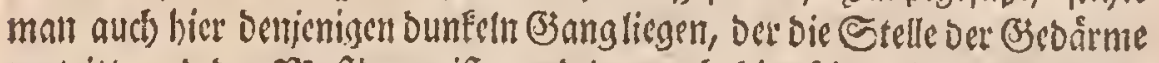

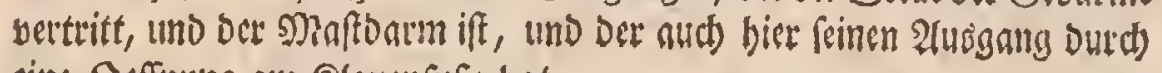
eine Deffnung am Rlauenfube bat.

Der Siefenfuge find, to viel id fehen fơnnen, nid)t meht nod wenis

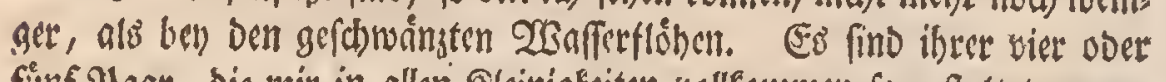
finf Jaar, bie mir in allen Fleinigfeiten yollformmen fo geftaltet vorges Fommen fino, wie id fie bey Der vorigen Gattung angesciget babe; Şits: 


\section{(69) 制}

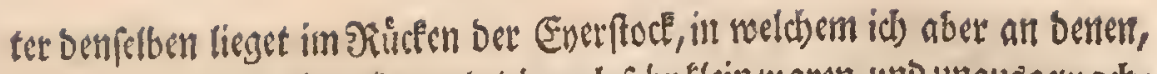

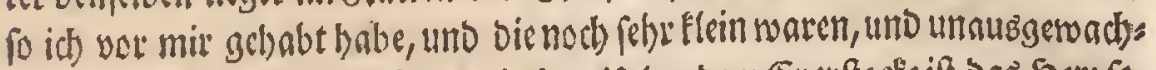

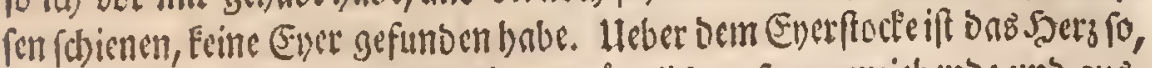

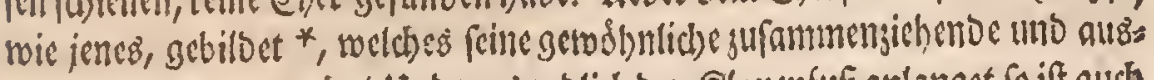

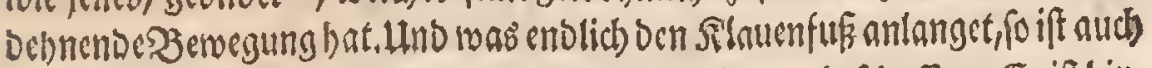
Diefer ber. Samupt fad)e nadh, wie ber idjon befdriebene, befdbaffen. Er if thitt ten breit uno gebogen; uno láuft vorn in cine vogelibnglicbe Silaue mit sween

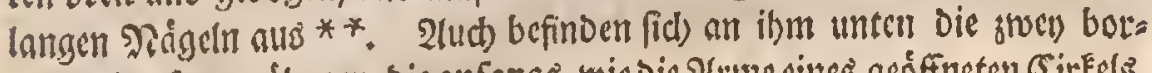

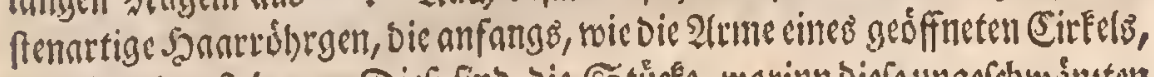

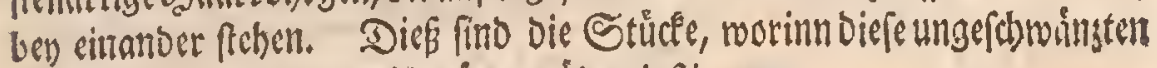

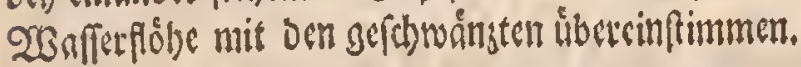

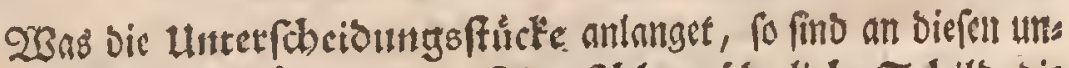

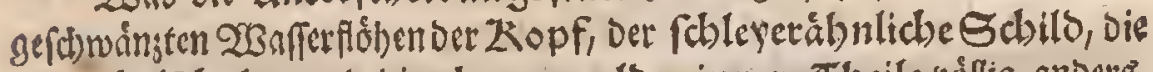
thrurabelfchale, und bie sben gemelote innere Cheile vólig anders, als an Den vorigen gebaute unb geftaltet. W3obin Denn aud) bie 2itr ibres Sch xointments, uno wie fie fich im 23 affer von einem Sorte sum anoern

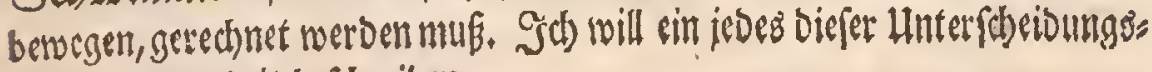
ftüde infonoetlycit befdreriben.

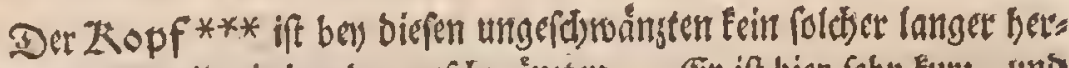

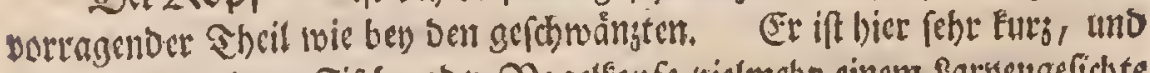

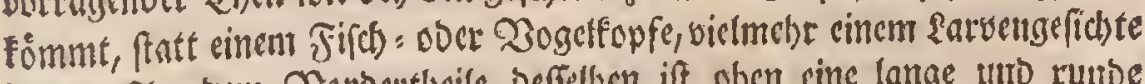

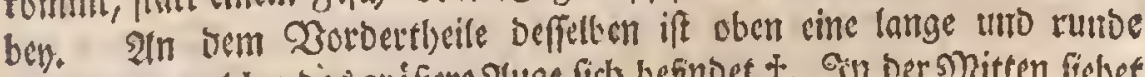

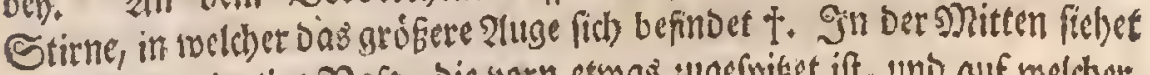
man cine fegelartige Nafe, Die vorn etwas jugefpitset ift, uno auf reldber,

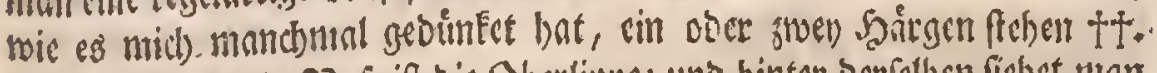
Diefe aurcheinende P2afe iff bie Sbertippe; und binter berfelben fielyet man Dent fleinern fobmarsen flecken, als Den Sort Der cinfacben 2 lugem. Die.

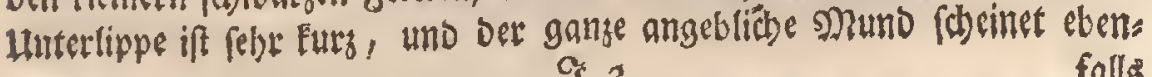
os 3

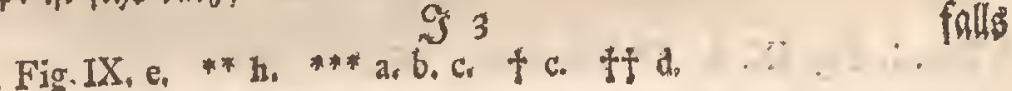




\section{(70)}

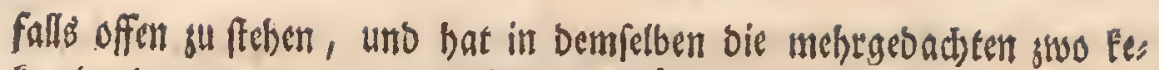

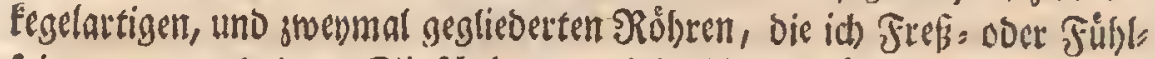

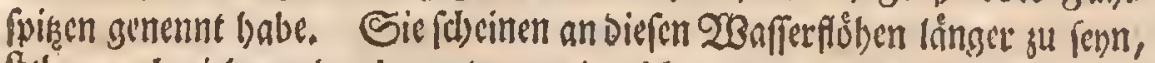
fteben auch viel geraber berunter, und reidben mebr in bie Mzurdselfdale hinein; als bey benen von Der yorigen Siattung.

Der Saintertbeil bes Eatoentopfes, if swat aud mit einem Sdbil= be bedectet *, es hat aber Daffelbe bier eime gang verichiedene uno befondere Bjeftalt. Es nimt obent über ber Stirne einen fel)r fumalen 2unfang; láuft auf ben Seiten nach uno nad ettwas breit berunter, uno wito unten und auf bemr SRucten runb. Nan fiethet an itsm biejenigen rinnenartigen Streifen uno Futrden nictt, bie id) bey bem Schlenerichilbe Der andern

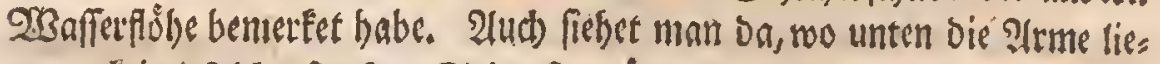
gen, feine foldbe ftarfen Scitenfortgånge, als Dort mit Den Ecfen eines Stbleners verglichen fino; mitbin weroen bie 2lume nur felye wes

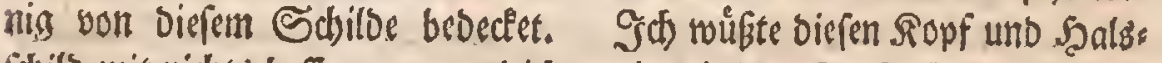

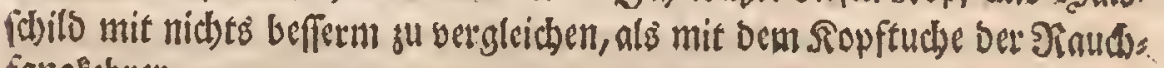
finglebrer.

Die HIufbeifchale bat bier, fonberlid oben; eine weit ftátfere Deffnung, nls Die Muschelichale ber vorigert. Cie if Darneben vorn, bitten unb unten, vóllig rumo, uno ctwas meniges linger, als fie breit

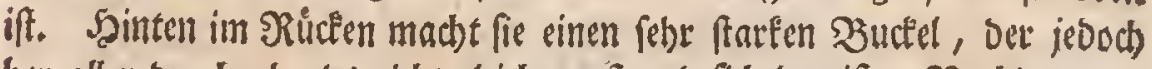

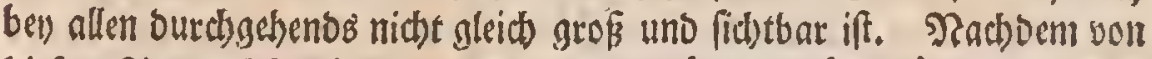

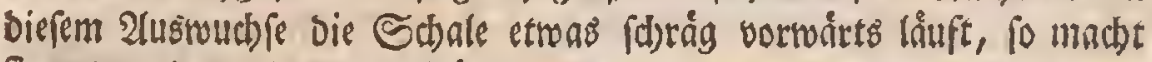
fie unten wieber ein Eleines Saugelgen, eben in ber Biegent, wo bey ans

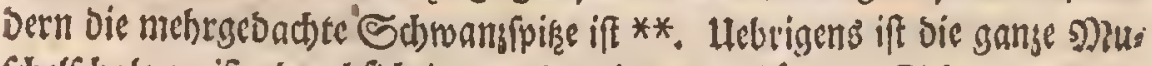

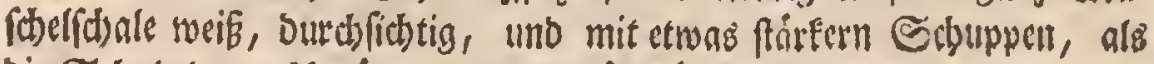

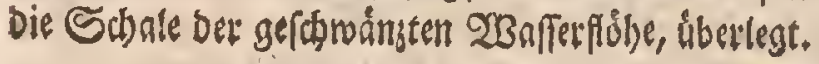

*Tab, I. Fig. LX, d. *Fab, I. Fig. IX, f: * 


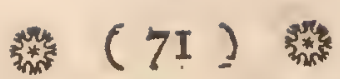

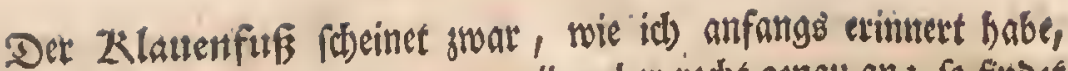
nichtò eigeness zu baben. Siebet man ibn aber redst genau an; fo finbet mall allerbings aud) an ibm veridjiedenes befonbere. Es feblen ibm for nobl bie bintern 2lnfåze und Fortge̊nge, von benen id) gemelbet babe,

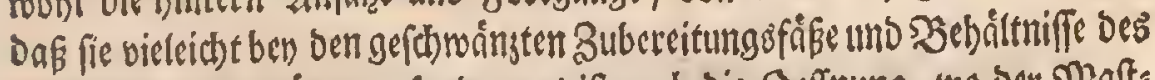

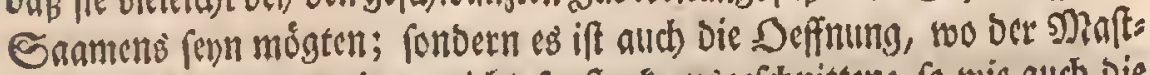

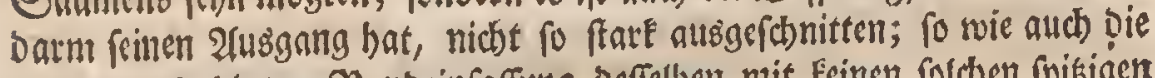

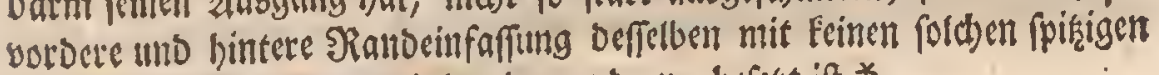
Zacfen ober Stacheln, wie bey Den ambern, befest ift *

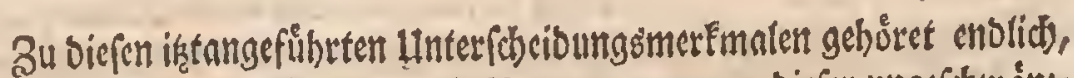

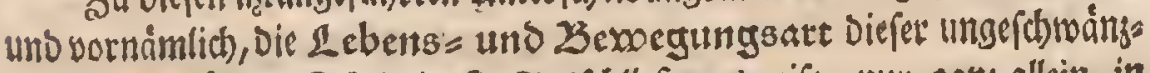

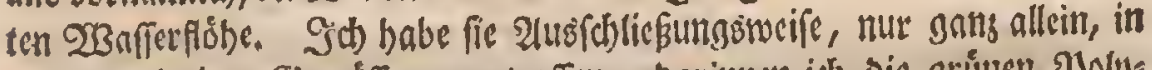
einem berjenigen (Bewóffer angetroffen, Darimnen ich) Die grituen Đolys

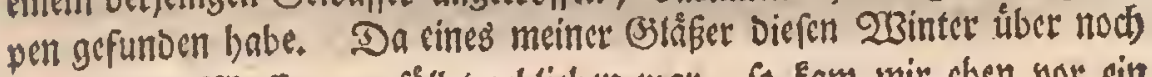
mit foldem 2 Saffer angefullet gebleben war, fo fam mir eben bor ein

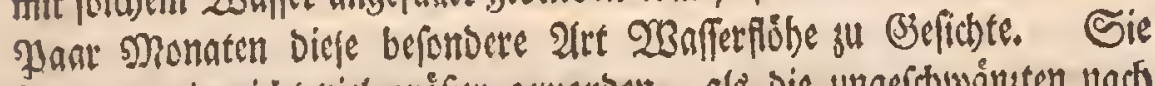

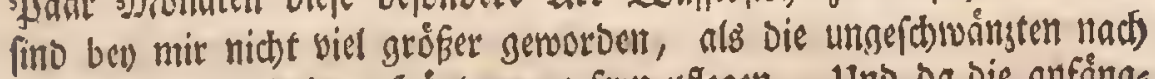

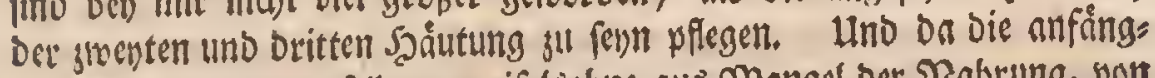

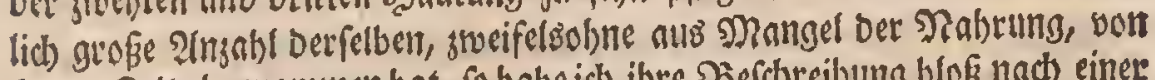

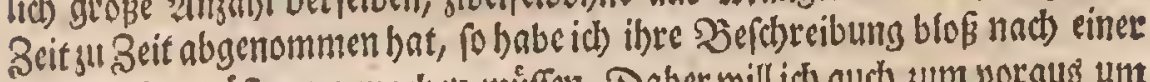

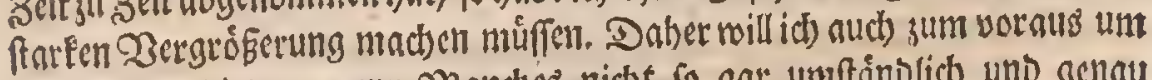

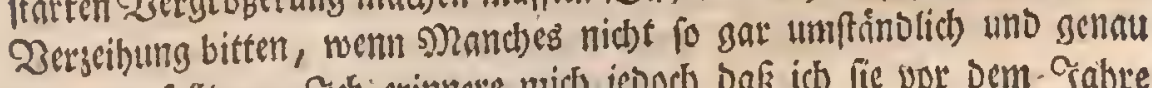

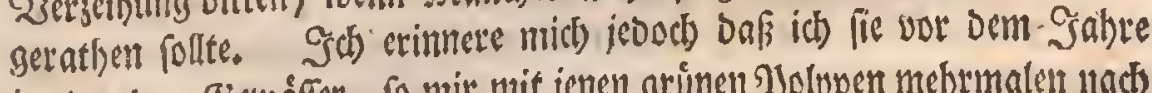
in eben Dem (J)

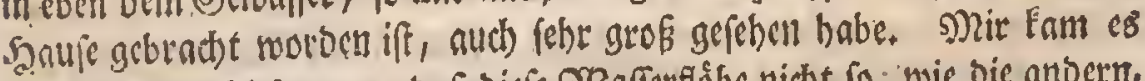

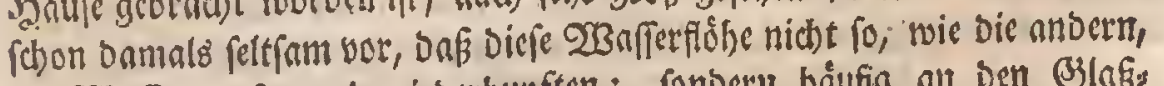
im 20 affer auf = uno nieberbupften; fonoew báufig an ben Blab: roin:

- Tab. I. Fig. IX. p. 


\section{新被 $(72)$}

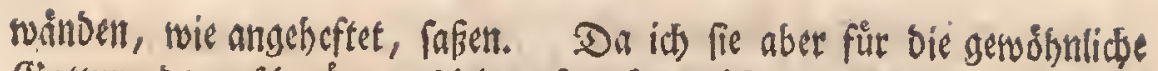

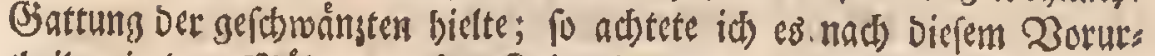
theile nie ber shinge werth, fie in eine weitere unterfudsung su nebs men.

Es ift aber bie 2 Benegung biefer ungefdroingten 23 afferfiobe in allem

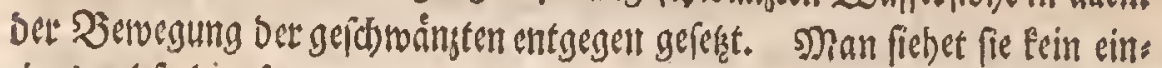

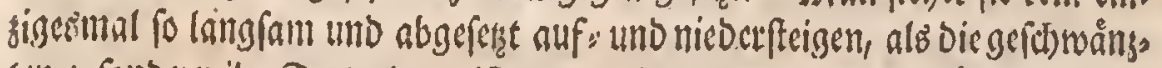

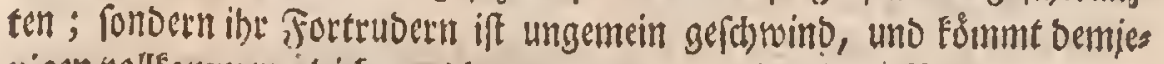
nigen sollfonmen gleich, wildes man an ben rorben bo afferfpinnen ges

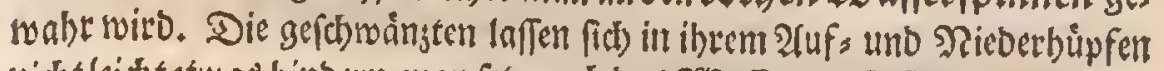

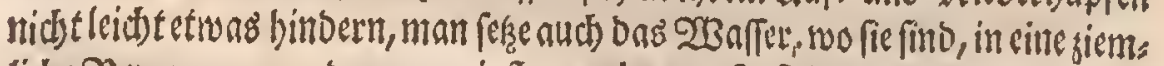
lidje Bewegung; und am roenigften serbergen fie fich im Sblamme, obet:

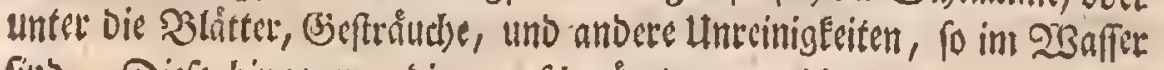
finb. Diefe bingegen, bie ungefdswiongten, verfobwinden ben 2 (ugen: blice im $23 a f f e r$, wenn fie such nur bie geringfte Siemegung beffelbent empfinben, obel fouft berůbret werben. Sie yerlaffen fegleid) Den

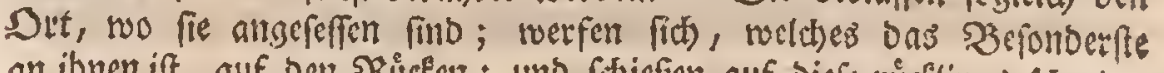

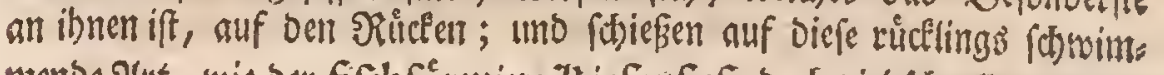

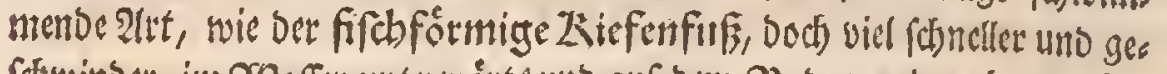

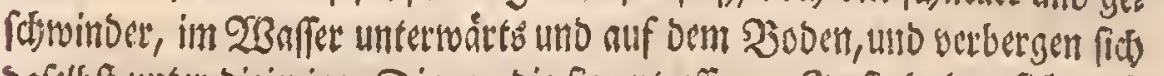
Daflloft untet biejenigen Dinge, die fie antreffen. Ja fic balten fich autb von felbft lange Beit unter bem (seftránd)e auf, fo oaf id manchmal

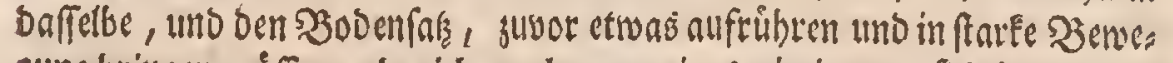
gung bringen miffen; ebe it) auch) nut cincs cinsigen anfichtig werben

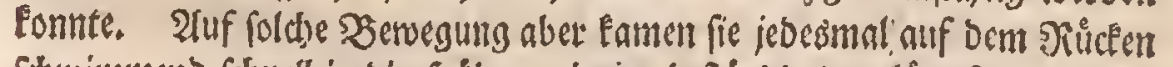

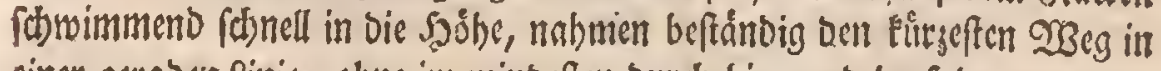
einer geraben simie, obne im minoefen burd bin = uno herfabren von igs:

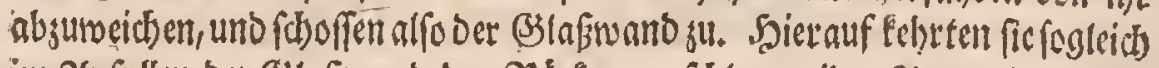

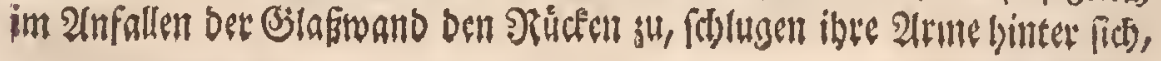




\section{( 73 )}

uno bielten fich entroeber mit einem allein, ober auch mit benden sugleids,

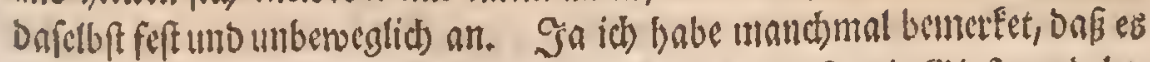

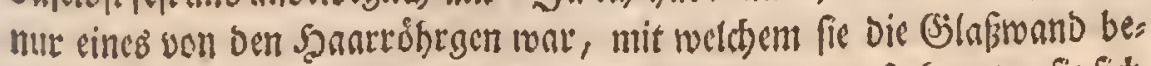

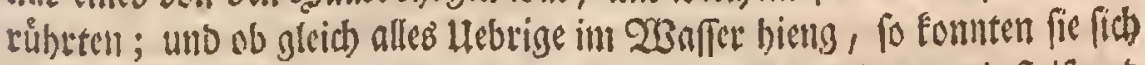

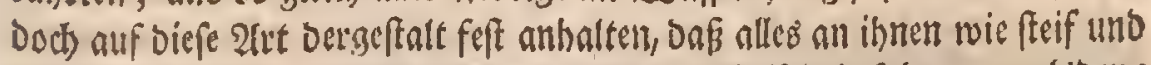

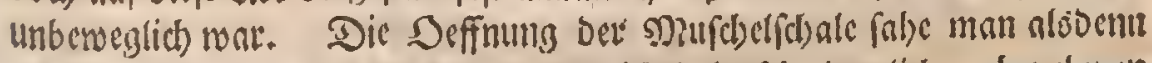

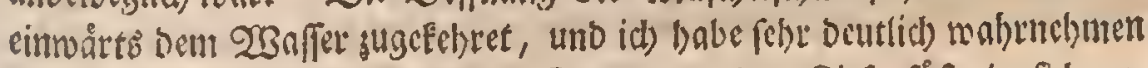

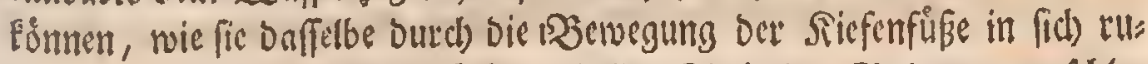

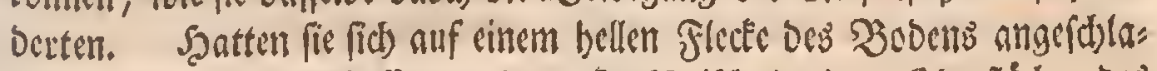

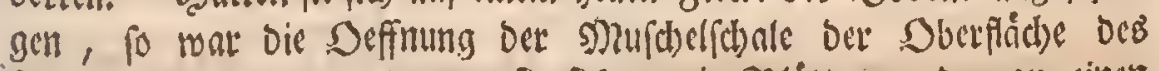

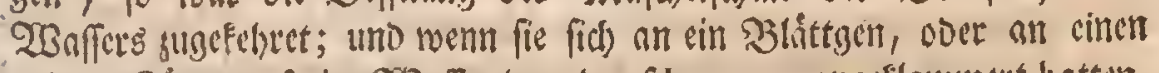

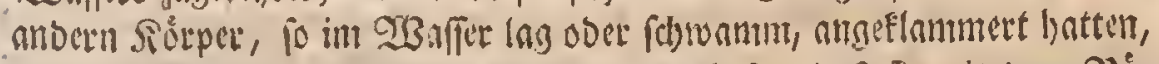
fo war auch oa ilyre Etellung und \&age allescit fo, Das fie mit Dem Sius

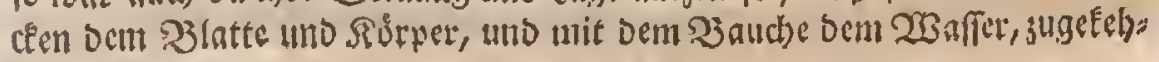
tet blicben.

Und biefes ming benn ben biefer neuen alt ber ungefdwaingten

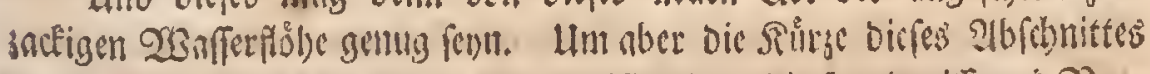

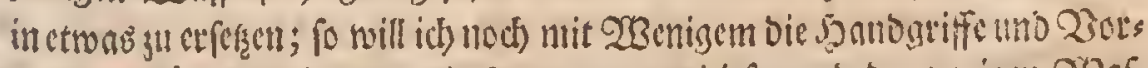

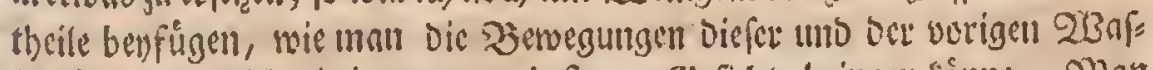

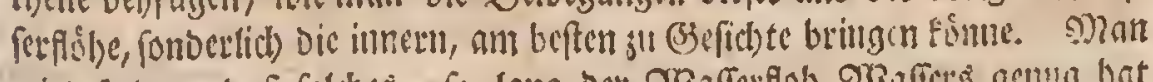

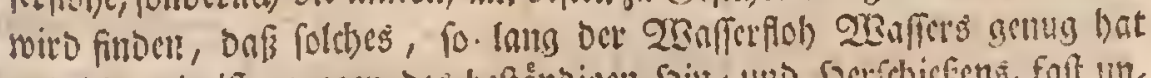
uno lebendig ift, wegen des beftambigen Sains und sacrifhicfens, fort un.

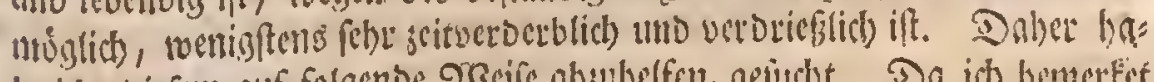

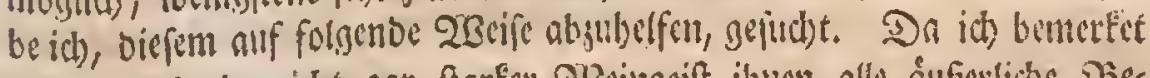
batte, ons ein nidst gar ftarfer $23 e$ eingeift ibnen alle sufertiche $25 e s$

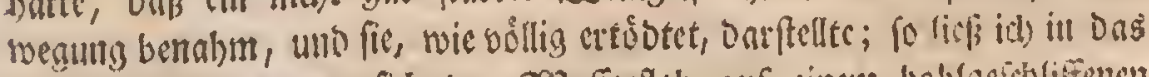

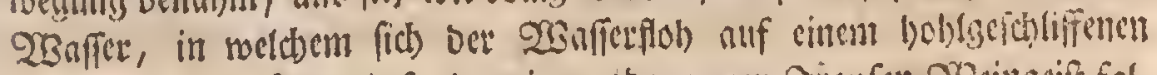

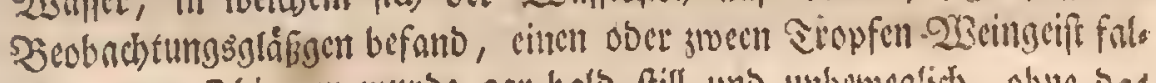
len. Das Sbiergen wurde gar bald ftill uno unbrocglid, chne bar

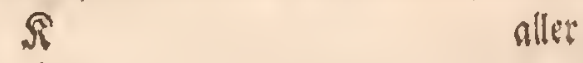




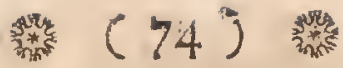

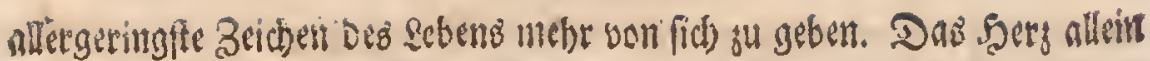

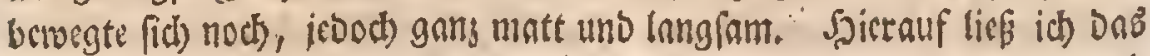

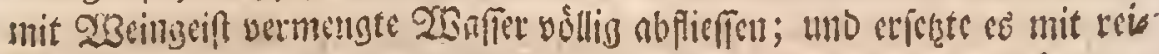

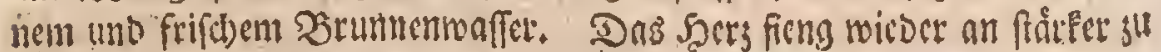
(d)hagen, bie Siefen false mannath uno und fich oon neuem ribben, und

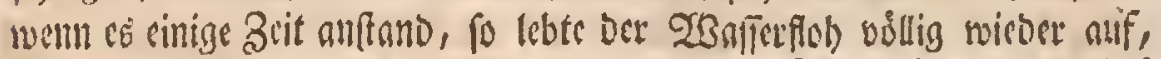

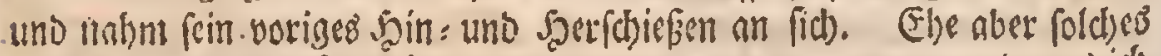
erfolgte, erbictt ith liberflúbige Zeit, slle innere Setwegungen, und was ich fonft sn ilyen feben mollte, ansumerfen uno abbilben zulafen.

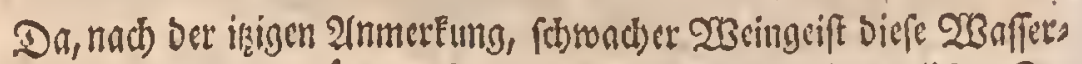

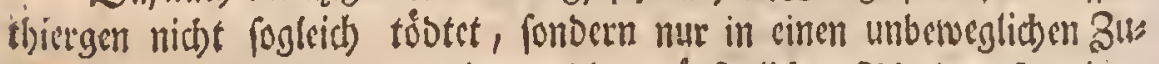

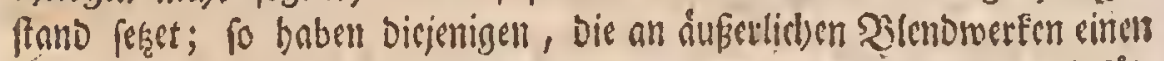

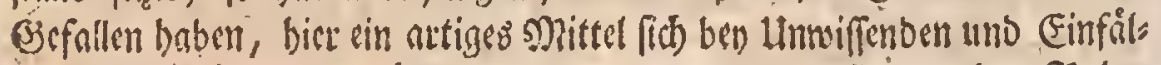
tigen, Die nur nad) Den ausern Sinnen zu urtbeiten pfiegen, Den Siubm

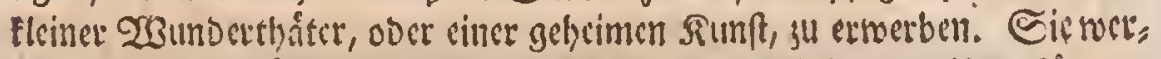

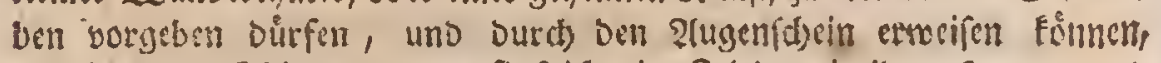

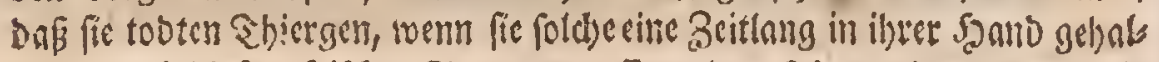

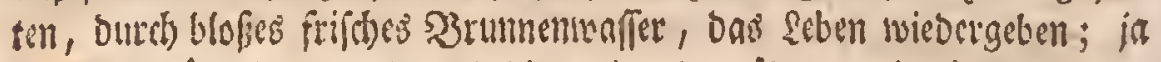

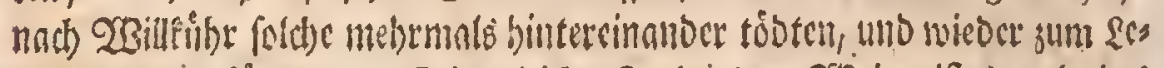
ben bringen formen. Die gleibe Garbe Des $2 B$ seingeiftes und Des

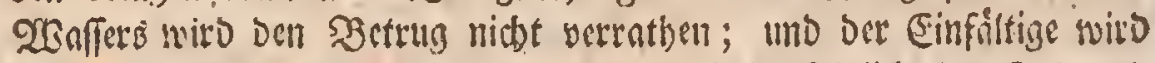

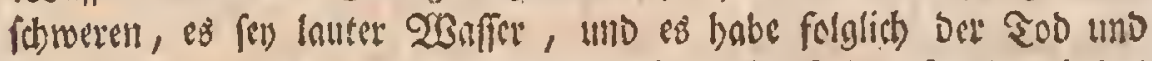
Das Scben Diefer Syberget von einer geheimen Sraft Ber Saltb uno DCB

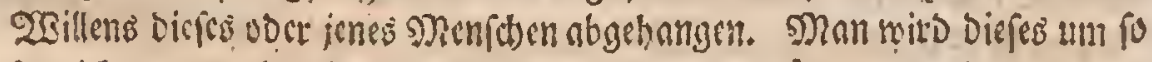

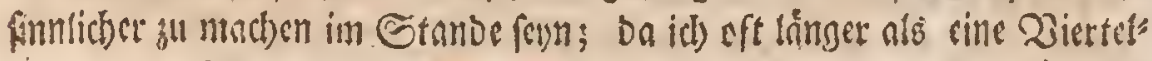
frumbe bisfe Bhiergen in 23 singeifte babe liegen laffen; uno bie, wemn ids

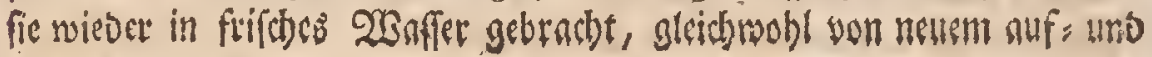
fortgriebrt baben. 


\section{繁 $(75)$ )}

*************************

\section{Sietter IGsidmitt.}

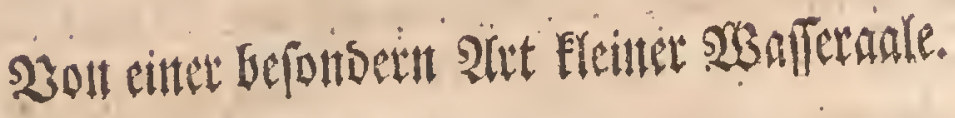

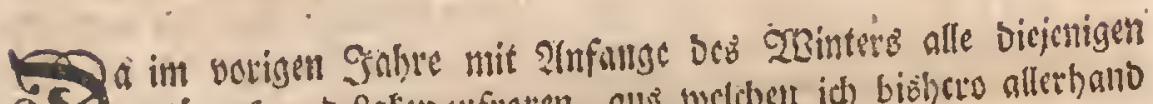
Simpfe und Safert zufreten, nus weldent id biobcro alterhano Snieften fü meine stmpolupen batte bolen laffert fo falbe ich

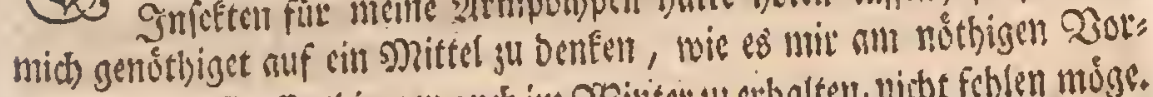

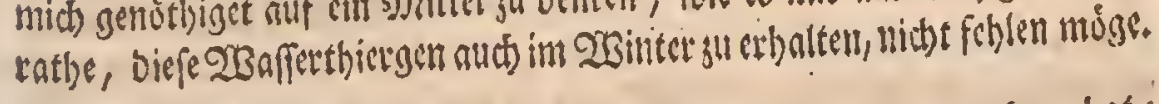

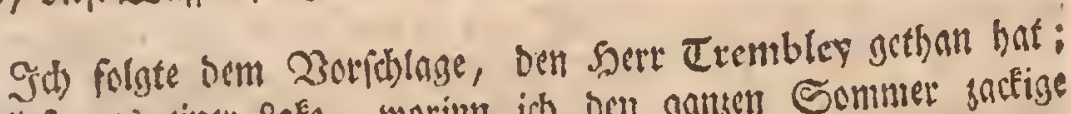

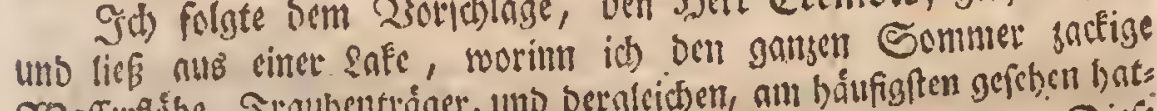

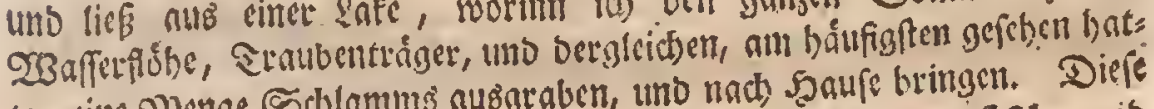

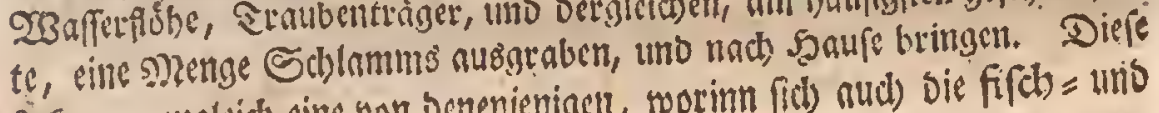

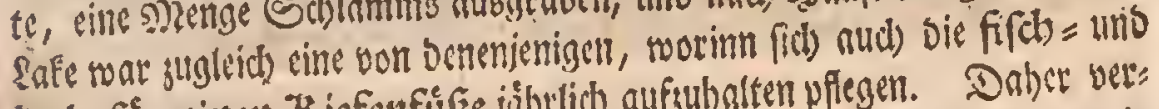

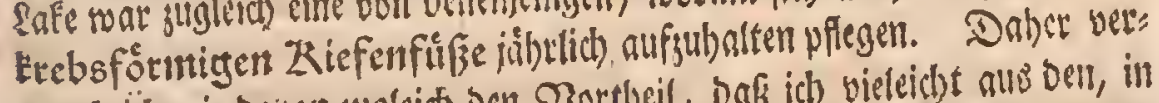

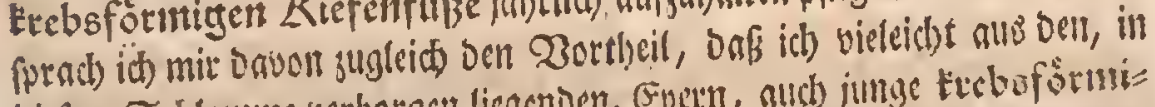

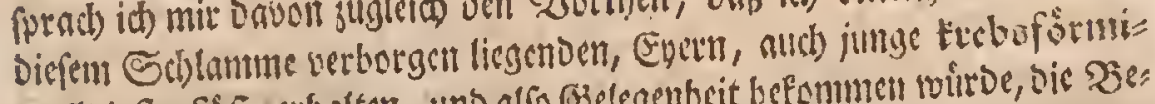

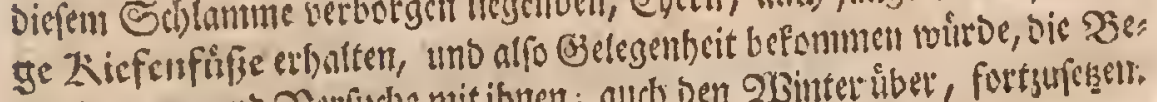

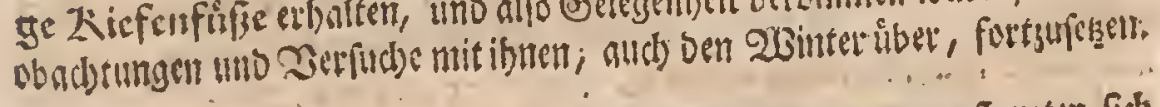

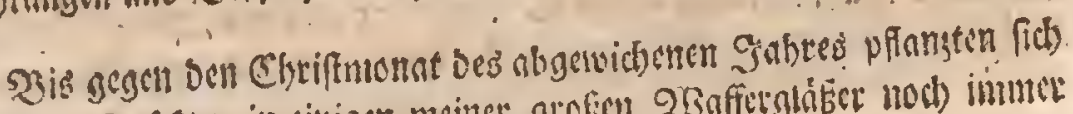

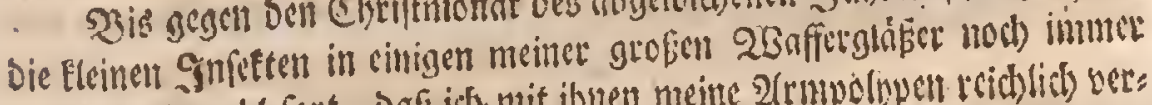

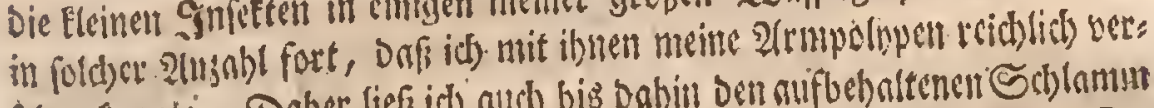
fehen Pounte. Daber lieb id) aud) bis bahin Den aufbebaltenert Soblamun

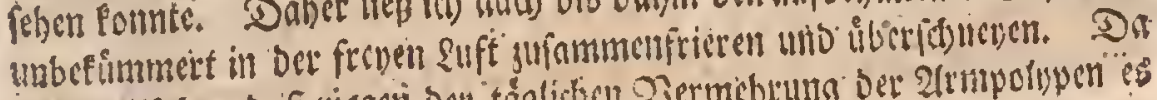

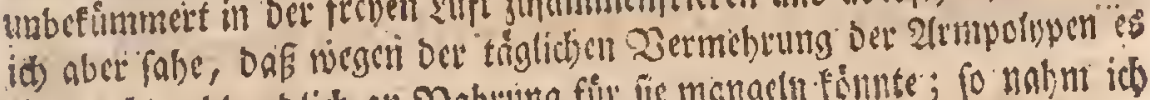

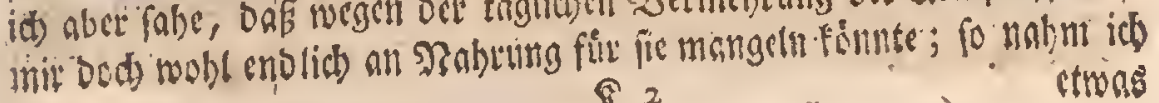
$\Re=$ intugs 


\section{( 76$)$ )}

etwa yon Diefem gefrotnen Schlanme; fillte bamit eines meiner grofiften

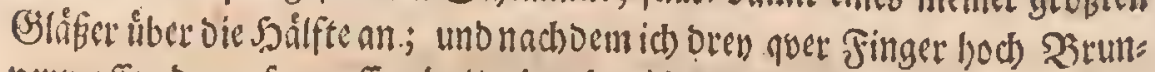

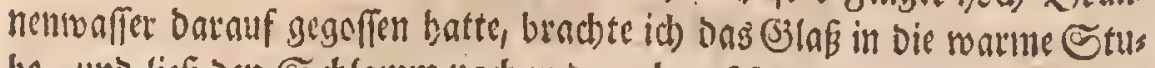
be, und lies Den Schlamm nad) uno mad) gufthauen und weid) sectben.

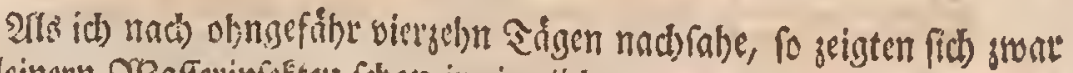

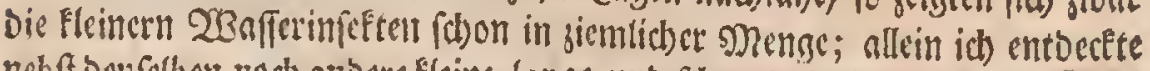

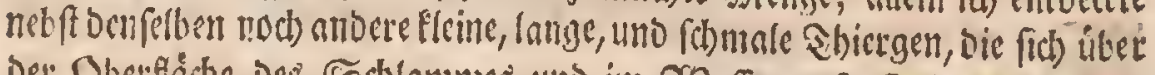

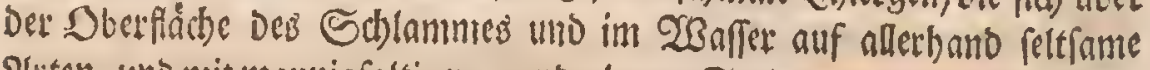
2liten, tmo nit mannigfaltigen munoerbaren Stellungen, Sagen und Sicb) tungen, bin uno ber berwenten *. Itno je melse ich ilbnen jufabe; je roums

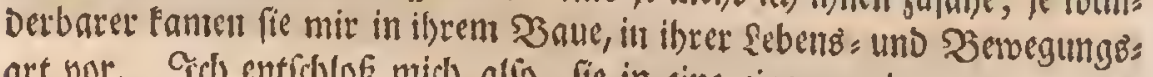

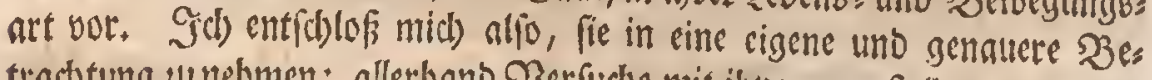

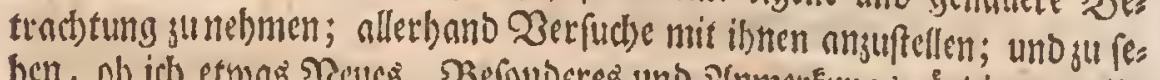

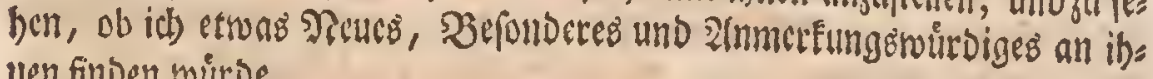
nen finden wurboe.

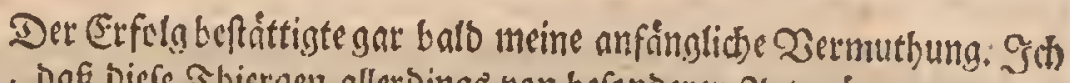

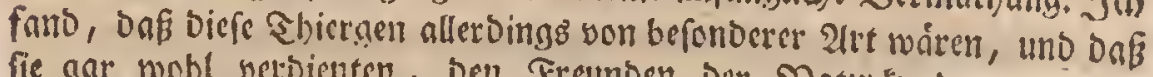
fie gar wobl betbienten, Den Freunben Der Naturfunde angejeiget und befanntgemacht zu werben. STh will zuerfe onsienige bon ibnen mels

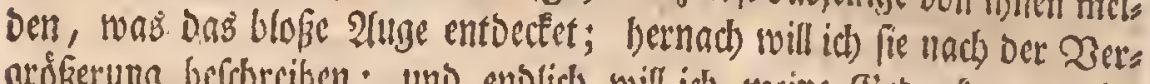

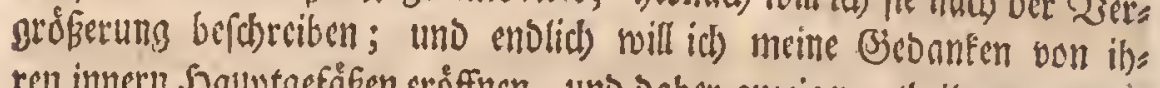
ren imnern Sauptsefósen eroffnen, und baben anzeigen, theils nas diefen Ebiergen mit uno vor anvern cigen iff, theils was id) wor Derfuche mit ibnen angeffellet habe.

Sabe id) Den, in einent reinen und beflen (Blape fid) befindenben, Echlamm etruas genau an, fo famb ich foglecit) mit bloken 2fugen nicht

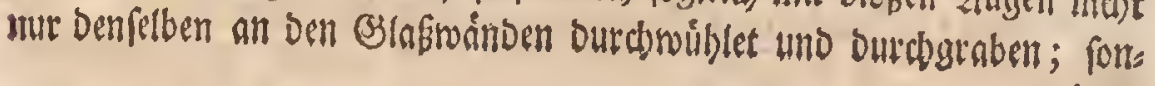

- Tab. IIL Fig.I. Detn 


\section{(7?) (7)}

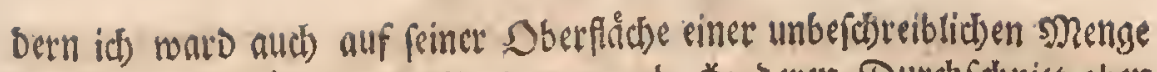

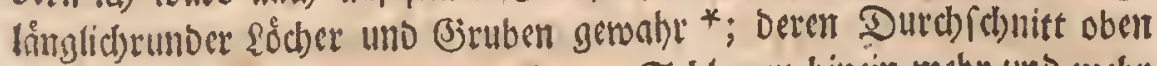

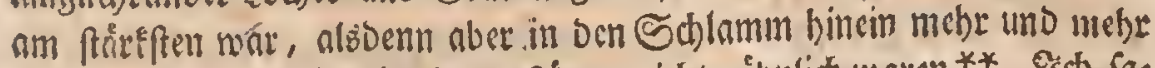

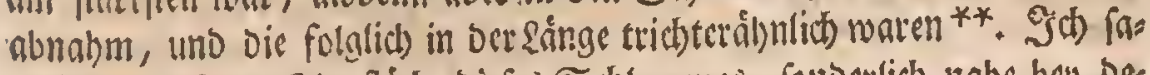
be ferner auf ber Sobethidse Diefes Sthlammes, folloerlich nabe ber) bes

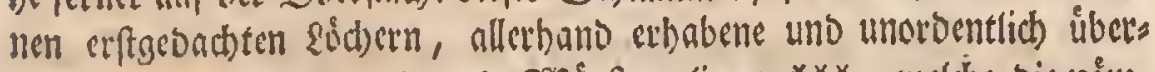
cinanderliegente lange uno runde $23^{3}$ irftgen liegen ***, weldhe die nåms. liche Forbe, wie bur Schlamm batten. Sorndunlich aber funden in

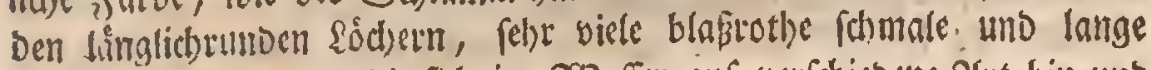

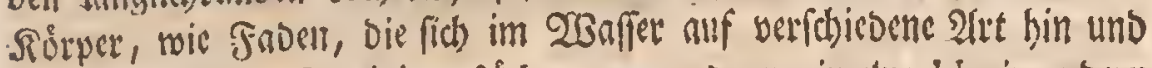
ber bewegent. Sin einigen Soddern waren Deren cinzelne ț, in anbern

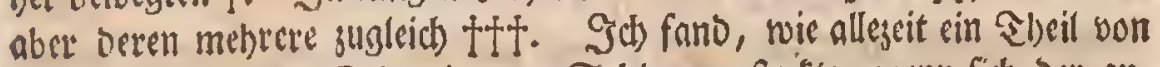

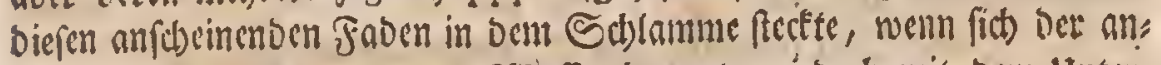
bere ciber Dem Sd)lamme in 23 affer berwegte; jebodh mit Dem Hnter:

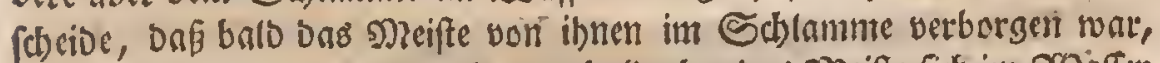

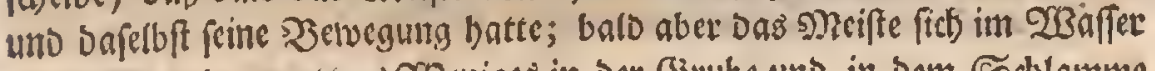
berwegte, umo nur etras 2 seniges in Der Brube uno in bem Schlamme fict) befanb.

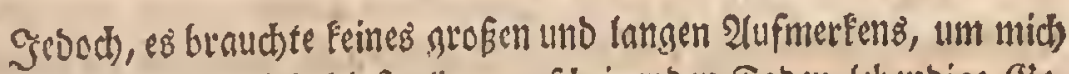

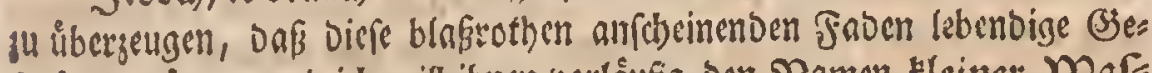

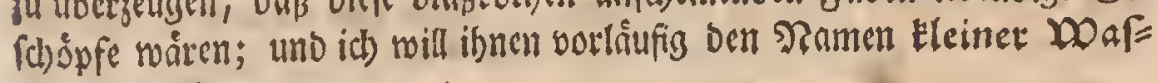
feraale beylegen.

2Bas zuerft bie Serwegung biefer 2 Baffernale anlanget, fo babe ich be: merfet, Dap fic theils eine einfache uno beffànoige, theils cine 3 llfam:

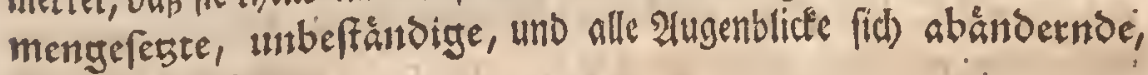
Senegung babsn.

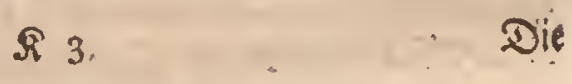

* Tab.III. Fig.l. a. a.a. a. "* c.c.c. *** d. †f.g.b.i. 1. m. n. p. q. r. tf .e. f. 1. n. q. o. s. ttf g. h. f.m. p. g. .x. : 


\section{(78)}

Die einfache unb beftánbige befebet barim, oap fie fid forvobl

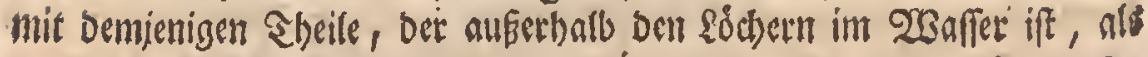
qud) mit einem Stúcte bebjenigen Sheiles, ber innetbalb Den \&ơdjern ftes ceet, nad) ber linfen uno red)eent Seite abmeesfetno, ulto fo wie bet

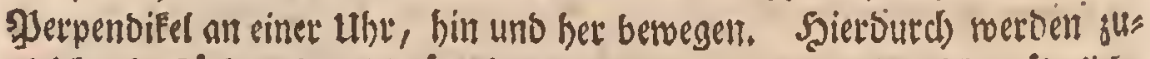

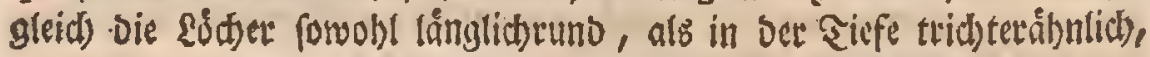
semadbt. Gn 2nfehung bes erfern mus gans nnturlich ber Soblamm ba am meifen auf bie Scite gefdoben; uno folglid) ons soch weiter metoen, wo bet 23 affernal bin uno ber fáhreet; uno in 2 (bfich) bes

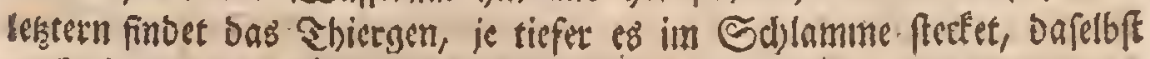

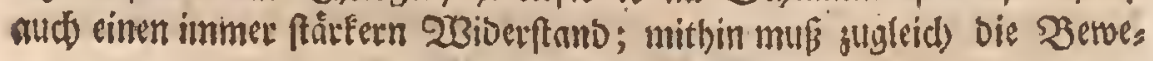
sung mebr uno mebr abnehmen, unt alfo ald bas sods einen immer

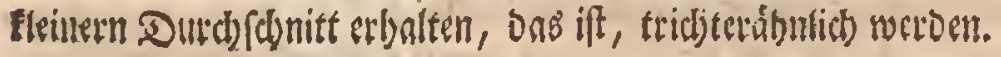

Die 3 ufammengeferte, tmbeffandige uno alle Sugenblicle fich

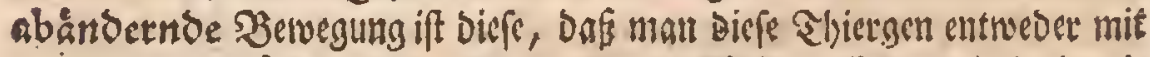

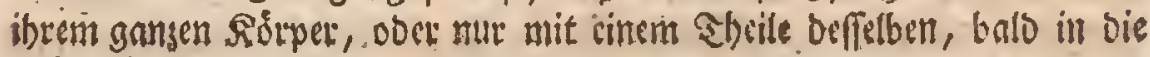

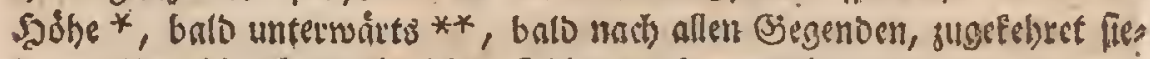

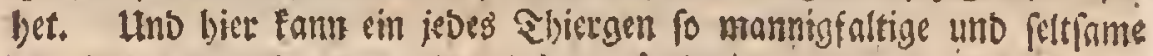

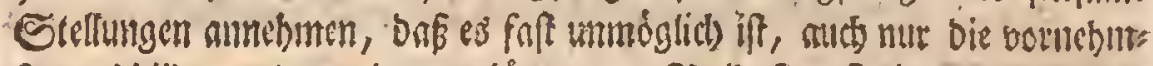

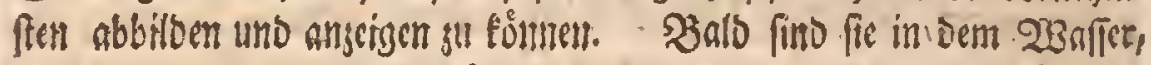

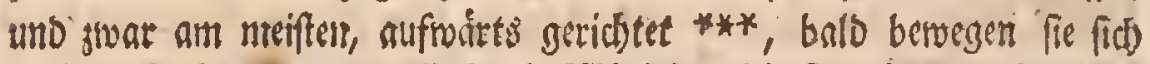
waferrecht $t$, unt unter allerband Wines(n, bie fie mit Dim Schlams

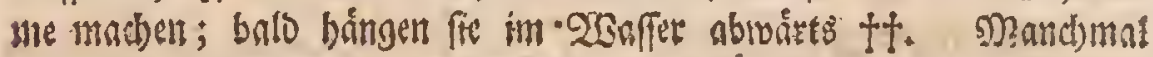

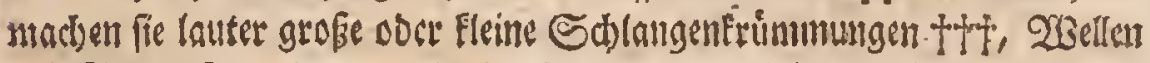
und 2iogen I, uno gmar, balo mit bem garten \&eibe, balo liur mit. Dem obern, ooer mittlem, ober untern Ebeile alfein. Nandumal erbebet fids ber \&cib obne alle אrummungen in bie Şơbe, uno balb Darauf madt Det

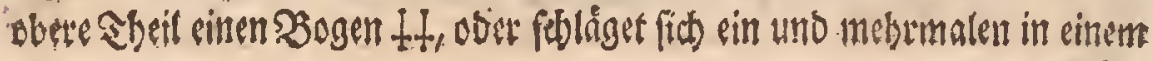

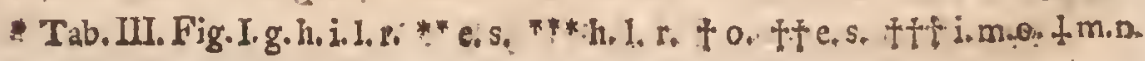




\section{$\left(79^{\circ}\right)$}

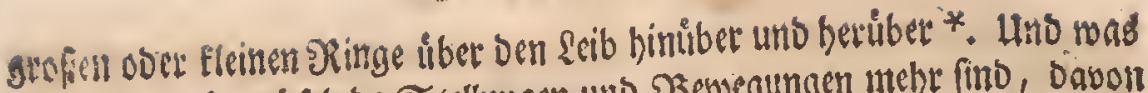
Dergleicben abwedbfelnoe Stellungen und $\mathfrak{B}$ envegungen melye fino, Dabon man fich alts Der abbiloung Die befte 3 orfellung wirb machen fónnern.

Die Sarbe biefer Shiergen ift Dem blofen Sluge inżgemein blafroth:

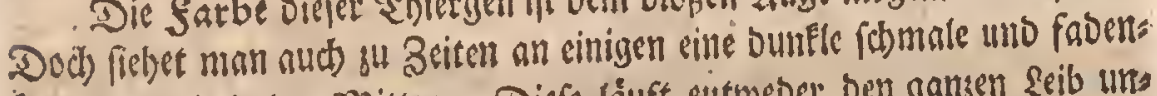

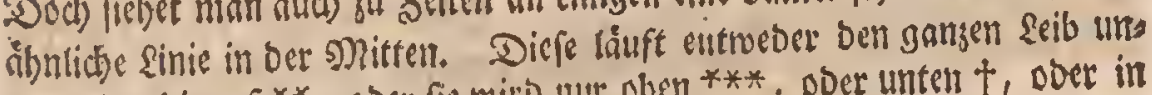

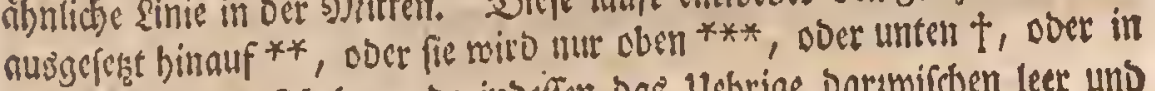

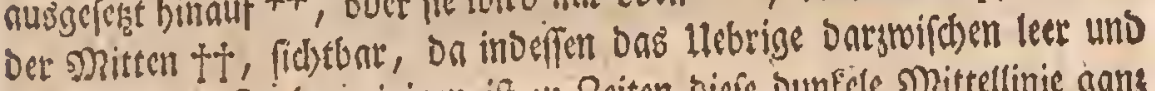

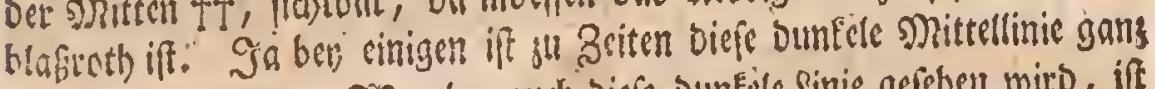
und gar unficistthat. 230 aber auch Diefe bunfele sinie gefehen wiro, ift

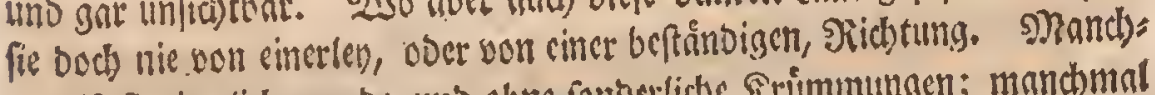
mal if fie jiemticl getabe, uno obne fortoerlictse frimmumgen; manchmal nber, uno bies faft meiffentbeilo, låuft fie in ciner meble doer weniger ges frúnmeten Soblangenlinic fort. Sben, wo Diefe Dunkle ginte fids ellbiget,

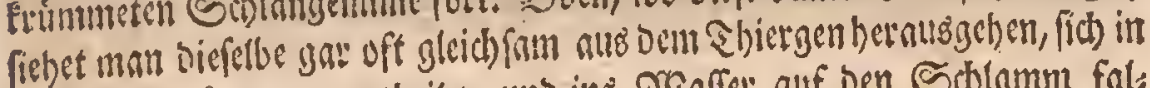

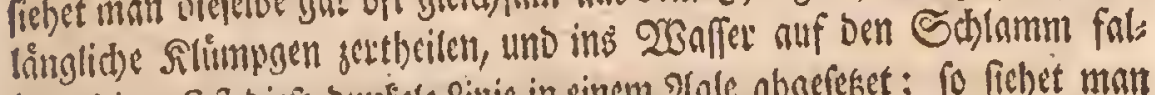

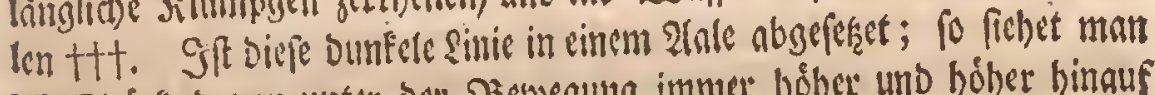
bic Sticte Davon unter ber 23 ewegung immer bober und bober binauf

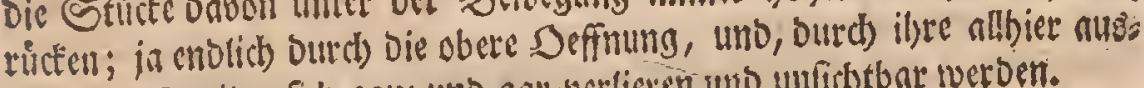
seftefene ₹beilc, fids gang uno gar werlieren mo unfichtbar werben.

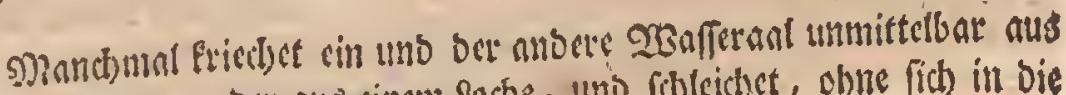

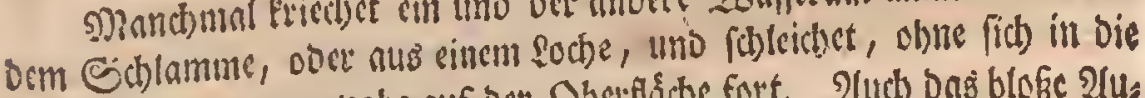

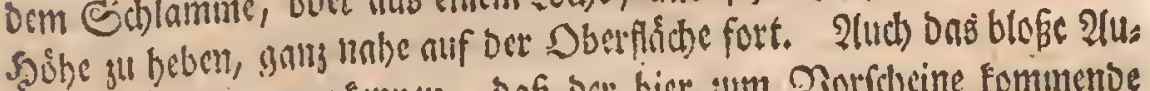

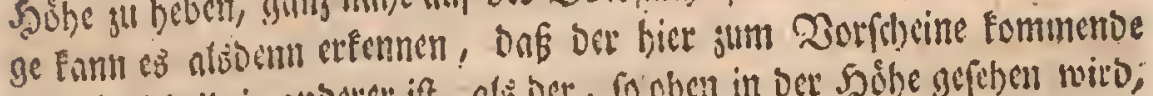

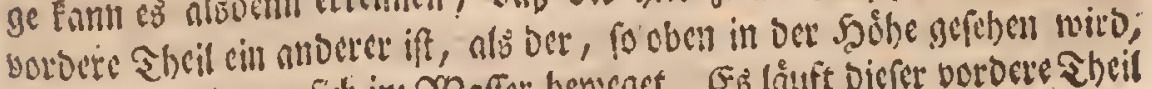

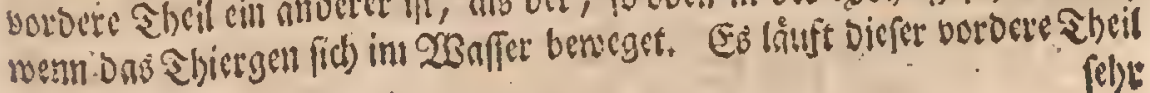

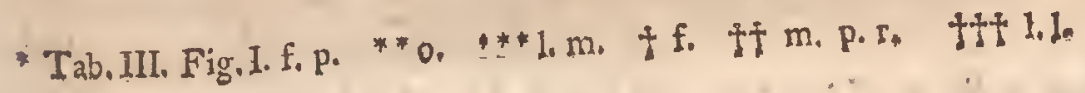




\section{(80)}

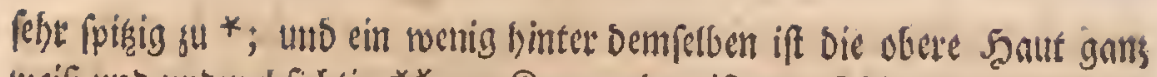
weí uno unourchfichtig ${ }^{* *}$. Saum aber ift oas Sliergen mit diefem Sheile aus orm sodse berausgefommen, uno bat fich auf Dem Sdblams me etwas fortgefdsoben, fo bobrt es unit Demfelben wieber in Den Sthlamm, uno wenn $e$ sinige Siefe errechet bat, fo jiehet es Dab llebrige Des Seibes in einen Bogen fahnell aus Dem vorigen \&odbe,

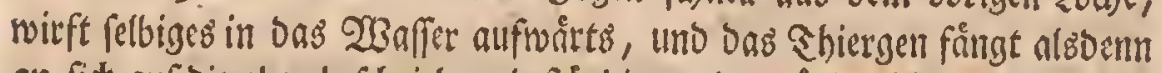
an, fich auf Dic oben befd)riebene beftánbige unb verionberliche alt ju berves

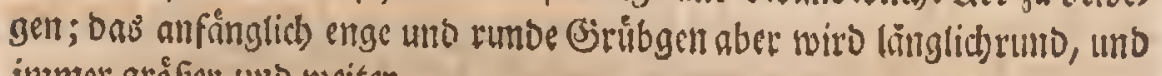
inmmer sróser uno weiter.

Man Eann audi) bie Sungen von ben 2llten mit bem blofen 2luge unter(d)ciber. Siene fino fehr flein uno (chmal ***; Diefe aber brciter uno långer; unb wenn fich jene felten eitnen Boll lang ưber ben Schlamm berausbegeten, fo thun es bingegen biefe zu Beiten orel, vier und funf 3ิoll lang.

$28 \mathrm{em}$ ber Sallanm in einem reinen uno faubern (j)

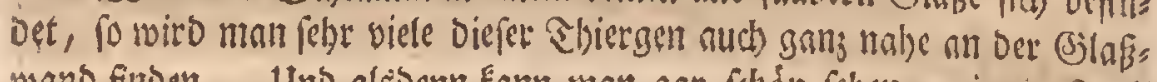

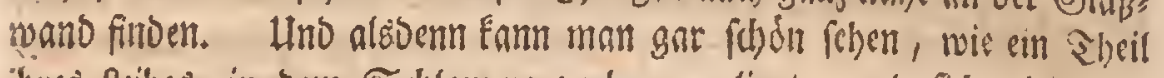
ibres fribes, in bem Gdlamme verborgen liegt, uno fich viel ooer

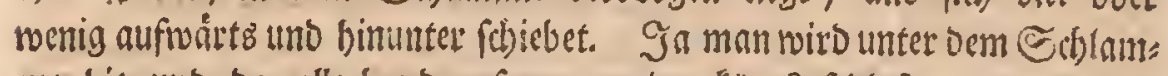
me bic unt on allerbant zufanmmengebrudete Euftblafen antreffen t,

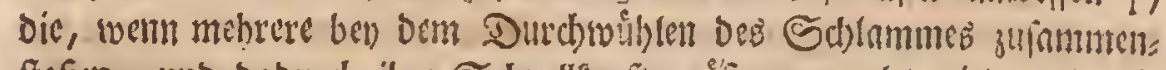

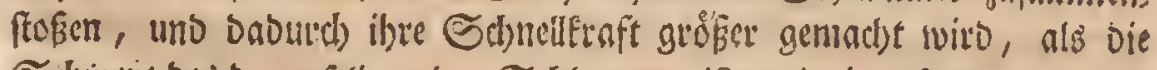

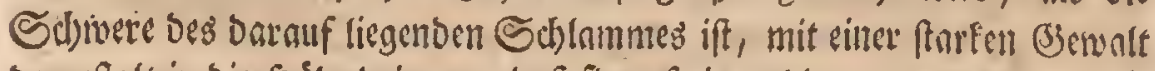
Dergeftalt in bie Shobe oringen, oaf fie auf einmal Den, wegen feiner 3 it: bigfeit feft ameinanber bo̊ngenben, Sd)lamm, ber ụber unt unn ilynen ift,

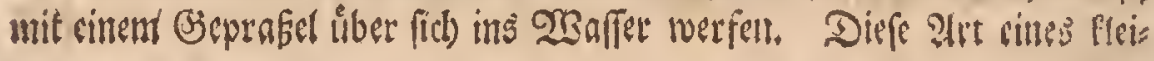

\footnotetext{
* Fig.II. a. III. a. ** c. c. c. "** Fig. I. .k k.* † b.b.
} 


\section{(8I)}

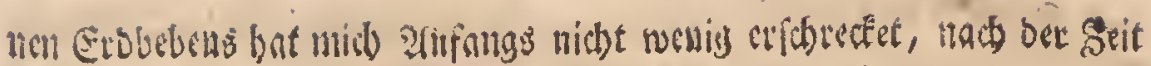

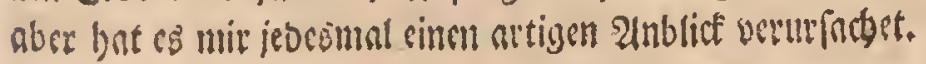

So siel entbecfet ons blobe 2Auge an uno bee biefen Sbiergen. Brits

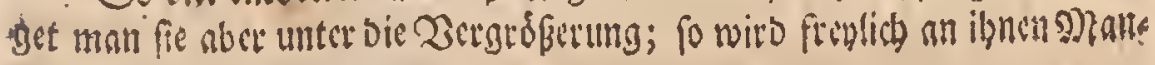

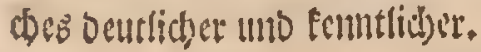

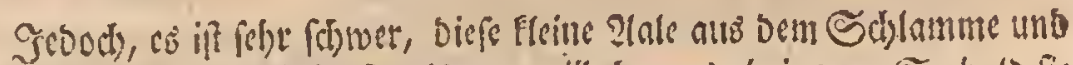
23anfer unversebte, uno fo oft, als man will, hernubjubringen. So babo fie nur im geringfen beriffect weroen, ooer audd nur Die mintiefte Bewegumg

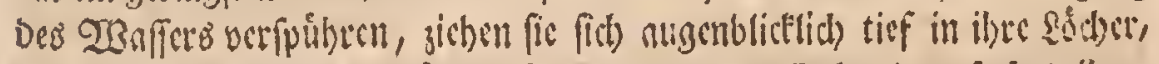

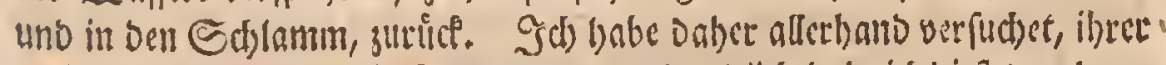

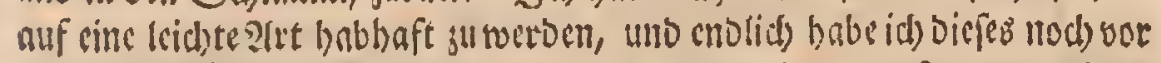

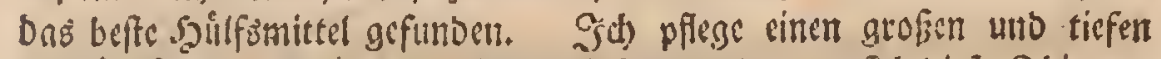

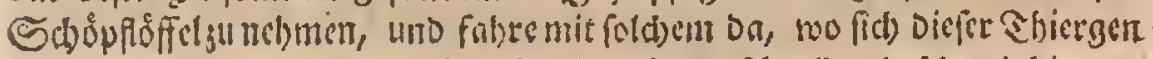

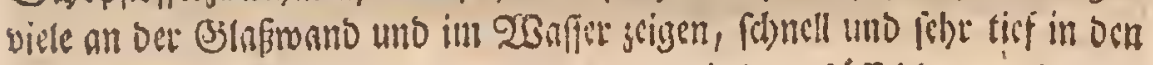

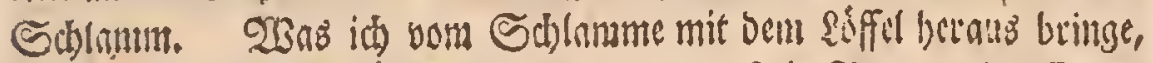

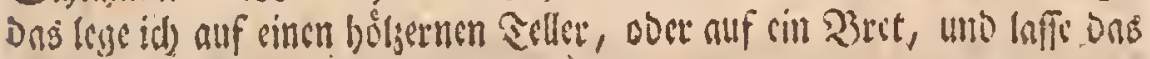

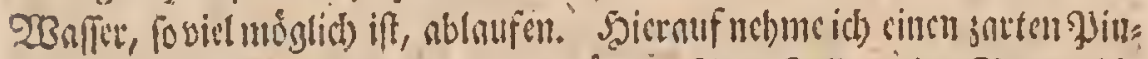

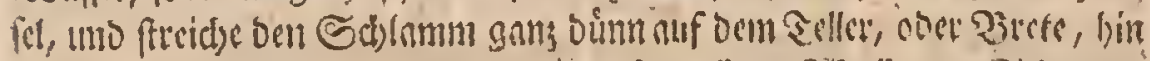

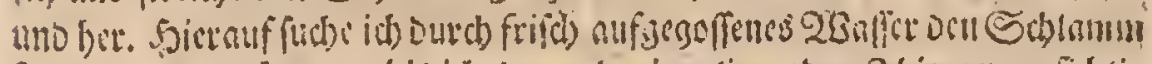

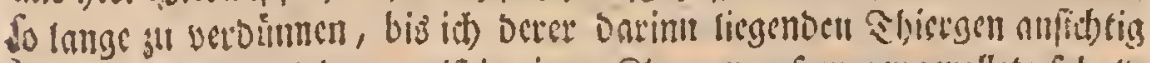

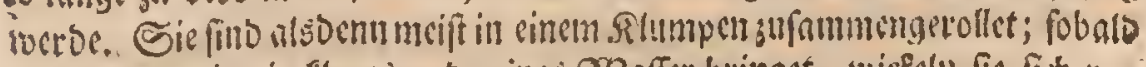
man fie aber in.cin Elares unb reines gzaffer bringet, wiefcll fie fitt won

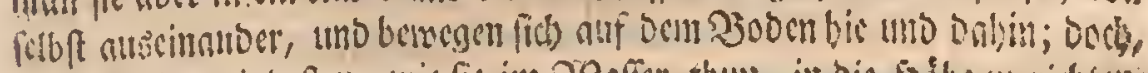

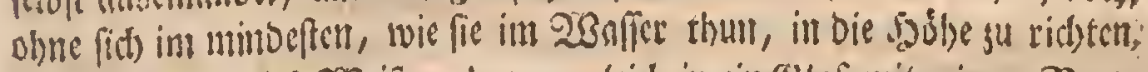

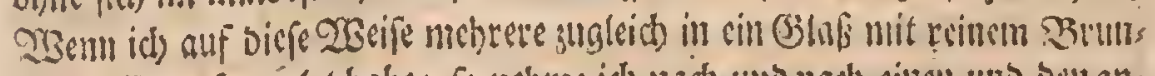

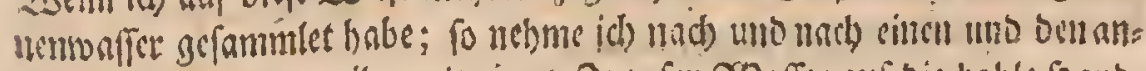
Dern beraus, bringe ith unit einem Sropfen 2 Saffer auf bie boble Sonno, umo befaber ibn folang mit einem naffen \binfel, bis aller Eblanim uno

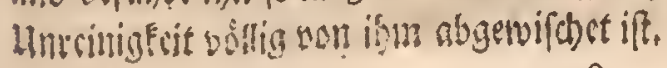




\section{(82)}

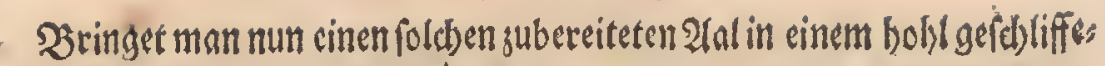

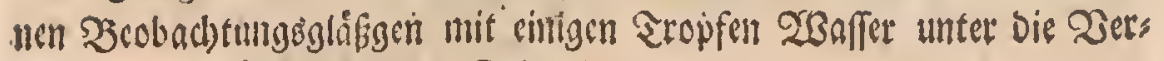
gróbcrung, to entoectect man Folgenver.

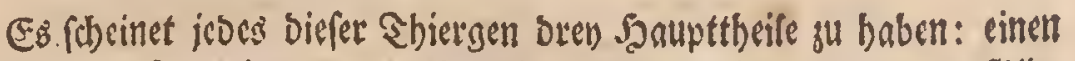

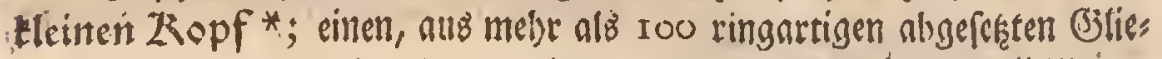
Dern beftebenden, Leib ${ }^{* *}$; wild einen etwas langen Schnonz ${ }^{* * *}$.

Der Ziopf lauft uorn in eine ftumpfe, etwas serwólbte, Spike aus, nlsoemn nber niro (r nacb uno nad) breiter. 2af fon Sciten feben cin pant

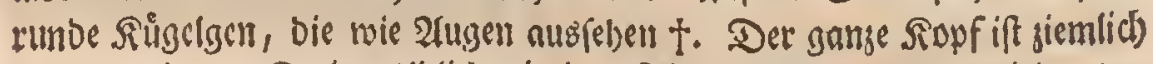
Durdfichtig, all Farbe gelblich), in Der Mitten aber wegen Der vielen, Das felbft fid) befindenten, Eleinen Acbergen róthlich.

গ2adi bem אopfe folget fogleid) Der Leib t†. Er if auf beyben

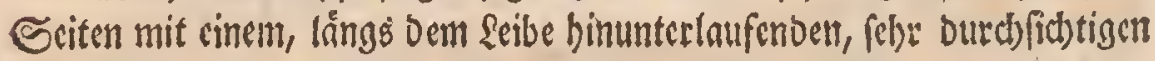
enopfigen unto faltigen ?anbe, Doer Saume, cinscfaffet; oben if er et:

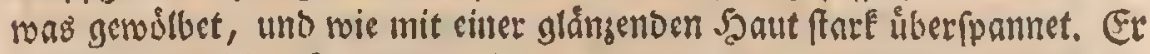
beftetset, wie ich enf gemetbet habe, aus mels als bunbert ringartigen

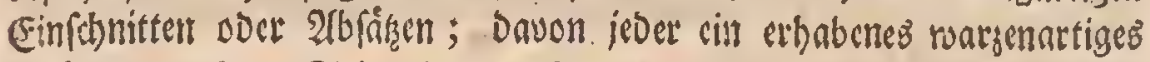

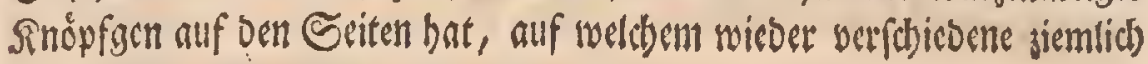
lange Doorfenbare gepeben werben.

Der erfte 2 bbfats ift etwas weniges breiter, nls ber Fopf; bie fols

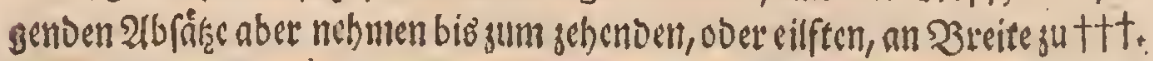
Won biefer fangen bie folgenten wiever Dergeftalt an nad) uno nadl an

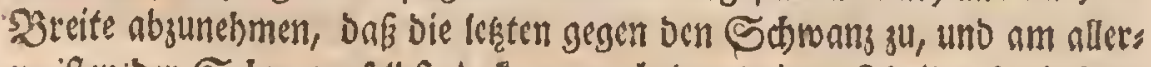
meiften ber Sdswans felbft t, Enum nod) Den britten Sheil so berit fino, nlo ber erfere 2lofás am Ropfe war.

Die

* Fig. II. a. III. a. "* Fig. II. b. b.b. Fig. III. c. d. e. *** Fig. II. c. III.f. Fig. III. b. to to Fig. II. b. b. b. Fig. lu. c. d. e. tto c. c. c. 


\section{( 83$)$ )}

Det 25orftenbaate, bie an ben Sciten auf ben 2 Barzen fteben,

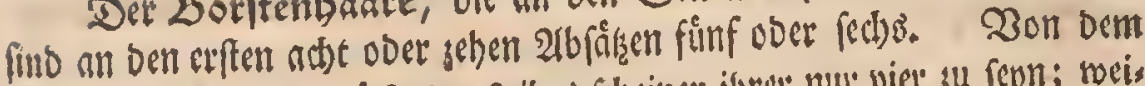

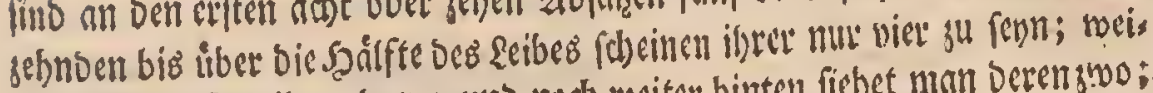
ter binunter fino ilfeer brel); und noch weiter binten fiebet man berengyoo:

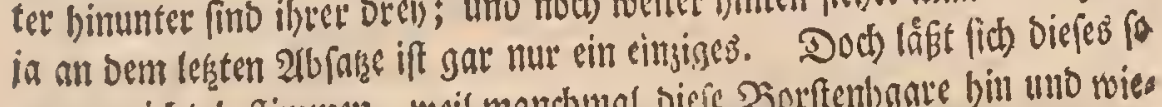
genau nicht beftimmen, weil mandbmal biefe $\mathfrak{b o r f t e n b a n e e ~ b i n ~ u n o ~ w i e s ~}$ Der feblen; und bameben oft to zulammenfleben unb aneinatioer liegen,

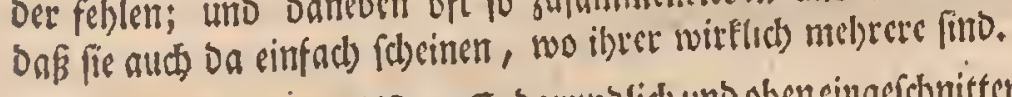

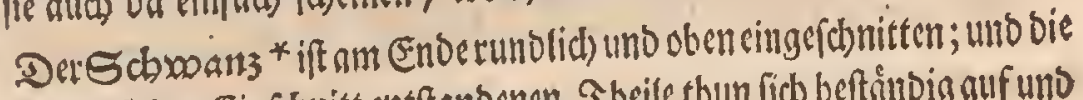

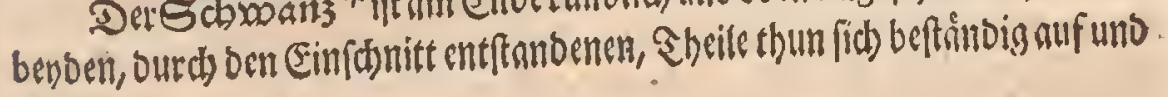
84**.

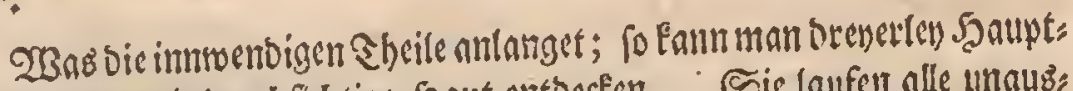

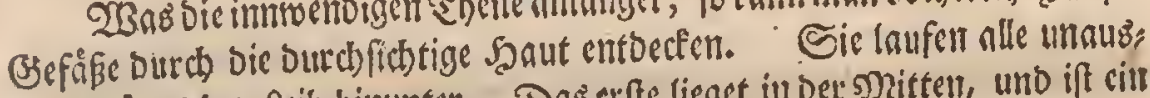

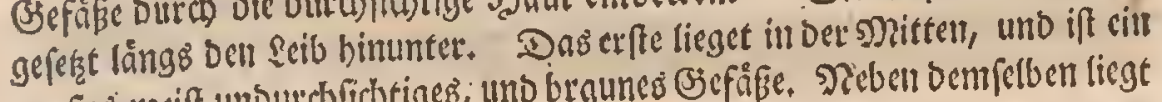

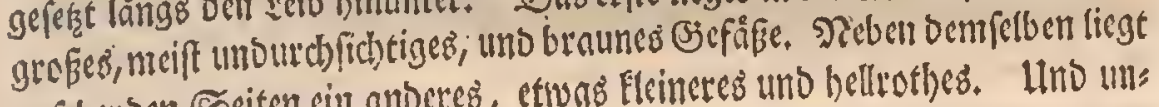

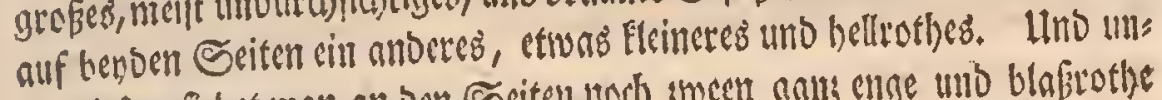
ter biefen fiebet man an ben Seiten nod) groent gang enge unb blafitothe Siange, bie, unter allerbano Firummungen, ibereinanber binlaufen.

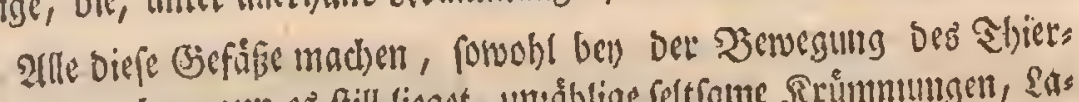

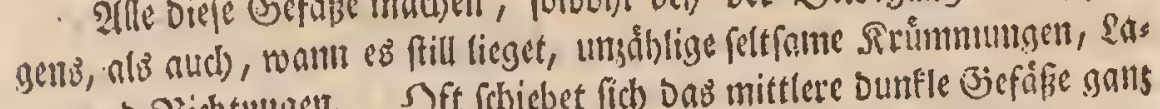

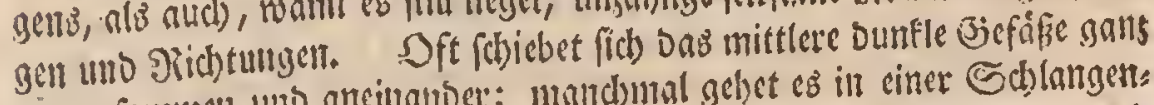

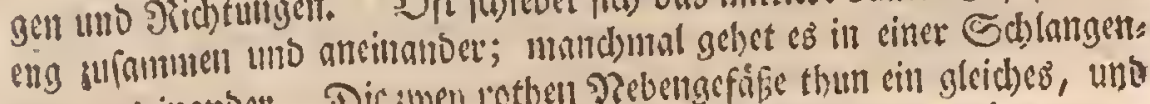

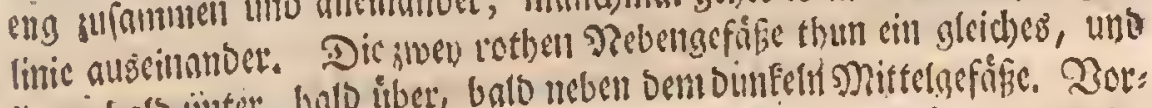

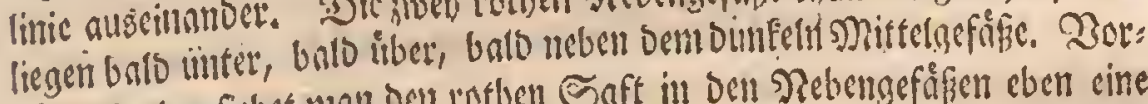
nimlich aber fieber man dent roftlen Sorft in ben Rebengefófen eben eine

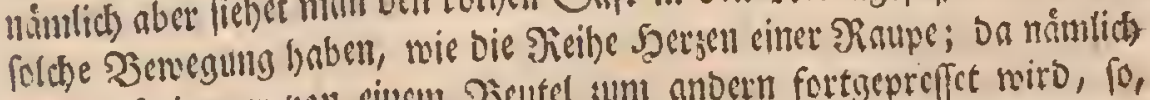

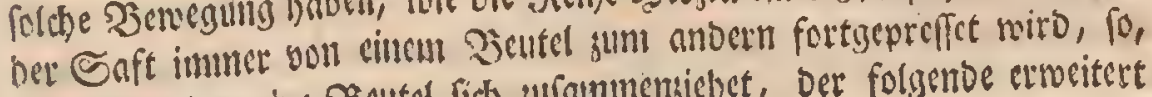

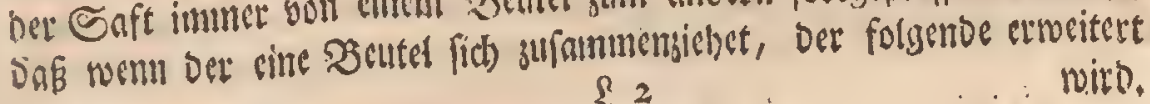
$\{2 \ldots$ wirb.

"Fig. II. c. Fig, VIll, E. ** Fig. II. d. III: g. 


\section{稳 ( 84 )}

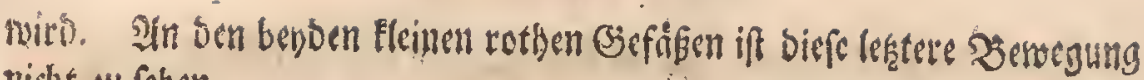
nicht ju fehen.

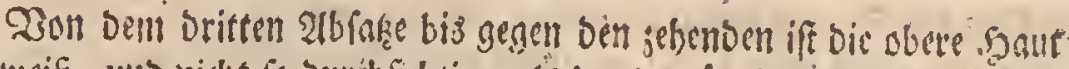
ganm weif, uno nidst fo buresficistig, als ben Den ibrigan Singen. Cis

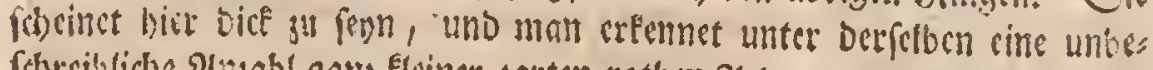

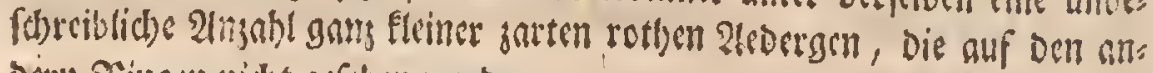
bern Bingen nidst gefeben weroen.

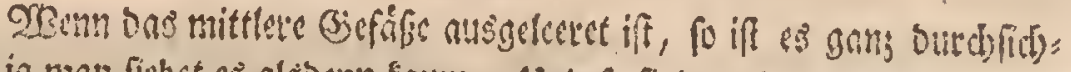

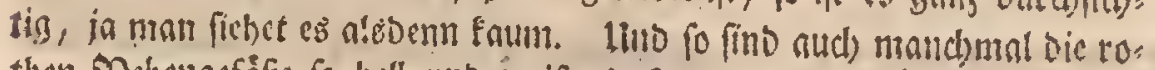

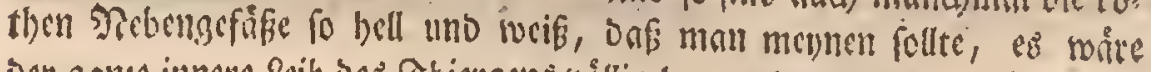

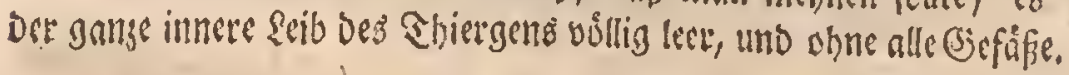

Da fich biefes S biergen, fo lange es lebet, beftindig ansochnet uns

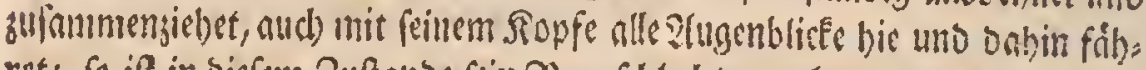

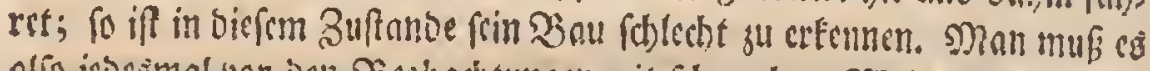

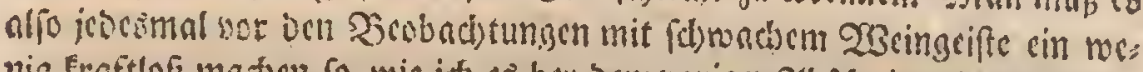

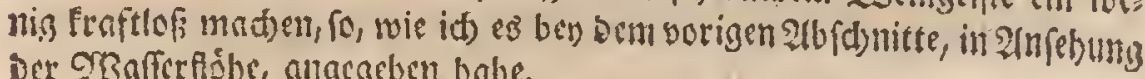
Der çafferfóbe, angegeben babe.

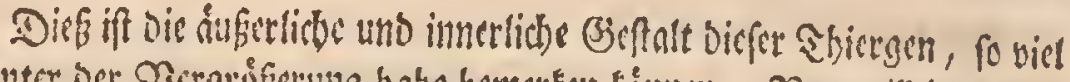

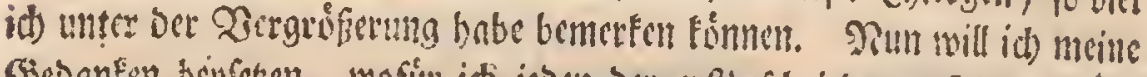

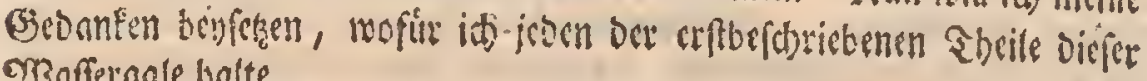
Eafferanle balte.

Da nan aus bem bintern Shrik, wenn fick bie Shiorgen über

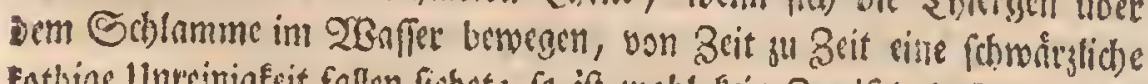

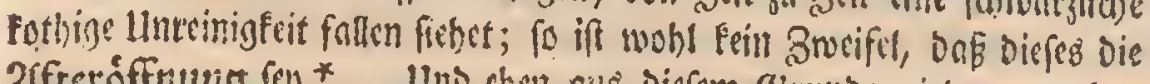

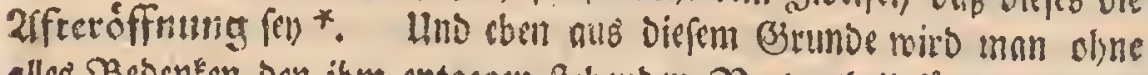
alles Bebenten Den ihm entsegen Pehenoen Dorbentheil fir Den ZKopf

T.Tab. III. Fig. R. 1. 1. II, d. III. g. 


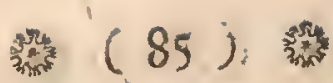

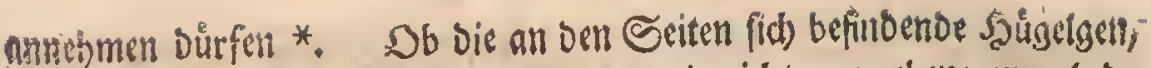

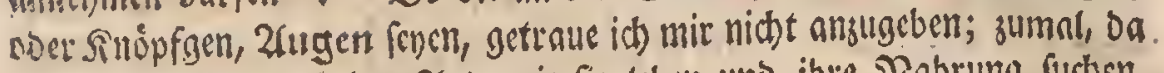

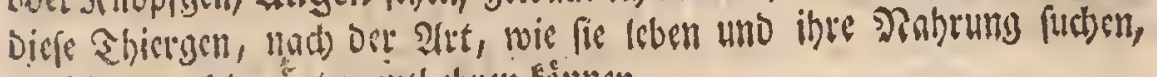
Derfellen noht mögten entbebren Esimen.

Zon Dem

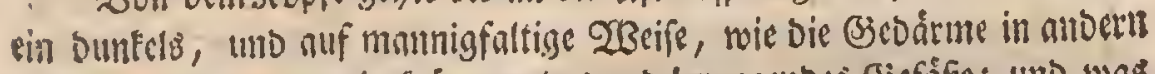
Fhieren, fich wurmartig Erummenoes und benegendes bjefífe; und was

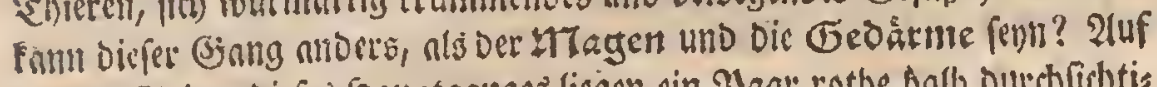

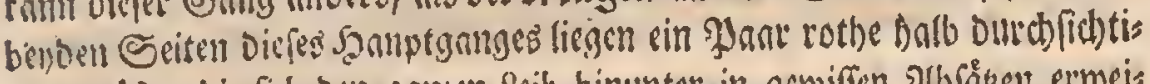

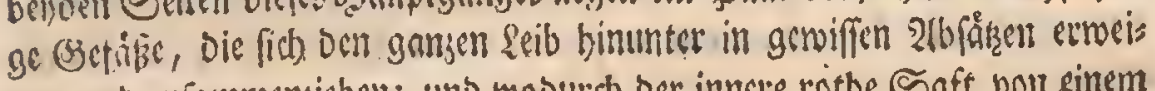
tern uno jufammenjiehen; uno woburdb ber inncte rothe Saft bon einem

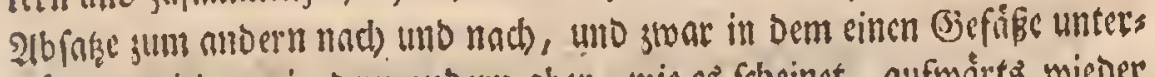

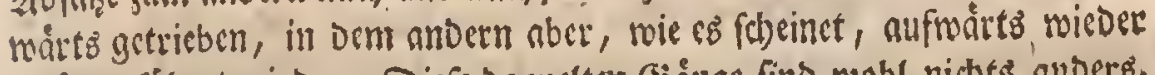

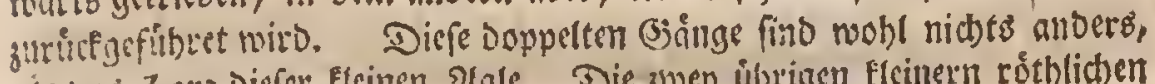

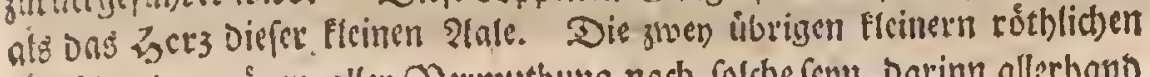

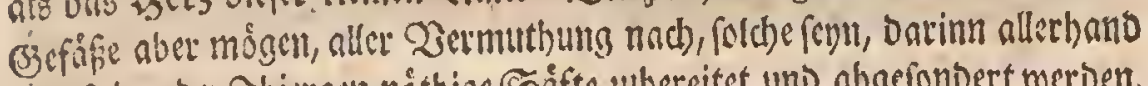
fum Scben ser Shiergen nóthige Sófte zubereitet uno abgefondert werben.

Die oben beidbricbenen Zorfen bienen wabrideinlidb oen sbiergen firl) in Dent Sdlamme und in Der Sicfe, oocr in einer gerviffen Stellungr

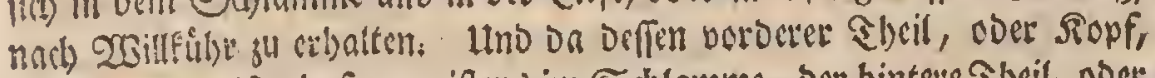
Daju gemndt) iff, Onf er.uncifen im Sd)(numme, Der hintere Sbeil, obet

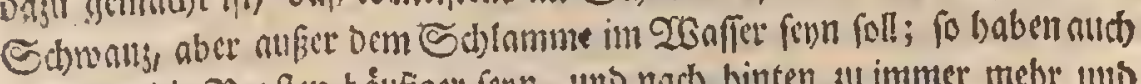
an jenem bie Borfen båufiger fenn, und nad binten zu immer metst ullo methe abnctymen múffen.

Do biefe Shiergen, wie ith bnto melben werbe, fich feltrftare fert:

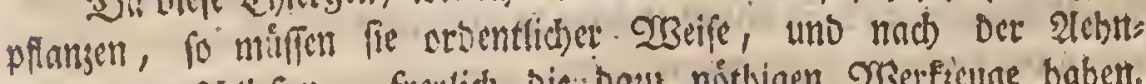

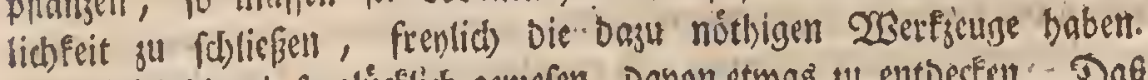

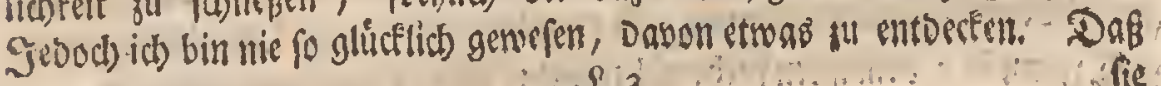

? Tab.Ill. Fig.u. a. IlI, a. 


\section{$(86)$ (}

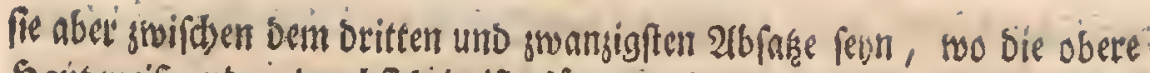

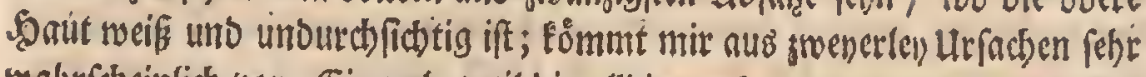
roalserbeinlich vor. Einmal, weil bic allhier mebr, alo an einem Sorte ber

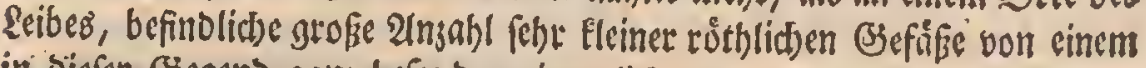
in biefer Begeno gam befondern innerlicten ßanue zeigen. Sobann, weil fich bon ben Regenwirmeen, an welden audh um biefe (Ses: gento bie Beugungsglieder angetroffen werben, gat wobl nuf biefe 23 af

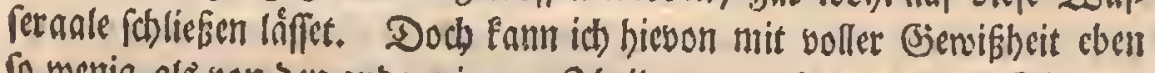
fo wetrig, als yon ben anoern innern Sheilen etwas fagen; Deren fít), allet

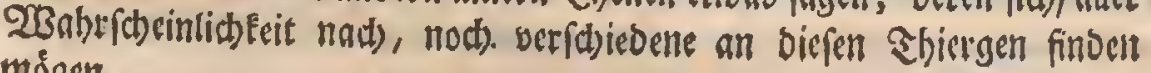
mógen.

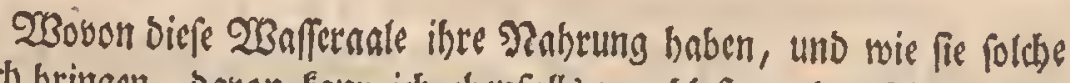
in fich bringen, Davon Fann ich ebinfallz nut blof muthmaflich reben; indem id) an Dem vorbern Theile, oder Fopfe, nientalbeinet Seffnumg, ober audb) nur einer foldsen ßrewegung geroabe worber bin, oap ich eine

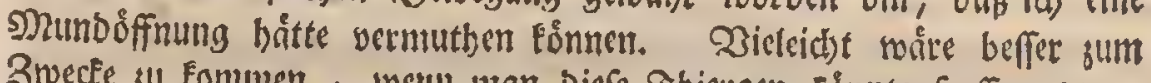
Brecte su Eommen, werun man Diese Ebjergen E\&nnte freffert feben.

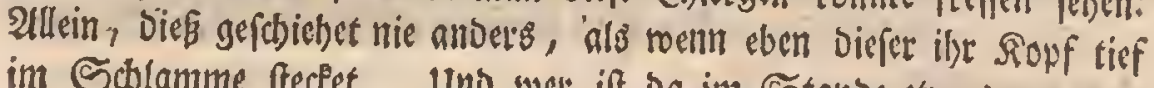

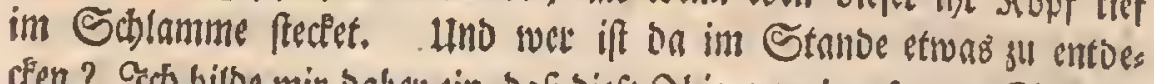

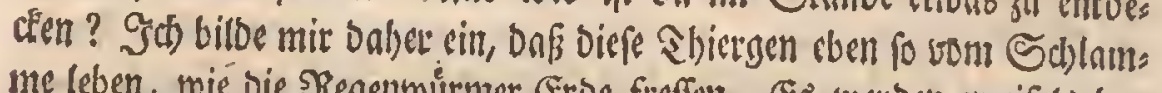

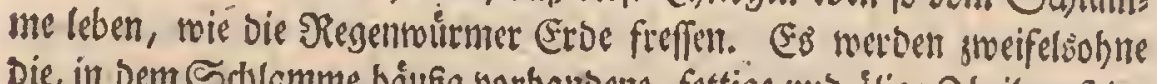
Die, in bem Sd)lamme båufis vorbanberte, fettige unt slige Sheile erft int Seibe felbft jur. शrabrung abgefondert. Denn weln fie bic nothigen શab:

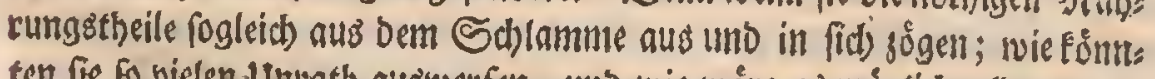
ten fie fo vielen Uturath) ausiverfen, uno wic wire es móglich alles fo gec

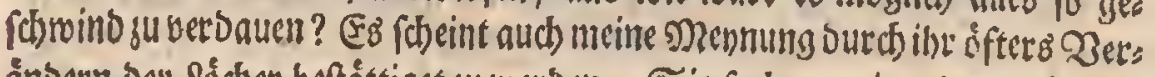
änoern ber \&ócher beftáttiget su weroen. Sie puchen, wie mir vorfónmmt,

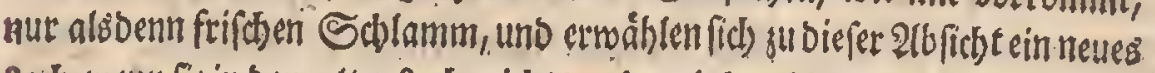

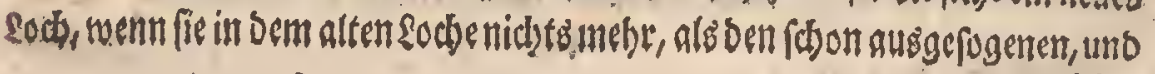

niebri: 


\section{(87)}

wieber von fich gelaffenen, Llmeatl) vor fich finber. 2 bie aber ber augges fogene शralstungefaft vere̊ndert, und Durth welche $23 e g e$ und (3efáfe er

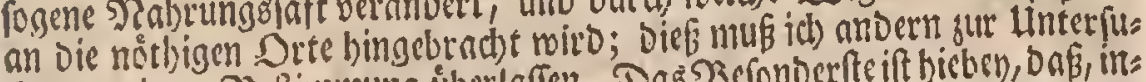

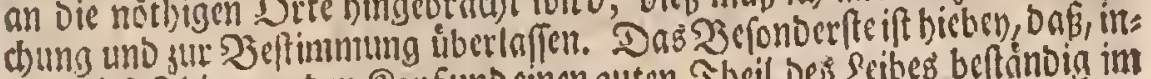

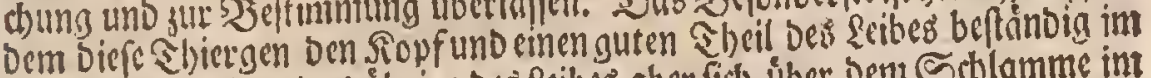
Schlamme baben, ias úbrige Des \&eibes aber fid úber Dent Solamme int

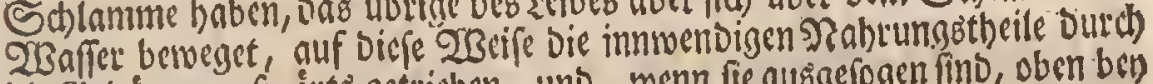
Die Sebárme aufwárto getrieben, uno, roenn fie ausgefogen fino, oben bes) Dem affer ausigeroorfon werben.

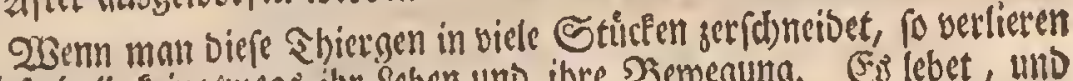
fie biefarbalb Eeineśnegs ibr geben und ihre Beroegung. Es lebet, unt berweget fich, aud) nadber ein jeoes Stricte fiu fich fort. fåfet mant die zerfdunittenen Etucte in lauterm 2 baffer liegen, fo ferben fie ltach einigen ₹agen $a b$, Dns cine eher ober fpater, als bas onbere. eeget man fie aber nuf einen Sdblamm, úber weld)en 2 Baffer genoflen ift, to begeben fie fid) fogleids in Denfelben, unb man wiro auf bicfe $23 e i f e$ viele

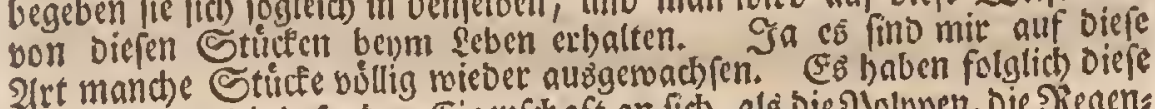

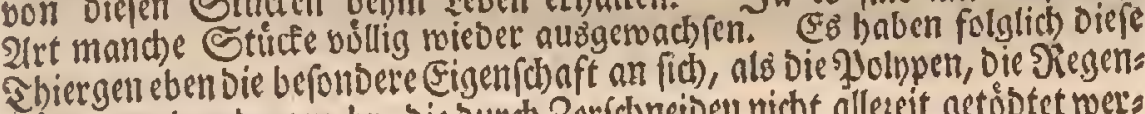
wurmer unb anbere mebr, bie burd) Ber(d) neibent nicht alleseit netobtet wen:

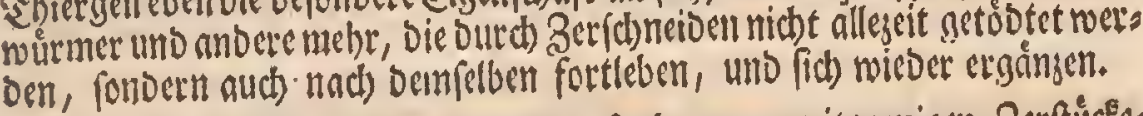

Da es mir indes nicht mit allen, fonbern nur mit menigen, Berftectes lungen gelingen wollte, baffie in oem, ihnen befonders gegebenen, Sodlanme fortgelebet uno fid) ergónget bátten: fo fomte id nid)t nmber's benfen, als oaf id) fie felbft Daran muffe sehindert baben. Sob verfutebte es baber auf

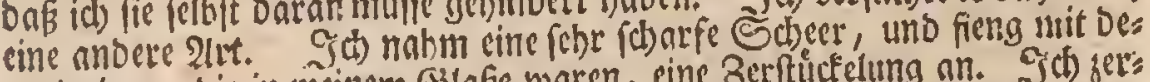
nenienizen, bie in meinem (J)lnke waren, eine Berftucfelung an. Jich fers: fdnitte unzablige, wern fie fid) cben nus ben gedjern berausbegeben hats ten, fogleich unter bem 2 Baffer, uno úberlief fre alsoenn ibrent Schictiale. Die sbeile, fo inz 26 affer gewefen roner, fielen auf oen Schlamm, uno sourben in Demielben unfichtbar; Der úbrige Sbeil aber zog fith gan:

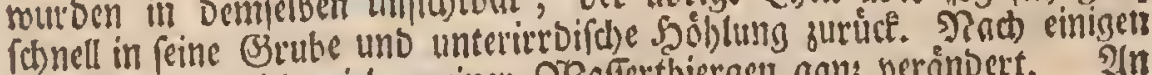

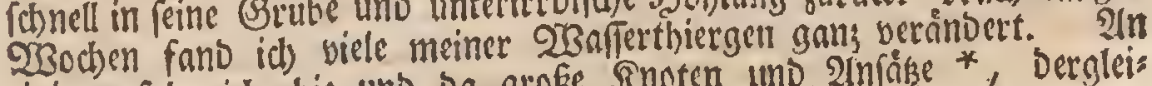

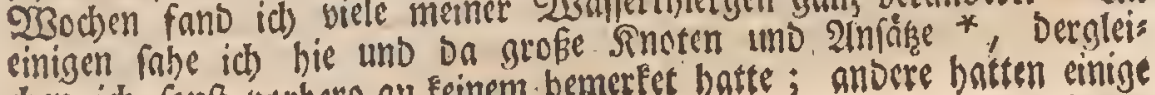
den id fonft burbero an feinem bemerfer batte; anbere bntten einige

Fig. I. g. 


\section{繁 (88)}

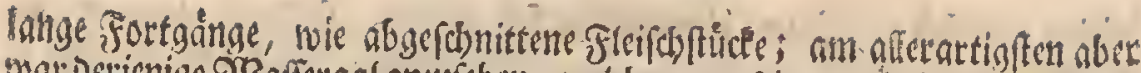

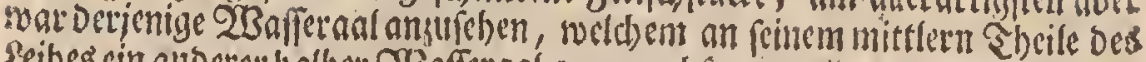

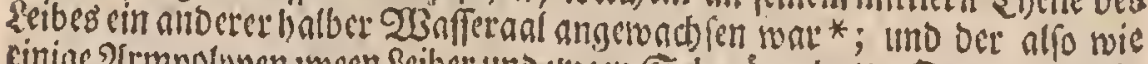

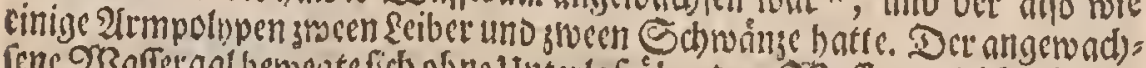

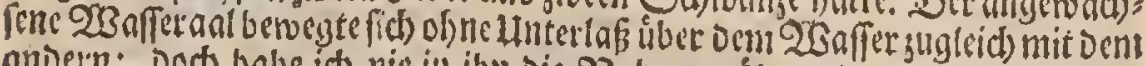

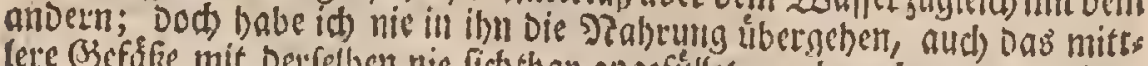

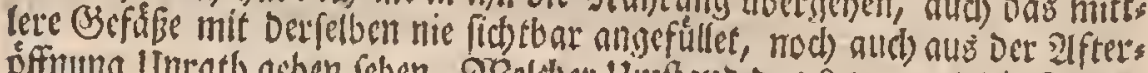

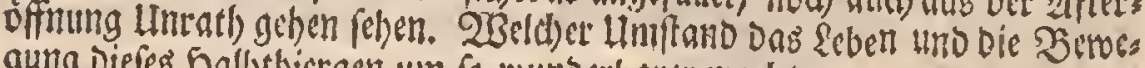
gung Diefers. Sallbethicrgen un fo numberbarer mad)te.

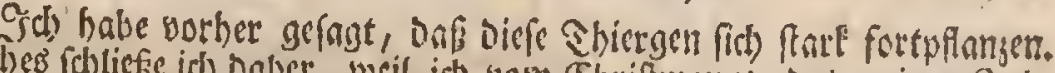

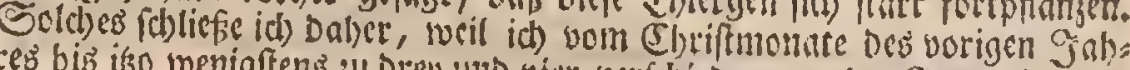

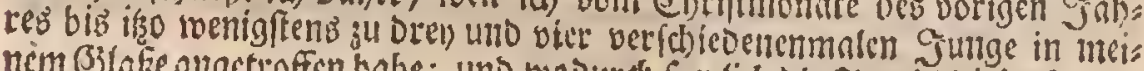

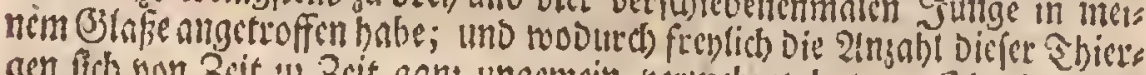

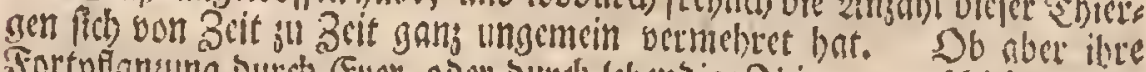

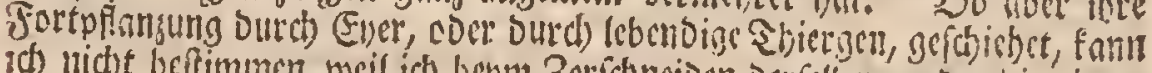

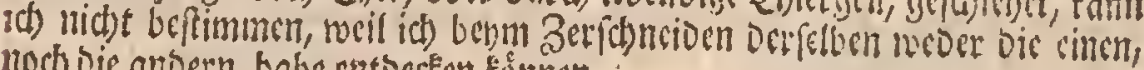
noch bie antern, babe entocéent fóment.

Diefes aber meis idh, bnf biefe 23 afferthiersem, wie bie 23 affer:

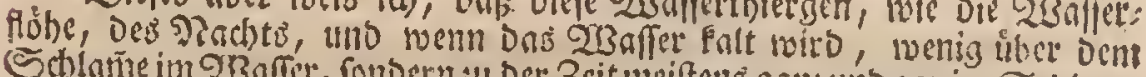

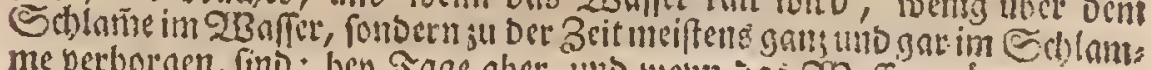

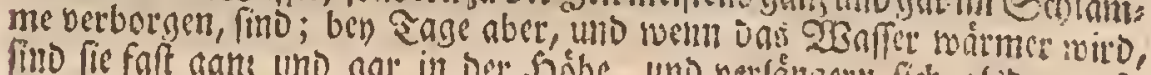

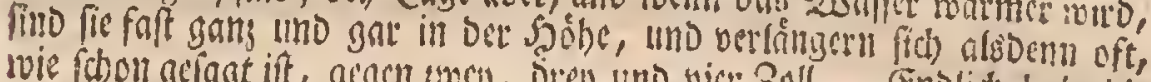

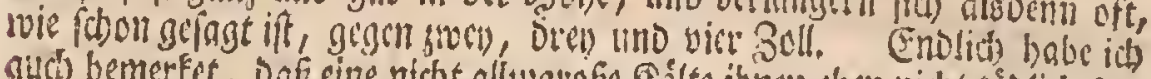

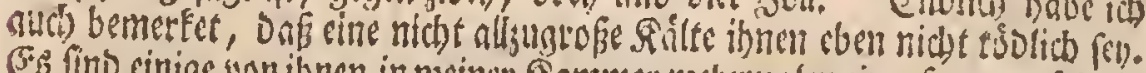

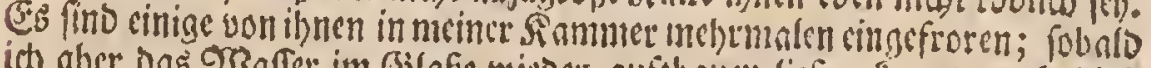

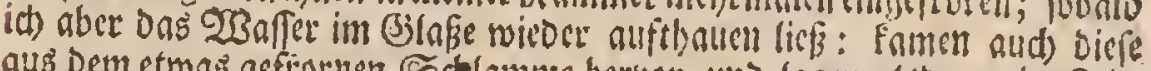
aus Deme etwas geftornen Scthmme beryor, uno lagen alsoenn eine 3eit,

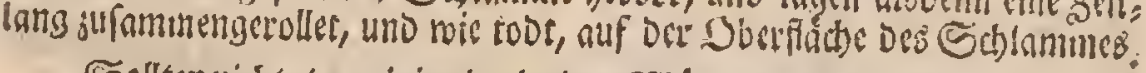

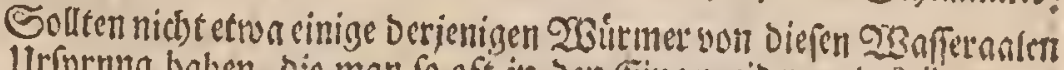
ifren lirfpernts baben, sie man fo oft in Den Eingetweiden uno Scibern Der

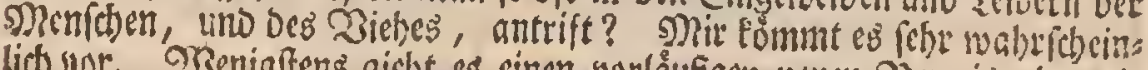
lic) vor. 23entigftens gicbt es cinen yortåufigen neuen $3 e m e i s a b$, wie

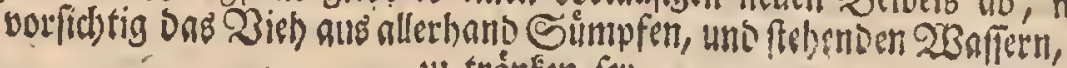

* Fig. I. h.

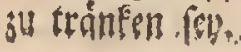

Ertfla: 


\section{(89) \\ Githlatututg Det situfertafeltr. \\ Die elifte Taffl.}

Sitg. I.

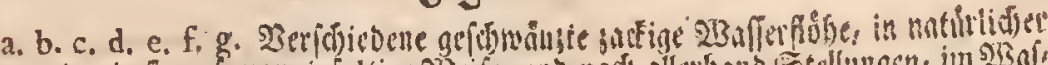

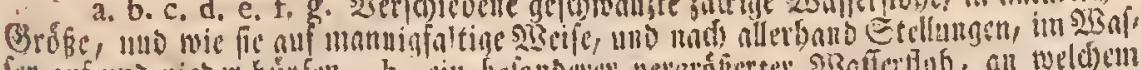

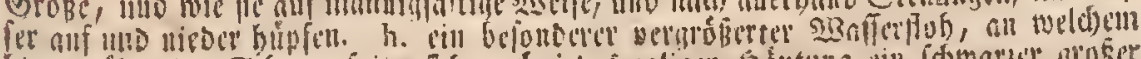

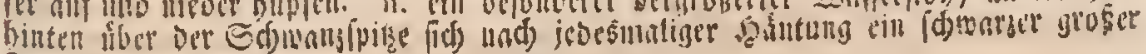
slect gesciget bat.

fig. II.

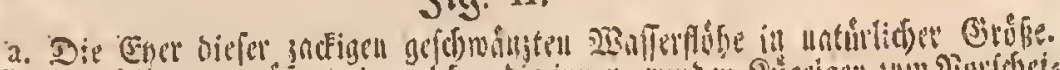

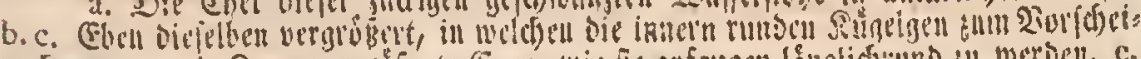

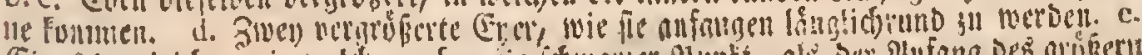

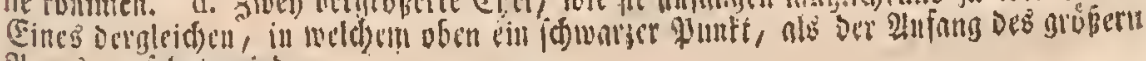
Inges̀, geicbeil wiro.

Sig. III.

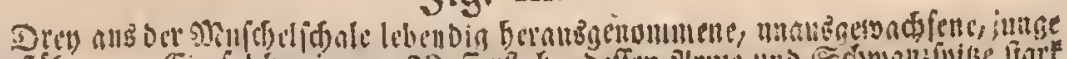

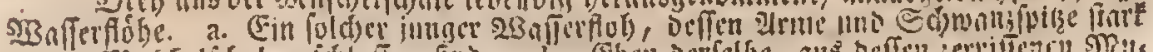

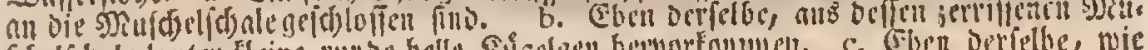

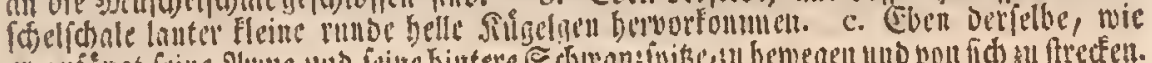

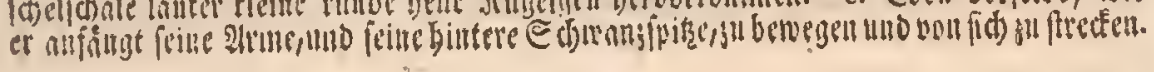

\section{fig. IV.}

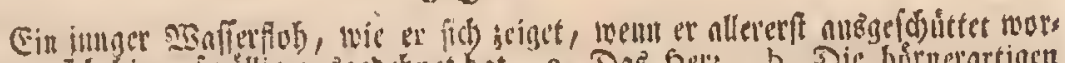

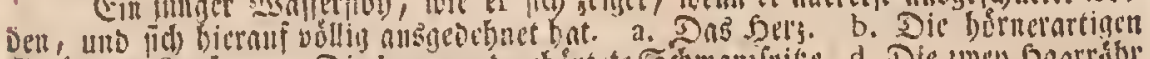

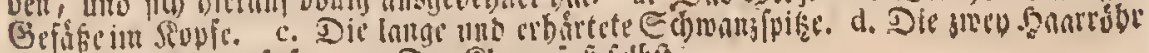

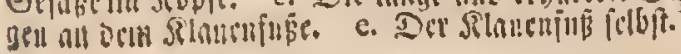

\section{fig. V.}

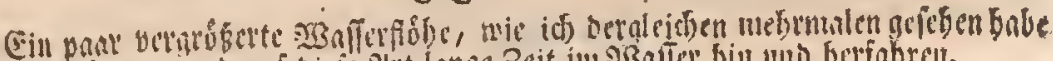

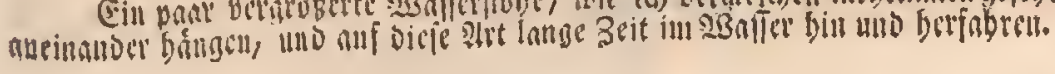

\section{Sig. VI.}

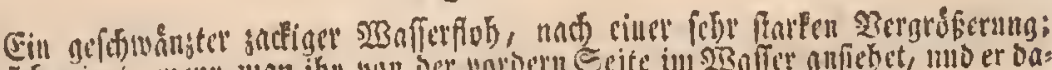

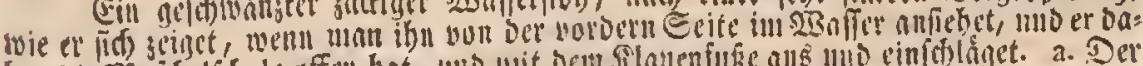

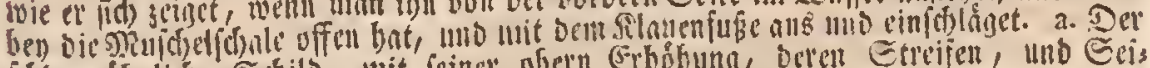

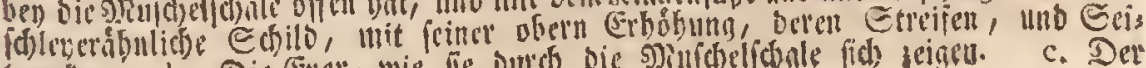
reterten.

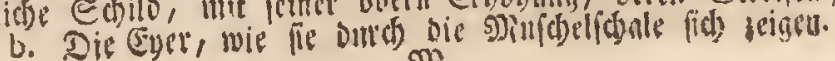
ख? c. Der

Silnuten: 


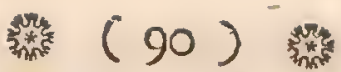

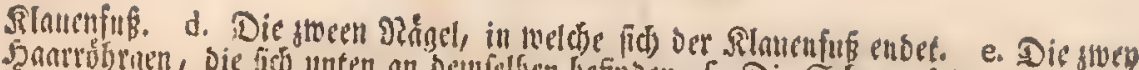

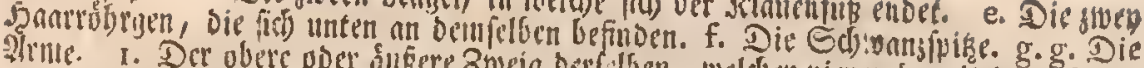

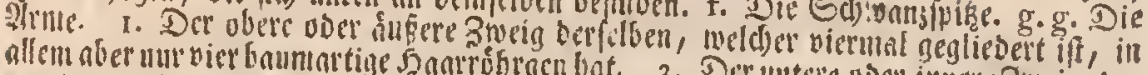

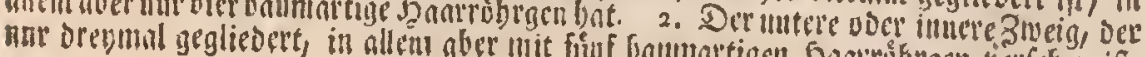

fig. VII.

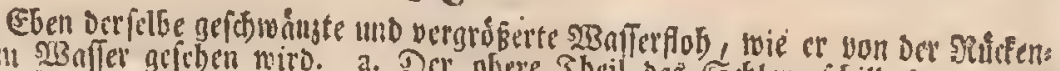

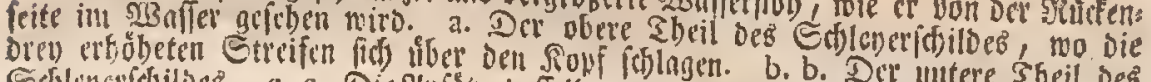

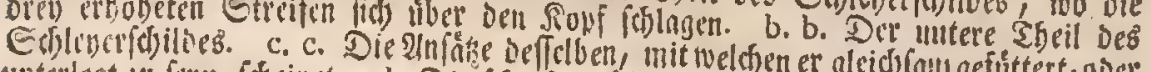

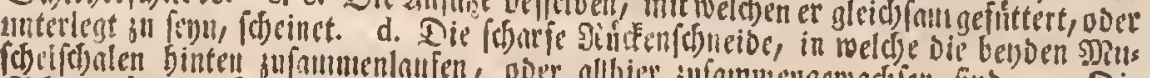

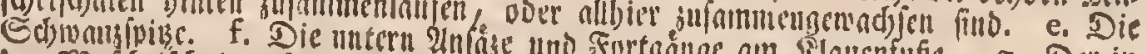

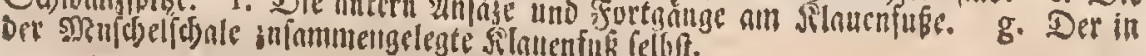

Sig. VIII.

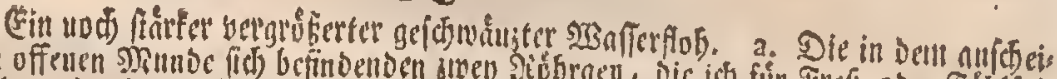

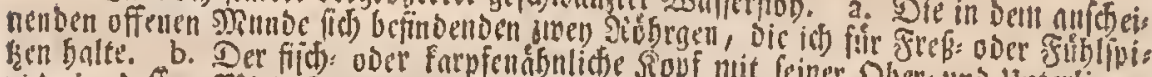

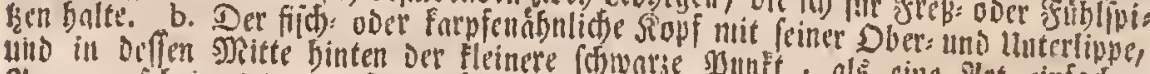

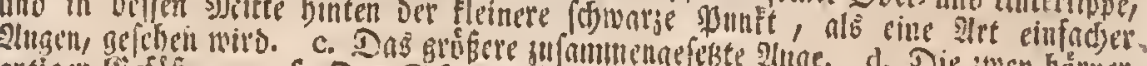
arfigen Befitze. e. f. Der Ecileserfósito.

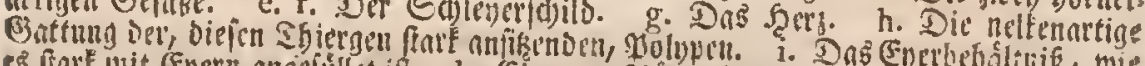

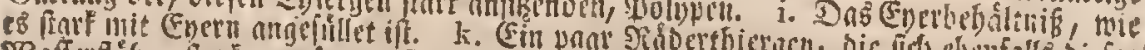

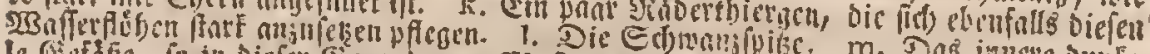

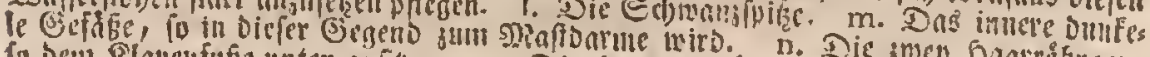

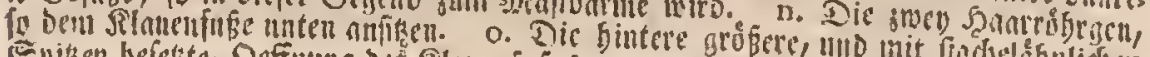

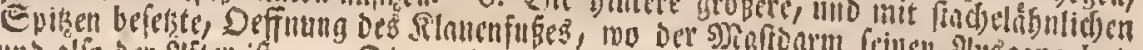

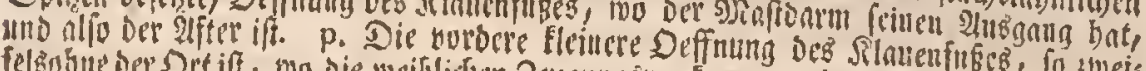

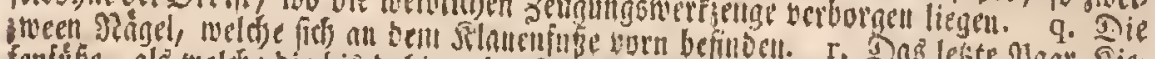

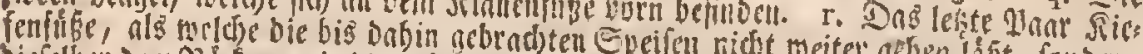

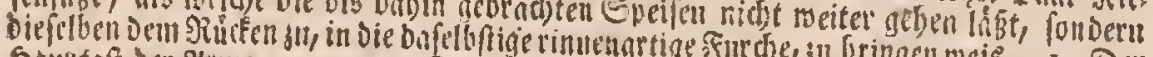

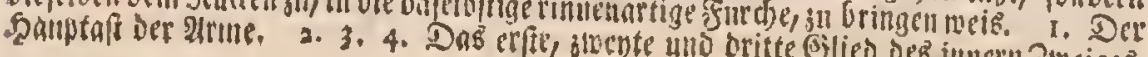

fig. IX.

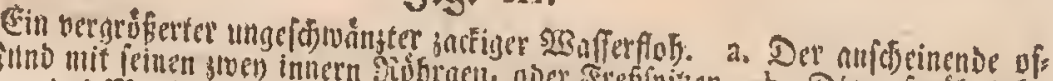

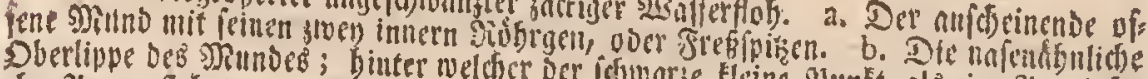

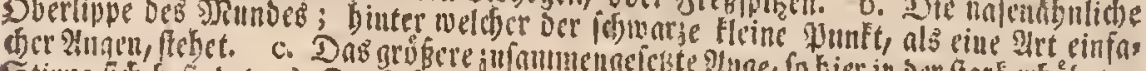

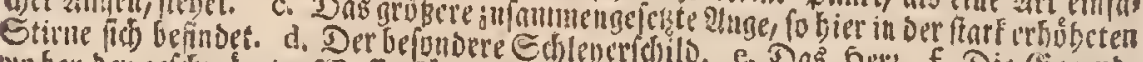

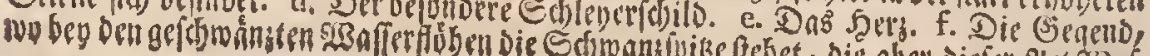




\title{
(
}

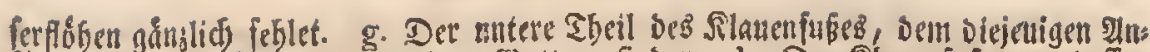
fäke feblen, die fid) beu Der andern Sintung finden. h. Det Rlauenfus, und Deflen yaroere s?âgel.

\author{
fig. X. XI. XII. XIII. XIV. XV.
}

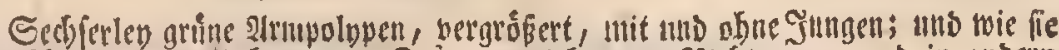

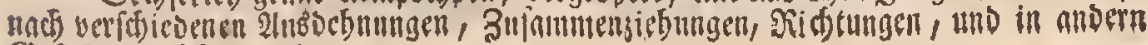
Befitalten/geichen werben.

\section{Die zweite Tafel.}

\author{
fig. I.
}

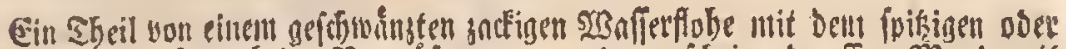

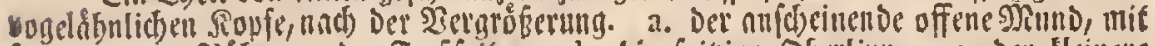
feiten innern Sióbren, oder Frebfuigen. b. bie fuitzige oberlipue. e. Der lleinere

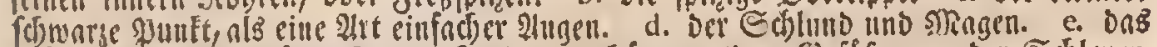

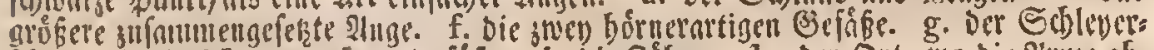

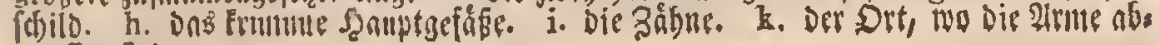
geriffer find.

fig. II.

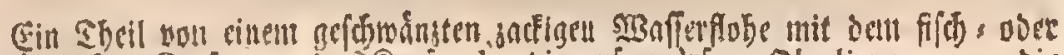
farpfentigntidjen Sopfe. a. ber" Sopt. b. bie aufgenorfene oberlippe. c. c. Die

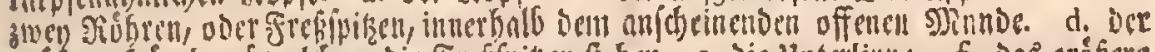

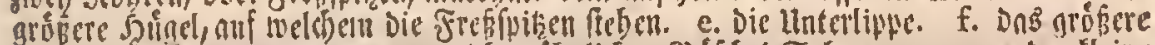

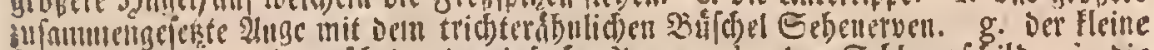

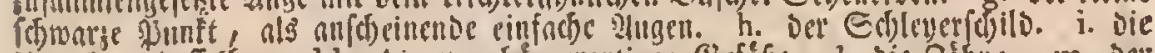
ulnterlnge Deffetben. kk. Dic zmo burnerartigen Giefáge. 1. bie 3ibne. $\mathrm{m}$. Det

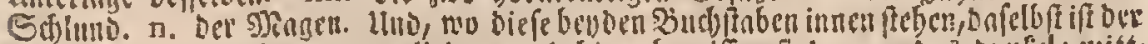

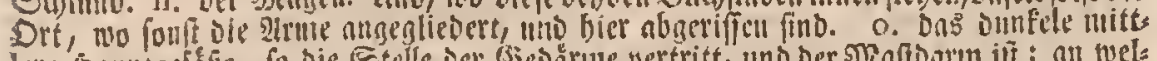

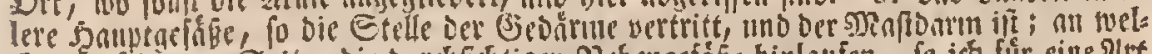

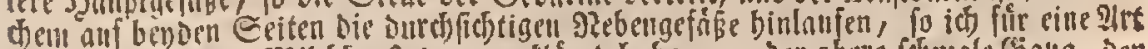

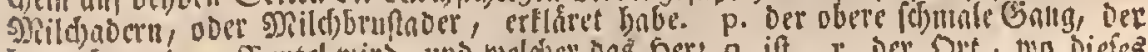

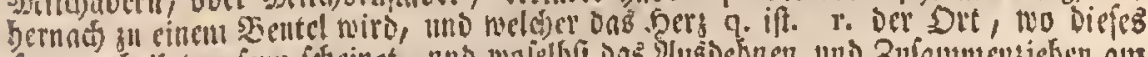

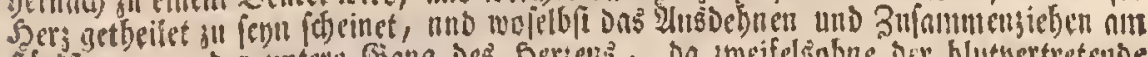

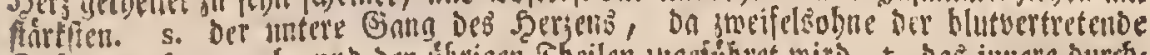

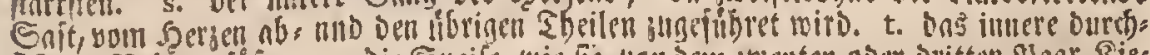

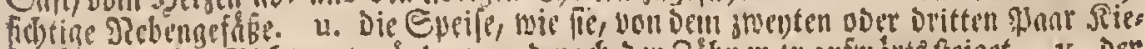

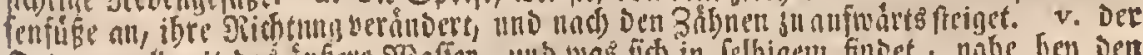

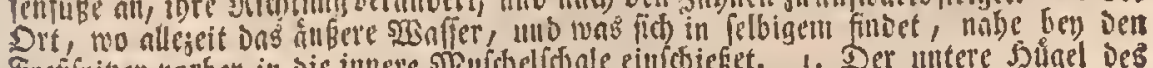

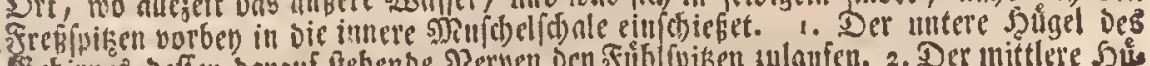

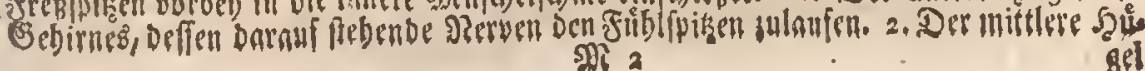




\section{(92)}

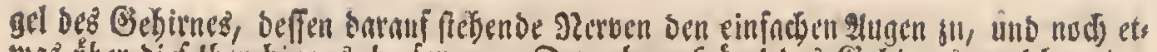

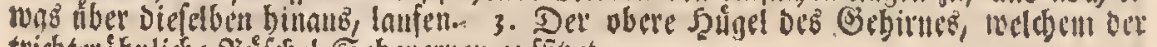

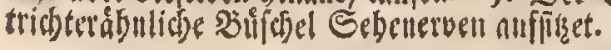

\section{fig. III.}

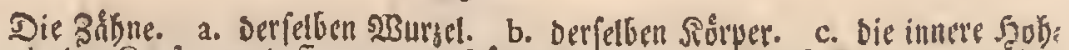

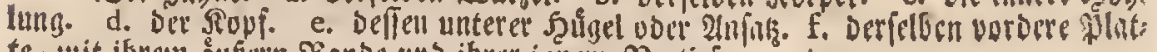

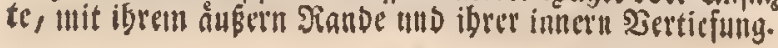

\section{fig. IV.}

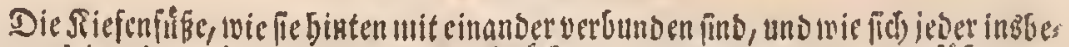

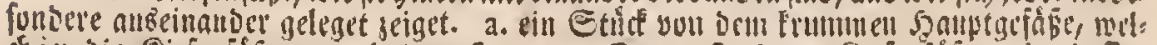

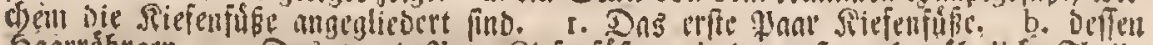

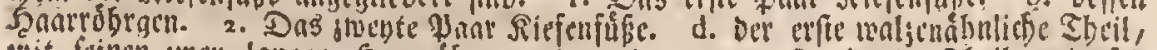

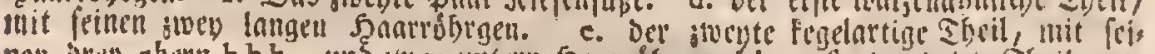
nen br't obern hh h, und wen untern sgarrobrgen i.i. f. Der oritte sbril, mit

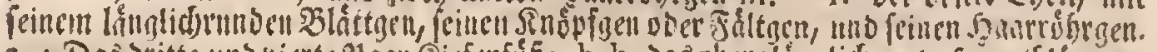

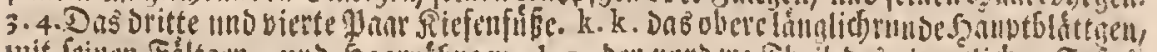

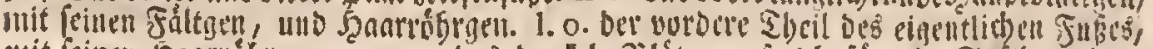

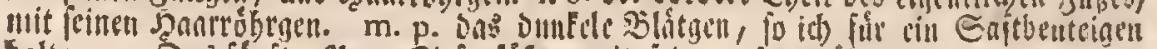

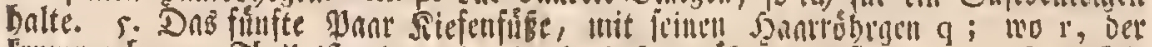

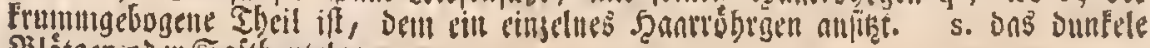
Slåtgen voer Eậtbeutelgeu.

\section{Sig. V.}

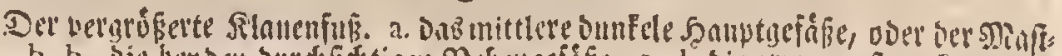

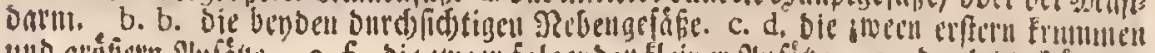

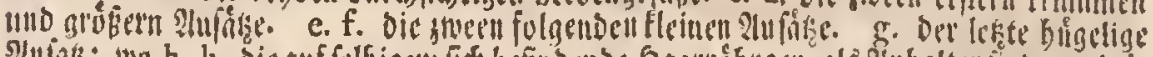

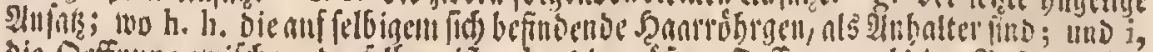

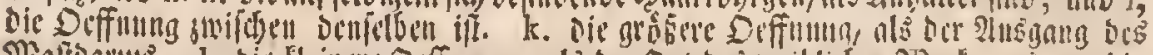

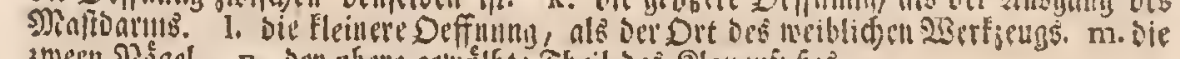

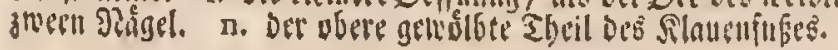

\section{fig. VI.}

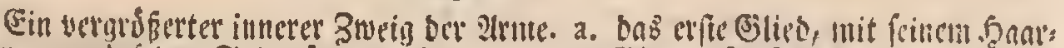

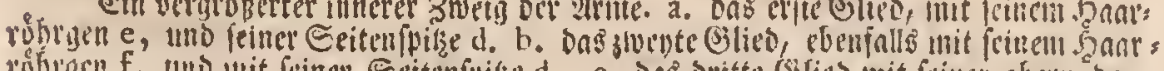

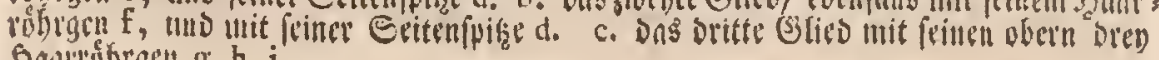
santribergen $g . h . j$.

\section{fitg. VII.}

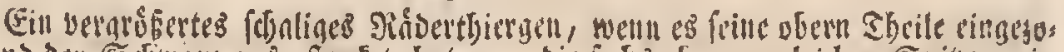

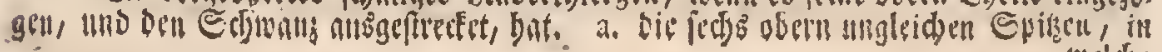
weldicic 


\section{(93)}

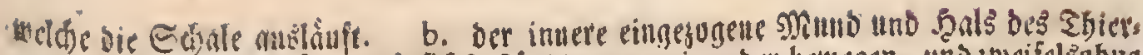

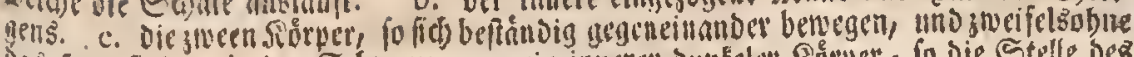

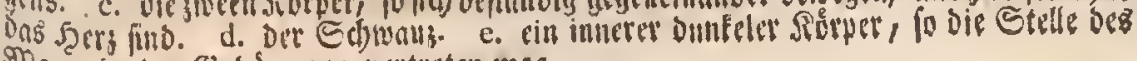
9hingens, Der Gesdrulle ze. vertreten mag.

\section{§ig. VIII.}

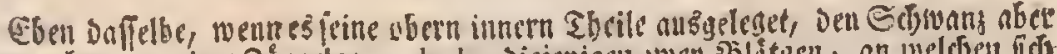

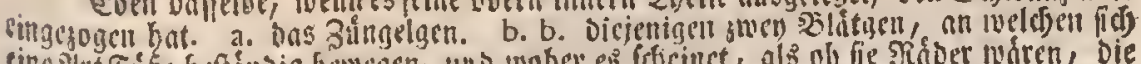

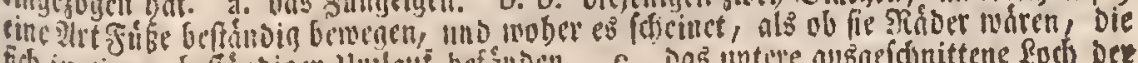

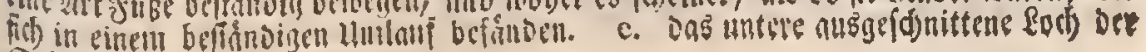
Eshalt.

\section{Sig. IX.}

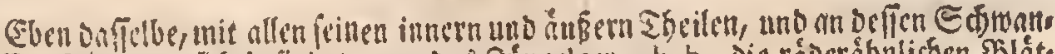

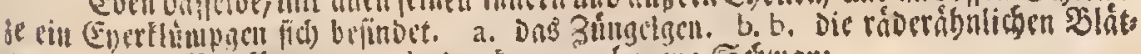
gen, c. Der Everthumen. d. Des Erutrigebogene Eegmans.

\section{fig. X. XI. XII.}

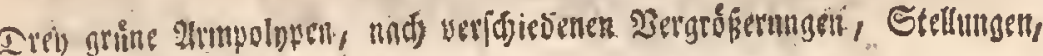
tind 23 entumgen.

\section{- Sie stitte Tafel.}

\section{Sig. $\mathbf{1}$.}

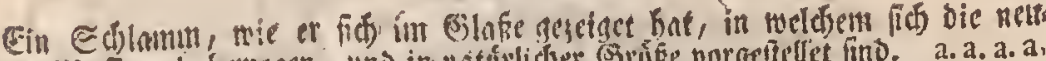

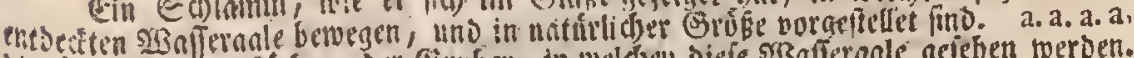

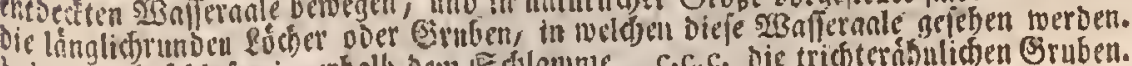

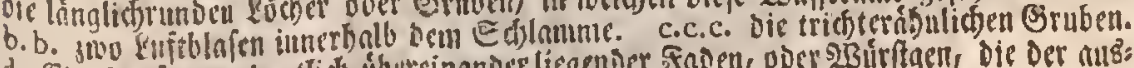

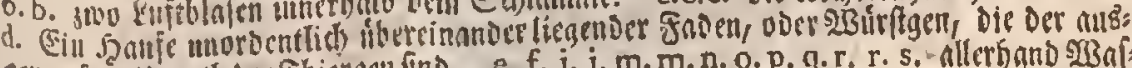

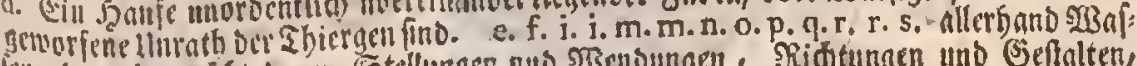

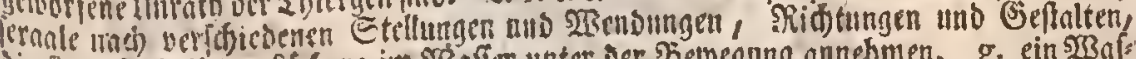

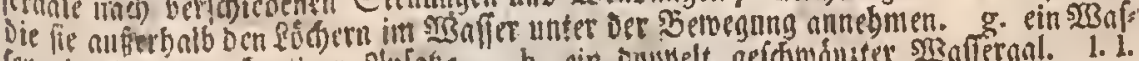

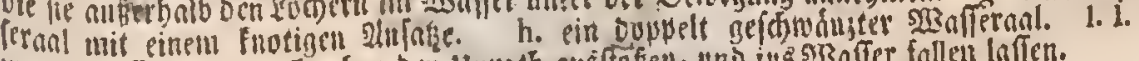

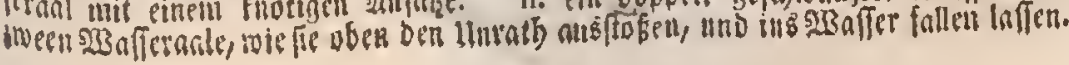

fig. II.

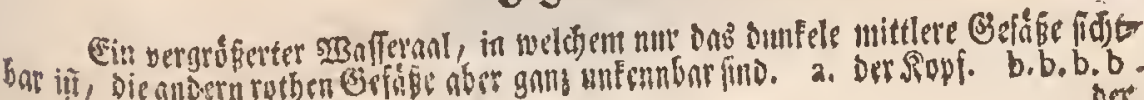




\section{(94)}

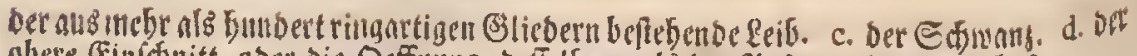

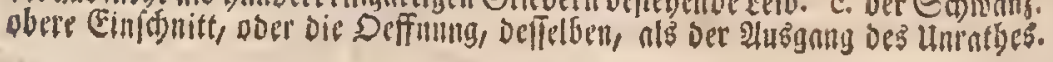

\section{fig. III.}

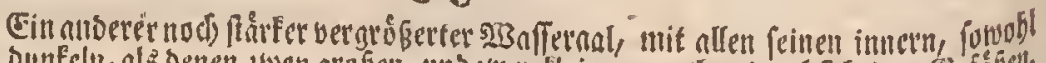

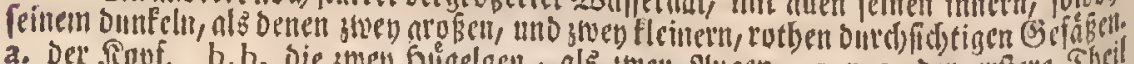

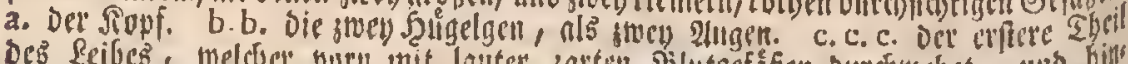

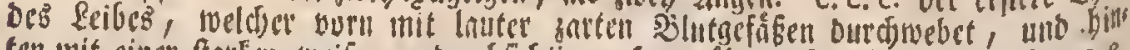

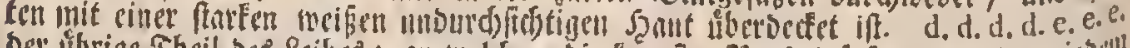

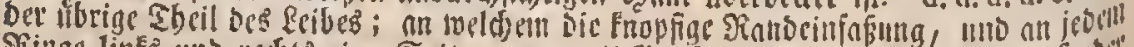

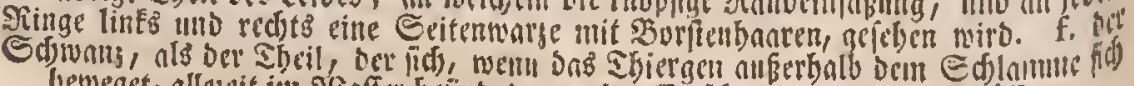

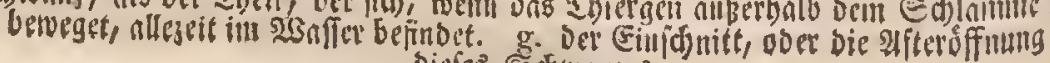
Diefes Édjwantcs.

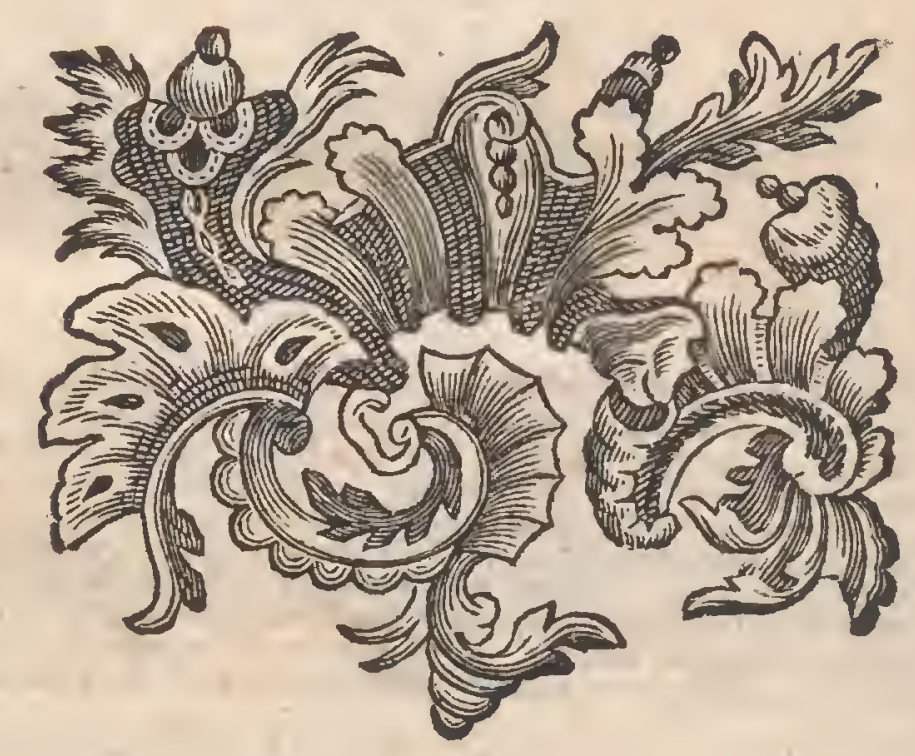




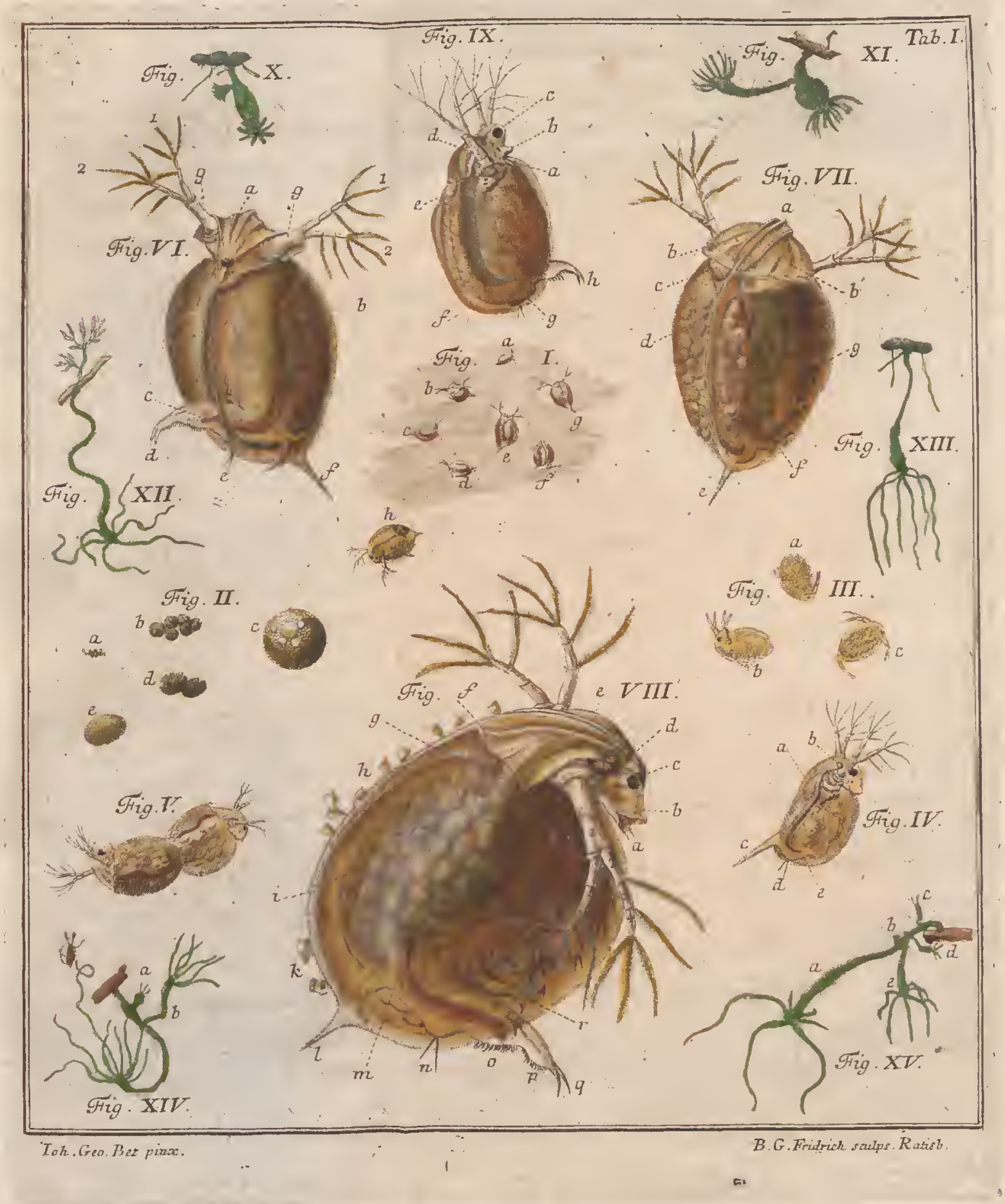





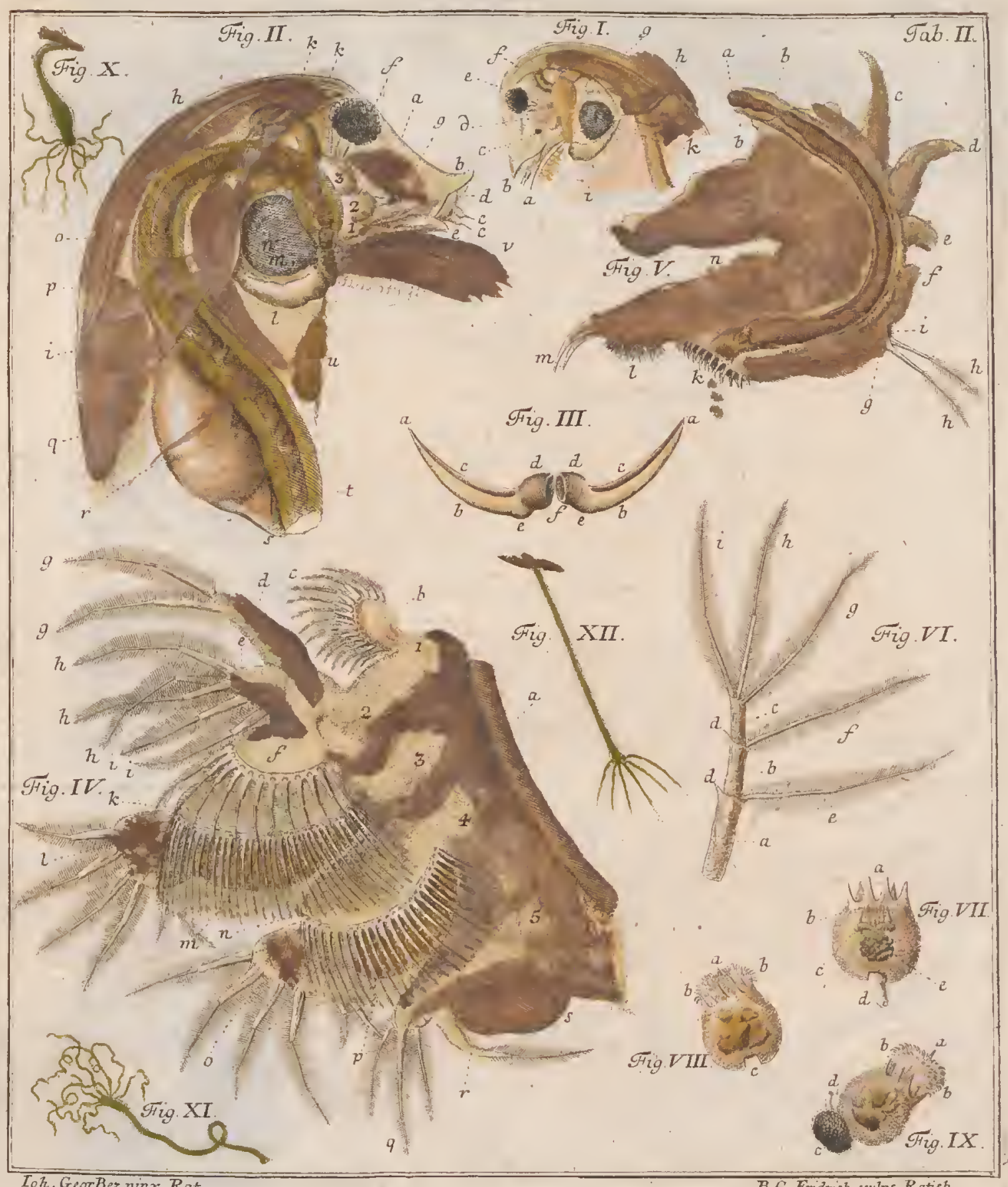

Be Fras sules Ratisb 



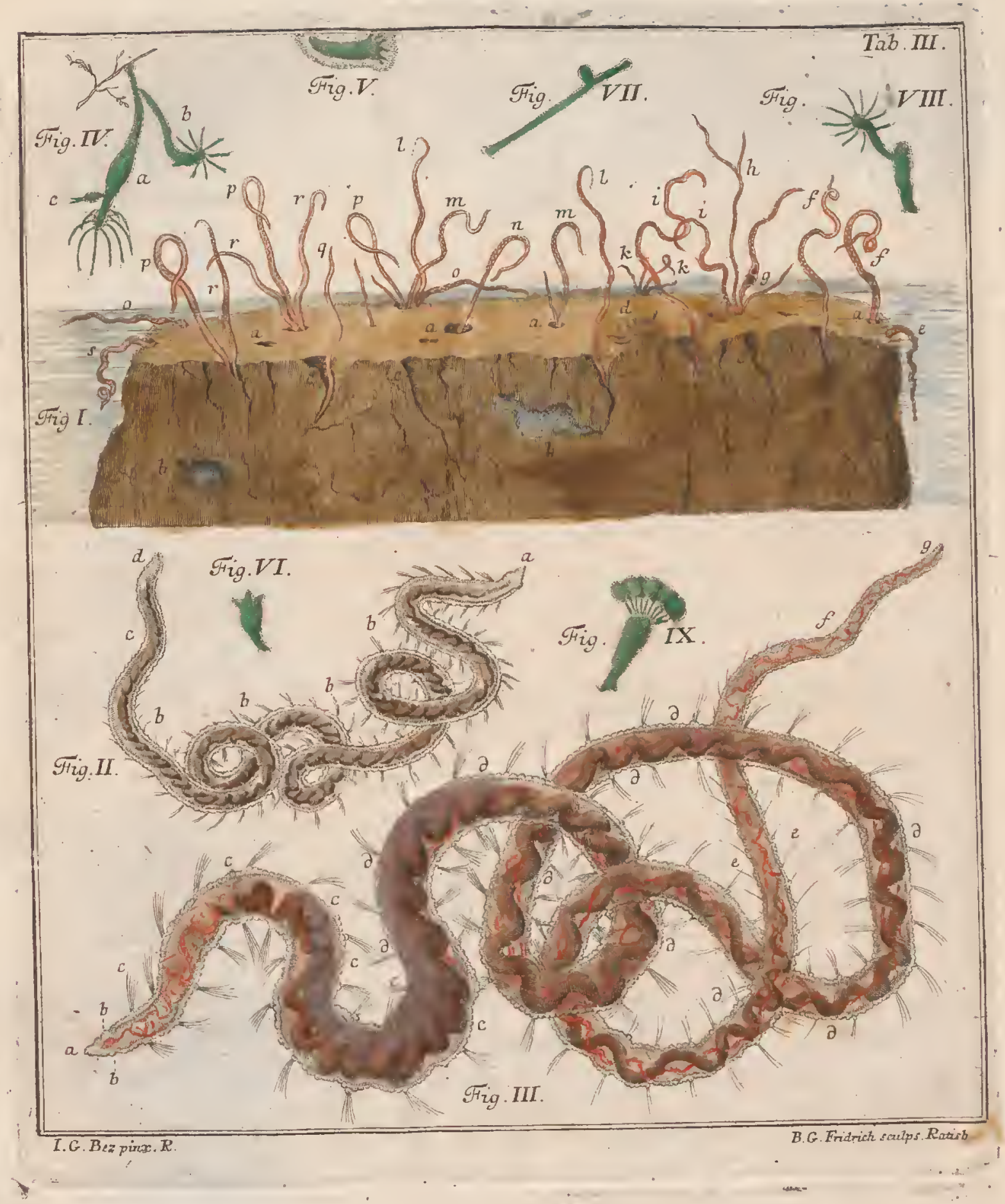


